\title{
The use of information and communication technologies (ICT) for the assessment of patients with Alzheimer's disease and related disorders
}

Citation for published version (APA):

König, A. V. (2015). The use of information and communication technologies (ICT) for the assessment of patients with Alzheimer's disease and related disorders. [Doctoral Thesis, Maastricht University]. Uitgeverij BOXPress. https://doi.org/10.26481/dis.20151022ak

Document status and date:

Published: 01/01/2015

DOI:

10.26481/dis.20151022ak

Document Version:

Publisher's PDF, also known as Version of record

Please check the document version of this publication:

- A submitted manuscript is the version of the article upon submission and before peer-review. There can be important differences between the submitted version and the official published version of record.

People interested in the research are advised to contact the author for the final version of the publication, or visit the DOI to the publisher's website.

- The final author version and the galley proof are versions of the publication after peer review.

- The final published version features the final layout of the paper including the volume, issue and page numbers.

Link to publication

\footnotetext{
General rights rights.

- You may freely distribute the URL identifying the publication in the public portal. please follow below link for the End User Agreement:

www.umlib.nl/taverne-license

Take down policy

If you believe that this document breaches copyright please contact us at:

repository@maastrichtuniversity.nl

providing details and we will investigate your claim.
}

Copyright and moral rights for the publications made accessible in the public portal are retained by the authors and/or other copyright owners and it is a condition of accessing publications that users recognise and abide by the legal requirements associated with these

- Users may download and print one copy of any publication from the public portal for the purpose of private study or research.

- You may not further distribute the material or use it for any profit-making activity or commercial gain

If the publication is distributed under the terms of Article $25 \mathrm{fa}$ of the Dutch Copyright Act, indicated by the "Taverne" license above, 


\section{THE USE OF INFORMATION AND COMMUNICATION TECHNOLOGIES (ICT) FOR THE ASSESSMENT OF PATIENTS WITH ALZHEIMER'S DISEASE AND RELATED DISORDERS}


Cover design: Andrea Grigolli, Mona Lisa by Manfred Beumers, reprinted with the permission of Carla and Galerie Beumers in Monschau, Germany

Layout and printing: Proefschriftmaken.nl II Uitgeverij BOXPress

๑) Copyright Alexandra König, Maastricht 2015

All rights reserved. No part of this thesis may be reproduced or transmitted in any form or by any means without prior written permission of the author. 


\title{
THE USE OF INFORMATION AND COMMUNICATION TECHNOLOGIES (ICT) FOR THE ASSESSMENT OF PATIENTS WITH ALZHEIMER'S DISEASE AND RELATED DISORDERS
}

\author{
PROEFSCHRIFT
}

Ter verkrijging van de graad van doctor aan de Universiteit Maastricht, op gezag van Rector Magnificius, Prof. Dr. L.L.G. Soete, volgens het besluit van het College van Decanen, in het openbaar te verdedigen op donderdag, 22 october 2015 om 10:00 uur

door

\section{Alexandra Veronika König}

Geboren op 26 April 1983 in Aachen, Duitsland 
Supervisors:

Co-supervisors:

Assessment committee: Prof. Rudolf Ponds, chair

Dr. Martin van Boxtel
Prof. Luc de Witte

Prof. Magda Tsolaki

Dr. Franka Meiland

Prof. Frans Verhey

Prof. Philippe Robert

Dr. Pauline Aalten

Dr. Renaud David

The research described in this thesis was performed at the Memory Clinic in the Geriatric Hospital in Nice, France, the research unit CoBTeK (Cognition-Behavior-Technology), University of Nice Sophia Antipolis, France and School for Mental Health and Neuroscience, Alzheimer Center Limburg, Maastricht University Medical Center, Maastricht, The Netherlands.

This research was performed within the framework of the European FP7 project "Dem@care" (http://www.demcare.eu/ - grant number 288199).

Printing of this thesis was kindly supported by: Maastricht University, Lundbeck, Internationale Stichting Alzheimer Onderzoek, Alzheimer Nederland, Novartis, Johson \& Johnson, Pfizer, Scienceplus, Stichting Alkemade-Keuls, Roche, Servier, AstraZeneca
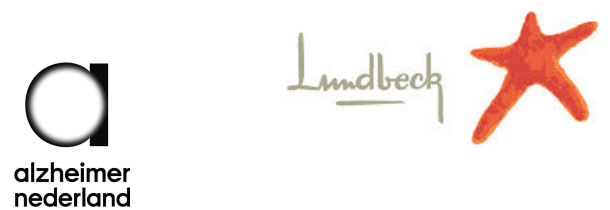
For my mother 
A computer would deserve to be called intelligent if it could deceive a human into believing that it was human

- Alan Turing- 


\section{CONTENTS}

CHAPTER 1 General Introduction, aims and outline of thesis

\section{PART I: Review and Recommendations for ICT use for assessment}

CHAPTER 2 A review of current information and communication technologies: can they be used to assess apathy? International Journal of Geriatric Psychiatry, 2013

CHAPTER 3 Recommendations for ICT use in Alzheimer's disease assessment: Monaco CTAD Expert Meeting. Journal of Nutrition, Health \& Aging, 2013

\section{PART II: Sensor-based studies}

CHAPTER 4

CHAPTER 5

CHAPTER 6

CHAPTER 7
Actigraphic motor activities in mild cognitive impairment patients carrying out short functional activity tasks: comparison between mild cognitive impairment with and without depressive symptoms. Journal of Alzheimer's Disease, 2014

Validation of an automatic video monitoring system for the detection of instrumental activities of daily living in dementia patients.

Journal of Alzheimer's Disease, 2014

120

Ecological assessment of autonomy in instrumental activities of daily living in dementia patients by the means of an automatic video monitoring system.

Frontiers in Aging Neuroscience, 2015

Automatic speech analysis for the assessment of pre-demented and Alzheimer patients. Alzheimer's \& Dementia :

Diagnosis, Assessment \& Disease Monitoring, 2015 


\section{PART III: Conclusion and future implications}

CHAPTER 8 The role of information and communication technologies in clinical trials with patients with Alzheimer's disease and related disorders.

Frontiers in Aging Neuroscience, 2015

CHAPTER 9

Recommendations for the use of serious games in people with Alzheimer's disease, related disorders and frailty.

Frontiers in Aging in Neuroscience, 2014

CHAPTER 10

General discussion 283

Summary

Knowledge valorization

Author affiliations

Publications

Author information

Acknowledgements 


\section{CHAPTER 1}

GENERAL INTRODUCTION

AIMS AND RESEARCH QUESTIONS

OUTLINE OF THESIS 


\section{A story to begin...}

Recently, researchers from the University of Arizona have found that with the use of new analysis methods, that Ronald Reagan's speech patterns gave undetected clues to his deteriorating mental state years before he was diagnosed with Alzheimer's disease.

The findings suggest that with the development of innovative technologies, alterations in speech and other functions might be used one day to predict development of Alzheimer's disease and other neurological conditions years before symptoms are clinically perceptible. 


\section{GENERAL INTRODUCTION}

This introduction is split into seven parts. The first and second describes Alzheimer's disease (AD) and its diagnosis as a means to situate the research problem. The following sections give an overview of current ICT use for clinical assessments namely of behavioral disturbances, cognitive abilities, physical activity and functionality in patients. The last part presents briefly the European project 'Dem@care' and its link to the main research questions of this thesis.

\section{Alzheimer's disease}

The occurrence of neurodegenerative disorders such as dementia has risen by unprecedented levels in part due to increases in average lifespan, thus engendering high socio-economic costs. AD is the most common type of dementia [1] and represents a central health problem in Western society: One in eight people aged 65 and older has AD [2]. Nearly half of the people aged 85 and older have AD and the total number of people with dementia grows each year as the proportion of the elderly population continues to increase. Prevalence studies estimate that the number of people affected will double every 20 years to 81.1 million worldwide by 2040 [3]. These findings have created a strong basis for the early detection of $\mathrm{AD}$ as a research priority [4].

$\mathrm{AD}$ is recognized mainly as a cognitive disorder, where memory functions are primarily affected in the early stages of the disease [5]. When making a diagnosis of $\mathrm{AD}$, physicians commonly refer to the NINCDS-ADRA criteria [6] or the Diagnostic and Statistical Manual of Mental Disorders ( $5^{\text {th }}$ ed.; DSM-5) [7] whereby the decline of cognitive abilities must be severe enough to interfere with a person's social and daily life. In order to meet the diagnostic criteria sufficiently, a decline in the level of functioning over time needs to be observable. Recently, new diagnostic criteria were proposed requiring the presence of a progressive episodic memory impairment and invivo biomarker evidence such as medial temporal lobe atrophy or abnormal cerebrospinal fluid (CSF) [8-9]. 


\section{Diagnosis of AD patients in early stages}

Diagnosis of AD has to be made mainly by the assessment of clinical features. Neuropsychological testing can help obtain objective signs of memory disturbances, yet neuroimaging, Computed tomography (CT scan) and Magnetic Resonance Imaging (MRI) likewise play an important part in diagnosis in order to exclude alternative causes of dementia, such as brain tumors or hematomas. Recent advances in the use of reliable biomarkers of $\mathrm{AD}$, such as cerebrospinal fluid (CSF), that provide in vivo evidence has stimulated the development of new research criteria. For example, amyloid and Tau neuroimaging through, for example, positron-emission tomography (PET) scans [1011] are other new methods based on biomarkers that can add useful information to the diagnostic procedure. In this line, the National Institute on Aging and the Alzheimer's Association (NIA) has subsequently redefined the diagnosis around both cognitive changes and structural/biological evidence of Alzheimer's pathology [12;9]. The incorporation of biomarkers into the new diagnostic formulations is expected to enhance pathophysiological specificity of the diagnosis of AD dementia and allow an earlier detection of relevant signs and symptoms [13]. During a preclinical phase of the disease, plaque and tangle load increases and at a certain threshold the first symptoms appear. This clinical phase is often designated as Mild Cognitive Impairment (MCI) and that is defined as a cognitive decline greater than expected for an individual's age but does not interfere notably with activities of daily life) [14-15]. Some people with MCI seem to remain stable or return even to a normal state over time, but more than half progress to dementia within 5 years. Therefore, MCI can be regarded as a risk state for dementia and its identification could lead to secondary prevention by intervening early enough [16]. Lately, emphasis is placed more and more on early diagnosis and detection of cognitive decline and related symptoms so that patients can benefit sufficiently from effective treatment and access to information, advice and support [17]. 
At the same time, clinical assessments of cognitive and functional changes in AD has traditionally relied on cognitive neuropsychological screening tests which can be biased and thus are not always sensitive to the earliest disease-related changes. Detecting early cognitive changes before clinical AD symptoms develop is crucial for the development and eventual success of therapeutic interventions. Moreover, biomarkers can involve invasive (eg, lumbar puncture), time-consuming (neuropsychological assessment) or expensive (PET) hospital-based procedures [18]. Better measures for cognitive and functional changes are therefore needed in the early stages of the disease. Assessment methods involving simple, noninvasive and more accessible cost-effective tools are greatly required.

For these reasons, information and communication technology (ICT), such as movement sensors and imaging and video processing, could be of interest because they enable the patients' performances and actions to be captured objectively, in real time, and in real life situations. The use of these types of ICT may allow early identification of subjects in preclinical stages of $\mathrm{AD}$ as well as monitoring of the disease's progression and treatment effects over time. Early detection through these means could also enhance the probability that the disease is treated successfully before irreversible changes in the brain arise.

\section{ICT and Alzheimer's disease - new opportunities for assessment?}

The inadequacy of existing methods combined with biased evaluations, points to a need for objective and systematic assessment tools and researchers aim to provide novel solutions [19-21]. Clinical expertise and literature review indicates that ICT are not yet able to provide a direct diagnosis of $\mathrm{AD}$ and related disorders, but can supply additional information for the assessment of specific domains (behavior, cognition, activity of daily living) [22]. This information can contribute with other clinical and biological data to earlier diagnosis of $\mathrm{AD}$ and related disorders. Several studies using ICT in 
the assessment of different domains show potential benefits of using ICT in clinical practice [23-24]. In general, technology has been identified as a means that can be used to support independent living [25] and improve quality of life for people with dementia and their careers [26].

In this thesis, new methods involving ICT - including automated speech and video analysis techniques as well as wearable accelerometers - are investigated in its utility and efficacy to provide clinically relevant information for the assessment, diagnosis and follow-up of patients with $\mathrm{AD}$ and related disorders.

Measuring physiological and activity-based parameters remotely and continuously via unobtrusive ambient or on-body sensors has the potential to revolutionize our ability to predict and pre-empt harmful changes in disease trajectory.

ICT and the use of embedded 'ambient' devices in a patient's environment to capture 'everyday cognition' is promising because these tools could be used among a large population at pre-dementia stages for a variety of purposes. For example, using technology to observe individuals in real-life scenarios, it may be possible to stage baseline function and observe changes in function over time during cognitive intervention studies or pharmaceutical studies. ICTs are becoming increasingly recognized as a potential way to help stage cognitive impairment.

Additionally, assistive technologies that continuously monitor the person with dementia's behavioral, cognitive, and emotional state facilitate more objective means of assessing, monitoring, and supporting the individual than that provided by traditional questionnaires. The relationship of behavioral and cognitive monitoring parameters to dementia-specific patterns can provide a promising and objective dementia assessment given the long-term 
nature of the measurements. Lastly, sensors that monitor cognitive decline, behavioral disturbances and activities of daily living can enable a person with dementia to remain independent for longer, reducing the burden on family/friends and decreasing healthcare costs.

\section{Assessment of behavioral disturbances through ICTs}

Non-invasive body sensor network technology has been successfully deployed for the detection of agitation in dementia patients [27]. Ambulatory actigraphy has been proposed as an observer-independent evaluation method in different disorders including sleep/wake disorders [28], Attention Deficit/Hyperactivity Disorder [29], and Periodic Limb Movement Disorder [30]. Several sensor technologies have been used to evaluate agitated behavior in neurodegenerative disorders [31-32], as well as psychomotor retardation in psychiatric disorders [33]. More recent studies have shown that actigraphic locomotor activity assessment can be useful to evaluate neuropsychiatric symptoms in dementia such as the severity of apathy [34; 20]. As mentioned previously, systematic observation through video monitoring may provide as well additional comprehensive view on the patient's life and status, thus presenting another objective method of clinical examination. So far, this method has been performed through visual analyses by a direct observer and therefore, risks to lack objectivity as well as reliability. Automatic computerbased analysis, which allows recognition of certain events and patients' behavioral patterns, may offer a new solution to those former assessment problems [35-36]. The contribution of this thesis is therefore one of the first attempts to assess whether computer-based analysis can be clinically relevant.

\section{Assessment of cognitive abilities through ICTs}

Different technologies and in particular computerized testing and serious games, represent new promising tools for the assessment of cognitive abilities. Plancher et al. studied the use of virtual reality to characterize episodic memory profiles in an ecological fashion, 
including healthy older subjects, MCI and AD patients [37]. Results highlighted specific cognitive differences between the three populations and may provide additional insight into the early diagnosis and rehabilitation of pathological aging. This thesis investigates the use of automatic speech analyses for an accurate cognitive staging of dementia patients based on extracted vocal features.

\section{Assessment of physical activity and functionality}

A review of the literature shows that studies of physical activities in elderly people focus essentially on three different types of physical activity: gait, posture and the activity patterns (mobility) assessment. These parameters are strongly associated with performance levels of functionality in activities of daily living and thus their detection could provide clinicians with autonomy-remated information [24]. Stucki et al. demonstrated that a wireless sensor system can acquire essential data for the detection of activities of daily living [25]. Chamberlin showed gait pattern differences (walking speed, stride length/width, and double support time) in patients with a pre-existing fear of falling by using GaitRite System, a carpet including 26000 pressure sensors that analyze gait by measuring spatio-temporal parameters [38]. Moreover, Sterke et al. showed that gait parameters measured with the GaitRite System can also be used for the prediction of short-term fall risk in nursing home residents with moderate to severe dementia [39]. Analyses of postures based on accelerometer technologies are as well conducted to qualify the level of physical activity in elderly people but results of technological performances are yet not promising to extract clinical conclusions [40-41].

\section{Dem@Care}

This thesis presents findings from the EU FP7-funded research project called "Dementia Ambient Care" (Dem@Care) [42]. The project is developing an integrated solution for the remote monitoring, diagnosis and support of people with MCI and mild dementia. Dem@Care 
investigates the use of multiple wearable (accelerometers, 2D/3D cameras, microphones) and ambient sensors (visual and infrared cameras, sleep sensors) for the recording of daily activities, behavior, lifestyle patterns, emotions, and speech, as well as the use of intelligent mechanisms for the assessment of an individual's condition at diagnosis, and over time in multiple care settings. Feedback is provided to clinicians, and directly to people with dementia and their caregivers. The innovative analysis of Dem@Care sensor data minimizes the subjectivity characterizing current clinical diagnosis protocols and facilitates automated objective assessment of autonomy in instrumental activities of daily living in clinical settings (pilot sites in France and Greece). The analysis of recurring patterns of behavior over time enables the formation of a comprehensive and objective picture of the individual's overall condition, which better informs the provision of appropriate treatment and care in home and in residential care settings.

\section{AIM OF THE THESIS AND OUTLINE}

The general aim of this thesis was to investigate the potential contribution of ICT use for clinical assessment of cognitive, behavioral and functional changes in patients with $\mathrm{AD}$ and related disorders, particularly in their early stages in order to allow earlier access to preventative intervention such as tailored cognitive and physical training through serious games. For this purpose, the use of different sensors such as actigraphy, video analyses or speech analyses, were investigated in clinical practice.

The thesis consists of three parts: first a review of ICT use for the specific case of apathy assessment and recommendations for ICT use for clinical assessment. In part II, different sensor-based studies are presented followed by part III, addressing the conclusion to consider the use of ICT within clinical trials for endpoint measures and followup. Finally, proposed recommendations are presented for the use of 
ICT-based Serious Games as a potential early intervention tool for patients.

\section{PART I: Review and Recommendations for ICT use for clinical assessment}

Part I addressed the following question:

1. Why considering ICTs for the assessment of dementia and predemented patients?

2. What is the contribution of ICT for clinical routine assessments?

3. What additional information can be provided by the use of ICT as opposed to commonly used assessment tool?

In order to address and operationalize the previous questions, an overview of current clinical assessment tools and their limitations is presented in Chapter 2, in particular for the case of apathy as well as new approaches to assessment methods involving ICTs. Furthermore, Chapter 3 provides basic recommendations concerning the development and the use of ICT for AD and related disorders. During the ICT and Mental Health workshop (CTAD meeting held in Monaco on the 30th October 2012) an expert panel was set up to prepare the first recommendations for the use of ICT in dementia research. The recommendations are divided into three sections corresponding to : a) the clinical targets of interest for the use of ICT ; b) the conditions, the type of sensors and the outputs (scores) that could be used and obtained; and c) finally the last section concerns specifically the use of ICT within clinical trials. 


\section{PART II: Sensor-based studies}

Part II addressed the following research questions:

4. What is the purpose of using actigraphy for the assessment of patients with MCI and early AD?

5. What factors need to be taken into consideration when using ICTs in clinical practice among dementia patients?

6. What is the purpose of using automatic video analyses for the assessment of autonomy in instrumental activities of daily living (IADLs) in patients?

7. What is the additional diagnostic value of automatic speech analyses?

In order to operationalize the previous questions, several sensor-based validation studies have been carried out and presented in Part II of the thesis. Chapter $\mathbf{4}$ assesses motor activity in MCI subjects carrying out short functional activity tasks using ambulatory actigraphy. In addition the influence of depressive symptoms on motor activity was investigated.

Chapter 5 investigates the use of a video monitoring system for automatic event recognition for the assessment of IADL in dementia patients carrying out a standardized scenario consisting of several IADLs such as making a phone call while they were recorded by $2 \mathrm{D}$ video cameras.

Chapter 6 further explores automatized quantitative assessment of the autonomy of dementia patients based on merging extracted features not only from the participants' performance on IADL but also from gait analysis recognized by an event monitoring system (EMS). Gait analysis applied to IADL assessment may provide a reliable and 
precise methodology to assess patients functioning in daily life, which could be used at both diagnostic and rehabilitation level.

Finally, Chapter 7 evaluates the interest of using automatic speech analyses for the assessment of MCI and early-stage AD.

\section{PART III: Conclusion and future implications}

The conclusion addresses the remaining research questions:

8. Could ICTs play a future role in clinical trials for screening and the assessment of treatment effects?

9. How can ICTs be used to provide interventions tailored to the patients' specific needs?

In order to address the previous questions, Chapter 8 suggests that new ICTs-including automated speech and video analysis techniques and wearable accelerometers- may be successfully used in clinical trials to improve the functional and cognitive assessment of patients and thus contributing to an earlier $\mathrm{AD}$ diagnosis and providing additional ecological and objective end-point measurements.

Chapter 9 aims to systematically analyze the Strengths, Weaknesses, Opportunities, and Threats (SWOT) of employing Serious Games, which are digital applications specially adapted for purposes other than entertaining, such as rehabilitation, training and education, with patients with $\mathrm{AD}$ and related disorders in order to provide practical recommendations for the development and use of Serious Games in these populations.

Lastly, Chapter 10 provides a general discussion about the main findings and their implication for future clinical research. 


\section{REFERENCES}

1. Alzheimer's Association. (2011). Alzheimer's \& Dementia, Alzheimer's Disease Facts and Figures, 7(2).

2. Alzheimer's Disease International. (2011). World Alzheimer Report 2011. The benefits of early diagnosis and intervention. Executive Summary, London: Alzheimer's Disease International., Retrieved February 08, 2012 from http://www.alz.co.uk/research/WorldAlzheimerReport2011Exe cutiveSummary.pdf.

3. Ferri, C. P., Prince, M., Brayne, C., Brodaty, H., Fratiglioni, L., Ganguli, M., et al. (2005). Global prevalence of dementia: a Delphi consensus study. Lancet, 366(9503), 2112-2117.

4. Ballard, C., Gauthier, S., Corbett, A., Brayne, C., Aarsland, D., \& Jones, E. (2011). Alzheimer's disease. Lancet, 377(9770), 1019-1031.

5. Agüero-Torres, Fragtiglioni, \& Windblad. (1998). Natural history of Alzheimer's disease and other dementias: review of the literature in the light of the findings from the Kungsholmen project. International journal of geriatric psychiatry, 13, 755766.

6. McKhann. (1984). Clinical diagnosis of Alzheimer's disease: report of the NINCDS-ADRDA Work Group under the auspices of Department of Health and Human Services Task Force on Alzheimer's Disease. Neurology, 34(7), 939-944.

7. American Psychiatric Association. (2013). Diagnostic and statistical manual of mental disorders (5th ed.). Washington, DC

8. Dubois, B, Feldman, HH, Jacova, C, Dekosky, ST, BarbergerGateau, P, Cummings, J, Delacourte, A, Galasko, D, Gauthier, S, Jicha, G, Meguro, K, O'Brien, J, Pasquier, F, Robert, P, Rossor, M, Salloway, S, Stern, Y, Visser, PJ, and Scheltens, P, Research criteria for the diagnosis of Alzheimer's disease: revising the NINCDS-ADRDA criteria. Lancet Neurol, 2007. 6(8): p. 734-46. 
9. Dubois, B, Feldman, HH, Jacova, C, Hampel, H, Molinuevo, JL, Blennow, K, DeKosky, ST, Gauthier, S, Selkoe, D, Bateman, R, Cappa, S, Crutch, S, Engelborghs, S, Frisoni, GB, Fox, NC, Galasko, D, Habert, MO, Jicha, GA, Nordberg, A, Pasquier, F, Rabinovici, G, Robert, P, Rowe, C, Salloway, S, Sarazin, M, Epelbaum, S, de Souza, LC, Vellas, B, Visser, PJ, Schneider, L, Stern, Y, Scheltens, P, and Cummings, JL, Advancing research diagnostic criteria for Alzheimer's disease: the IWG-2 criteria. Lancet Neurol, 2014. 13(6): p. 614-29.

10. Masdeu, J. C., Kreisl, W. C., \& Berman, K. F. (2012). The neurobiology of Alzheimer disease defined by neuroimaging. Curr Opin Neurol, 25(4), 410-420.

11. Small, G. W., Siddarth, P., Kepe, V., Ercoli, L. M., Burggren, A. C., Bookheimer, S. Y., et al. (2012). Prediction of cognitive decline by positron emission tomography of brain amyloid and tau. Arch Neurol, 69(2), 215-222.

12. Dubois, B., Feldman, H. H., Jacova, C., Cummings, J. L., Dekosky, S. T., Barberger-Gateau, P., et al. (2010). Revising the definition of Alzheimer's disease: a new lexicon. Lancet Neurol, 9(11), 1118-1127.

13. McKhann, G. M., Knopman, D. S., Chertkow, H., Hyman, B. T., Jack, C. R., Jr., Kawas, C. H., et al. (2011). The diagnosis of dementia due to Alzheimer's disease: recommendations from the National Institute on Aging-Alzheimer's Association workgroups on diagnostic guidelines for Alzheimer's disease. Alzheimers Dement, 7(3), 263-269.

14. Gauthier, S., Reisberg, B., Zaudig, M., Petersen, R. C., Ritchie, K., Broich, K., et al. (2006). Mild cognitive impairment. Lancet, 367(9518), 1262-1270.

15. Petersen, Smith, Waring, Ivnik, Tangalos, \& Kokmen. (1999). Mild cognitive impairment: clinical characterization and outcome. Arch Neurol, 56(3), 303-308.

16. Albert, M. S., DeKosky, S. T., Dickson, D., Dubois, B., Feldman, H. H., Fox, N. C., et al. (2011). The diagnosis of mild cognitive impairment due to Alzheimer's disease: recommendations from the National Institute on AgingAlzheimer's Association workgroups on diagnostic guidelines for Alzheimer's disease. Alzheimers Dement, 7(3), 270-279. 
17. Sperling, R. A., Aisen, P. S., Beckett, L. A., Bennett, D. A., Craft, S., Fagan, A. M., et al. (2011). Toward defining the preclinical stages of Alzheimer's disease: recommendations from the National Institute on Aging-Alzheimer's Association workgroups on diagnostic guidelines for Alzheimer's disease. Alzheimers Dement, 7(3), 280-292.

18. Laske, C, Sohrabi, HR, Frost, SM, Lopez-de-Ipina, K, Garrard, P, Buscema, M, et al. (2014). Innovative diagnostic tools for early detection of Alzheimer's disease. Alzheimers Dement.

19. Robert, PH, Konig, A., Andrieu, S., Bremond, F., Chemin, I., Chung, P. C., Dartigues, J. F., Dubois, B., Feutren, G., Guillemaud, R., Kenisberg, P. A., Nave, S., Vellas, B., Verhey, F., Yesavage, J., Mallea, P. (2013). Recommendations for ICT Use in Alzheimer's Disease Assessment: Monaco CTAD Expert Meeting. J Nutr Health Aging, 17(8), 653-660.

20. David, Mulin, Friedman, Duff, Cygankiewicz, Deschaux, et al. (2011). Decreased Daytime Motor Activity Associated With Apathy in Alzheimer Disease: An Actigraphic Study. Am J Geriatr Psychiatry, 20(9):806-14.

21. Siraly, E, Szabo, A, Szita, B, Kovacs, V, Fodor, Z, Marosi, C, Salacz, P, Hidasi, Z, Maros, V, Hanak, P, Csibri, E, and Csukly, G, Monitoring the early signs of cognitive decline in elderly by computer games: an MRI study. PLoS One, 2015. 10(2): p. e0117918.

22. Kenigsberg, PA, Aquino, JP, Berard, A, Gzil, F, Andrieu, S, Banerjee, S, Bremond, F, Buee, L, Cohen-Mansfield, J, Mangialasche, F, Platel, H, Salmon, E, and Robert, P, Dementia beyond 2025: Knowledge and uncertainties. Dementia (London), 2015.

23. Montero-Odasso, M, Bergman, $\mathrm{H}$, Phillips, NA, Wong, $\mathrm{CH}$, Sourial, N, and Chertkow, H, Dual-tasking and gait in people with mild cognitive impairment. The effect of working memory. BMC Geriatr, 2009. 9: p. 41.

24. Hayes, TL, Abendroth, F, Adami, A, Pavel, M, Zitzelberger, TA, and Kaye, JA, Unobtrusive assessment of activity patterns associated with mild cognitive impairment. Alzheimers Dement, 2008. 4(6): p. 395-405. 
25. Stucki, RA, Urwyler, P, Rampa, L, Muri, R, Mosimann, UP, and Nef, T, A web-based non-intrusive ambient system to measure and classify activities of daily living. J Med Internet Res, 2014. 16(7): p. e175.

26. Cavallo, F, Aquilano, M, and Arvati, M, An ambient assisted living approach in designing domiciliary services combined with innovative technologies for patients with Alzheimer's disease: a case study. Am J Alzheimers Dis Other Demen, 2015. 30(1): p. 69-77.

27. Bankole, A, Anderson, M, Smith-Jackson, T, Knight, A, Oh, $\mathrm{K}$, Brantley, J, Barth, A, and Lach, J, Validation of noninvasive body sensor network technology in the detection of agitation in dementia. Am J Alzheimers Dis Other Demen, 2012. 27(5): p. 346-54.

28. Yesavage, Friedman, Kraemer, Noda, Wicks, Bliwise, Sheikh, Tinklenberg, and Zarcone, A follow-up study of actigraphic measures in home-residing Alzheimer's disease patients. J Geriatr Psychiatry Neurol, 1998. 11(1): p. 7-10.

29. Dane, Schachar, and Tannock, Does actigraphy differentiate ADHD subtypes in a clinical research setting? J Am Acad Child Adolesc Psychiatry, 2000. 39(6): p. 752-60.

30. Kemlink, Pretl, Sonka, and Nevsimalova, A comparison of polysomnographic and actigraphic evaluation of periodic limb movements in sleep. Neurol Res, 2008. 30(3): p. 234-8.

31. Mahlberg and Walther, Actigraphy in agitated patients with dementia. Monitoring treatment outcomes. Z Gerontol Geriatr, 2007. 40(3): p. 178-84.

32. Nagels, Engelborghs, Vloeberghs, Van Dam, Pickut, and Deyn, D, Actigraphic measurement of agitated behaviour in dementia. Int J Geriatr Psychiatry, 2006. 21(4): p. 388-93.

33. Volkers, Tulen, Van Den Broek, Bruijn, Passchier, and Pepplinkhuizen, 24-Hour motor activity after treatment with imipramine or fluvoxamine in major depressive disorder. Eur Neuropsychopharmacol, 2002. 12(4): p. 273-8.

34. David, R, Ambulatory actigraphy correlates with apathy in mild Alzheimer's disease. Dementia: The International Journal of Social Research and Practice, 2010, 9(4), 509-516. 
35. Romdhane, R, Mulin, E, Derreumeaux, A, Zouba, N, Piano, J, Lee, L, Leroi, I, Mallea, P, David, R, Thonnat, M, Bremond, F, and Robert, $\mathrm{P}$, Automatic video monitoring system for assessment of Alzheimer's disease symptoms. J Nutr Health Aging, 2012. 16(3): p. 213-8.

36. Sacco, G, Joumier, V, Darmon, N, Dechamps, A, Derreumaux, A, Lee, JH, Piano, J, Bordone, N, Konig, A, Teboul, B, David, $\mathrm{R}$, Guerin, O, Bremond, F, and Robert, P, Detection of activities of daily living impairment in Alzheimer's disease and mild cognitive impairment using information and communication technology. Clin Interv Aging, 2012. 7: p. 539-49.

37. Plancher, G, Tirard, A, Gyselinck, V, Nicolas, S, and Piolino, $\mathrm{P}$, Using virtual reality to characterize episodic memory profiles in amnestic mild cognitive impairment and Alzheimer's disease: influence of active and passive encoding. Neuropsychologia, 2012. 50(5): p. 592-602.

38. Chamberlin, ME, Fulwider, BD, Sanders, SL, and Medeiros, JM, Does fear of falling influence spatial and temporal gait parameters in elderly persons beyond changes associated with normal aging? J Gerontol A Biol Sci Med Sci, 2005. 60(9): p. 1163-7.

39. Sterke, CS, van Beeck, EF, Looman, CW, Kressig, RW, and van der Cammen, TJ, An electronic walkway can predict shortterm fall risk in nursing home residents with dementia. Gait Posture, 2012.

40. Denkinger, MD, Franke, S, Rapp, K, Weinmayr, G, DuranTauleria, E, Nikolaus, T, Peter, R, and Acti, FEUSG, Accelerometer-based physical activity in a large observational cohort--study protocol and design of the activity and function of the elderly in Ulm (ActiFE Ulm) study. BMC Geriatr, 2010. 10: p. 50.

41. Taraldsen, K, Askim, T, Sletvold, O, Einarsen, EK, Bjastad, KG, Indredavik, B, and Helbostad, JL, Evaluation of a bodyworn sensor system to measure physical activity in older people with impaired function. Phys Ther, 2011.91(2): p. 27785. 
42. Dementia Ambient Care: Multi-Sensing Monitoring for Intelligent Remote Management and Decision Support. Available at: http:// www.demcare.eu/. Accessed March 20, 2015. 


\section{PART I}

REVIEW AND RECOMMENDATIONS FOR ICT USE FOR THE ASSESSMENT

OF AD PATIENTS AND RELATED

DISORDERS 


\section{CHAPTER 2}

\section{A REVIEW OF CURRENT INFORMATION AND COMMUNICATION TECHNOLOGIES : CAN THEY BE USED TO ASSESS}

APATHY?

International Journal of Geriatric Psychiatry 2013; 29(4): 345-58

König, A, Aalten, P, Verhey, F, Bensadoun, G, Petit, PD, Robert, P, and David, R 


\section{ABSTRACT}

\section{Background}

Neuropsychiatric symptoms, such as apathy, have an important impact on the quality of life of both patients diagnosed with dementia and their caregivers and represent a strong predictor of progression of the illness. Current clinical assessment methods risk bias resulting from the assessor's subjectivity, pointing to a need for additional objective and systematic assessment tools. Therefore, the use of information and communication technologies (ICT) such as actigraphy and automatized video monitoring are of interest in addition to current assessment methods.

\section{Aim}

The goal of this study is to give an overview of current assessment tools for apathy in clinical practice and new approaches to assessment methods with the help ICT.

\section{Methods}

This study was conducted with the use of narrative literature overview.

\section{Results}

There is evidence that apart from the currently used assessment methods for apathy, new ICT approaches could provide clinicians with valuable additional information for an earlier detection and therefore more accurate diagnosis of apathy.

\section{Conclusions}

There are no ICT techniques specifically designed for the assessment of apathy, but nevertheless several techniques seem to be promising and deserve more study. 


\section{INTRODUCTION}

Neuropsychiatric symptoms (NPS) are increasingly recognized as an important aspect of dementia. Several studies demonstrated their early presence in the disease process as well as their impact on the quality of life of both patients and their caregivers [1-5]. The majority of epidemiological studies show that the subsyndrome apathy is one of the most common neuropsychiatric syndromes, occurring in almost $65 \%$ of dementia patients $[6-7 ; 4]$ being associated with a higher degree of global functional impairment [8] and therefore loss of autonomy in activities of daily living (ADL) [9-11].Recently, Robert et al. proposed a consensus definition in terms of a set of diagnostic criteria for apathy in Alzheimer's disease (AD) [12-14]. According to those criteria, apathy diagnosis should meet the following requirements: first, the core feature of apathy, diminished motivation, must be present for at least four weeks; second, two of the three dimensions of apathy (reduced goal-directed behavior (GDB), goaldirected cognitive activity, and emotions) must be present; third, there should be identifiable functional impairments attributable to apathy. Most recent models consider apathy particularly in terms of an 'absence of responsiveness to stimuli as demonstrated by lack of selfinitiated action' [15-16].

In patients with mild cognitive impairment (MCI), the presence of the apathy dimension 'lack of interest' is the strongest predictor for conversion to AD [17]. Therefore, early accurate assessment of NPS and, in particular, apathy is of high importance and in this respect also the improvement of the quality of the current clinical instruments.

During the past years, various assessment scales for apathy have been developed even if their application for early detection is rather limited because of its dependency on human observer. Several obstacles can emerge in the process of evaluating the presence of apathy; Loss of motivation, for instance, is often interpreted as emotionally disturbed 
or an oppositional behavior [1]. Likewise, apathy can often be misdiagnosed as depression because of frequent comorbidities and a considerable overlap in key symptoms, such as diminished interest, psychomotor retardation, fatigue/hypersomnia, lack of insight, social withdrawal, and lack of initiation [18-19].

To date, consensus criteria for apathy [12] can be used as a starting point for the development of other new additional ways of assessment without clinical judgment, which can be of use in for instance home or nursing home situations. In this line, information and communication technologies (ICT) could potentially improve the accuracy of NPS assessment by adding objectively measured data.

The primary aim of this article is to give an overview of available new ICT approaches that can contribute to the objective assessment of apathy. Secondly, for considering the additional value of ICT assessments, those will be compared with current apathy assessment tools commonly used in both research and daily clinics. The present overview will result in a critical discussion about future use of ICT assessment for the diagnostics of apathy in dementia. 


\section{METHODOLOGY}

Because there is none to limited structured psychometric data available of the new ICT assessments, the present study will be descriptive in nature. In order to establish the narrative overview, several research papers and reviews dating from the year 1998 (first article found about apathy assessment) to 2012 were screened using the following search terms in PubMed: « dementia OR Alzheimer OR mild cognitive impairment OR apathy OR goal-oriented behavior OR motor retardation or motion » AND « assessment OR evaluation OR sreening OR monitoring» AND « new methods OR new technologies OR ICT OR (Information and Communication Technologies) OR actigraphy OR infrared sensors OR assistive technologies OR smart homes OR GPS ». Searches were limited to articles written in English and relevant to the assessment of apathy. 


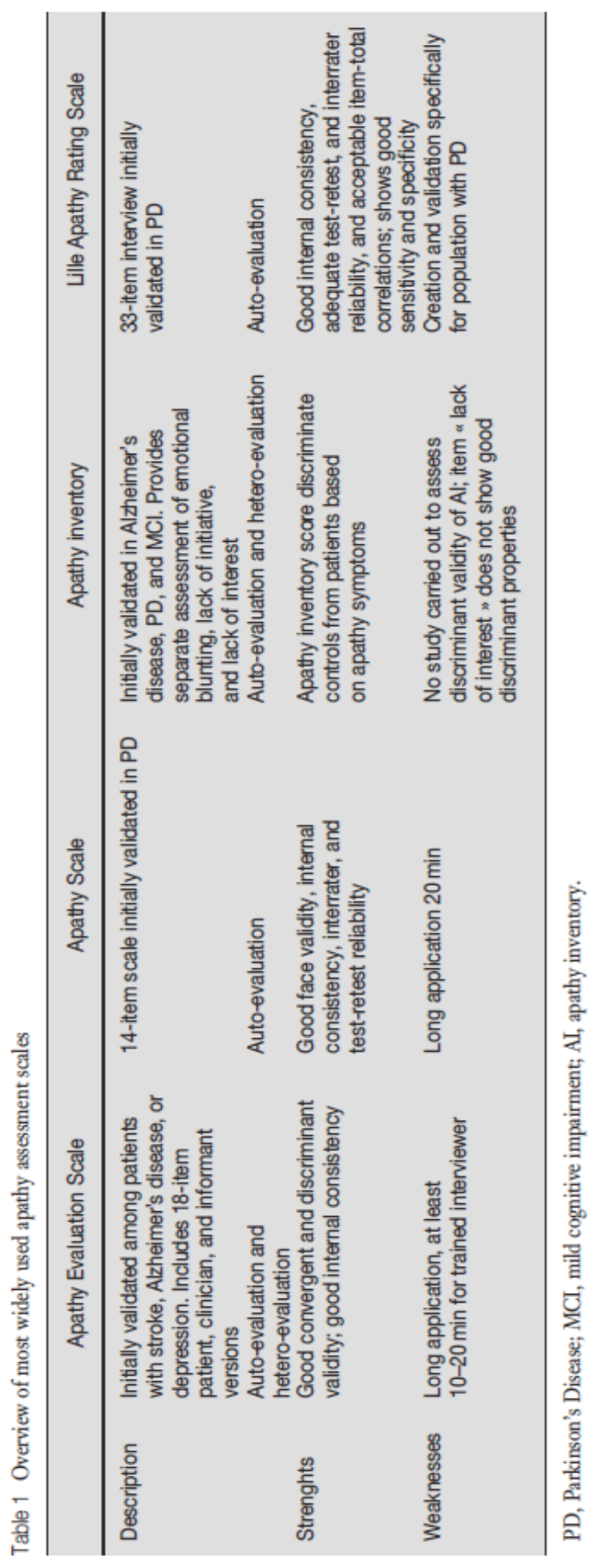




\section{Current assessment tools}

Global behavioral assessment tools. Ideally, the assessment should be structured with input fromthe caregiver and/or the patient but should also incorporate the clinician's perspective. Apathy in dementia patients can be partly detected by the use of global behavioral assessment scales, which have been previously reviewed by Perrault and Forester [20-21].

The most widely used scale is the Neuropsychiatric Inventory (NPI), that is, a global multidimensional assessment tool that measures apathy as a specific domain [22] based on a structured interview with a caregiver who is familiar with the patient. It assesses 12 types of neuropsychiatric symptoms [23]. Most of the studies used the NPI total score representing the sum of the 12 neuropsychiatric 'frequency $x$ severity score'. Nevertheless, the NPI total score has the disadvantage that it does not provide information on specific NPS [24], and thus, the use of NPI single item score is preferable [4].

\section{Symptom-specific behavioral assessment tools for apathy}

The common method to assess apathy is so far through specific rating scales (Table 1) whereby motivation can only be inferred from the observation of behavior. Marin et al. [25-27] were the first to develop an assessment instrument for apathy, the Apathy Evaluation Scale (AES). The AES is an 18-item scale, consisting of three forms: a selfrating scale (AES-S), a caregiver paper-and-pencil test (AES-I), and a clinician administered test (AES-C) [27]. Starkstein et al. adapted and shortened Marin's scale, resulting in the Apathy Scale (AS). The Lille Apathy Rating Scale [28] and the Apathy Inventory (AI) [29] correspond to more specific measurement tools. The AI was developed [29] as an extension to the apathy domain of the NPI in order to provide a separate assessment of the emotional, behavioral, and cognitive aspects of apathy [30-31]. The Lille Apathy Rating Scale, developed by Sockeel et al. is based on a structured interview 
with the patient, consisting of 33 items, divided into nine domains including reduction in everyday productivity, lack of interest, lack of initiative, extinction of novelty seeking and motivation, blunting of emotional responses, lack of concern, poor social life, and extinction of self-awareness [28].

\section{Limitations of current assessment tools}

According to recent studies by Clarke et al. examining reliability and validity of the various scales [32-33] the most psychometrically robust and widely used measures for assessing apathy appear to be the AES and the NPI. Nevertheless, the clinical assessment of apathy is still problematic because of the use of ad hoc severity rating scales with arbitrary cutoff scores [34-36] and the lack of objective measurement tools. Concerning the NPI, results indicate high standard deviations of measurement within trials reflecting important variability [36]. Levy criticizes [16] that important quotation differences can be noted between patients and caregivers because of their lack of awareness and subjective evaluation of apathy presence. Further, no information can be provided about the underlying mechanisms responsible for apathy. Leentjens et al. [30] states that none of the available scales are specifically suited to assess apathy in the different phases of motor fluctuations ('on' vs. 'off' states). Hence, the lack of generally accepted diagnostic criteria for apathy as a syndrome means that there is no gold standard to assess such psychometric properties as the sensitivity and specificity of scales. Increasingly, the development of new methods to assess apathy is considered because existing tools do not reflect the construct of apathy closely enough.

\section{New approaches of assessment}

The ICT have been proposed in several studies as a new approach for the evaluation of NPS, because they can provide a more objective assessment in clinical trials than currently used tools [37-38]. In particular ICT assessments involving measurement of physical 
behavior by movement sensors and imaging and video processing, are of interest because they allow capturing the patients' performances and actions in real time and real life situations as well as changes induced by apathy at a level that is not yet detectable by a human observer. Likewise, ICT can provide additional indirect information about the presence of apathetic behavior, like the assessment of GDB [39] and autonomy in instrumental activities of daily living (IADL), which are negatively associated with apathy [9].

In general, technology has been mainly identified as one tool that can be used to support independent living and improve quality of life for people with dementia and their carers [40]. Several studies using ICT in the assessment of different domains show potential benefits of considering such devices in clinical practice as well for the evaluation of apathy. Some of those new employed technologies, currently available or in development, are presented in the following sections.

Actigraphy.

Ambulatory actigraphy, consisting of a small device containing a piezoelectric accelerometer, is frequently used to monitor motor activity and has been proposed as an observer-independent evaluation method in different disorders (Table 2.). Van Someren discussed actigraphy in the context of rest-activity rhythms in aging, $\mathrm{AD}$, and Parkinson's Disease [41] concluding that it is a useful tool for assessing rhythm disturbances in the natural environment of the patient. In this sense, the motivational disturbances causing apathy are often reflected by a general motor retardation and are therefore detectable as an abnormally low activity level [42] by an actigraph worn for example during a common neuropsychological consultation or even at home.

The lower the measured index of activity, the higher its probability to correlate positively with apathy severity, which can serve the clinician as an additional objective source of information. Thus, more recent 
studies have shown that actigraphic locomotor activity assessment can be useful to evaluate NPS in dementia such as agitation [43-45], depression [46], and apathy [47].

Recently, two studies with AD patients showed that the patients' obtained apathy scores on neuropsychiatric assessment scales correlate negatively with mean motor activity measured by the actigraph [47; 48]. This validates the use of such objective measurement devices for evaluating selfinitiated action of participants during different time periods of observation in different environments (controlled and uncontrolled). Mulin et al. [13-14] have studied the relationship between apathy and sleep/wake patterns in individuals with AD using as well ambulatory actigraphy. It was shown that the AD patients with apathy had significantly lower daytime mean motor activity, higher wake after sleep onset, time in bed, sleep latency, and night-time mean motor activity. Green et al. [49] described a quantitative method for the assessment of cognitive decline, which is commonly associated with apathy [50], by using quantitative movement parameters derived frombody-worn inertial sensors.Hence, it must be underlined that actigraphy may be inadequate in patients with comorbid mobility problems (Parkinsonism or arthritis) as they may enhance or decrease levels of motor activity. Consequently, in the majority of actigraphic studies, presence of mobility problems represents a non-inclusion criterion for patients.

\section{Other technologies.}

Other technologies such as automatized video recognition, infrared sensors, computerized tests, tracking technologies, or robotics could also show interest for a more objective evaluation of NPS, even if they were, likewise, not initially designed for this purpose. An overview of studies using different technologies for assessment, monitoring, and support in the healthcare field and its link to potential apathy evaluation is represented in Table 2. 


\section{Infrared sensors}

In several articles, pattern recognition models for assessing behavioral rhythms with the help of motion detection sensors are described. The absence or decrease of certain behavioral rhythms could therefore be easily detected and linked with possible presence of apathy, and in particular the dimension of lack of initiative, if symptoms were already beforehand reported to a clinician. Bannerjee et al. [51] developed an automated surveillance system based on passive infrared sensors that show the ability to identify correctly $89 \%$ sequences of movement, in comparison with manual analysis.

Likewise in Japan, Suzuki et al. was able to identify the pattern of daily indoor living activities as well as duration times of older people in a nursing home by using sensor outputs of an infrared monitoring system [52-55]. Within a telecare project to help older people in France, a multisensor home monitoring system has been developed to observe mobility changes that may indicate abnormal events [56]. Dodge et al. used infrared sensors that were installed on the ceiling of the homes of older individuals in order to measure walking speed and its variability and successfully distinguish healthy participants from those with MCI [57]. Chan et al. described an experimental system for monitoring older patient's mobility [58]. Sensors were installed in a hospital room in a long-stay setting for the older people and physicians had defined preestablished activity patterns in the form of sensor sequence triggering for the experiments. Patients were monitored, showing good agreement between the system obtained data and the findings of the caring staff. Within the longitudinal community cohort study of Kaye et al., the deployment of an unobtrusive homebased assessment platform for seniors was investigated. Sensors have been installed in the homes of 265 older persons for an average of 33 months, creating different metrics such as total daily activity, time out-of-home, and walking speed. The continuous monitoring of a 4-week period provided a practical summary of a persons' cognitive status and behavioral patterns. Those 
studies show promising results for the use of technologies in healthcare settings and, in particular, for the assessment of apathy in dementia patients because a patient's functional status in daily living activities can be measured more objectively.

\section{Tracking technologies.}

Geo-localization methods using tracking technologies such as global positioning system (GPS) can also be employed for the assessment of mobility behavior and therefore indirectly diminished self-initiated behavior often present in apathy. By convincing a patient to carry a smart-phone with him, the GPS is easy to employ because it is mostly integrated and would help in particular to assess outof- home mobility behavior, which serves in turn as an indicator for the amount of goaloriented behavior, for example, pleasure reasons, such as going for a walk or meeting a friend. The data transfer and alarm signal sending to the family and caregiver could be programmed and performed automatically by a connected computer system. Recently, Shoval et al. published a research protocol describing a project that aims to measure mobility in 360 dementia patients, MCI and impaired controls by taking advantage of advanced tracking technologies [59]. Wahl et al. examined the hypothesis that in older adults, cognitive resources are more closely linked with out-of-home behavior than motivational resources by using GPS technology [60]. In the last few years, different geo-location devices have been developed in order to minimize risk and manage unsafe wandering. Faucounau et al. explored the needs and perceptions of wandering persons towards existing tracking devices as well as their acceptability and usability [61]. It can be concluded that information about a patients' out-ofhome behavior, by means of GPS, can be used as a reliable derivative for the assessment of a patients' motivational level to initiate social interaction, exercise, or other usually rewarding activities. 


\section{Computerized testing.}

Computerized testing offers accurate recording of reaction times, automatic capture, processing of data (minimizing human errors), standardization of test administration, and automatic scoring (minimizing sources of response bias) and could therefore be proposed for the evaluation of apathy in terms of the lack of responsiveness to a stimulus [16]. The overall motor retardation often found in patients with apathy may be because of deficits in motivational decisionmaking processes and therefore be reflected in a slowing down of reaction time responses [62]. Those tests could be simply integrated in a usual neuropsychological assessment battery and may be linked with a measurement of skin conductance in order to capture stress levels, which could serve as an indicator for possible absence of emotional expressivity, one of the key symptoms of apathy.

David et al. proposed a computerized reaction time (RT) task for apathy assessment in MCI and AD patients [63], and demonstrated that patients with apathy had significantly higher RT than patients without apathy during a decision-making task. Further, Dubal, and Jouvent noted as well longer RTs in anhedonic subjects performing a response competition task which can potentially be related to lack of interest [64]. This is in line with the findings of Njombo et al. who likewise attempted to investigate the role of apathy and, in particular, the behavioral aspect of goal-directed activity, in motivated decision making on the Iowa Gambling Task [65]. The results showed that brain damaged patients with apathy were distinctively impaired on the task compared to nonapathetic brain damaged patients and healthy controls. Although slowing of RT may not be useful as an early diagnostic marker for dementia, there seems to be evidence that it may be linked to the presence of apathy. Furthermore, it has to be underlined that computerized testing in particular seems to be of relevance for some additional objective information that can be used for diagnostics. Nevertheless, at present, these tests will probably never be able to replace traditional clinical assessments. 


\section{Computerized video analyses}

Systematic observation through video monitoring may provide an additional comprehensive view on the patient's life and functional status, thus presenting another objective method of clinical examination [66]. Functionality in IADL has been demonstrated to correlate significantly with apathy severity and thus could be detected by long-term video analyses in a patient's natural environment. Once apathy symptoms have been reported, a system could automatically detect activities and confirm through data extracted in real time if functionality in daily life decreased or not. This type of evaluation has been investigated in geriatric psychiatry in particular [67]. So far, this method has been performed through visual analyses by a direct observer and therefore risks lack of objectivity as well as reliability. Automatic computer based analysis, which allows recognition of certain events and patients' behavioral patterns, may offer a new solution to those former assessment problems [68] is known about the use of systematic or automatic observation of apathetic behaviors and thus evokes a promising field of research. The use of these technologies embodies an innovative methodology with a high level of ecological validity, which can lead to a better understanding of apathy, and might result in new diagnostic tools and treatment approaches. Recently, Sacco et al. demonstrated that it is possible using a video monitoring system to obtain a quantifiable assessment of IADLs in $\mathrm{AD}$ and in MCI patients [69]. Robinovitch et al. demonstrated that digital video cameras installed in common areas provide insight into sequences of events that most commonly lead to falls and lead therefore to more valid and effective approaches for balance assessment and fall prevention in long-term care [70].

\section{Smart homes.}

Recent work suggests that many sensors placed throughout a home environment in combination with a few sensors worn on the body may permit a system to automatically recognize and monitor everyday 
activities, and therefore could serve further as an indicator for apathy presence. By merging multisensor data, a more accurate and complete profile of a patient's status can be obtained and transferred to the clinician including information about apathy-like behavior such as loss of interest, often characterized by an important reduction in motor activity combined with an absence of emotional responsivity, measurable by, for example, an actigraph that can measure as well skin conductance. Evans et al. discuss the use of 'smart homes', in their definition, homes that are outfitted with technology that automate data capture and provide interventions related to health, as an opportunity to assist in identifying slowly evolving events such as cognitive impairment and decline in functionality [71]. Many, socalled smart home projects have been undertaken and described [72]. Several reviews have been published so far, outlining the current status of smart homes projects around the world [73-75]. Lee [76] described how to design ubiquitous home sensor systems that can monitor how well individuals carry out everyday activities important to independence, but also being associated with apathy [11]. A paper published by Riikonen et al. emphasizes the notion of user needs and perceived efficacy of the usefulness of the employed technologies when it comes to acceptability of such smart homes [77]. These data show that smart homes might be a promising tool for getting more objective data about a patient's daily activities, and in this respect also the assessment of executive functioning, which is related to apathy, in particular in the early phases of cognitive decline and often characterized by poor levels of initiative [9]. 


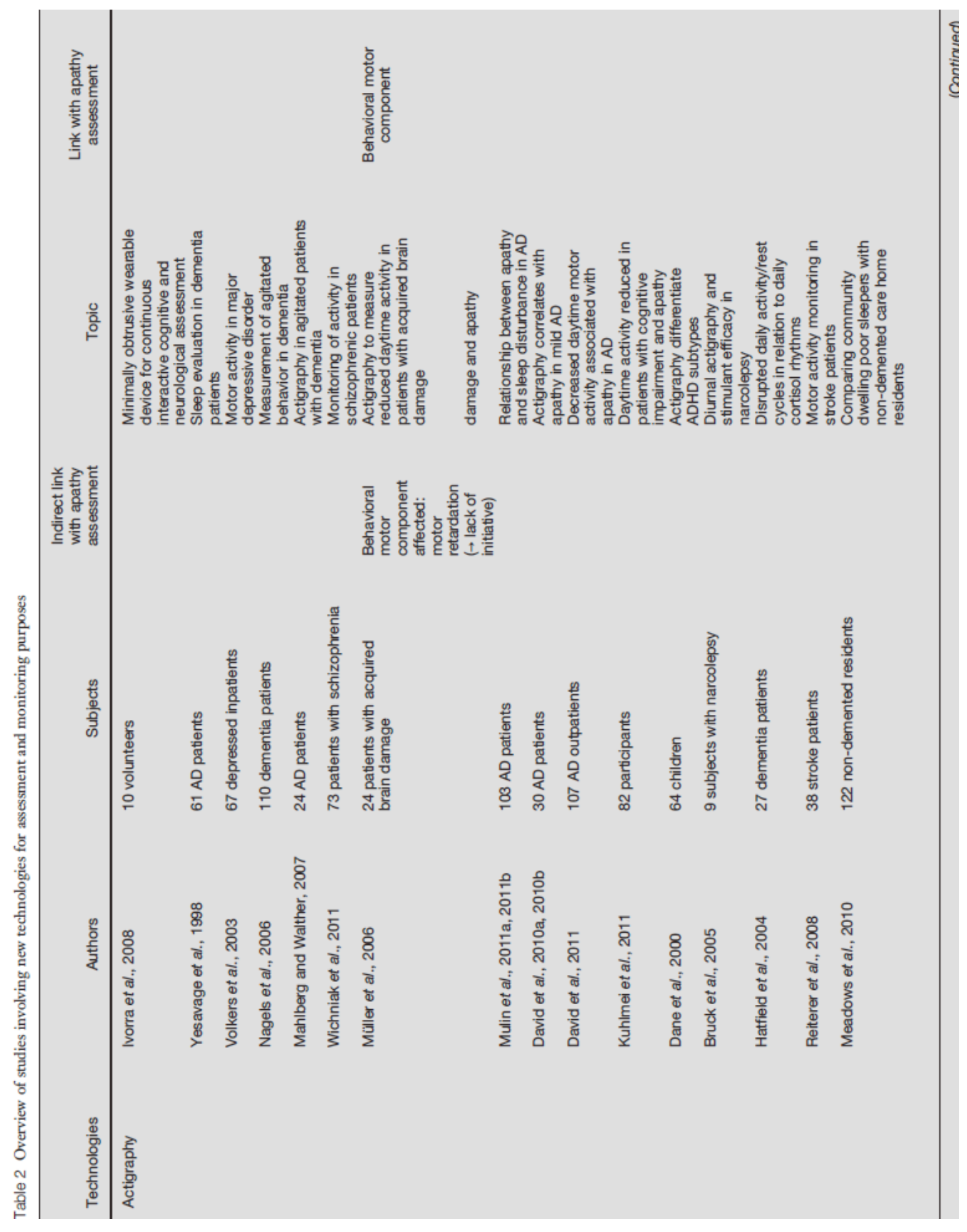




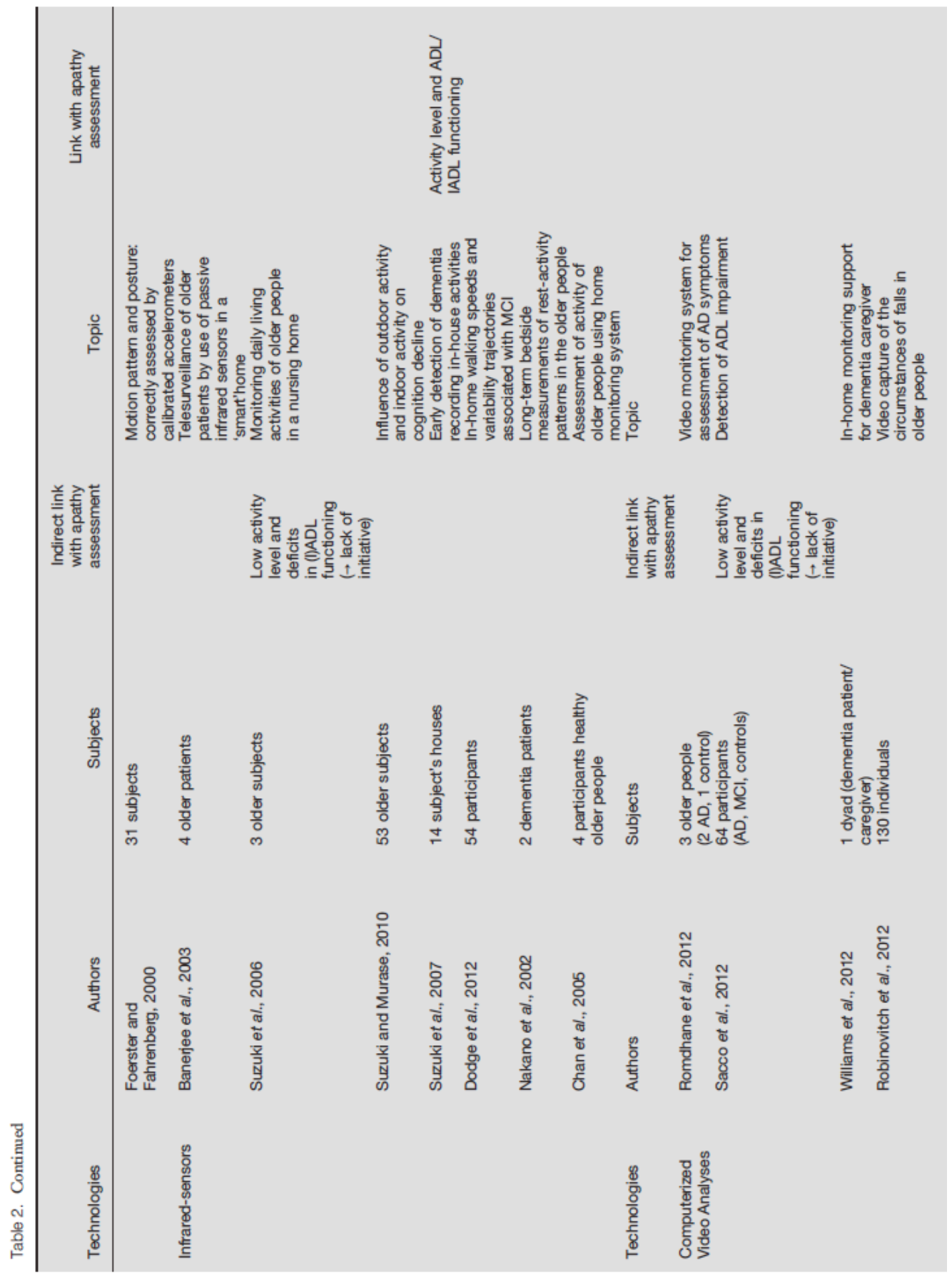



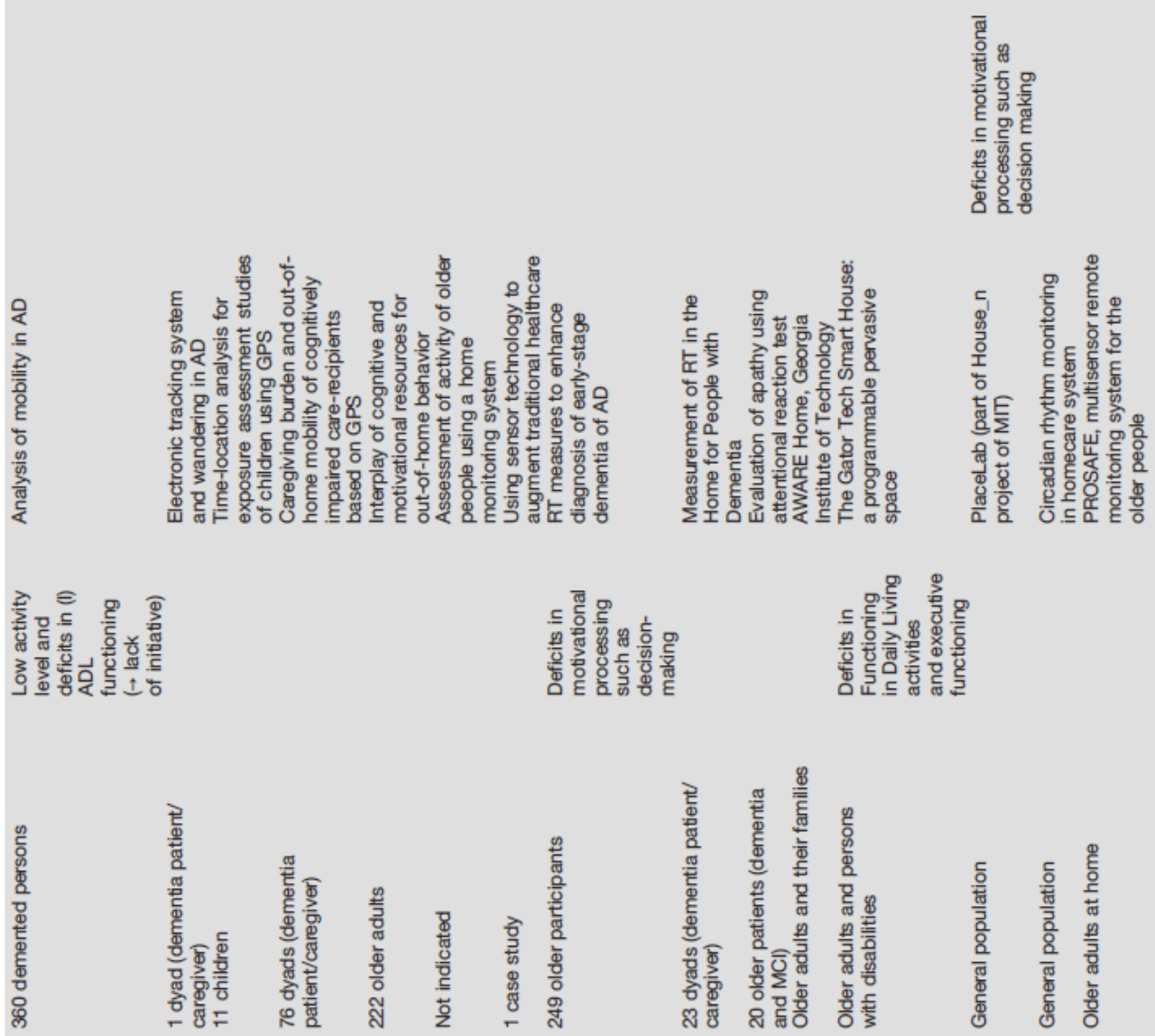

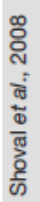

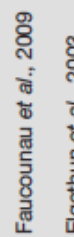

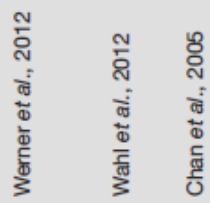

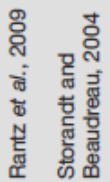

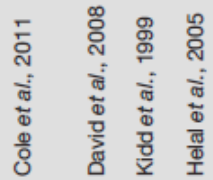

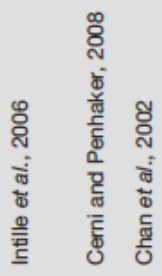

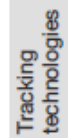
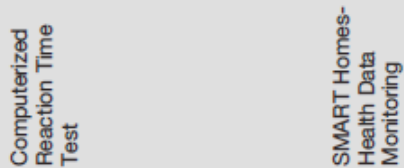


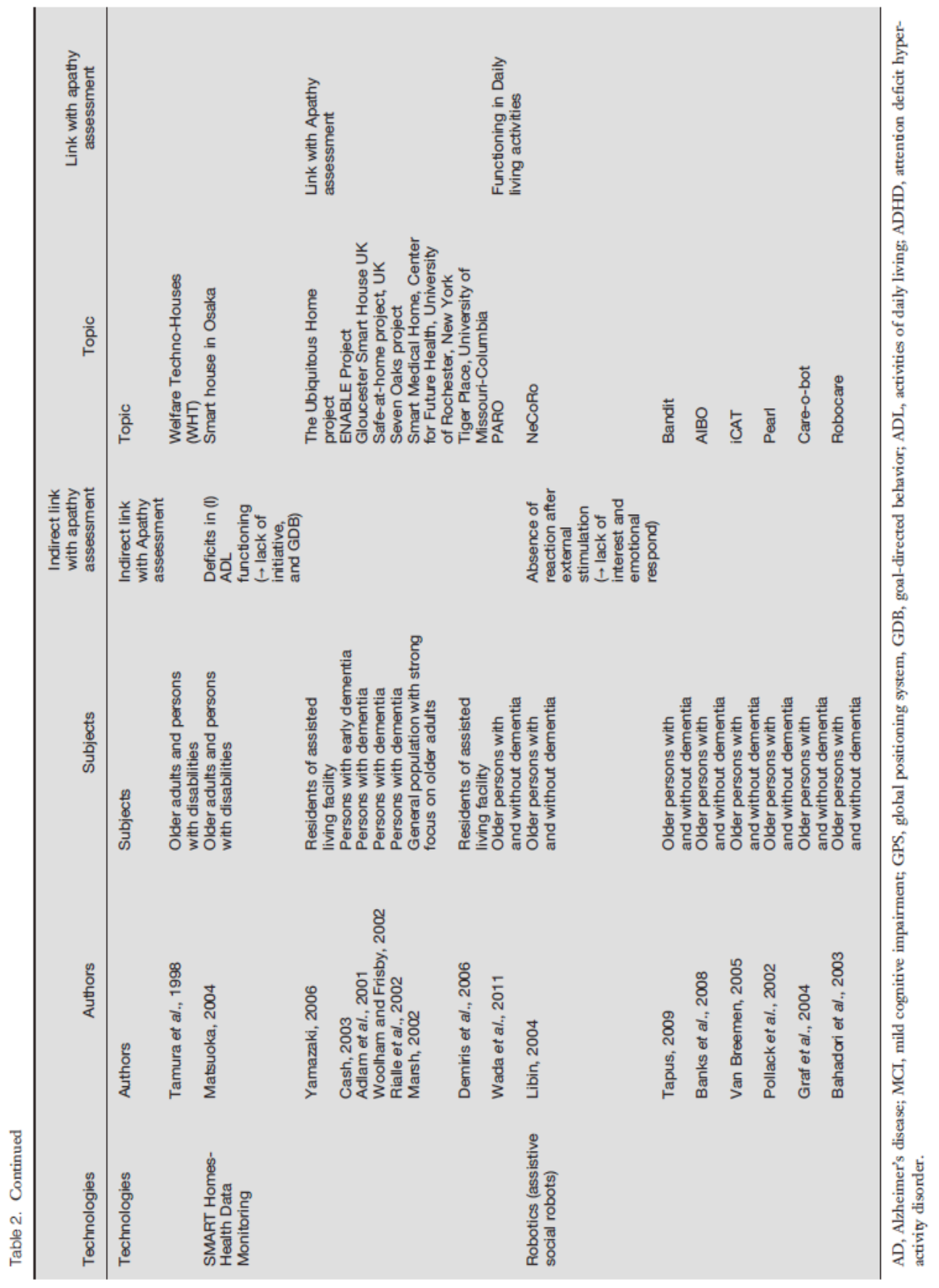




\section{DISCUSSION}

The main aim of the present review was to provide an overview of well-known and new potential ICT tools for the assessment of apathy. The overall results are in line with the recently suggested recommendations for ICT use in AD assessment coming from an expert panel held during the Clinical Trials on Alzheimer's Disease meeting in Monaco last October [78]. It can be summarized that apathy-related behavioral changes can manifest themselves indirectly in motion patterns and therefore be detected by various ICT devices. The strength of this approach is that assessment by means of ICT can be acquiredover a long-term period and can be incorporated easily into a person's everyday environment withoutthe risk of observer's biases. Further, automated detection of apathy could be possible at an earlier stage, leading to an improvement of care and a possible increase of earlypreventive interventions for disease progression.

Until now, several difficulties can emerge while assessing apathy; one important difficulty is, for example, to determine if reduction in behavior from the patients' premorbid state, in general signs of diminished effort or lowered responsiveness, is either because of cognitive decline commonly present in $\mathrm{AD}$, or poor motivation [1]. Therefore, apathy can be easily confounded or overlooked. Hence, the rating scales fail to fully capture the complexity of the symptom apathy, and this can lead to delayed diagnosis. Brown and Pluck underline that apathy has a considerable overlap with negative symptoms [39], namely the absence of normal movement, cognition, and emotional states. These symptoms might reflect fundamental impairments in basic brain mechanisms involved in motivational processes that underlie GDB [26]. This is in line with neurological models suggesting that apathy follows dysfunction in frontalsubcortical brain circuits for motivation-related executive processing $[79 ; 38]$. When it comes to the assessment of reduction in GDB and apathy, until today, no tool has been yet developed, able to fully 
capture its clinical phenomenology. Therefore, we are still limited to focus just on behavioral aspects of apathy or relevant associations that can serve as indicators and hence contribute with other clinical and biological data to the diagnosis of apathy. For example, the commonly affected motor component of apathy [80] can be reflected in low activity levels or motor retardation and objectively detected by the help of actigraphy [38].

Further, in addition to cognitive decline, persistent apathy plays a significant role in rapid functional decline, and the loss of autonomy in IADL $[81 ; 11]$ and its perseverance might be a negative factor [82]. Likewise, Boyle et al. demonstrate that executive cognitive dysfunction and apathy are highly associated with functional impairment in patients with $\mathrm{AD}$ [9]. Consequently, the detection of this functional decline in ADL and IADL via video monitoring, infrared sensors, or other technological devices could possibly indicate as well presence of apathy in terms of a reduction in selfinitiated behavior. It has to be underlined that although several ICT techniques seem to be promising new tools for the assessment of apathy, none of them was specifically designed for the assessment of apathy and there is much work to be carried out before these technologies can actually be used for assisting in the diagnosis of apathy. In particular, neither one screening tool has been developed yet able to detect changes in all three dimensions of apathy (emotion, cognition, and behavior) simultaneously. ICT are less accurate when it comes to recognizing more complex patterns such as emotional aspects compared to motor activity or RTs. Therefore, emotional blunting has been the most difficult subsymptom of apathy to detect as it can be often mistaken, for example, as depression. Nevertheless, although emotions are unobservable, many objective expressions, and behavioral responses to emotional stimuli could further serve for assessment purposes [83] and be integrated in the development of new evaluation methods such as automatic facial emotion recognition or electrodermal conduction. Several technologies that can detect certain subsymptoms of apathy 
have been described in this review to stimulate clinicians to considerate other strategies for the assessment of apathy next to the traditional questionnaires, as they can suffer from the clinicians subjectivity. Each technology has its strengths and weaknesses and has to be consequently chosen accordingly to resources and clinical settings. The use of actigraphy, for example, doesn't require advanced expertise and can be easily implemented in standard assessment procedures during visits in daily clinics. Whereas other technologies such as the use of whole sensor systems, similar to in smart home studies, are more designed for research purposes and requires the implication of experts from the field such as engineers or computer scientists.

The strength of the present review is that it has provided an extensive critical review of new ICT technologies that might be used as an objective assessment of apathy. However, because only few previous epidemiological studies have been performed into the use of ICT for the assessment of NPS, the present study was limited to being a narrative review.

To conclude, ICT could more easily help for the assessment of two specific dimensions of apathy: lack of initiative (by examining RTs, motor activity levels), and lack of interest (lack of out-of-home mobility using GPS, monitoring via infrared sensors). Furthermore, actigraphy measurements, for example, can serve as an indirect marker of levels of 'internal energy', leading to the ability to take decisions or to be interested in something [39].

Certain goal-oriented behavior models tested among animals [84] could further be an interesting testable model for apathy in humans, whereas the 'wanting' dimension of motivation could be assessed with actigraphy or RT tests. Nevertheless, in order to differentiate between various causes for motor retardation such as depression or diseases that affect mobility functions and apathy, it is of great importance to 
'tease' out those other possible causes to ensure a valid and complete evaluation of apathy. This can be carried out by the usual applied neuropsychological assessment, supplementary extensive interviews with the family or caregivers, clinical observations during assessments, and a detailed study of the medical history of the patient, in those cases where the causes of the abnormal motor behavior is uncertain. For this reason, we propose to apply an integrative approach, whereupon a multidimensional assessment is carried out consisting of combining clinical data obtained, for example, from a caregiver and medical results with data obtained by ICT that indicate the possible presence of certain apathy components or relevant associations. In order to move this field forward, future studies with stronger methodology and bigger population sizes are needed to investigate and validate the efficacy of the use of ICT for the assessment of apathy.

Furthermore, an automatized fusion (integration approach) of the multiple sensor measurements is needed in order to capture ideally simultaneously all subsymptoms of apathy and to facilitate the use of such technologies in clinical practice by being able to provide immediate visual feedback to the clinician, caregiver, and patient with the help, for example, of a tablet. Another further advancement needed would be to link the automatized detection of apathy symptoms with certain early intervention strategies promoted directly by the technology itself such as, for example, with serious games or robotics. 


\section{REFERENCES}

1. Landes AM, Sperry SD, Strauss ME, Geldmacher DS. 2001. Apathy in Alzheimer's d isease. J Am Geriatr Soc 49: 1700-1707.

2. Aalten P, De Vugt ME, Lousberg R, et al. 2003. Behavioral problems in dementia: a factor analysis of the neuropsychiatric inventory. Dement Geriatr Cogn Disord 15: 99-105.

3. Allegri RF, Sarasola D, Serrano CM, et al. 2006. Neuropsychiatric symptoms as a predictor of caregiver burden in Alzheimer's disease. Neuropsychiatr Dis Treat 2: 105-110.

4. Aalten P, Verhey FR, Boziki M. 2007. Neuropsychiatric syndromes in dementia. Results from the European Alzheimer Disease Consortium: part I. Dement Geriatr Cogn Disord 24: 457463.

5. Hurt C, Bhattacharyya S, Burns A, et al. 2008. Patient and caregiver perspectives of quality of life in dementia. An investigation of the relationship to behavioural and psychological symptoms in dementia. Dement Geriatr Cogn Disord 26: 138-146.

6. Benoit M, Dygai I, Migneco O, et al. 1999. Behavioral and psychological symptoms in Alzheimer's disease. Relation between apathy and regional cerebral perfusion. Dement Geriatr Cogn Disord 10: 511-517.

7. Robert PH, Verhey FR, Byrne EJ, et al. 2005. Grouping for behavioral and psychological symptoms in dementia: clinical and biological aspects. Consensus paper of the European Alzheimer disease consortium. Eur Psychiatry 20: 490-496.

8. Wadsworth LP, Lorius N, Donovan NJ, et al. 2012. Neuropsychiatric Symptoms and Global Functional Impairment along the Alzheimer's Continuum. Dement Geriatr Cogn Disord 34: 96-111. 
9. Boyle PA, Malloy PF, Salloway S, et al. 2003. Executive dysfunction and apathy predict functional impairment in Alzheimer disease. Am J Geriatr Psychiatry 11: 214-221.

10. Starkstein SE, Jorge R, Mizrahi R, Robinson RG. 2006. A prospective longitudinal study of apathy in Alzheimer's disease. J Neurol Neurosurg Psychiatry 77: 8-11.

11. Lechowski L, Benoit, M, Chassagne, P, et al. 2009. Persistent apathy in Alzheimer's disease as an independent factor of rapid functional decline: the REAL longitudinal cohort study. Int $\mathrm{J}$ Geriatr Psychiatry 24: 341-346.

12. Robert PH, et al. 2009. Proposed diagnostic criteria for apathy in Alzheimer's disease and other neuropsychiatric disorders. Eur Psychiatry 24: 98-104.

13. Mulin E, Leone E, Dujardin K, et al. 2011a. Diagnostic criteria for apathy in clinical practice. Int $\mathrm{j}$ geriatric psychiatry 26 : 158-165.

14. Mulin E, Zeitzer JM, Friedman L, et al. 2011b. Relationship between apathy and sleep disturbance in mild and moderate Alzheimer's disease: an actigraphic study. J Alzheimers Dis 25: 85-91.

15. Stuss DT, Van Reekum R, Murphy KJ. 2000. Differentiation of States and Causes of Apathy. In The Neuropsychology of Emotion, Borod J (ed.). Oxford University Press: New York.

16. Levy R. 2012. Apathy: a pathology of goal-directed behaviour. A new concept of the clinic and pathophysiology of apathy. Rev Neurol (Paris) 168: 585-597.

17. Robert PH, Berr C, Volteau M, et al. 2008. Importance of lack of interest in patients with mild cognitive impairment. Am J Geriatr Psychiatry 16: 770-776.

18. Yeager CA, Hyer L. 2008. Apathy in dementia: relations with depression, functional competence, and quality of life. Psychol Rep 102: 718-722. 
19. Tagariello P, Girardi P, Amore M. 2009. Depression and apathy in dementia: same syndrome or different constructs? A critical review. Arch Gerontol Geriatr 49: 246-249.

20. Demers L, Oremus M, Perrault A, Champoux N, Wolfson C. 2000. Review of outcome measurement instruments in Alzheimer's disease drug trials: psychometric properties of functional and quality of life scales. J Geriatr Psychiatry Neurol 13: 170-180.

21. Forester BP, Oxman TE. 2003. Measures to assess the noncognitive symptoms of dementia in the primary care setting. Prim Care Companion J Clin Psychiatry 5: 158-163.

22. Cummings JL, Mega M, Gray K, et al. 1994. The neuropsychiatric inventory: comprehensive assessment of psychopathology in dementia. Neurology 44: 2308-2314.

23. Cummings JL. 1997. The neuropsychiatric inventory: assessing psychopathology in dementia patients. Neurology 48: 10-16.

24. Robert P, Verhey FR, Aalten P, Cortes F, Byrne EJ. 2007. Neuropsychiatric outcome for clinical trials. J Nutr Health Aging 11:345-347.

25. Marin RS. 1990. Differential diagnosis and classification of apathy. Am J Psychiatry 147: 2230.

26. Marin RS. 1991. Apathy: a neuropsychiatric syndrome. J Neuropsychiatry Clin Neurosci 3: 243-254.

27. Marin RS, Biedrzycki RC, Firinciogullari S. 1991. Reliability and validity of the Apathy Evaluation Scale. Psychiatry Res 38: $143-162$.

28. Sockeel P, Dujardin K, Devos D, et al. 2006. The Lille apathy rating scale (LARS), a new instrument for detecting and quantifying apathy: validation in Parkinson's disease. J Neurol Neurosurg Psychiatry 77: 579-584.

29. Robert PH, et al. 2002. The apathy inventory: assessment of apathy and awareness in Alzheimer's disease, Parkinson's disease and mild cognitive impairment. Int $J$ Geriatric 
Psychiatry 17: 1099-1105.

30. Leentjens AF, Dujardin K, Marsh L. 2008. Apathy and anhedonia rating scales in Parkinson's disease: critique and recommendations. Mov Disord 23: 2004-2014.

31. Stella F, De Andrade LP, Garuffi M, et al. 2013. Validation of the Brazilian version of the Apathy Inventory. Int J Geriatr Psychiatry 28(9): 979-986.

32. Clarke DE, Van Reekum R, Patel J, Simard M, Gomez E, Streiner DL. 2007. An appraisal of the psychometric properties of the Clinician version of the Apathy Evaluation Scale (AESC). Int J Methods Psychiatr Res 16: 97-110.

33. Clarke DE, Ko JY, Kuhl EA, et al. 2011. Are the available apathy measures reliable and valid? A review of the psychometric evidence. J Psychosom Res 70: 73-97.

34. Starkstein SE, Petracca G, Chemerinski E, Kremer J. 2001. Syndromic validity of apathy in Alzheimer's disease. Am J Psychiatry 158: 872-877.

35. Starkstein SE, Ingram L, Garau ML, Mizrahi R. 2005. On the overlap between apathy and depression in dementia. J Neurol Neurosurg Psychiatry 76: 1070-1074.

36. Connor DJ, Sabbagh MN, Cummings JL. 2008. Comment on administration and scoring of the Neuropsychiatric Inventory in clinical trials. Alzheimers Dement 4:390-394.

37. David R, Mulin E, Mallea P, Robert PH. 2010b. Measurement of neuropsychiatric symptoms in clinical trials targeting Alzheimer's disease and related disorders. Pharmaceuticals Open Access 3: 2387-2397.

38. Robert PH, Mulin E, Mallea P, David R. 2010. REVIEW: apathy diagnosis, assessment, and treatment in Alzheimer's disease. CNS Neurosci Ther 16: 263-271.

39. Brown RG, Pluck G. 2000. Negative symptoms: the 'pathology' of motivation and goal-directed behaviour. Trends Neurosci 23: 412-417. 
40. Lauriks, S, Reinersmann, A, Van Der Roest, HG, et al. 2007. Review of ICT-based services for identified unmet needs in people with dementia. Ageing Res Rev 6: 223-246.

41. Van Someren EJ. 1997. Actigraphic monitoring of movement and rest-activity rhythms in aging, Alzheimer's disease, and Parkinson's disease. IEEE Trans Rehabil Eng 5: 394-398.

42. Marin RS, Fogel BS, Hawkins J, Duffy J, Krupp B. 1995. Apathy: a treatable syndrome. J Neuropsychiatry Clin Neurosci 7: 23-30.

43. Nagels G, Engelborghs S, Vloeberghs E, et al. 2006. Actigraphic measurement of agitated behaviour in dementia. Int J Geriatr Psychiatry 21: 388-393.

44. Mahlberg R, Walther S. 2007. Actigraphy in agitated patients with dementia. Monitoring treatment outcomes. Z Gerontol Geriatr 40: 178-184.

45. Mahlberg R, Walther S, Eichmann U, Tracik F, Kunz D. 2007. Effects of rivastigmine on actigraphically monitored motor activity in severe agitation related to Alzheimer's disease: a placebo-controlled pilot study. Arch Gerontol Geriatr 45: 1926.

46. Volkers, AC, Tulen, JH, Van Den Broek, WW, et al. 2003. Motor activity and autonomic cardiac functioning in major depressive disorder. J Affect Disord 76: 23-30.

47. David R, et al. 2010a. Ambulatory actigraphy correlates with apathy in mild Alzheimer's disease. Dementia: Int. J. Social Res. Pract 9: 509-516.

48. David R, Mulin E, Friedman L, et al. 2011. Decreased daytime motor activity associated with apathy in alzheimer disease: an actigraphic study. Am J Geriatr Psychiatry 20(9): 806-814.

49. Greene BR, Kenny RA. 2012. Assessment of cognitive decline through quantitative analysis of the timed up and go test. IEEE Trans Biomed Eng 59: 988-995. 
50. Richard E, Schmand B, Eikelenboom P, et al. 2012. Symptoms of apathy are associated with progression from mild cognitive impairment to Alzheimer's disease in non-depressed subjects. Dement Geriatr Cogn Disord 33: 204-209.

51. Banerjee S, Steenkeste F, Couturier P, Debray M, Franco A. 2003. Telesurveillance of elderly patients by use of passive infra-red sensors in a 'smart' room. J Telemed Telecare 9:2329.

52. Suzuki R, Ogawa M, Otake S, et al. 2004. Analysis of activities of daily living in elderly people living alone: singlesubject feasibility study. Telemed J E Health 10: 260-276.

53. Suzuki R, Otake S, Izutsu T, Yoshida M, Iwaya T. 2006. Monitoring daily living activities of elderly people in a nursing home using an infrared motion-detection system. Telemed J E Health 12: 146-155.

54. Suzuki T, Murase S, Tanaka T, Okazawa T. 2007. New approach for the early detection of dementia by recording inhouse activities. Telemed J E Health 13: 41-44.

55. Suzuki T, Murase S. 2010. Influence of outdoor activity and indoor activity on cognition decline: use of an infrared sensor to measure activity. Telemed J E Health 16: 686-690.

56. Chan M, Campo E, Esteve D. 2005. Assessment of activity of elderly people using a home monitoring system. Int J Rehabil Res 28: 69-76.

57. NC, Dodge HH, Mattek Austin D, Hayes TL, Kaye JA. 2012. In-home walking speeds and variability trajectories associated with mild cognitive impairment. Neurology 78: 1946-1952.

58. Chan M, Campo E, Laval E, Esteve D. 2002. Validation of a remote monitoring system for the elderly: application to mobility measurements. Technol Health Care 10: 391-399.

59. Shoval N, Auslander GK, Freytag T, et al. 2008. The use of advanced tracking technologies for the analysis of mobility in Alzheimer's disease and related cognitive diseases. BMC 
Geriatr 8: 7.

60. Wahl HW, Wettstein M, Shoval N, et al. 2012. Interplay of Cognitive and Motivational Resources for Out-of-Home Behavior in a Sample of Cognitively Heterogeneous Older Adults: Findings of the SenTra Project. J Gerontol B Psychol Sci Soc Sci 68(5): 691-702.

61. Faucounau V, Riguet M, Orvoen G, et al. 2009. Electronic tracking system and wandering in Alzheimer's disease: a case study. Ann Phys Rehabil Med 52: 579-587.

62. Robert G, Le Jeune,F, Lozachmeur C, et al. 2012. Apathy in patients with parkinson disease without dementia or depression: a PET study. Neurology 79: 1155-1160.

63. David R, Collazzo G, Siccardi L, et al. 2008. Evaluation of apathy using attentional reaction test in neurodegenerative diseases. Eur Psychiatry 23: 193.

64. Dubal S, Jouvent R. 2004. Time-on-task effect in trait anhedonia. Eur Psychiatry 19: 285 -291.

65. Njomboro P, Deb S, Humphreys GW. 2012. Apathy symptoms modulate motivational decision making on the Iowa gambling task. Behav Brain Funct 8: 63.

66. Fernandez-Llatas C, Garcia-Gomez JM, Vicente J, et al. 2011. Behaviour patterns detection for persuasive design in nursing homes to help dementia patients. Conf Proc IEEE Eng Med Biol Soc 2011: 6413-6417.

67. Bowie PM, Mountain G. 1993. Using direct observation to record the behaviour of long-stay patients with dementia. Int $\mathrm{J}$ Geriatr Psychiatry 8: 857-864.

68. Romdhane R, Mulin E, Derreumeaux A, et al. 2012. Automatic video monitoring system for assessment of Alzheimer's disease symptoms. J Nutr Health Aging 16: 213-218.

69. Sacco G, Joumier V, Darmon N, et al. 2012. Detection of activities of daily living impairment in Alzheimer's disease and mild cognitive impairment using information and communication technology. Clin Interv Aging 7: 539-549. 
70. Robinovitch SN, Feldman F, Yang Y, et al. 2012. Video capture of the circumstances of falls in elderly people residing in long-term care: an observational study. Lancet 381(9860): 47-54.

71. Evans DA, Grodstein F, Loewenstein D, Kaye J, Weintraub S. 2011. Reducing case ascertainment costs in U.S. population studies of Alzheimer's disease, dementia, and cognitive impairment-Part 2. Alzheimers Dement 7: 110-123.

72. Chapman A. 2001. There's no place like a smart home. Journal of Dementia Care 9: 28.

73. Demiris G, Hensel BK. 2008. Technologies for an aging society: a systematic review of 'smart home' applications. Yearb Med Inform 2008: 33-40.

74. Chan M, Campo E, Esteve D, Fourniols JY. 2009. Smart homes - current features and future perspectives. Maturitas 64 : 90-97.

75. Gentry T. 2009. Smart homes for people with neurological disability: state of the art. NeuroRehabilitation 25: 209-217.

76. Lee Matthews L. 2010. Creating salient summaries of home activity lifelog data. CHI 2010 -The 28th Annual CHI Conference on Human Factors in Computing Systems, Conference Proceedings and Extended Abstracts.

77. Riikonen M, Mäkelä K, Perälä S. 2010. Safety and monitoring technologies for the homes of people with dementia. Gerontechnology 9(1): 32-45.

78. Robert PH, Konig A, Andrieu S, et al. 2013. Recommendations for ICT use in Alzheimer's Disease assessment: Monaco CTAD expert meeting. The J Nutr Health and Aging, in press.

79. Tekin S, Cummings JL. 2002. Frontal-subcortical neuronal circuits and clinical neuropsychiatry: an update. J Psychosom Res 53: 647-654.

80. Robert G, Le Jeune,F, Lozachmeur C, et al. 2012. Apathy in patients with parkinson disease without dementia or 
depression: a PET study. Neurology 79: 1155-1160.

81. Okura T, Plassman BL, Steffens DC, et al. 2010. Prevalence of neuropsychiatric symptoms and their association with functional limitations in older adults in the United States: the aging, demographics, and memory study. J Am Geriatr Soc 58: 330-337.

82. Kamat R, Woods SP, Marcotte TD, Ellis RJ, Grant I. 2012. Implications of apathy for everyday functioning outcomes in persons living with HIV infection. Arch Clin Neuropsychol 27: 520-531.

83. Kelley AE, Berridge KC. 2002. The neuroscience of natural rewards: relevance to addictive drugs. J Neurosci 22: 33063311.

84. Berridge KC. 2009. Wanting and liking: observations from the neuroscience and psychology laboratory. Inquiry (Oslo) 52: 378.

Table References :

Adlam T, Gibbs C, Orpwood R. 2001. The Gloucester Smart House bath monitor for people with dementia. Phys Med 17: 189.

Bahadori S, Cesta A, Grisetti G, et al. 2003. RoboCare: an Integrated Robotic System for the Domestic Care of the Elderly. Proceedings of workshop on Ambient Intelligence AI. Pisa, Italy.

Banks MR, Willoughby LM, Banks WA. 2008. Animal-assisted therapy and loneliness in nursing homes: use of robotic versus living dogs. J Am Med Dir Assoc 9: 173-177.

Bruck D, Kennedy GA, Cooper A, Apel S. 2005. Diurnal actigraphy and stimulant efficacy in narcolepsy. Hum Psychopharmacol 20: 105113. 
Cash M. 2003. Assistive technology and people with dementia. Reviews in Clinical Gerontology 13: 313-319.

Cerni M, Penhaker M. Circadian rhythm monitoring in homecare systems. 13th international conference on biomedical engineering, 2008 Singapore.

Cole CS, Mennemeier M, Bost JE, Smith-Olinde L, Howieson D. 2011. Measurement of Reaction Time in the Home for People With Dementia: A Feasibility Study. Biol Res Nurs 15(2): 179-184.

Dane AV, Schachar RJ, Tannock R. 2000. Does actigraphy differentiate ADHD subtypes in a clinical research setting? J Am Acad Child Adolesc Psychiatry 39: 752-760.

Demiris G, Skubic M, Keller J, et al. 2006. Nurse participation in the design of user interfaces for a smart home system. In: BELFAST, N. I. (ed.) Proceedings of the International Conference on Smart Homes and Health Telematics.

Elgethun K, Fenske RA, Yost MG, Palcisko GJ. 2003. Time-location analysis for exposure assessment studies of children using a novel global positioning system instrument. Environ Health Perspect 111: $115-122$.

Evans DA, Grodstein F, Loewenstein D, Kaye J, Weintraub S. 2011. Reducing case ascertainment costs in U.S. population studies of Alzheimer's disease, dementia, and cognitive impairment-Part 2. Alzheimers Dement 7: 110-123.

Foerster F, Fahrenberg J. 2000. Motion pattern and posture: correctly assessed by calibrated accelerometers. Behav Res Methods Instrum Comput 32: 450-457. 
Graf B, Hans,M, Schraft RD. 2004. Care-O-bot II-development of a next generation robotic home assistant. Autonomous Robots 16: 193205.

Hatfield CF, Herbert J, Van Someren EJ, Hodges JR, Hastings MH. 2004. Disrupted daily activity/rest cycles in relation to daily cortisol rhythms of home-dwelling patients with early Alzheimer's dementia. Brain 127: 1061-1074.

Helal S, Mann W, El-Zabadani H, et al. 2005. The gator tech smart house: a programmable pervasive space. IEEE Computer Society 38(3): 64-74.

Intille S, Larson K, Munguia Tapia E, et al. 2006. Using a Live-in Laboratory for Ubiquitous Computing Research. In Proceedings of PERVASIVE 2006; vol. LNCS,

Fishkin KP, Schiele B, Nixon P, Quiley A (eds). Springer-Verlag: Berlin, Heidelberg; 3968.

Ivorra A, Daniels C, Rubinsky B. 2008. Minimally obtrusive wearable device for continuous interactive cognitive and neurological assessment. Physiol Meas 29: 543-554.

Kidd CD, Orr R, Abowd GD, et al. 1999. The aware home: a living laboratory for ubiquitous computing research. Proceedings of CoBuild'99. Position paper.

Kuhlmei A, Walther B, Becker T, Müller U, Nikolaus T. 2011. Actigraphic daytime activity is reduced in patients with cognitive impairment and apathy. Eur Psychiatry 28(2): 94-97. 
Libin C-M. 2004. Therapeutic robocat for nursing home residents with dementia: preliminary inquiry. Am J Alzheimers Dis Other Demen 19(2): 111-116.

Marsh J. 2002. House Calls. Rochester Rev 64: 22-26.

Matsuoka K. Aware home understanding life activities. Towards a humanfriendly assistive environment. In: PRESS, I., ed. International conference on smart homes and health telematics, 2004; 186-193.

Meadows, R, Luff, R, Eyers, I, et al. 2010. An actigraphic study comparing community dwelling poor sleepers with non-demented care home residents. Chronobiol Int 27: 842-854.

Müller U, Czymmek J, Thöne-Otto A, Von Cramon D. 2006. Reduced daytime activity in patients with acquired brain damage and apathy: A study with ambulatory actigraphy. Brain Inj 20: 157-160.

Nakano T, Koyama E, Nakamura T, et al. 2002. Use of an infrared sensor system to take long-term bedside measurements of rest-activity patterns in the elderly with dementia. Psychiatry Clin Neurosci 56: 287-288.

Pollack M, Engberg S, Matthews JT, et al. 2002. Pearl: a mobile robotic assistant for the elderly. AAAI Workshop on Automation as Eldercare.

Rantz MJ, Skubic M, Miller SJ. 2009. Using sensor technology to augment traditional healthcare. Conf Proc IEEE Eng Med Biol Soc 2009: 6159-6162.

Reiterer V, Sauter C, Klosch G, Lalouschek W, Zeitlhofer J. 2008. Actigraphy - a useful tool for motor activity monitoring in stroke patients. Eur Neurol 60: 285-2891. 
Rialle V, Duchene F, Noury N, Bajolle L, Demongeot J. 2002. Health 'Smart' home: information technology for patients at home. Telemed J E Health 8: 395-409

Richard E, Schmand B, Eikelenboom P, et al. 2012. Symptoms of apathy are associated with progression from mild cognitive impairment to Alzheimer's disease in non-depressed subjects. Dement Geriatr Cogn Disord 33: 204-209.

Storandt M, Beaudreau S. 2004. Do reaction time measures enhance diagnosis of early-stage dementia of the Alzheimer type. Arch Clin Neuropsychol 19: 119-124

Tamura T, Togawa T, Ogawa M, Yoda M. 1998. Fully automated health monitoring system in the home. Med Eng Phys 20: 573-579.

Tapus A. 2009. The role of the physical embodiment of a music therapist robot for individuals with cognitive impairments: longitudinal study. Virtual Rehabilitation International Conference. Haifa, Israel.

Tekin S, Cummings JL. 2002. Frontal-subcortical neuronal circuits and clinical neuropsychiatry: an update. J Psychosom Res 53: 647654.

Van Breemen AJN. 2005. ICat: experimenting with animabotics. AISB 2005 Creative Robotics Symposium. Hatfield, England.

Wada K. 2011. Robot therapy: a new approach for mental healthcare of the elderly - a mini-review. Gerontology 57: 378-386.

Werner S, Auslander GK, Shoval N, et al. 2012. Caregiving burden and out-of-home mobility of cognitively impaired care-recipients based on GPS tracking. Int Psychogeriatr 24: 18361845. 
Wichniak A, Skowerska A, Chojnacka-Wojtowicz J, et al. 2011. Actigraphic monitoring of activity and rest in schizophrenic patients treated with olanzapine or risperidone. J Psychiatr Res 45: 1381-1386.

Williams K, Arthur A, Niedens M, Moushey L, Hutfles L. 2012. Inhome monitoring support for dementia caregivers: a feasibility study. Clin Nurs Res 22(2): 139-150.

Woolham J, Frisby B. 2002. How techology can help people feel safe at home. J Dementia Care 10: 27-29.

Yamazaki T. Beyond the smart home. In: ICHIT'06, ed. International conference on hybrid information technology. 2006. 350-355.

Yesavage, JA, Friedman, L, Kraemer, HC, et al. 1998. A follow-up study of actigraphic measures in home-residing Alzheimer's disease patients. J Geriatr Psychiatry Neurol 11:7-10. 
69 


\section{CHAPTER 3}

\section{RECOMMENDATIONS FOR ICT USE IN ALZHEIMER'S DISEASE ASSESSMENT: MONACO CTAD EXPERT MEETING}

Journal of Nutrition, Health \& Aging, 17(8): 653-60.

Robert, PH, König, A, Andrieu, S, Bremond, F, Chemin, I, Chung, PC, Dartigues, JF, Dubois, B, Feutren, G, Guillemaud, R, Kenisberg, PA, Nave, S, Vellas, B, Verhey, F, Yesavage, J, and Mallea, P 


\begin{abstract}
Alzheimer disease (AD) and other related dementia represent a major challenge for health care systems within the aging population. It is therefore important to develop better instruments for assessing disease severity and disease progression to optimize patient's care and support to care providers, and also provide better tools for clinical research. In this area, Information and Communication Technologies (ICT) are of particular interest. Such techniques enable accurate and standardized assessments of patients' performance and actions in real time and real life situations. The aim of this article is to provide basic recommendation concerning the development and the use of ICT for Alzheimer's disease and related disorders. During he ICT and Mental Health workshop (CTAD meeting held in Monaco on the 30th October 2012) an expert panel was set up to prepare the first recommendations for the use of ICT in dementia research. The expert panel included geriatrician, epidemiologist, neurologist, psychiatrist, psychologist, ICT engineers, representatives from the industry and patient association. The recommendations are divided into three sections corresponding to 1 / the clinical targets of interest for the use of ICT, 2/ the conditions, the type of sensors and the outputs (scores) that could be used and obtained, $3 /$ finally the last section concerns specifically the use of ICT within clinical trials.
\end{abstract}




\section{INTRODUCTION}

Alzheimer disease (AD) and other related dementia represent a major challenge for health care systems within the aging population. Today clinician and researchers already used in clinical practice or in clinical trials several robust standardised tools such as the Mini Mental Score Examination (MMSE) for cognitive global assessment [1], the Alzheimer Disease Assessment Scale (ADAS) to measure the severity changes of the most important cognitive symptoms [2], the Neuropsychiatric Inventory (NPI) interview for Behavioral and psychological symptoms [3] and the Clinical Dementia Rating (CDR) to quantify the severity of symptoms of Dementia [4]. In AD, "dementia" is diagnosed when the disease has reached the stage where cognitive or behavioral (neuropsychiatric) symptoms interfere with social functioning or instrumental activities of daily living [5] (E). It is also recommended that the core clinical criteria, based on "functional impairment", should be used to diagnose all causes of dementia, including $\mathrm{AD}$, in all clinical settings [6] (E).

Dementia is a diagnosis merely based on clinical judgement, for which appropriate assessment instruments are of vital importance. Finding a reliable method to assess functional impairment is of high interest since disease domains other than cognition are increasingly recognized as important outcome measures in clinical practice as well as in clinical trials for antidementia drugs. The choice of outcome measures in these trials is often constrained by tradition and availability. Therefore, cognition-based psychometric measures are usually the preferred option. However, the clinical relevance and « meaningfulness » of such measures has been questioned as they may not adequately identify responders to therapy or address important aspects of outcome [7] (E). One of the main limitations remains that clinical assessments through questionnaires, scales or observations risk bias resulting from the assessor's subjectivity or the usually interviewed caregiver. Due to the time restraint, clinicians have often 
just limited access to diagnosis relevant information, particularly in cases of patients lacking awareness of their own condition. Neuropsychological tests are generally accused of being artificial and lacking ecological value. Furthermore, test results can show variability depending on many factors such as emotional state and may therefore not always fully reflect a patient's capacities and the complexity of the disease, which can lead to delayed diagnosis. In this line, Information and communication technology (ICT) may be of great interest because they enable the patients' performances and actions to be captured and accurately evaluated in real time and real life situations.

Additionally, ICT is a means to cope with the increasing number of patients with chronic diseases in our aging society. As indicated by Eghdam \& al [8] for individuals with chronic illness affecting cognitive capacities either directly (eg, dementia) or indirectly (eg, diabetes), ICT has become a fundamental part in their daily lives by providing a wide range of useful services and tools to use at home, work, or anywhere else [9].

Over the last few years, research has focused on the development and use of various sensors to monitor activities of the elderly as well as of AD patients. These include cameras and microphones for activity recognition [10] embedded sensors [11] or sensors placed on the body [12]. For instance, as part of the EXERCISE-ON study [13] whereas the impact of physical exercise on the progression of dementia symptoms was investigated, an actiwatch was used in order to monitor activity levels over a longer period of time objectively.

Other studies propose the use of such device for the screening of sleep/wake disorders [14], agitation [15] or depression [16]. With the help of infra-red sensors for motion detection, Banerjee et al. [17] developed an automated surveillance system that identifies correctly $89 \%$ sequences of movement in comparison with manual analysis. Within a telecare project to help elderly people in France [18], a multisensor home monitoring system has been developed to observe 
mobility changes that may indicate abnormal events. European Union also recognizes the confronting issues encountered by the aging populations and has initiated Framework Programme (FP 6 and FP7) to support the research into the development of process for healthy aging, biomedical advances, as well as prevention and disease management. For example, the successful FP6 COGKNOW project (http://www.cogknow.eu/) was strongly user-driven with 42 people with dementia and their informal careers involved throughout the project in specifying and testing functionalities in the four most important areas of unmet needs (memory support, daily activities, social contacts and feeling safe). In the FP7 project CONFIDENCE (http://www.confidence-eu.org/), monitoring of elderly takes place for unusual event detection and setting off the relevant alarms, but there is no direct focus on dementia, with life-logging and the appropriate feedback, such as cognitive exercises, not being offered to the people with dementia. The FP7 Hermes project (http://www.fp7- hermes.eu/) offers memory support for elderly with normal aging-related cognitive decline. Similarly, the MemoryLane project (http://www.memorylane.nu/) aima at capturing pictures of the life of people with mild dementia. However these ICT devices are mostly research prototypes which have not been completely validated. Data analysis methods are tested by using simulated physiological data. The detected activities are mostly only to measure simple motion patterns. Furthermore, these devices still need to be validated against clinically accepted standards in a clinical environment.

Most of the works done on home sensing previously have been tested with a small number of users in experimental environment or at the researchers' homes and their affiliates. While there has been progress on the algorithms that monitor elderly people's homes and interpret the signals of the sensors, what is acquired is often very limited. Nonetheless, clinical expertise and scientific literature review indicates that ICT are not able today to provide a direct diagnosis of Alzheimer's disease (AD) and related disorders. 
However, ICT provide information for the assessment of specific domains (behaviour, cognition, activity of daily living) and those indicators contribute with other clinical and biological data to the diagnosis of $\mathrm{AD}$ and related disorders. The aim of this article is to provide recommendation concerning the development and the use of ICT for Alzheimer's disease and related disorders.

\section{METHODS}

CoBTek (for Cognition - Behaviour - Technologies) is a Research Unit at Sophia-Antipolis University (UNS) in Nice, France. CoBTek missions are, using Information and Communication Technologies, and most particularly imaging and video analytic techniques: 1/ To improve diagnostic and treatment of behavioural and cognitive symptoms in Alzheimer disease and related disorders 2/ To develop new strategies in order to prevent, help and assist elderly people 3/ To improve autonomy in the elderly.

The ICT and Mental Health workshop took place during the CTAD meeting in Monaco on the 30th October 2012. The workshop was organized by the CoBTeK team and the Centre National de Référence Santé à domicile et autonomie. An expert panel was set up to prepare the first recommendations for the use of ICT in dementia research. The expert panel included geriatricians, epidemiologists, neurologists, psychiatrists, psychologists, ICT engineers, representatives from the industry and patient association. The starting presentation was held by the CoBTeK team as well as the discussion, which was audio recorded. The letter (E) after an article reference number indicates if the reference is related to the expert presentation and discussion directly at the time of the meeting. Two drafts of the recommendations regarding the use of ICT in $\mathrm{AD}$ were circulated to experts in December 2012. It includes a literature review, which is summarized in Table 1. about different studies using ICT for monitoring and screening purposes in elderly subjects. For the review research articles and reviews dating from the year 1998 to 2012 were identified in 
PubMed using the following search terms : « dementia OR alzheimer OR mild cognitive impairment » AND « assessment OR evaluation OR sreening OR monitoring» AND « new methods OR new technologies OR ICT OR (Information and Communication Technologies) OR actigraphy OR infra-red sensors OR assistive technologies OR smart homes OR GPS ». Searches were limited to articles written in English. The experts were encouraged to revise their former comments provided during the meeting in ligh of the 2 drafts. 
Table 1

Studies using ICT in elderly subjects and patients with $\mathrm{AD}$ and related disorders

\begin{tabular}{|c|c|c|c|}
\hline Technologies & Authors & Subjects & Topic \\
\hline \multirow[t]{14}{*}{ Actigraphy } & Ivorra et al., 2008 (39) & 10 volunteers & $\begin{array}{l}\text { Minimally obtrusive wearable device for continuous interactive cognitive and } \\
\text { neurological assessment }\end{array}$ \\
\hline & Yesavage et al., 1998 (40) & $61 \mathrm{AD}$ patients & Sleep evaluation in dementia patients \\
\hline & Volkers et al., 2003 (41) & 67 depressed inpatients & Motor activity in major depressive disorder \\
\hline & Nagels et al., 2006 (42) & 110 dementia patients & Measurement of agitated behavior in dementia \\
\hline & Mahlberg et al., 2007 (43) & $24 \mathrm{AD}$ patients & Actigraphy in agitated patients with dementia \\
\hline & Müller et al., 2006 (44) & $\begin{array}{l}24 \text { patients with acquired } \\
\text { brain damage }\end{array}$ & $\begin{array}{l}\text { Actigraphy to measure reduced daytime activity in patients with acquired brain } \\
\text { damage and apathy }\end{array}$ \\
\hline & Mulin et al., 2011 (45) & $103 \mathrm{AD}$ patients & Relationship between apathy and sleep disturbance in AD \\
\hline & David et al., 2010 (46) & $30 \mathrm{AD}$ patients & Actigraphy correlates with apathy in mild $\mathrm{AD}$ \\
\hline & David et al., 2011 (47) & $107 \mathrm{AD}$ outpatients & Decreased daytime motor activity associated with apathy in $\mathrm{AD}$ \\
\hline & Kuhlmei et al., 2011 (48) & 82 participants & Daytime activity reduced in patients with cognitive impairment and apathy \\
\hline & Hatfield et al., 2004 (49) & 27 dementia patients & Disnupted daily activity/rest cycles in relation to daily cortisol mythms \\
\hline & Reiterer et al., 2008 (50) & 38 stroke patients & Motor activity monitoring in stroke patients \\
\hline & Meadows et al., 2010 (51) & 122 non-demented residents & $\begin{array}{l}\text { Comparing community dwelling poor sleepers with non-demented care home } \\
\text { residents }\end{array}$ \\
\hline & Foerster, et al., 2000 (12) & 31 subjects & Motion pattern and posture: correctly assessed by calibrated accelerometers \\
\hline \multirow[t]{7}{*}{ Infrared-sensors } & Banerjee et al., 2003 (17) & 4 elderly patients & $\begin{array}{l}\text { Telesurveillance of elderly patients by use of passive infra-red sensors in a } \\
\text { 'smarthome }\end{array}$ \\
\hline & Suzuki et al., 2006 (52) & 3 elderly subjects & Monitoring daily living activities of elderly in a nursing home \\
\hline & Suzuki et al., 2010 (53) & 53 elderly subjects & Influence of outdoor activity and indoor activity on cognition decline \\
\hline & Suzuki et al., 2007 (54) & 14 subject's houses & Early detection of dementia recording in-house activities \\
\hline & Dodge et al., 2012 (55) & 54 participants & In-home walking speeds and variability trajectories associated with MCI \\
\hline & Nakano et al., 2002 (56) & 2 dementia patients & Long-term bedside measurements of rest-activity patterns in the elderly \\
\hline & Chan et al., 2005 (18) & 4 participants & Assessment of activity of elderly people using home monitoring system \\
\hline Computerized Video & Romdhane et al., 2012 (57) & 3 elderly ( $2 \mathrm{AD}, 1$ Control) & Video Monitoring system for assessment of $\mathrm{AD}$ symptoms \\
\hline \multirow[t]{3}{*}{ Analyses } & Sacco et al., 2012 (33) & $\begin{array}{l}64 \text { participants }(\mathrm{AD}, \mathrm{MCI}, \\
\text { Controls) }\end{array}$ & Detection of activities of daily living impairment \\
\hline & Williams et al., 2012 (58) & $\begin{array}{l}1 \text { dyad (dementia patient } \\
\text { /caregiver) }\end{array}$ & In-Home Monitoring support for dementia caregiver \\
\hline & Robinovitch et al., 2012 (24) & 130 individuals & Video capture of the circumstances of falls in elderly people \\
\hline Tracking & Shoval et al., 2008 (59) & 360 demented persons & Analysis of mobility in $\mathrm{AD}$ \\
\hline \multirow[t]{6}{*}{ technologies } & Faucounau et al., 2009 (60) & $\begin{array}{l}1 \text { dyad (dementia patient/ } \\
\text { caregiver) }\end{array}$ & Electronic tracking system and wandering in $\mathrm{AD}$ \\
\hline & Elgethun et al., 2003 (61) & 11 children & Time-location analysis for exposure assessment studies of children using GPS \\
\hline & Werner et al., 2012 (62) & $\begin{array}{l}76 \text { dyads(dementia patient/ } \\
\text { caregiver) }\end{array}$ & $\begin{array}{l}\text { Caregiving burden and out-of-home mobility of cognitively impaired care- } \\
\text { recipients based on GPS }\end{array}$ \\
\hline & Wahl et al., 2012 (63) & 222 older adults & Interplay of cognitive and motivational resources for out-of-home behavior \\
\hline & Chan et al., 2005 (18) & Not indicated & Assessment of activity of elderly people using a home monitoring system \\
\hline & Rantz et al., 2009 (64) & 1 case study & Using sensor technology to augment traditional healthcare \\
\hline \multicolumn{4}{|l|}{ Target audience } \\
\hline $\begin{array}{l}\text { SMART Homes- } \\
\text { Health Data }\end{array}$ & Kidd et al., 1998 (65) & $\begin{array}{l}\text { Older adults and their } \\
\text { families }\end{array}$ & AWARE Home, Georgia Institute of Technology \\
\hline \multirow[t]{15}{*}{ Monitoring } & Helal et al., 2005 (66) & $\begin{array}{l}\text { Older adults and persons } \\
\text { with disabilities }\end{array}$ & The Gator Tech Smart House: a programmable pervasive space \\
\hline & Intille et al., 2006 (67) & General population & PlaceLab (part of House_n project of MIT) \\
\hline & Cemi et al., 2006 (68) & General population & Circadian thythm monitoring in homecare system \\
\hline & Chan et al., 2005 (18) & Older adults at home & PROSAFE, multisensor remote monitoring system for the elderly \\
\hline & Demongeot et al., 2008 (69) & Older adults at home & Health Integrated Smart Home HIS, Information system TIMC-IMAG \\
\hline & Tamura et al., 1998 (70) & $\begin{array}{l}\text { Older adults and persons } \\
\text { with disabilities }\end{array}$ & Welfare Techno-Houses (WHT) \\
\hline & Matsuoka et al., 2004 (71) & $\begin{array}{l}\text { Older adults and persons } \\
\text { with disabilities }\end{array}$ & Smart house in Osaka \\
\hline & Yamazaki et al., 2006 (72) & $\begin{array}{l}\text { Residents of assisted living } \\
\text { facility }\end{array}$ & The Ubiquitous Home project \\
\hline & Cash et al., 2001 (73) & Persons with early dementia & ENABLE Project \\
\hline & Adlam et al., 2000 (74) & Persons with dementia & Gloucester Smart House UK \\
\hline & Cook et al., $2001(75)$ & General population & MavHome University of Texas at Arlington \\
\hline & Woolham et al., 2002 (76) & Persons with dementia & Safe-at-home project, UK \\
\hline & Rialle et al., 2002 (77) & Persons with dementia & Seven Oaks project \\
\hline & Marsh et al., 2002 (78) & $\begin{array}{l}\text { General population with } \\
\text { strong focus on older adults }\end{array}$ & $\begin{array}{l}\text { Smart Medical Home, Center for Future Health, University of Rochester, New } \\
\text { York }\end{array}$ \\
\hline & Demiris et al., 2006 (79) & $\begin{array}{l}\text { Residents of assisted living } \\
\text { facility }\end{array}$ & Tiger Place, University of Missouri-Columbia \\
\hline
\end{tabular}




\section{Recommendations}

The recommendations are divided into three sections corresponding to $1 /$ the clinical targets of interest for the use of ICT, 2/ the conditions, the type of sensors and the outputs (scores) that could be used and obtained, 3/ finally the last section concerns specifically the use of ICT within clinical trials.

\section{What are the Clinical targets?}

\section{Cognition}

Cognitive tests are assessments of human cognitive capacities. The administered tests include various forms. Throughout the 20th century, "paper and pencil" cognitive tests were commonly used to measure intelligence, assist with the diagnosis of brain disorders such as Alzheimer's disease, and measure recovery from brain disease or injury. The first computerized cognitive tests were developed in the 1970s [19]. Computerized testing offers accurate recording of reaction times, electronic capture and processing of data (minimizing human error) and standardization of test administration and automatic scoring (minimizing sources of response bias). Today, they can be used, according to the clinician experience, as an alternative to «paper and pencil tests » in clinical research and practice. The advantage is a better usability but they do not improve ecological validity of the assessment. In fact, for a research study, ecological validity means that methods, material and settings of the study approximate a real-world context that is being examined.

Experience sampling methodology (ESM) is a potential way to achieve this goal. ESM refers to a set of empirical methods that are designed to allow respondents to document their thoughts, feelings and actions outside the walls of a laboratory and within the context of everyday life [20] (E). ICT and most particularly wearable smart phones can be of interest for the assessment of cognition. This has been already done for working memory evaluations [21] (E) and could 
be applied as well to episodic memory tasks. For instance, as part of the cohort study AMI (Agrica-MSA-ISPED) [22] (E) of 1002 retired farmers, an ancillary project has been developed in which 60 subjects received an MRI with the use of the mobile phone PALM. This phone allowed to collect four times a day during a week (Computerized Ambulatory Monitoring) information regarding the activities of daily living of the subjects as well as their performances in neuropsychological tests of semantic memory and episodic memory. The obtained results of these tests are better associated with the brain imaging data (size of the hippocampus in particular) as with the test results conducted by neuropsychologists.

Following these examples the expert panel underlined the interest to develop simple devices with easy and understandable scores, with as added value, in comparison to the present tools, ecological validity, reliability and limitation of the interjudge variability.

\section{Behaviors}

Behavioral and psychological symptoms of dementia (BPSD) are frequently associated with cognitive deficits during the progression of Alzheimer disease (AD) and other dementia.

BPSD assessment is usually based on a structured interview, using subjective input from either the caregiver and/or the patient. For instance apathy, which is the most frequent BPSD, [23] (E) is usually assessed in clinical practice and research with the Neuropsychiatric Inventory (NPI) apathy domain. It has also been proposed that ICT such as actigraphy could provide an objective assessment. This demonstrates that ICT use could be a source of additional information for the assessment of BPSD. 
Other ICT tools can also be used for the assessment and the understanding of motor disturbances. Recently, Robinovitch [24] (E) demonstrated that Digital video cameras installed in common living areas (dining rooms, lounges, hallways) may provide insight into the sequences of events that most commonly lead to falls and, further to more valid and effective approaches for balance assessment and fall prevention in longterm care.

Activities of daily living

Behavior is not only BPSD but also the ability of a subject to be involved in activities of daily living [25] (E). One of the key clinical features of Alzheimer's disease (AD) is impairment in daily living functioning [26] (E). The inability to perform Instrumental Activities of Daily Living (ADL) [27] (E) is present from the early stages of cognitive decline [28] (E). As indicated in the recommendations from the NIA-AA [29] (E) persons with Mild Cognitive Impairment (MCI) commonly have slight problems performing complex tasks [30] (E). Methods to assess IADL comprise self-reported questionnaires, performance-based assessment and informant-based questionnaires. These measurements have some limitations because they do not offer accurate, reproducible, objective and ecological perspectives. Moreover, these assessment batteries and standardized tools rely on quantitative scales, which are often lacking sensitivity. For this reason, information and communication technology (ICT), in particular, techniques involving imaging and video processing are of interest, and may overcome these limitations by reducing the inter/intra rater variability due to human interpretation bias. Goal directed behavior (GDB) is another definition presented during the discussion. GDB is a construct used to operationalize a broad spectrum of purposeful actions and their determinants from the simplest single movement to the most complex patterns behaviors. GDB is a set of related processes (including cognition, emotion, motivation) by which an internal state is translated through action into the attainment of a goal [31] (E). It is important to differentiate the semi directed (prespecified) activities 
from self initiated GDB activities. The first one can be directly assessed by proposing a patient to carry out a series of prespecified tasks [32] (E) and using this strategy it is possible to assess activities in real life time using ICT (Box 1) [33] (E).

\section{Box 1}

Example of a scenario aiming to test activities of daily living

\section{SCENAROO INIYIAL REQUUREMENT}

- Relevant for patient and caregiver

- Close to real life

- Using motor functions

- Using cognitive processing

- Not too long scenario

"Your task is to perform this list of 10 activities in a logical manner within 15 $\mathrm{min}$. These 15 minutes represent a typical morning period of everyday life"

- Read the newspaper

- Water the plant

- Answer the phone

- Call the taxi

- Prepare the medication for today

- Make the check for the Electricity Company

- Leave the room when you are finished with all activities

- Watch the TV

- Prepare a hot tea

- Write the shopping list for the lunch

(1) watch the TV before the phone call

(2) water the flower just before leaving the room

(3) call the taxi, which will arrived in 10 minutes and ask the driver to drive you to the market 
The second one can also be tested by giving the patient a complex order (follow a recipe) and assess how he/she deals with the general recommendation in order to test initiation as well as execution. This type of assessment is very difficult to organize and time consuming. ICT sensors review and description Table 1 summarizes studies done in elderly subjects with AD and related disorders. The general recommendations concerning the use of ICT are listed in table 2. The different types of sensors need to be simple and easy to use to avoid a population selection based on their ability to understand device utilization. Various potential sensors exist, and therefore, the choice should be done accordingly to study conditions (in a clinical consultation setting, in Nursing home, at home) and to population groups (patients, family caregiver, professional carer). Technical progress may allow the implementation of one device with multiple sensors (eg actigraphy, body temperature, audio recording). The choice of devices depends on available budget and agreements between clinicians, ICT engineers and end users. In addition the quality of sensor processing often depends on a correct installation / calibration and some sensors have practical issues such as battery life for wearable sensors or data storage/transmission.

Following these examples the expert panel underlines:

- For the assessment of BPSD objective data covering day and night behavior are needed

- BPSD real time assessment must be validated in comparison to the NPI domains.

- ICT devices enable the patients' performances and actions to be captured in real time and real life situations and to be accurately evaluated. This is particularly important for activities of daily living and the semi directed activities

- The potential interest of serious games for assessing self initiated goal directed behaviour should be explored 


\section{Table 2}

Sensors characteristics according to recommendations and types

Characteristics

- Sensitive to change in the type and intensity of patient activity

- Sensor easy to install / wear

- Immediate output for the clinician

- Self explanatory (easy explanation) for the user

- Understandable feed back information for the clinician

- Easy maintenance of the equipment

Sensors types

- Accelerometry/Actigraphy

- Video 2\&3D - ambient

- Video $2 \& 3 \mathrm{D}$ - wearable

- Speech tracking

- Multi modal sensors

- Infra-red sensors

- Tracking technologies (Global Positioning System)

- Smart Phone and Tablet

- Serious game

Concerning the audio and video recording devices, it is particularly important to employ automatic recording and analysis of the data. This is crucial when long term monitoring is required, such as for the assessment of behavioural disturbances. In order to develop this type of automatic recording, clinicians must describe in full details to the ICT engineers the characteristics of the behavioural sequences that need to be captured. Use of ICT devices in everyday life raises several issues that must be discussed in each specific situation. However, ICT tools utilization may also have some positive effects, at least for a short-term period, for example by involving more actively the patient or empower the couple patient/ caregiver in the assessment procedure. 
The use of video recording devices (wearable or static) is particularly often discussed: "Is there any change in the way of life of the people when there is a camera in the room?" This is mostly depending on the person. However, long term use of such devices seems to indicate a good acceptance. Usually, the person only notices the presence of the video sensor at the beginning of the experimentation but this awareness disappears rapidly [34] (E). A very important factor to increase acceptance is the understanding of the reason for installing the sensor. Furthermore, it is important to provide the subject with systematic feedback about the data that are collected.

In this respect, the experience sampling method using the psymate may be relevant [35]. The "Psymate" is a small electronic device that momentary assesses daily changes in functioning, emotions, which may contribute to identifying environmental risk factors and symptom patterns, as well as provide sensitive evaluations for treatment. This "PsyMate," was specifically developed to implement momentary assessment in clinical practice. It has been applied in psychotic patients, in whom it was shown that self-monitoring of both positive and negative psychotic symptoms is feasible, provides a much more detailed and fine-grained picture of symptoms, and reveals patterns of behavior that may be relevant for treatment. Furthermore, the PsyMate could be instrumental for real-time and real-world delivery of psychological interventions [36]. A trial using the Psymate for patients with dementia, and their caregivers is ongoing. As these technologies rely on the acquisition of a large number of data collected in the context of the daily life of individuals, there is a need to consider first the respect of privacy and the protection of individual data. It is important to conduct this ethical reflection on a case-by-case basis for each project, as these innovative technologies may elicit specific ethical questions. Concerning the output coming from the devices used for assessments, the following points have been underlined: - In everyday clinical practice the output (the clinical score) needs to be simple as possible and easily understandable. The score needs to be 
obtained automatically or at least be understandable to users without high technical competences (patient, caregiver, clinician, researcher). Correlation should be established between ICT scores and classical tools scores.

- ICT characteristics allow combining different scores coming from one single domain (cognition) or from different domains (e.g. cognition, motricity, emotion, nutrition). However, this type of combination needs to be defined and described in a preliminary step between the clinician and the engineers after taking into account the end user point of view [37] (E).

ICT in outcome measures for clinical trials for Alzheimer's disease Most of the information indicated in the previous sections can be applied as well to the particular case of clinical research. It is possible to separate expert suggestions into two parts: the wishes and the requirements.

\section{Wishes}

- In clinical studies, including therapeutic pharmacological and non pharmacological trials, and most particularly cohort follow up studies, one of the major cause for drop outs is that patient are reluctant to return to the center. With the use of ICT, it may be possible to assess cognition, behaviour and/or activities of daily living directly in the patient's home environment and by therefore decrease the number of visit in the center.

- ICT use may be able to help to keep blinding about the evolution of the patient

- ICT may help to have a more objective and homogeneous assessment of behavioural disturbances and by reducing variability. 
- The use of serious games can be of interest to train the investigator and/or staff members on how to rate or manage certain behavioural problems

The association of ICT and biological data may help to foster new ideas and solve common medical problems (falls, sleep disorders). For example the ICT device can provide researchers with some information on sleep parameters (e.g. apnea, Co2 Level). Having a biological component being part of the discussion process could only aid to the hypothesis generation as well as to the hypothesis testing.

\section{Requirements}

Before using ICT devices in clinical trials, several steps need to be achieved:

- ICT needs to be accepted by as a valid study endpoint by Health Authorities. In fact, it seems hard to shift from a well establish end point into a surrogate marker. Unless we get this new endpoint to be approved, technologies are interesting but only as investigational technologies for clinical trial. This explains the importance of introducing ICT into clinical practice in a first step before getting it accepted as a validated clinical endpoint by drug regulators.

- It is important to understand the correlation between ICT data and results obtained by classical assessment tools.

- For BPSD, long-term data need to be collected (24h during one month). It is particularly important to assess whether the frequency of the behavior described by the caregiver (using the NPI) is the same as the one recorded by the ICT device. 


\section{CONCLUSION}

To summarize, special attention should be given to ICT solutions that provide personalized information and more objective assessment that indirectly help people with $\mathrm{AD}$ and their caregivers to better understand BPSD and provide help with their daily living activities [38]. One of the obvious results of this ICT and Mental Health workshop is to allow the interaction between ICT engineers and health professionals. For clinicians it is important to establish the exact type of indicators that are clinically relevant and that can provide useful information in daily practice. Secondly, for ICT engineers, the challenge is to adapt the constraints of the technology to the needs of the clinician. The adopted approach tries to emphasize the clinician's user needs. In the next step, more attention should be paid to the user needs from patient / caregiver and to tool designs considering end user perspectives. It is of great importance that patients and caregivers be engaged in the assessment process and be able to give feedback on the feasibility and tolerability of the ICT sensors. 


\section{REFERENCES}

1. Folstein MF, Folstein SE, McHugh PR. "Mini-mental state". A practical method for grading the cognitive state of patients for the clinician. J Psychiatr Res., 1975. 12(3): p. 189-98.

2. Rosen, W.G., Mohs, R.C., Davis, K.L., A new rating scale for Alzheimer's disease. Am J Psychiatry, 1984. 141: p. 13561364.

3. Cummings JL, Mega M, Gray K, Rosenberg-Thompson S, Carusi DA, Gornbein J. The Neuropsychiatric Inventory: comprehensive assessment of psychopathology in dementia. Neurology, 1994. 44(12): p. 2308-2314.

4. Morris, J.C., The Clinical Dementia Rating (CDR): Current vision and scoring rules. Neurology, 1993: p. 2412-2414.

5. Dubois B, Feldman HH, Jacova C, Cummings JL, Dekosky ST, Barberger-Gateau P, Delacourte A, Frisoni G, Fox NC, Galasko D, Gauthier S, Hampel H, Jicha GA, Meguro K, O'Brien J, Pasquier F, Robert P, Rossor M, Salloway S, Sarazin M, de Souza LC, Stern Y, Visser PJ, Scheltens P. Revising the definition of Alzheimer's disease: a new lexicon. Lancet Neurol, 2010. 9(11): p. 1118-27.

6. McKhann, G.M., D.S. Knopman, H. Chertkow, B.T. Hyman, C.R. Jack, Jr., C.H. Kawas, W.E. Klunk, W.J. Koroshetz, J.J. Manly, R. Mayeux, R.C. Mohs, J.C. Morris, M.N. Rossor, P. Scheltens, M.C. Carrillo, B. Thies, S. Weintraub, and C.H. Phelps, The diagnosis of dementia due to Alzheimer's disease: recommendations from the National Institute on AgingAlzheimer's Association workgroups on diagnostic guidelines for Alzheimer's disease. Alzheimers Dement, 2011. 7(3): p. 263-9.

7. Sampaio, C., Clinical relevance on Alzheimer's disease endpoints. J Nutr Health Aging, 2007. 11(4): p. 316-7. 
8. Eghdam, A., J. Scholl, A. Bartfai, and S. Koch, Information and communication technology to support self-management of patients with mild acquired cognitive impairments: systematic review. J Med Internet Res, 2012. 14(6): p. e159.

9. Meijer, W.J. and P.L. Ragetlie, Empowering the patient with ICT-tools: the unfulfilled promise. Stud Health Technol Inform, 2007. 127: p. 199-218.

10. Clarkson, B.S.N., Pentland, A. , Auditory context awareness via wearable computing, in The Perceptual User Interfaces Workshop, P.o. PUI'98, Editor 1998. p. p. p. 37-42.

11. Wang, S., Common sense based joint training of human activity recognizers, in The 20th IEEE International Joint Conference on Artificial Intelligence P.o.I. 2007, Editor 2007. p. p. p. 2237- 42 .

12. Foerster, F. and J. Fahrenberg, Motion pattern and posture: correctly assessed by calibrated accelerometers. Behav Res Methods Instrum Comput, 2000. 32(3): p. 450-7.

13. Hooghiemstra, A.M., L.H. Eggermont, P. Scheltens, W.M. van der Flier, J. Bakker, M.H. de Greef, P.A. Koppe, and E.J. Scherder, Study protocol: EXERcise and cognition in sedentary adults with early-ONset dementia (EXERCISE-ON). BMC Neurol, 2012. 12: p. 75.

14. Yesavage, Friedman, Kraemer, Noda, Wicks, Bliwise, Sheikh, Tinklenberg, and Zarcone, A follow-up study of actigraphic measures in home-residing Alzheimer's disease patients. J Geriatr Psychiatry Neurol, 1998. 11(1): p. 7-10.

15. Nagels, Engelborghs, Vloeberghs, Van Dam, Pickut, and D. Deyn, Actigraphic measurement of agitated behaviour in dementia. Int J Geriatr Psychiatry, 2006. 21(4): p. 388-93.

16. Volkers, Tulen, Van Den Broek, Bruijn, Passchier, and Pepplinkhuizen, 24-Hour motor activity after treatment with imipramine or fluvoxamine in major depressive disorder. Eur Neuropsychopharmacol, 2002. 12(4): p. 273-8. 
17. Banerjee, S., F. Steenkeste, P. Couturier, M. Debray, and A. Franco, Telesurveillance of elderly patients by use of passive infra-red sensors in a 'smart' room. J Telemed Telecare, 2003. 9(1): p. 23-9.

18. Chan, M., E. Campo, and D. Esteve, Assessment of activity of elderly people using a home monitoring system. Int J Rehabil Res, 2005. 28(1): p. 69-76.

19. Wild, K., D. Howieson, F. Webbe, A. Seelye, and J. Kaye, Status of computerized cognitive testing in aging: a systematic review. Alzheimers Dement, 2008. 4(6): p. 428-37.

20. Christensen, T.C., Feldman-Barrett, L., and E. Bliss-Moreau, Lebo, K., Kaschub C., A Practical Guide to Experiencesampling Procedures. Journal of Happiness Studies 2003. 4: p. 53-78.

21. Kane, M.J., A.R. Conway, T.K. Miura, and G.J. Colflesh, Working memory, attention control, and the N-back task: a question of construct validity. J Exp Psychol Learn Mem Cogn, 2007. 33(3): p. 615-22.

22. Lassalle-Lagadec, S., M. Allard, B. Dilharreguy, P. Schweitzer, J. Swendsen, and I. Sibon, Linking MRI to daily life experience: the example of poststroke depression. Neurology, 2012. 78(5): p. 322-5.

23. Robert, P.H., et al., Proposed diagnostic criteria for apathy in Alzheimer's disease and other neuropsychiatric disorders. European Psychiatry, 2009. 24(2): p. 98-104.

24. Robinovitch, S.N., F. Feldman, Y. Yang, R. Schonnop, P.M. Lueng, T. Sarraf, J. Sims-Gould, and M. Loughin, Video capture of the circumstances of falls in elderly people residing in long-term care: an observational study. Lancet, 2012.

25. Katz, S., A.B. Ford, R.W. Moskowitz, B.A. Jackson, and M.W. Jaffe, Studies of Illness in the Aged. The Index of Adl: A Standardized Measure of Biological and Psychosocial Function. JAMA, 1963. 185: p. 914-9. 
26. Lakhan, P., M. Jones, A. Wilson, and L.C. Gray, The Decline in Activities of Daily Living at Discharge (DADLD) Index: Stratifying Patients at Lower and Higher risk. J Nutr Health Aging, 2012. 16(10): p. 919-2

27. Lawton, M.P. and E.M. Brody, Assessment of older people: self-maintaining and instrumental activities of daily living. Gerontologist, 1969. 9(3): p. 179-86.

28. Tuokko, H., C. Morris, and P. Ebert, Mild cognitive impairment and everyday functioning in older adults. Neurocase, 2005. 11(1): p. 40-7.

29. Albert, M.S., S.T. DeKosky, D. Dickson, B. Dubois, H.H. Feldman, N.C. Fox, A. Gamst, D.M. Holtzman, W.J. Jagust, R.C. Petersen, P.J. Snyder, M.C. Carrillo, B. Thies, and C.H. Phelps, The diagnosis of mild cognitive impairment due to Alzheimer's disease: recommendations from the National Institute on Aging- Alzheimer's Association workgroups on diagnostic guidelines for Alzheimer's disease. Alzheimers Dement, 2011. 7(3): p. 270-9.

30. De Vriendt, P., E. Gorus, E. Cornelis, A. Velghe, M. Petrovic, and $T$. Mets, The process of decline in advanced activities of daily living: a qualitative explorative study in mild cognitive impairment. Int Psychogeriatr, 2012. 24(6): p. 974-86.

31. Brown, R.G. and G. Pluck, Negative symptoms: the 'pathology' of motivation and goal-directed behaviour. Trends Neurosci, 2000. 23(9): p. 412-7.

32. Shallice, T. and P.W. Burgess, Deficits in strategy application following frontal lobe damage in man. Brain, 1991. 114 (Pt 2): p. 727-41. 
33. Sacco, G., V. Joumier, N. Darmon, A. Dechamps, A. Derreumaux, J.H. Lee, J. Piano, N. Bordone, A. Konig, B. Teboul, R. David, O. Guerin, F. Bremond, and P. Robert, Detection of activities of daily living impairment in Alzheimer's disease and mild cognitive impairment using information and communication technology. Clin Interv Aging, 2012. 7: p. 539-49.

34. Zouba N., Bremond F., Thonnat M., Anfosso A., Pascual É., Malléa P., Mailland V., Guerin O. A computer system to monitor older adults at home: Preliminary results. Gerontechnology 2009; 8(3):p 129-139.

35. Myin-Germeys, I., M. Birchwood, and T. Kwapil, From environment to therapy in psychosis: a real-world momentary assessment approach. Schizophr Bull, 2011. 37(2): p. 244-7.

36. Wichers, M., C.J. Simons, I.M. Kramer, J.A. Hartmann, C. Lothmann, I. Myin-Germeys, A.L. van Bemmel, F. Peeters, P. Delespaul, and J. van Os, Momentary assessment technology as a tool to help patients with depression help themselves. Acta Psychiatr Scand, 2011. 124(4): p. 262-72.

37. Mulin E., Joumier V., Leroi I., Lee J.H., Piano J., Bordone N., Derreumeaux A., Malléa P., Brocker P., Dechamps A., Romdhane R., Thonnat M., Bremond F., David R., Robert P. Functional dementia assessment using a video monitoring system: Proof of concept. Gerontechnology, 10(4) : 244-248, 2012

38. Lauriks, S., A. Reinersmann, H.G. Van der Roest, F.J. Meiland, R.J. Davies, F. Moelaert, M.D. Mulvenna, C.D. Nugent, and R.M. Droes, Review of ICT-based services for identified unmet needs in people with dementia. Ageing Res Rev, 2007.6(3): p. 223-46.

39. Ivorra, A., C. Daniels, and B. Rubinsky, Minimally obtrusive wearable device for continuous interactive cognitive and neurological assessment. Physiol Meas, 2008. 29(5): p. 543-54. 
40. Yesavage, J.A., L. Friedman, H.C. Kraemer, A. Noda, D. Wicks, D.L. Bliwise, J. Sheikh, J. Tinklenberg, and V. Zarcone, A follow-up study of actigraphic measures in homeresiding Alzheimer's disease patients. J Geriatr Psychiatry Neurol, 1998. 11(1): p. 7-10.

41. Volkers, A.C., J.H. Tulen, W.W. van den Broek, J.A. Bruijn, J. Passchier, and L. Pepplinkhuizen, Motor activity and autonomic cardiac functioning in major depressive disorder. J Affect Disord, 2003. 76(1-3): p. 23-30.

42. Nagels, G., Engelborghs, S., Vloeberghs, E., Van Dam, D., Pickut, B.A., De Deyn, P.P., Actigraphic measurement of agitated behaviour in dementia. Int J Geriatr Psychiatry, 2006. 21(4): p. 388-93.

43. Mahlberg, R. and S. Walther, Actigraphy in agitated patients with dementia.Monitoring treatment outcomes. Z Gerontol Geriatr, 2007. 40(3): p. 178-84.

44. Müller, U., Czymmek, J., Thöne-Otto, A. \& Von Cramon, D, Reduced daytime activity in patients with acquired brain damage and apathy: A study with ambulatory actigraphy. Brain Injury, 2006. 20(2): p. 157-160.

45. Mulin, E., Zeitzer, J.M., Friedman, L., Le Duff, F., Yesavage, J., Robert, P.H., David, R., Relationship between apathy and sleep disturbance in mild and moderate Alzheimer's disease: an actigraphic study. Journal of Alzheimer's Disease, 2011.25(1): p. 85-91.

46. David, R., Ambulatory actigraphy correlates with apathy in mild Alzheimer's disease. Dementia: The International Journal of Social Research and Practice, 2010.9(4): p. 509-516.

47. David, R., Mulin, E., Friedman, L., Duff, F.L., Cygankiewicz, E., Deschaux, O., Garcia, R., Yesavage, J.A., Robert, P.H., Zeitzer, J.M., Decreased Daytime Motor Activity Associated With Apathy in Alzheimer Disease: An Actigraphic Study. Am J Geriatr Psychiatry, 2012. 20 (9) : p. 94-97. 
48. Kuhlmei, A., Walther, B., Becker, T., Müller, U., Nikolaus, T., Actigraphic daytime activity is reduced in patients with cognitive impairment and apathy. European Psychiatry, 2011: 28 (2) : p. 806-814.

49. Hatfield, C.F., J. Herbert, E.J. van Someren, J.R. Hodges, and M.H. Hastings, Disrupted daily activity/rest cycles in relation to daily cortisol rhythms of homedwelling patients with early Alzheimer's dementia. Brain, 2004. 127(Pt 5): p. 1061-74.

50. Reiterer, V., C. Sauter, G. Klosch, W. Lalouschek, and J. Zeitlhofer, Actigraphy - a useful tool for motor activity monitoring in stroke patients. Eur Neurol, 2008. 60(6): p. 28591.

51. Meadows, R., R. Luff, I. Eyers, S. Venn, E. Cope, and S. Arber, An actigraphic study comparing community dwelling poor sleepers with non-demented care home residents. Chronobiol Int, 2010. 27(4): p. 842-54.

52. Suzuki, R., S. Otake, T. Izutsu, M. Yoshida, and T. Iwaya, Monitoring daily living activities of elderly people in a nursing home using an infrared motion-detection system. Telemed J E Health, 2006. 12(2): p. 146-55.

53. Suzuki, T. and S. Murase, Influence of outdoor activity and indoor activity on cognition decline: use of an infrared sensor to measure activity. Telemed J E Health, 2010. 16(6): p. 68690 .

54. Suzuki, T., S. Murase, T. Tanaka, and T. Okazawa, New approach for the early detection of dementia by recording inhouse activities. Telemed J E Health, 2007 13(1): p. 41-4.

55. Dodge, H.H., N.C. Mattek, D. Austin, T.L. Hayes, and J.A. Kaye, In-home walking speeds and variability trajectories associated with mild cognitive impairment. Neurology, 2012. 78(24): p. 1946-52. 
56. Nakano, T., E. Koyama, T. Nakamura, T. Ito, K. Tamura, and M. Yaginuma, Use of an infrared sensor system to take longterm bedside measurements of rest-activity patterns in the elderly with dementia. Psychiatry Clin Neurosci, 2002. 56(3): p. 287- 8 .

57. Romdhane, R., E. Mulin, A. Derreumeaux, N. Zouba, J. Piano, L. Lee, I. Leroi, P. Mallea, R. David, M. Thonnat, F. Bremond, and P.H. Robert, Automatic video monitoring system for assessment of Alzheimer's disease symptoms. J Nutr Health Aging, 2012. 16(3): p. 213-8.

58. Williams, K., A. Arthur, M. Niedens, L. Moushey, and L. Hutfles, In-Home Monitoring Support for Dementia Caregivers: A Feasibility Study. Clin Nurs Res,2012.

59. Shoval, N., G.K. Auslander, T. Freytag, R. Landau, F. Oswald, U. Seidl, H.W. Wahl, S. Werner, and J. Heinik, The use of advanced tracking technologies for the analysis of mobility in Alzheimer's disease and related cognitive diseases. BMC Geriatr, 2008. 8: p. 7.

60. Faucounau, V., M. Riguet, G. Orvoen, A. Lacombe, V. Rialle, J. Extra, and A.S.Rigaud, Electronic tracking system and wandering in Alzheimer's disease: a case study. Ann Phys Rehabil Med, 2009. 52(7-8): p. 579-87.

61. Elgethun, K., R.A. Fenske, M.G. Yost, and G.J. Palcisko, Time-location analysis for exposure assessment studies of children using a novel global positioning system instrument. Environ Health Perspect, 2003. 111(1): p. 115-22.

62. Werner, S., G.K. Auslander, N. Shoval, T. Gitlitz, R. Landau, and J. Heinik, Caregiving burden and out-of-home mobility of cognitively impaired care-recipients based on GPS tracking. Int Psychogeriatr, 2012. 24(11): p. 1836-45. 
63. Wahl, H.W., M. Wettstein, N. Shoval, F. Oswald, R. Kaspar, M. Issacson, E. Voss, G. Auslander, and J. Heinik, Interplay of Cognitive and Motivational Resources for Out-of-Home Behavior in a Sample of Cognitively Heterogeneous Older Adults: Findings of the SenTra Project. J Gerontol B Psychol Sci Soc Sci, 2012.

64. Rantz, M.J., M. Skubic, and S.J. Miller, Using sensor technology to augment traditional healthcare. Conf Proc IEEE Eng Med Biol Soc, 2009. 2009: p. 6159-62.

65. Kidd, C.D., Orr, R., Abowd, G.D., Atkeson, C.G., Essa, I.A., MacIntyre, B., et al., The Aware Home: A Living Laboratory for Ubiquitous Computing Research, in Proceedings of CoBuild'99October 1999, Position paper.

66. Helal, S., Mann, W., El-Zabadani, H., King, J., Kaddoura, Y., Jansen, E., The Gator Tech Smart House: a programmable pervasive space. Computer, 2005. 38(50-60).

67. Intille, S., Larson, K, Munguia Tapia E, Beaudin JS, Kaushik P, Nawyn J, Rockinson, R., Using a 1 ive-in laboratory for ubiquitous computing research, in Proceedings of PERVASIVE 2006; vol. LNCS, S.B. Fishkin KP, Nixon P, Quiley A, editors., Editor 2006: 3968. Berlin, Heidelberg: Springer-Verlag; p. p. 349-65.

68. Cerni, M., Penhaker, M. Circadian rhythm monitoring in homecare systems. in 13th international conference on biomedical engineering. 2008. Singapore.

69. Demongeot, J., G. Virone, F. Duchene, G. Benchetrit, T. Herve, N. Noury, and V.Rialle, Multi-sensors acquisition, data fusion, knowledge mining and alarm triggering in health smart homes for elderly people. C R Biol, 2002. 325(6): p. 673-82.

70. Tamura, T., T. Togawa, M. Ogawa, and M. Yoda, Fully automated health monitoring system in the home. Med Eng Phys, 1998. 20(8): p. 573-9. 
71. Matsuoka, K. Aware home understanding life activities. Towards a humanfriendly assistive environment. in International conference on smart homes and health telematics. 2004.

72. Yamazaki, T. Beyond the smart home. in International conference on hybrid information technology. 2006.

73. Cash, M., Assistive technology and people with dementia. Reviews in Clinical Gerontology, 2003. 13(4): p. 313-9.

74. Adlam, T., Gibbs, C., Orpwood, R., The Gloucester Smart House bath monitor for people with dementia. Phys Med, 2001. 17(3): p. 189.

75. Demiris, G. and B.K. Hensel, Technologies for an aging society: a systematic review of "smart home" applications. Yearb Med Inform, 2008: p. 33-40.

76. Woolham, J., Frisby, B., How techology can help people feel safe at home. Journal of Dementia are, 2002. 10(2): p. 27-9.

77. Rialle, V., F. Duchene, N. Noury, L. Bajolle, and J. Demongeot, Health "Smart" home: information $t$ echnology for patients at home. Telemed J E Health, 2002. 8(4): p. 395409.

78. Marsh, J., House Calls. Rochester Review, 2002. 64(3): p. 226.

79. Demiris, G., Skubic, M, Keller, J, Rantz, MJ, Parker Oliver D, Aud MA, et al., Nurse Participation in the Design of User Interfaces for a Smart Home System., in Proceedings of the International Conference on Smart Homes and Health Telematics, N.I. Belfast, Editor 2006. p. 66-73. 


\section{PART II}

SENSOR STUDIES 


\section{CHAPTER 4}

\section{ACTIGRAPHIC MOTOR ACTIVITY I MILD COGNITIVE}

IMPAIRMENT PATIENTS

CARRYING OUT SHORT FUNCTIONAL ACTIVITY TASKS: COMPARISON BETWEEN MILD COGNITIVE IMPAIRMENT WITH AND WITHOUT DEPRESSIVE SYMPTOMS

Journal of Alzheimer's Disease 2014 ; 40(4), 869-875

Yakhia, M, König, A, van der Flier, WM, Friedman, L, Robert, PH, David, R 


\begin{abstract}
Background

Individuals with mild cognitive impairment (MCI) may exhibit changes in motor activity in conducting their activities of daily living. Depression, one of the most frequent neuropsychiatric symptoms, might affect motor activity in MCI.
\end{abstract}

\title{
Objective
}

To assess motor activity in MCI subjects carrying out short functional activity tasks using ambulatory actigraphy. Secondly, we sought to investigate the influence of depressive symptoms on motor activity.

\section{Methods}

$20 \mathrm{MCI}$ and 14 healthy subjects carried out a 30-minute standardized scenario while wearing a chest actigraph. The protocol consisted of directed activities (execution of motor tasks), semi-directed activities (execution of Instrumental Activities of Daily Living, IADL), and undirected 'free' activities. Several common assessment scales (GDS, MADRS, and NPI) were used to diagnose depression.

\section{Results}

MCI subjects had significantly reduced mean motor activity while carrying out directed and semi-directed activities, compared to healthy control subjects. Nodifferencewas found in motor activity between MCI subjects with or without depression.

\section{Conclusion}

Actigraphic measurement of motor activity during the evaluation of IADLs and motor tasks is a potential objective tool in detecting early changes in MCI. Depressive symptoms seem not to be associated with motor activity in MCI subjects. 


\section{INTRODUCTION}

Alzheimer's disease (AD) is the most common neurodegenerative disorder and major cause of mortality in old age $[1,2]$. The progression of $\mathrm{AD}$ affects different domains of functioning, including cognitive, behavioral, and daily functioning [3]. Instrumental activities of daily living (IADLs) are complex activities required for independent living in a community [4]. Independent living requires the ability to perform activities such as managing money, taking medications, shopping, and housekeeping. IADLs are impaired in AD and subsequently lead to patients' loss of autonomy [5]. Patients with mild cognitive impairment (MCI) may show mild deficits in performance of complex activities of daily living [6]. Since assessment of IADLs is based on questionnaires, it is limited to some extent in reproducibility and objectivity. A French project launched under the name Sweet-HOME (2012) aimed to assess AD and MCI subjects' performance of the IADLs they would normally encounter in their home environment.

The project used a video monitoring system coupled with several additional monitoring devices including actigraphy [7]. The assessment protocol consisted of three parts: (1) directed activities, (2) semi-directed activities, and (3) undirected ("free") activities. In the 'directed scenario', all participants' gait, balance, and mobility were assessed while they followed specific instructions. In the 'semidirected scenario', memory and executive functions were evaluated while participants were instructed to followinstructions in a specific order. The 'free scenario' sought to provide information about the degree of interest and initiative that participants manifested on their own, without specific instructions. More details will be described in the methods section. The current study is an ancillary research to the 'Sweet-HOME project', specifically aimed at evaluating actigraphic measurements collected during IADLs' assessment, motor task performance, and a free scenario phase. Ambulatory actigraphy, 
consisting of a piezoelectric accelerometer designed to record body locomotor activity, has been previously used to evaluate various disorders including sleep-wake disorders, hyperactivity disorders, and dementia [8-10].

Recent studies have shown that daytime motor activity is reduced in AD patients compared to healthy controls [11-13]. Additionally, AD and MCI patients with apathy have been found to have reduced motor activity compared to those without apathy [13]. Neuropsychiatric disturbances are often observed in MCI and $\mathrm{AD}$ and frequently worsen during the progression of the disease [14, 15]. Alongside apathy, depression is one of the most common neuropsychiatric symptoms in $\mathrm{AD}$ with an estimated prevalence ranging from $20-50 \%[16,17]$. Depressive symptoms are associated with premature institutionalization and lower quality of life in early-stage AD patients $[3,18]$.

Furthermore, depression in patients with MCI increases the risk of developing $\mathrm{AD}$ [19]. These symptoms are also frequently observed in MCI and associated with greater brain atrophy and higher likelihood of progression to $\mathrm{AD}$ [20]. Hence, the presence of depressive symptoms in MCI might predict conversion from MCI to AD [21-23]. Furthermore, AD patients with depression have more difficulties in Activities of Daily Living (ADLs) compared to AD patients without depression [14]. A recent study by Vital et al. found that higher physical activity in $\mathrm{AD}$ patients is associated with fewer depressive symptoms [24]. The presence of depressive symptoms in MCI might be associated with motor activity changes during functional activity tasks.

The main aim of the present study was to evaluate levels of motor activity in MCI and healthy subjects carrying out a standardized scenario consisting of directed, semi-directed, and undirected activities, as described in the Sweet-HOME project. 
A second aim was to investigate the influence of depressive symptoms on mean motor activity (MMA) in MCI individuals carrying out the protocol. Our main hypotheses were: (i) MMAwill be lower in MCIparticipants than in healthy control subjects; and (ii) MMA will be lower in MCI participants with depressive symptoms than in MCI participants without depressive symptoms and in healthy controls.

\section{METHODS}

\section{Participants and clinical assessment}

Participants aged 65 or older were recruited at the memory center in Nice located at the Geriatric department of the University Hospital. MCI diagnosis was conducted according to Petersen criteria [25]. Participants were excluded if they had a history of head trauma, loss of consciousness, aberrant motor behavior; scored higher than 0 on the Unified Parkinson's Disease Rating scale [26], and/or met criteria for major depression disorder according to DSM-IV [27]. However, participants with depressive symptoms were included in the study.

The study was approved by a local ethics committee and all participants gave informed consent. General cognitive status was assessed using neuropsychological tests including: Mini-Mental State Examination (MMSE) [28], Frontal Assessment Battery (FAB) [29], and Instrumental Activities of Daily Living scale (IADLE) [30]. Additionally, neuropsychiatric symptoms were assessed using the Neuropsychiatric Inventory scale (NPI) [31]. Since the prevalence of depressive symptoms in a group depends on the classification systems employed different classification scales were used: Montgomery- ${ }^{\circ}$ sberg Depression Rating Scale (MADRS) [32], Geriatric Depression Scale (GDS) [33], and NPI depression subscale. The NPI depression subscale was ultimately selected as the measure for depression, since other neuropsychiatric related sub-symptoms such as anxiety and sleep disturbances are included in the MADRS and GDS [34, 35]. 
Participants were divided into two sub-groups based on their NPI depression scores. An NPI sub-score higher than three characterizes relevant clinical symptoms [36], thus individuals with a sub-score of 4 or higher on the NPI depression domain were included in the MCI subgroup with depressive symptoms. Depression was also separately diagnosed using GDS cutoff $>10$, MADRS cutoff $>6$, and NPI cutoff $>0$ to assess different diagnostic classification systems.

Ecological assessment of IADLs In the Sweet-HOME project, impairment of daily functioning in MCI subjects was assessed using Information and Communication Technologies (ICT) such as a video monitoring system and actigraphy [7]. Participants were instructed to carry out a list of 10 activities in an observation room equipped with everyday objects: an armchair, a table, a tea preparation counter (equipped with the necessary material to prepare a cup of tea), a television set, a personal computer, and a library. Activity was also recorded with two monocular video cameras in the observation room. As mentioned earlier the protocol consisted of three different conditions. In the directed scenario, the examiner asked the participant to perform various physical exercises: a walking test, a balance exercise, a stand-up and go exercise, and a repeated rising from a chair to a stand test (10 $\mathrm{min})$.

In the semi-directed scenario participants had to carry out a set of daily living like activities such as making a phone call or preparing a pillbox in a specific order within a timeframe of 15 minutes. In the undirected activity scenario, participants were given 5 minutes free time in the observation room. Actigraphic assessment The Motionpod has been validated as a measurement of movement in several studies [37-39]. One of the objectives of our study was to validate the use the Motionpod Actigraph for the detection of motor activity levels in MCI and healthy subjects. The SVELTE project sought to develop an autonomous actimeter able to accurately record physical activity and associated energy expenditure with the MotionPod providing a highly 
accurate identification of physical activity patterns. Bonnet et al. [37] demonstrated the use of the MotionPod sensor for the detection of epileptic seizures. The MotionPod is an Inertial Measurement Unit that incorporates a 3-axis accelerometer, a 3-axis gyroscope, and a 3axis magnetometer with a wireless interface. It cannot measure steps, but it indirectly measures energy expenditure using a dedicated algorithm.

During the course of the scenario, participants wore an actigraph (MotionPod $($ ) attached to their chest using a dedicated band. Actigraph recording started from the beginning of the directed and semi-directed activities until the end of the ecological evaluation. The total recording time consisted of approximately 30 minutes, including directed, semi-directed, and free activities. Collected data consisted of integrated activity expressed in arbitrary units per second (Software Actigui 1.2.1, sampling frequency $=1 \mathrm{~Hz}(1 \mathrm{data} / \mathrm{s}))$.

In addition, each of the three activity scenarios was individually recorded on the actigraph. Statistics analyses Prior to analysis, data was verified for normality, potential outliers, and missing values. The distribution of the data was not normal, therefore group comparisons were made using non parametric Mann-Whitney U-Test. Categorical testing for gender and education was calculated using the chi-square test. Correlations were calculated using Spearman's rank-order correlation coefficient. All statistical analyses were computed using SPSS 14.0.

\section{RESULTS}

Characteristics of MCI subjects $(\mathrm{n}=20, \mathrm{Age}=75.40 \pm 6.69, \mathrm{MMSE}=$ $25.95 \pm 2.19)$ and healthy controls $(\mathrm{n}=14$, Age $=73.71 \pm 6.57$, MMSE $=28.07 \pm 1.07)$ are presented in Table 1 . The two groups did not significantly differ in age, gender, and education level. As expected, MCI and healthy controls had significantly different MMSE and FAB scores $(p<0.05)$. Furthermore, GDS and MADRS scores 
were significantly higher in MCI participants than in healthy controls $(\mathrm{p}<0.05)$. No difference in IADL-E scorewas found between MCI and healthy controls. MCI participants, however, showed reducedMMAin the directed and semi-directed activity scenario $(\mathrm{p}<$ 0.05 ) compared to healthy controls, but not in the free and total activity scenario ( $p=0.122$ and $p=0.07$, respectively).

Subsequently, the MCI sample was divided into two subgroups; MCI with and without depressive symptoms, based on NPI score in the depression domain using a NPI-depression cut off score $>3$. Data of four participants were excluded because their NPI scores were not assessed. Table 2 represents characteristics for MCIsubjects without depressive symptoms $(\mathrm{n}=10$, Age $=76.60 \pm 6.72, \mathrm{MMSE}=25.80 \pm$ $2.44)$ and MCI with depressive symptoms $(\mathrm{n}=6$, Age $=77.17 \pm 7.90$, $\mathrm{MMSE}=25.5 \pm 2.26$ ). No significant difference was found in age, gender, education level, MMSE, FAB, and IADLs scores, between MCI with and MCI without depressive symptoms. The two subgroups were equivalent on all NPI-scored domains expect depression and total NPI score. MCI subjects with depressive symptoms had significantly higher MADRS score $(\mathrm{p}<0.05)$, whereas the difference in GDS was not statistically significant $(\mathrm{p}=0.06)$. In all three scenarios, MMA did not significantly differ between the two subgroups. Results were similar when defining depression using GDS (cutoff $>10$ ), MADRS (cutoff $>6$ ), or NPI $>0$ cut-off score. 
Table 1

Characteristics and group comparisons for healthy controls and MCI subjects. Group comparisons were made using Mann-Whitney U test $(p<0.05)$ and chi-square $(p<0.05)$ for categorical testing. Categorical testing for education was analyzed with Pearson chi-square. Data shown as mean $\pm \mathrm{SD}$

\begin{tabular}{|c|c|c|c|}
\hline & $\begin{array}{l}\text { Controls } \\
(n=14)\end{array}$ & $\begin{array}{c}\text { MCI } \\
(n=20)\end{array}$ & $p$ \\
\hline Gender (female/male) & $8 / 6$ & $8 / 12$ & 0.49 \\
\hline Age (years) & $73.71 \pm 6.57$ & $75.40 \pm 6.69$ & 0.46 \\
\hline Education category & & & 0.59 \\
\hline Primary & $3 / 14$ & $5 / 20$ & \\
\hline Secondary & $5 / 14$ & $9 / 20$ & \\
\hline College & $1 / 14$ & $3 / 20$ & \\
\hline University & $5 / 14$ & $3 / 20$ & \\
\hline $\begin{array}{l}\text { Mini-mental state } \\
\text { examination }\end{array}$ & $28.07 \pm 1.07$ & $25.95 \pm 2.19$ & 0.01 \\
\hline Frontal assessment battery & $15.71 \pm 1.54$ & $13.95 \pm 2.19$ & 0.03 \\
\hline $\begin{array}{l}\text { Instrumental activities of } \\
\text { daily living }\end{array}$ & $9.64 \pm 1.15$ & $9.47 \pm 1.89$ & 0.65 \\
\hline Geriatric depression scale & $6.00 \pm 6.3$ & $10.75 \pm 5.73$ & 0.02 \\
\hline MADRS & $2.86 \pm 2.66$ & $6.75 \pm 6.34$ & 0.02 \\
\hline NPI delusion & $*$ & $0.00 \pm 0.00$ & - \\
\hline NPI hallucination & $*$ & $0.00 \pm 0.00$ & - \\
\hline NPI agitation & $*$ & $0.93 \pm 3.00$ & - \\
\hline NPI depression & $*$ & $2.17 \pm 2.43$ & - \\
\hline NPI anxiety & $*$ & $1.50 \pm 2.25$ & - \\
\hline NPI euphoria & $*$ & $0.00 \pm 0.00$ & - \\
\hline NPI apathy & $*$ & $1.50 \pm 3.22$ & - \\
\hline NPI disinhibition & $*$ & $0.57 \pm 2.00$ & - \\
\hline NPI aberrant motor & $*$ & $0.00 \pm 0.00$ & - \\
\hline NPI sleep & $*$ & $1.75 \pm 2.38$ & - \\
\hline NPI appetite & $*$ & $0.50 \pm 1.37$ & - \\
\hline NPI total & $*$ & $10.32 \pm 7.56$ & - \\
\hline MMA total (30 min) & $0.050 \pm 0.01$ & $0.045 \pm 0.01$ & 0.074 \\
\hline $\begin{array}{l}\text { MMA directed activities } \\
\qquad(10 \mathrm{~min})\end{array}$ & $0.065 \pm 0.02$ & $0.054 \pm 0.01$ & 0.033 \\
\hline $\begin{array}{l}\text { MMA semi-directed activities } \\
\text { (15 min) }\end{array}$ & $0.047 \pm 0.01$ & $0.040 \pm 0.01$ & 0.022 \\
\hline MMA free activities (5 min) & $0.038 \pm 0.01$ & $0.028 \pm 0.01$ & 0.122 \\
\hline
\end{tabular}




\section{DISCUSSION}

The present study found that MCI participants showed significantly reduced MMA while carrying out directed and semi-directed activities, compared to healthy controls. Previous actigraphic studies have found lower levels of motor activity in dementia compared to healthy controls, and can discriminate between MCI andADpatients with and without apathy [11-13]. However, one study specifically investigated motor activity in MCI subjects over a 5-day nondirected actigraphic assessment period [13] and found reduced motor activity in MCI subjects with apathy but not in MCI subjects without apathy. In the present study, we did not find differences in motor activity during the undirected free scenario. Hence, our study is the first one demonstrating that MCI subjects have lower motor activity level compared to healthy controls, while carrying out IADLs and motor tasks in a clinical setting. Even though, it has been previously shown that depression is often associated with decreased motor activity [1113, 40-42], we did not find any association between depressive symptoms in MCI subjects and motor activity. In the present study, depressive symptoms, as measured by GDS and MADRS scores, were more frequently observed in MCI subjects than in healthy controls. The prevalence of depressive symptoms depends on the classification systems employed [43].Asub-score above 0 has previously been used to define mild depressive symptoms in the NPI [20]. However, in this study, we used an NPI cut-off score greater than three as the main diagnostic test for indicating clinically significant depressive symptoms [36]. Additionally, we found no association between motor activity and depressive symptoms when defining depression in MCI using the GDS, MADRS, and NPI cut-off score above 0. No significant correlation was found between depression scale scores and motor activity in MCI and healthy controls. The prevalence of depressive symptoms varied across depression scales used for this study, with the highest prevalence rate $(68.7 \%)$ when we used the NPI $>0$ cutoff score, and $37.5 \%$ when we used both MADRS and NPI $>3$; 
group assignment was different however for six participants. Overall, this study, in agreement with previous studies reporting high variability in the prevalence of depressive symptoms in MCI [17], shows that prevalence of depressive symptoms in MCI depends on the diagnostic criteria used. This might be related to methodological differences, such as different diagnostic criteria, variability in cutoff scores, and environmental factors.

Hence, our study further underlines the difficulties in diagnosing depressive symptoms in MCI patients. Since no differences between motor activity among MCI subjects with or without depression were found even when using different scales, it may be that depression, contrary to apathy, is not associated with motor activity in MCI patients. 
Table 2

Characteristics and group comparisons for MCI with and without depressive symptoms. Groups were analyzed with Mann-Whitney U test $(p<0.05)$ and chi-square $(p<0.05)$ for categorical testing. Categorical testing for education was analyzed with Pearson chi-square test. Data shown as mean $\pm S D$

\begin{tabular}{|c|c|c|c|}
\hline & $\begin{array}{l}\text { MCI without depressive } \\
\text { symptoms }(n=10)\end{array}$ & $\begin{array}{c}\text { MCI with depressive } \\
\text { symptoms }(n=6)\end{array}$ & $p$ \\
\hline Gender (female/male) & $5 / 5$ & $3 / 3$ & 1.00 \\
\hline Age (years) & $77.6 \pm 6.72$ & $77.17 \pm 7.90$ & 0.30 \\
\hline Education category & & & 0.62 \\
\hline Primary & $2 / 10$ & $3 / 6$ & \\
\hline Secondary & $4 / 10$ & $2 / 6$ & \\
\hline College & $2 / 10$ & $0 / 6$ & \\
\hline University & $2 / 10$ & $1 / 6$ & \\
\hline Mini-mental state examination & $25.8 \pm 2.44$ & $25.5 \pm 2.26$ & 0.58 \\
\hline Frontal assessment battery & $14.00 \pm 2.62$ & $13.67 \pm 1.97$ & 0.87 \\
\hline Instrumental activities of daily living & $9.50 \pm 2.12$ & $8.80 \pm 1.92$ & 0.71 \\
\hline Geriatric depression scale & $8.70 \pm 5.96$ & $13.50 \pm 3.67$ & 0.06 \\
\hline MADRS & $5.00 \pm 2.16$ & $7.00 \pm 3.58$ & 0.03 \\
\hline NPI delusion & $0.00 \pm 0.00$ & $0.00 \pm 0.00$ & 1.00 \\
\hline NPI hallucination & $0.00 \pm 0.00$ & $0.00 \pm 0.00$ & 1.00 \\
\hline NPI agitation & $1.20 \pm 3.79$ & $0.50 \pm 8.36$ & 0.34 \\
\hline NPI depression & $0.70 \pm 8.23$ & $5.00 \pm 1.67$ & 0.00 \\
\hline NPI anxiety & $0.90 \pm 1.29$ & $2.50 \pm 3.20$ & 0.48 \\
\hline NPI euphoria & $0.00 \pm 0.00$ & $0.00 \pm 0.00$ & 1.00 \\
\hline NPI apathy & $0.80 \pm 1.69$ & $2.67 \pm 4.84$ & 0.47 \\
\hline NPI disinhibition & $0.90 \pm 2.51$ & $0.00 \pm 0.00$ & 0.26 \\
\hline NPI irritability & $0.70 \pm 1.89$ & $2.17 \pm 3.00$ & 0.07 \\
\hline NPI aberrant motor & $0.00 \pm 0.00$ & $0.00 \pm 0.00$ & 1.00 \\
\hline NPI sleep & $1.60 \pm 1.78$ & $2.00 \pm 3.35$ & 0.90 \\
\hline NPI appetite & $0.40 \pm 1.26$ & $0.67 \pm 1.63$ & 0.70 \\
\hline NPI total & $7.20 \pm 7.77$ & $15.00 \pm 3.33$ & 0.02 \\
\hline MMA total $(30 \mathrm{~min})$ & $0.047 \pm 0.011$ & $0.039 \pm 0.004$ & 0.13 \\
\hline MMA directed activities (10 min) & $0.055 \pm 0.010$ & $0.053 \pm 0.012$ & 1.00 \\
\hline MMA semi-directed activities (15 min) & $0.040 \pm 0.004$ & $0.035 \pm 0.004$ & 0.12 \\
\hline MMA free activities (5 min) & $0.030 \pm 0.011$ & $0.039 \pm 0.040$ & 0.44 \\
\hline
\end{tabular}

Bold characters represent significant $p$-values $<0.05$. MADRS, Montgomery-Åsberg Depression Rating Scale; MMA, mean motor activity; NPI, Neuropsychiatric Inventory. 
Therefore, actigraphy could be a more effective tool for objectively assessing apathy rather than depression in subjects with MCI. Nevertheless, our failure to find an association between depressive symptoms and motor activity in MCI subjects could be due to the limited power of our study.

The main limitation of this study is the small sample size. A second limitation is that the MCI subjects, in our study, had lowNPI subscores for agitation, depression, anxiety, apathy, irritability, and disinhibtion, all of which could potentially influence levels of motor activity using actigraphy. Apathy, although known to influence actigraphic analyses, was not frequent in our sample [12, 13]. According to the diagnostic criteria for apathy proposed by Robert at al. only 3 out of 20 MCI subjects were diagnosed with apathy [44]. Impairment in motor function is a common manifestation in AD [45, 46]. Changes in subcortical white matter, hippocampus, and the dopaminergic system have been implicated in motor impairment found in $\mathrm{AD}[47,48]$. It is known that motor function and motor activity levels are related, however, this phenomenon remains largely unstudied. In a recent study, James et al. assessed motor function by measuring muscle strength and a broad range of motor performance such as walking and balance. Further, physical activity was measured by a wrist-worn actigraph [49]. The study showed that lower levels of daily physical activity measured by actigrahy were associated with lower levels of motor function. Additionally, motor activity and motor function were both lower in demented participants. Interestingly, we found reduced motor activity in MCI subjects in the directed and semi-directed scenario, which involved different components of motor function. No difference in motor activity between MCI and healthy controls was observed during the undirected scenario. This can be explained by the fact that during this scenario almost all participants in both groups passively sat on the couch for a period of 5 minutes. Hence, it may be that motor activity in MCI results from impaired 
motor function. Nevertheless, the same neurobiological mechanism could underlie both impaired motor function and motor activity. Further research is needed to understand the relationship between motor function and motor activity levels.

This study presents some major novel findings: (1) MCI patients carrying out directed and semidirected activities have lower motor activity compared to healthy controls; and (2) actigraphic measurement of motor activity during the evaluation of IADLs and motor tasks is a potential objective tool in detecting early changes in MCI, with higher accuracy and sensitivity than the IADL-E, because no significant difference was found in the IADL-E. This finding could have a significant impact on diagnosis and assessment of MCI in clinical practice. Assessments of IALDs and motor performance can easily be conducted in clinical practice. Clinicians could employ this assessment procedure during a regular consultation to improve diagnosis and detect early changes in MCI.

Future studies could be carried out in participants' home environments combining actigraphy with other ICTs such as movement sensors, imaging, and video processing. This approach could aid in detecting early changes in motor performance and activity in cognitively impaired patients. 


\section{REFERENCES}

1. Scarpini E, Scheltens P, Feldman H (2003) Treatment of Alzheimer's disease: Current status and new perspectives. Lancet Neurol 2, 539-547.

2. Selkoe DJ (2000) The origins of Alzheimer disease: A is for amyloid. JAMA 283, 1615-1617.

3. Karttunen K, Karppi P, Hiltunen A, Vanhanen M, Valimaki T, Martikainen J, Valtonen H, Sivenius J, Soininen H, Hartikainen S, Suhonen J, Pirttila T (2011) Neuropsychiatric symptoms and quality of life in patients with very mild and mild Alzheimer's disease. Int J Geriatr Psychiatry 26, 473-482.

4. Lawton MP, Brody EM (1969) Assessment of older peaple self-maintening and instrumental activities of daily living. Gerontologist 0, 179-186.

5. Andersen CK, Wittrup-Jensen KU, Lolk A, Andersen K, Kragh-Sorensen P (2004) Ability to perform activities of daily living is the main factor affecting quality of life in patients with dementia. Health Qual Life Outcome 2, 52.

6. Farias ST, Mungas D, Reed BR, Harvey D, Cahn-Weiner D, Decarli C (2006) MCI is associated with deficits in everyday functioning. Alzheimer Dis Assoc Disord 20, 217-223.

7. Romdhane R, Mulin E, Derreumeaux A, Zouba N, Piano J, Lee L, Leroi I, Mallea P, David R, Thonnat M, Bremond F, Robert PH (2012) Automatic video monitoring system for assessment of Alzheimer's disease symptoms. J Nutr Health Aging 16, 213-218.

8. Deak M (2009) Use of actigraphy in neurological patient populations. Neurol Bull 1, 1723.

9. Hatfield CF, Herbert J, van Someren EJ, Hodges JR, Hastings MH (2004) Disrupted daily activity/rest cycles in relation to daily cortisol rhythms of home-dwelling patients with early Alzheimer's dementia. Brain 127, 1061-1074. 
10. Dane AV, Schachar RJ, Tannock R (2000) Does actigraphy differentiate ADHD subtypes in a clinical research setting? J Am Acad Child Adolesc Psychiatry 39, 752-760.

11. David R, RivetA, Robert PH, MaillandV, Friedman L, Zeitzer JM, Yesavage J (2010) Ambulatory actigraphy correlates with apathy in mild Alzheimer's disease. Dementia 9, 409- 516.

12. David R, Mulin E, Friedman L, Duff FL, Cygankiewicz E, Deschaux O, Garcia R, Yesavage JA, Robert PH, Zeitzer JM (2012) Decreased daytime motor activity associated with apathy in Alzheimer disease: An actigraphic study. Am J Geriatr Psychiatry 20, 806-814.

13. Kuhlmei A, Walther B, BeckerT, Muller U, Nikolaus,T (2013) Actigraphic daytime activity is reduced in patients with cognitive impairment and apathy. Eur Psychiatry 28, 9497.

14. Cummings JL (2000) Cognitive and behavioral heterogeneity in Alzheimer's disease: Seeking the neurobiological basis. Neurobiol Aging 21, 845-861.

15. Hwang TJ, Masterman DL, Ortiz F, Fairbanks LA, Cummings JL (2004) Mild cognitive impairment is associated with characteristic neuropsychiatric symptoms. Alzheimer Dis Assoc Disord 18, 17-21.

16. Tatsch MF, Bottino CM, Azevedo D, Hototian SR, Moscoso MA, Folquitto JC, Scalco AZ, Louza MR (2006) Neuropsychiatric symptoms in Alzheimer disease and cognitively impaired, nondemented elderly from a communitybased sample in Brazil: Prevalence and relationship with dementia severity. Am J Geriatr Psychiatry 14, 438-445.

17. Benoit $\mathrm{M}$, Berrut $\mathrm{G}$, Doussaint $\mathrm{J}$, Bakchine S, BoninGuillaume S, Fremont P, Gallarda T, Krolak-Salmon P, Marquet T, Mekies C, Sellal F, Schuck S, David R, Robert P (2012) Apathy and depression in mild Alzheimer's disease: Across-sectional study using diagnostic criteria. J Alzheimers Dis 31, 325-334. 
18. Hoe J, Katona C, Orrell M, Livingston G (2007) Quality of life in dementia: Care recipient and caregiver perceptions of quality of life in dementia: The LASER-AD study. Int J Geriatr Psychiatry 22, 1031-1036.

19. Modrego PJ, Ferrandez J (2004) Depression in patients with mild cognitive impairment increases the risk of developing dementia of Alzheimer type. Arch Neurol 61, 1290-1293.

20. Lee GJ, Lu PH, Hua X, Lee S, Wu S, Nguyen K, Teng E, Leow AD, Jack CR Jr, Toga AW, Weiner MW, Bartzokis G, ThompsonPM(2012) Depressive symptoms in mild cognitive impairment predict greater atrophy in Alzheimer's diseaserelated regions. Biol Psychiatry 71, 814-821.

21. Copeland MP, Daly E, Hines V, Mastromauro C, Zaitchik D, Gunther J, Albert M (2003) Psychiatric symptomatology and prodromal Alzheimer's disease. Alzheimer Dis Assoc Disord 17, 1-8.

22. Palmer K, Berger AK, Monastero R, Winblad B, Backman L, Fratiglioni L (2007) Predictors of progression from mild cognitive impairment to Alzheimer disease. Neurology 68, 1596-1602.

23. Peters KR, Rockwood K, Black SE, Bouchard R, Gauthier S, Hogan D, Kertesz A, Loy-English I, Beattie BL, Sadovnick AD, Feldman HH (2006) Characterizing neuropsychiatric symptoms in subjects referred to dementia clinics. Neurology 66, 523-528.

24. Vital TM, Hernandez SS, Stein AM, Garuffi M, Corazza DI, de Andrade LP, Costa JL, Stella F (2012) Depressive symptoms and level of physical activity in patients with Alzheimer's disease. Geriatr Gerontol Int 12, 637-642.

25. Petersen RC, Smith GE, Waring SC, Ivnik RJ, Tangalos EG, Kokmen E (1999) Mild cognitive impairment: Clinical characterization and outcome. Arch Neurol 56, 303-308. 
26. Fahn SE, RL. (1987) Members of the UPDRS Development Committee. Unified Parkinson's Disease Rating Scale In Recent Developments in Parkinson's Disease, Information MHC, ed., Florahm Park, NJ, pp. 153-164.

27. American Psychiatric Association (1994) Diagnostic and statistical manual of mental disorders, fourth edition, American Psychiatric Association, Washington, DC.

28. Folstein MF, Folstein SE, McHugh PR (1975) "Mini-mental test". A practical method for grading the cognitive state of patients for the clinician. J Psychiatry Res 12, 189-198.

29. Dubois B, SlachevskyA, Litvan I, PillonB(2000) The FAB:A Frontal Assessment Battery at bedside. Neurology 55, 16211626.

30. Mathuranath PS, George A, Cherian PJ, Mathew R, Sarma PS (2005) Instrumental activities of daily living scale for dementia screening in elderly people. Int Psychogeriatr 17, 461-474.

31. Cummings JL, Mega MS, Gray K, Rosemberg-Thompson S, Gornbein T (1994) The Neuropsychiatric Inventory: Comprehensive assessment of psychopathology in dementia. Neurology 44, 2308-2314.

32. Montgomery S, A“ sberg M (1979) A new depression scale designed to be sensitive to change. Br J Psychiatry 134, 382389.

33. Yesavage JA, Brink TL, Rose TLea (1983) Development and validation of a geriatric depression scale: A preliminary report. J Psychiatry Res 17, 37-49.

34. Hall JR, O'Bryant SE, Johnson LA, Barber RC (2011) Depressive symptom clusters and neuropsychological performance in mild Alzheimer's and cognitively normal elderly. Depress Res Treat 2011, 396958.

35. Andersson S, Krogstad JM, Finset A (1999) Apathy and depressed mood in acquired brain damage: Relationship to lesion localization and psychophysiological reactivity. Psychol Med 29, 447-456. 
36. Aalten P, de Vugt ME, Jaspers N, Jolles J, Verhey FR (2005) The course of neuropsychiatric symptoms in dementia. Part I: Findings from the two-year longitudinal Maasbed study. Int J Geriatr Psychiatry 20, 523-530.

37. Bonnet S, Jallon P, Bourgerette A, Antonakios M, Guillemaud R, Caritu Y, Becq G, Kahane P, Chapat P, Thomas-Vialettes B, Thomas-Vialettes F, Gerbi D, Ejnes D (2011) An Ethernet motion-sensor based alarm system for epilepsy monitoring. IRBM 32, 155-157.

38. Doron M, Bastian T, Maire A, Dugas J, Perrin E, Gris F, Guillemaud R, Deschamps T, Bianchi P, Caritu Y, Simon C, Jallon P (2013) Estimation of physical activity monitored during the day-to-day life by an autonomous wearable device (SVELTE project). Conf Proc IEEE Eng Med Biol Soc 2013, 4629-4632.

39. Bensamoun D, Derreumaux A,Verzeroli M, Teboul B, Robert PH, David R (2013) Comparative study of postural recognition from four actigraphs during activities of daily living. 21st European Congress of Psychiatry in Nice, France, 2013.

40. Finazzi ME, Mesquita ME, Lopes JR, Fu LI, Oliveira MG, Del Porto JA (2010) Motor activity and depression severity in adolescent outpatients. Neuropsychobiology 61, 33-40.

41. Volkers AC, Tulen JH, Van Den BroekWW, Bruijn JA, Passchier J, Pepplinkhuizen L (2002) 24-Hour motor activity after treatment with imipramine or fluvoxamine in major depressive disorder. Eur Neuropsychopharmacol 12, 273-278.

42. Volkers AC, Tulen JH, van den Broek WW, Bruijn JA, Passchier J, Pepplinkhuizen L (2003) Motor activity and autonomic cardiac functioning in major depressive disorder. $\mathrm{J}$ Affect Disord 76, 23-30. 
43. Vilalta-Franch J, Garre-Olmo J, Lopez-Pousa S, TuronEstrada A, Lozano-Gallego M, Hernandez-Ferrandiz M, Pericot-Nierga I, Feijoo-Lorza R (2006) Comparison of different clinical diagnostic criteria for depression in Alzheimer disease. Am J Geriatr Psychiatry 14, 589-597.

44. Robert P, Onyike CU, Leentjens AF, Dujardin K, Aalten P, Starkstein S, Verhey FR, Yessavage J, Clement JP, Drapier D, Bayle F, Benoit M, Boyer P, Lorca PM, Thibaut F, Gauthier S, Grossberg G, Vellas B, Byrne J (2009) Proposed diagnostic criteria for apathy in Alzheimer's disease and other neuropsychiatric disorders. Eur Psychiatry 24, 98-104.

45. Hebert LE, Scherr PA, McCann JJ, Bienias JL, Evans DA (2008) Change in direct measures of physical performance among persons with Alzheimer's disease. Aging Ment Health $12,729-734$.

46. Hebert LE, Bienias JL, McCann JJ, Scherr PA, Wilson RS, Evans DA (2010) Upper and lower extremity motor performanceand functional impairment in Alzheimer's disease. Am

J Alzheimers Dis Other Dement 25, 425-431.

47. Annweiler C, Beauchet O, Celle S, Roche F, Annweiler T, Allali G, Bartha R, Montero-Odasso M (2012) Contribution of brain imaging to the understanding of gait disorders in Alzheimer's disease: A systematic review. Am J Alzheimers Dis Other Dement 27, 371-380.

48. Reeves S, Mehta M, Howard R, Grasby P, Brown R (2010) The dopaminergic basis of cognitive and motor performance in Alzheimer's disease. Neurobiol Dis 37, 477-482.

49. James BD, Boyle PA, Bennett DA, Buchman AS (2012) Total daily activity measured with actigraphy and motor function in community-dwelling older persons with and without dementia. Alzheimer Dis Assoc Disord 26, 238-245. 


\section{CHAPTER 5}

\section{VALIDATION OF AN AUTOMATIC VIDEO MONITORING SYSTEM FOR THE DETECTION OF INSTRUMENTAL ACTIVITIES OF DAILY LIVING IN DEMENTIA PATIENTS}

Journal of Alzheimer's Disease 2015 ; 44(2), 675-685

König, A, Crispim Junior, CF, Derreumaux, A, Bensadoun, G, Petit, PD, Bremond, F, David, R, Verhey, F, Aalten, P, Robert, P 


\begin{abstract}
Over the last few years, the use of new technologies for the support of elderly people and in particular dementia patients received increasing interest. We investigated the use of a video monitoring system for automatic event recognition for the assessment of instrumental activities of daily living (IADL) in dementia patients. Participants (19 healthy subjects (HC) and 19 mild cognitive impairment (MCI) patients) had to carry out a standardized scenario consisting of several IADLs such as making a phone call while they were recorded by $2 \mathrm{D}$ video cameras. After the recording session, data was processed by a platform of video signal analysis in order to extract kinematic parameters detecting activities undertaken by the participant. We compared our automated activity quality prediction as well as cognitive health prediction with direct observation annotation and neuropsychological assessment scores. With a sensitivity of $85.31 \%$ and a precision of $75.90 \%$, the overall activities were correctly automatically detected. Activity frequency differed significantly between MCI and HC participants $(\mathrm{p}<0.05)$. In all activities, differences in the execution time could be identified in the manually and automatically extracted data. We obtained statistically significant correlations between manually as automatically extracted parameters and neuropsychological test scores $(\mathrm{p}<0.05)$. However, no significant differences were found between the groups according to the IADL scale. The results suggest that it is possible to assess IADL functioning with the help of an automatic video monitoring system and that even based on the extracted data, significant group differences can be obtained.
\end{abstract}




\section{INTRODUCTION}

The increase of persons with dementia is accompanied by the need to identify methods that allow for an easy and affordable detection of decline in functionality in the disorder's early stages. Consequently, the development of computerized assessment systems for the elderly is of high interest, and represents a promising new research domain that aims to provide clinicians with assessment results of higher ecological validity. Dementia is one of the major challenges affecting the quality of life of the elderly and their caregivers.

Progressive decline in cognitive function represents a key symptom and results often in the inability to perform activities of daily living (ADL) and instrumental activities of daily living (IADL) [1] such as managing finances or cooking. Many efforts are currently being undertaken to investigate dementia pathology and develop efficient treatment strategies considering its rapidly increasing prevalence. Mild cognitive impairment (MCI) [2-4] is considered as a pre-dementia stage for Alzheimer's disease (AD), as many MCI patients convert to $\mathrm{AD}$ over time [5]. Studies showthat impairment in complex functional tasks, notably due to slower speed of execution [6], may already be detectable in the early stages of cognitive decline and therefore gradually becomes an important target in clinical assessments [7, 8]. Rating scales and questionnaires constitute the essential tools for the assessment and monitoring of symptoms, treatment effects, as well as (I)ADL functioning.

Nevertheless, changes in (I)ADL functioning observed in MCI may be too subtle to be detected by traditional measures assessing global ADLs [9, 10]. Thus, standard tools are limited to some extent in ecological validity, reproducibility, and objectivity [11]. They do not fully capture the complexity of a patient's cognitive, behavioral, and functional statuses, which do not always evolve in parallel but rather idiosyncratically. 
To overcome these problems, Schmitter-Edgecombe et al. developed a naturalistic task in a realworld setting to examine everyday functioning in individuals with MCI using direct observation methods [12]. However, this method can also suffer from possible observation biases and difficulties in reproducibility. For this reason, information and communication technology (ICT) involving imaging and video processing could be of interest by adding more objectively measured data to the diagnostic procedure. Functionality in (I)ADL, which is very closely linked to executive functions $[13,14]$, may be reflected in activity patterns measurable through computerized systems such as automatic video detection of activities.

Dawadi et al. showed that it is possible to automatically quantify the task quality of daily activities and to perform limited assessment of the cognitive functioning of individuals in a 'smart' home environment (equipped with various sensors) as long as the activities are properly chosen and the learning algorithms are appropriately trained [15]. Sablier and colleagues developed a technological solution designed for people with difficulties managing ADL, providing a schedule manager as well as the possibility to report occurrences of experiences of symptoms such as depression and agitation [16]. However, indicators of cognitive functioning and autonomy were measured using a test battery and scales [16]. Okahashi et al. created a Virtual Shopping Test-using virtual reality technology to assess cognitive functions in brain-injured patients - correlating variables on the virtual test with scores of conventional assessments of attention and memory [17]. Similar work has been done by Werner et al. using a virtual action planning Supermarket game for the diagnosis of MCI patients [18]. Along this line, a project was launched under the name Sweet-HOME (2012), defining a standardized scenario where patients are asked to carry out a list of autonomy relevant (I)ADLs, such as preparing tea, making a phone call, or writing a check, in an experimental room equipped with video sensors.Within this project, Sacco et al. performed a functional assessment with the help of visual analyses by 
computing a DAS (Daily Activity Scenario) score able to differentiate MCI from healthy control (HC) subjects [19]. However, analysis was based purely on annotations made by a direct observer, and therefore still risked lack of objectivity and reliability. Automatic, computerbased video analysis, which allows for the recognition of certain events and patients' behavioral patterns, may offer a new solution to the aforementioned assessment problems. To date, automatic video event recognition has been employed in clinical practice simply for feasibility studies with small samples [20-22]. Banerjee et al. presented video-monitoring for fall detection in hospital rooms by extracting features from depth information provided by a camera [23].Wang et al. used automatic vision analyses for gait assessment using two cameras to differentiate between the gait patterns of residents participating in realistic scenarios [22].

In order to further evaluate the potential contribution of such technologies for clinical practice, this study aims to validate the use of automatic video analyses for the detection of IADL performance within a larger group of MCI patients and HC subjects carrying out a predefined set of activities. More specifically, the objectives of the study are (1) to compare IADL performances of elderly HC subjects and patients with MCI in a predefined scenario; (2) to compare automatically extracted video data with so-called 'ground-truth' (GT) annotations made manually by a human observer; and (3) to assess the importance of automatic video analyses data for the differentiation between the two populations. As a secondary objective, we investigate the relationship between the participants' performance in the scenario and the results of classical neuropsychological testing, in order to verify whether or not the performance in the created scenario is associated with the status of cognitive functioning. We expect automatically extracted video detection to achieve results as GT annotations when differentiating between the MCI group and the HC group. We also hypothesize that individuals with MCI will perform poorer in the predefined IADL scenario than $\mathrm{HC}$ subjects and that 
difficulties in executive functioning will be related to the amount of completed activities. Further, we expect a significant relationship between the video captured performance in the scenario and the classical neuropsychological test results such as the Frontal Assessment Battery (FAB) [24] or the Mini- Mental State Examination (MMSE) [25] and IADL scales [26].

\section{METHODS}

\section{Participants}

The study was approved by the local Nice ethics committee and only participants with the capacity to consent to the study were included. Each participant gave informed consent before the first assessment. Participants aged 65 or older were recruited at the memory center in Nice located at the Geriatric Department of the University Hospital. For the MCI group, patients with a MMSE score higher than 24 were included using the Petersen clinical criteria [4]. Participants were excluded if they had any history of head trauma, loss of consciousness, psychotic aberrant motor behavior, or a score higher than 0 on the Unified Parkinson's Disease Rating scale (UPDRS) [27] in order to control for any possible motor disorders influencing the ability to carry out IADLs.

\section{Assessments}

Participants were administered a cognitive and behavioral examination prior to completing the video monitoring session. General cognitive status was assessed using neuropsychological tests including: MMSE [25], Frontal Assessment Battery (FAB) [24], Instrumental Activities of Daily Living scale (IADL-E) [28], Montgometry-Asberg Depression Rating Scale (MADRS) [29], and Geriatric Depression Scale (GDS) to assess depression levels [30]. Additionally, neuropsychiatric symptoms were assessed using the Neuropsychiatric Inventory Scale (NPI) [31]. 


\section{Clinical scenario: The ecological assessment}

The ecological assessment of IADLs was conducted in an observation room located in the Nice Research Memory Center. This room was equipped with everyday objects for use in ADLs and IADLs, e.g., an armchair, a table, a tea corner, a television, a personal computer, and a library (see Figure 1). Two fixed monocular video cameras (eight frames per second) were installed to capture the activity of the participants during the experiment. Using an instruction sheet, participants had to carry out 10 daily-living-like activities, such as making a phone call or preparing a pillbox, in a particular order within a timeframe of $15 \mathrm{~min}$ (Table 1).The aim of this ecological assessment of autonomy was to determine to which extent the participant could undertake a list of daily activities with respect of some constraints after being given a set of instructions. After each participant carried out the scenario, a clinician verified the amount of activities initiated and carried out completely and correctly, as well as repetitions and omissions. The information was manually annotated and entered into the database via a tablet. The scenario was recorded using a 2D-RGB video camera (AXIS, Model P1346, 8 frames per second) and a RGBD camera (Kinect, Microsoft). 
Table 1. List of the activities proposed to the patient during the ecological assessment

\section{Daily Living scenario associated with the protocol}

Activities

"Your task is to perform this list of 10 activities in a

\section{Activities} logical manner within $15 \mathrm{~min}$. These 15 minutes represent a typical morning period of everyday life. »

- Read the newspaper

- Water the plant

- Answer the phone

- Call the taxi

- Prepare today's medication

- Make the check for the Electricity Company

- Leave the room when you have finished all activities

Constraints

- Watch TV

- Prepare a hot tea

- Write a shopping list for lunch

1. Watch TV before the phone call

2. Water the plant just before leaving the room

3. Call the taxi which will take 10 min to arrive and ask the driver to bring you to the market

For a more detailed analysis, the main focus was placed particularly on three IADLs, namely preparing a pillbox, making a phone call, and preparing tea, because they fall within the commonly used IADLLawton scale, and are the most challenging activities for appropriately representing a patient's general autonomy level. However, all other activities were included in the overallIADLassessment procedure and analyses. 
Automatic video monitoring system and event recognition

In the first step, after each assessment, a clinician manually gathered data of the amount of activities carried out by the participants. This included parameters such as activity occurrence, activity initiation, and the number of activities carried out completely and correctly. In the next step, a computer vision algorithmwas used to automatically extract different parameters representing movement patterns of the participants during the ecological assessment period.

The Automatic Video Monitoring System (AVMS) herein used has been fully described [32]. It is composed of two main modules: the vision and the event recognition. The vision module is responsible for detecting and tracking people on the scene. The event recognition module uses the generic constraint-based ontology language proposed by Zouba et al. [33] for event modeling and the reasoning algorithm proposed by $\mathrm{Vu}$ and colleagues [34] to describe and detect the activities of daily living of interest in this study. The vision module detects people in the scene using an extension of the Gaussian Mixture Model algorithm for background subtraction proposed by Nghiem et al. [35]. People tracking over time is performed by a multi-feature algorithm proposed by Chau et al. using features such as $2 \mathrm{D}$ size, 3D displacement, color histogram, and dominant color. The detected people and their tracking information (their current and previous positions in the scene) are then passed to the event recognition module [36].

The event recognition module is composed of a framework for event modeling and a temporal scenario recognition algorithm which assess whether the constraints defined in the event models are satisfied [34]. Event models are built taking into account a priori knowledge of the experimental scene and attributes dynamically obtained by the vision module. Event modeling follows a declarative and intuitive ontologybased language that uses natural terminology to allow end users (e.g., medical experts) to easily add and modify modify the 
models. The a priori knowledge consists of a decomposition of a 3D projection of the room's floor plan into a set of spatial zones (see Figure 1) that have semantic information regarding the events of interest (e.g., TV position, armchair position, desk position, tea preparation). The ontology employed by the system hierarchically categorizes event models according to their complexity, described here in ascending order:

- Primitive State models an instantaneous value of a property of a person (posture or position inside a certain zone.

- Composite State refers to a composition of two or more primitive states.

- Primitive Event models a change in a value of person's property (e.g., change in posture to model whether or not a person changes from a Sitting to a Standing state).

- Composite Event refers to the composition of two of the previous event model types in terms of a temporal relationship (e.g., Person changes from Sitting to Standing posture before Person in Corridor).

\section{IADL modeling}

The semantic information of the observation room where patients conducted the activities of daily living was defined. Contextual or Semantic Elements were defined at the locations where the activities of daily living would be carried out (e.g., telephone zone at top-left corner, tea and plant zones at top-right corner, and pharmacy zone at bottom-left corner). The activity modeling was performed with the support of domain experts. The models were mostly made taking into account one or more of the following constraints: the presence of the person in a specific zone, their posture, and their proximity to the object of daily living (when static, e.g., the telephone). These constraints were defined as primitive state models. The combination of these models, along with their temporal order, was defined as a composite event. Duration constraints were also used to establish a minimum time of execution for the whole or sub-components of the composite event. 


\section{Statistical analysis}

Spearman's correlations were performed to determine the association between the extracted video parameters and the established assessment tools in particular for executive functioning, e.g., the FAB. Comparison between the two groups (i.e., MCI patients and HC subjects) was performed with a Mann-Whitney test for each outcome variable of the automatic video analyses. Differences were reported as significant if $\mathrm{p}<0.05$.

\section{Automatic activity recognition evaluation}

The evaluation compared the performance of the AVMS at automatically detecting IADL with respect to the annotations manually made by human experts. The AVMS performance was measured based on the indices of recall and precision, described in Equations 1 and 2, respectively. Recall index measures the percentage of how many of the targeted activities have been detected compared to how many existed. Precision index evaluates the performance of the system at discriminating a targeted activity type from others.

\section{Recall $=\mathrm{TP} /(\mathrm{TP}+\mathrm{FN})$ 2. Precision $=\mathrm{TP} /(\mathrm{TP}+\mathrm{FP})$}

TP: True Positive rate, FP: False Positive rate, FN: False Negative rate.

\section{RESULTS}

\section{Population}

$19 \mathrm{MCI}$ patients $($ age $=75.2 \pm 4.25)$ and $19 \mathrm{HC}($ age $=71.7 \pm 5.4)$ were included. Table 2 shows the clinical and demographic data of the participants. Significant intergroup differences in demographic factors (gender and age) were not seen. However, significant differences were found between for the MMSE score with a mean of $25.8( \pm 2.2)$ for the MCI group and $28.8( \pm 1.0)$ for the HC group (p, 0.001), as well as for the FAB score with a mean of $14.16( \pm 1.92)$ for the MCI group 
and $16.2( \pm 1.44)$ for the HC group. The mean IADL-E scores did not differ between groups, with a mean IADL-E score of $9.9( \pm 1.7)$ for the MCI group and $9.6( \pm 1.1)$ for the HC group.

Table 2. Characteristics of the participants

\begin{tabular}{|c|c|c|c|c|}
\hline Characteristics & $\begin{array}{l}\text { Healthy } \\
\text { group } \\
\mathrm{N}=19\end{array}$ & Control & $\begin{array}{l}\text { MCI group } \\
\mathrm{N}=19\end{array}$ & $p$ \\
\hline Female, n (\%) & $15(78.9 \%)$ & & $9(47.4 \%)$ & 0.091 \\
\hline Age, years mean ST & $71.7 \pm 5.37$ & & $75.2 \pm 4.25$ & 0.070 \\
\hline \multicolumn{5}{|l|}{ Level of Education, n (\%) } \\
\hline Unknown & $2(10.5 \%)$ & & $2(10.5 \%)$ & 1.00 \\
\hline No formal education & $0(0 \%)$ & & $0(0 \%)$ & - \\
\hline Elementary school & $1(5.3 \%)$ & & $5(26.3 \%)$ & 0.405 \\
\hline Middle school & $4(21.0 \%)$ & & $7(36.8 \%)$ & 0.269 \\
\hline High school & $4(21.0 \%)$ & & $3(15.8 \%)$ & 1.00 \\
\hline Post-secondary education & $8(42.1 \%)$ & & $2(10.5 \%)$ & 0.062 \\
\hline MMSE, mean \pm SD & $28.8 \pm 1.03$ & & $25.8 \pm 2.22$ & $0.001 * *$ \\
\hline $\mathbf{F A B}$, mean $\pm \mathrm{SD}$ & $16.2 \pm 1.44$ & & $14.16 \pm 1.92$ & $0.002 *$ \\
\hline IADL-E, mean \pm SD & $9.6 \pm 1.12$ & & $9.9 \pm 1.73$ & 0.488 \\
\hline NPI total, mean $\pm S D$ & $0.42 \pm 1.43$ & & $6.16 \pm 6.73$ & $0.00 *$ \\
\hline
\end{tabular}

Abbreviations: MCI: mild cognitive impairment

Data shown as mean $\pm \mathrm{SD}$. Bold characters represent significant $\mathrm{p}$-values $<0.05$.

Scores on the Mini Mental State Examination (MMSE) range from 0 to 30, with higher scores indicating better cognitive function; Scores on the Instrumental Activities of Daily Living for Elderly (IADL-E) range from 0 to 36, with lower score indicating a better functional independency; Scores on the Montgomery Asberg Depression Rating Scale (MADRS) range from 0 to 60 (10 items range from 0 to 6), with higher scores indicating depressive state; Scores on the Geriatric Depression Scale (GDS) range from 0 to 30, with higher scores indicating depressive state. 
Automatic video monitoring results versus ground-truth annotation The participants performed differently on the IADL scenario according to their diagnostic group; in all three activities (preparing the pillbox, preparing tea, and making/receiving a phone call), the obtained parameters (manually as automatic) showed variations. All results are presented in detail in Table 3. The total frequency of activities as well as the number of correctly completed activities according to manual annotations differed significantly between MCI and $\mathrm{HC}$ groups $(\mathrm{p}<0.05)$. Two activities, namely preparing the pillbox and making/receiving the phone call, generally took the MCI participants a longer time to carry out. In turn, for the activity of preparing tea, HC participants took a longer time. The same trends, even if not significant, were detected as well by the automatic video analyses; a significant difference was found between MCI and $\mathrm{HC}$ groups $(\mathrm{p}<0.05)$ in the phone call time. Furthermore, MCI and HC participants differed in the total amount of detected activities carried out; the same activities, preparing the pillbox and making/receiving a phone call took longer for MCI participants whereas making tea took longer for the HC group. 
Table 3. Comparison of parameters from video analyses between groups

\begin{tabular}{|c|c|c|c|}
\hline Video analyses data & $\begin{array}{l}\mathrm{HC} \\
\mathrm{N}=19\end{array}$ & $\begin{array}{l}\text { MCI } \\
\mathrm{N}=19 \\
\end{array}$ & $P$ \\
\hline \multicolumn{4}{|l|}{ Manually annotated: } \\
\hline $\begin{array}{l}\text { Activities carried out } \\
\text { completely and } \\
\text { correctly } \dagger\end{array}$ & $9.68 \pm 0.48$ & $8.21 \pm 1.48$ & $\begin{array}{l}0.00 * \\
0.007 *\end{array}$ \\
\hline $\begin{array}{l}\text { Activity frequency total } \\
\text { (activities initiated) } \$\end{array}$ & $1.05 \pm 0.23$ & $0.89 \pm 0.32$ & 0.086 \\
\hline $\begin{array}{l}\text { Preparing Pillbox }(f) \\
\text { Preparing Pillbox time }\end{array}$ & $41.17 \pm 17.04$ & $46.17 \pm 31.18$ & 0.609 \\
\hline $\begin{array}{l}\text { Making tea }(f) \\
\text { Making tea time }\end{array}$ & $\begin{array}{l}2.68 \pm 0.82 \\
41.21 \pm 30.60\end{array}$ & $\begin{array}{l}2 \pm 1 \\
32.16 \pm 35.3\end{array}$ & $\begin{array}{l}0.068 \\
0.175\end{array}$ \\
\hline $\begin{array}{l}\text { Phone call }(f) \\
\text { Phone call time }\end{array}$ & $\begin{array}{l}2 \pm 0.47 \\
66.61 \pm 21.75\end{array}$ & $\begin{array}{l}2.21 \pm 0.53 \\
83.30 \pm 30.96\end{array}$ & $\begin{array}{l}0.198 \\
0.118\end{array}$ \\
\hline $\begin{array}{l}\text { Automatically extracted: } \\
\text { Activity frequency total }\end{array}$ & $13.26 \pm 3.89$ & $10.95 \pm 3.15$ & 0.056 \\
\hline $\begin{array}{l}\text { Preparing Pillbox }(f) \\
\text { Preparing Pillbox time }\end{array}$ & $\begin{array}{l}1.05 \pm 0.23 \\
47.64 \pm 22.28\end{array}$ & $\begin{array}{l}1.17 \pm 0.38 \\
70.26 \pm 38.01\end{array}$ & $\begin{array}{l}0.271 \\
0.204\end{array}$ \\
\hline $\begin{array}{l}\text { Making tea }(f) \\
\text { Making tea time }\end{array}$ & $\begin{array}{l}2.74 \pm 1.33 \\
102.3 \pm 77.3\end{array}$ & $\begin{array}{l}2.12 \pm 1.22 \\
79.57 \pm 40.92\end{array}$ & $\begin{array}{l}0.136 \\
0.531\end{array}$ \\
\hline $\begin{array}{l}\text { Phone call }(f) \\
\text { Phone call time }\end{array}$ & $\begin{array}{l}1.95 \pm 0.52 \\
60.32 \pm 21.52\end{array}$ & $\begin{array}{l}2.17 \pm 0.79 \\
112.61 \pm 46.31\end{array}$ & $\begin{array}{l}0.380 \\
\mathbf{0 . 0 0 0} *\end{array}$ \\
\hline
\end{tabular}

Mann-Whitney test : ${ }^{*} P<0.05,{ }^{*} P<0.01 . ; \mathrm{HC}=$ Healthy Control Subjects, MCI $=$ Mild Cognitive Impairment Subjects; (f) $=$ mean frequency of detected event; $\uparrow$ : Represents the total amount of completely carried out activities without a mistake, $\ddagger$ : Represents the total of simply initiated activities which are not always necessarily accomplished completely and without mistakes 


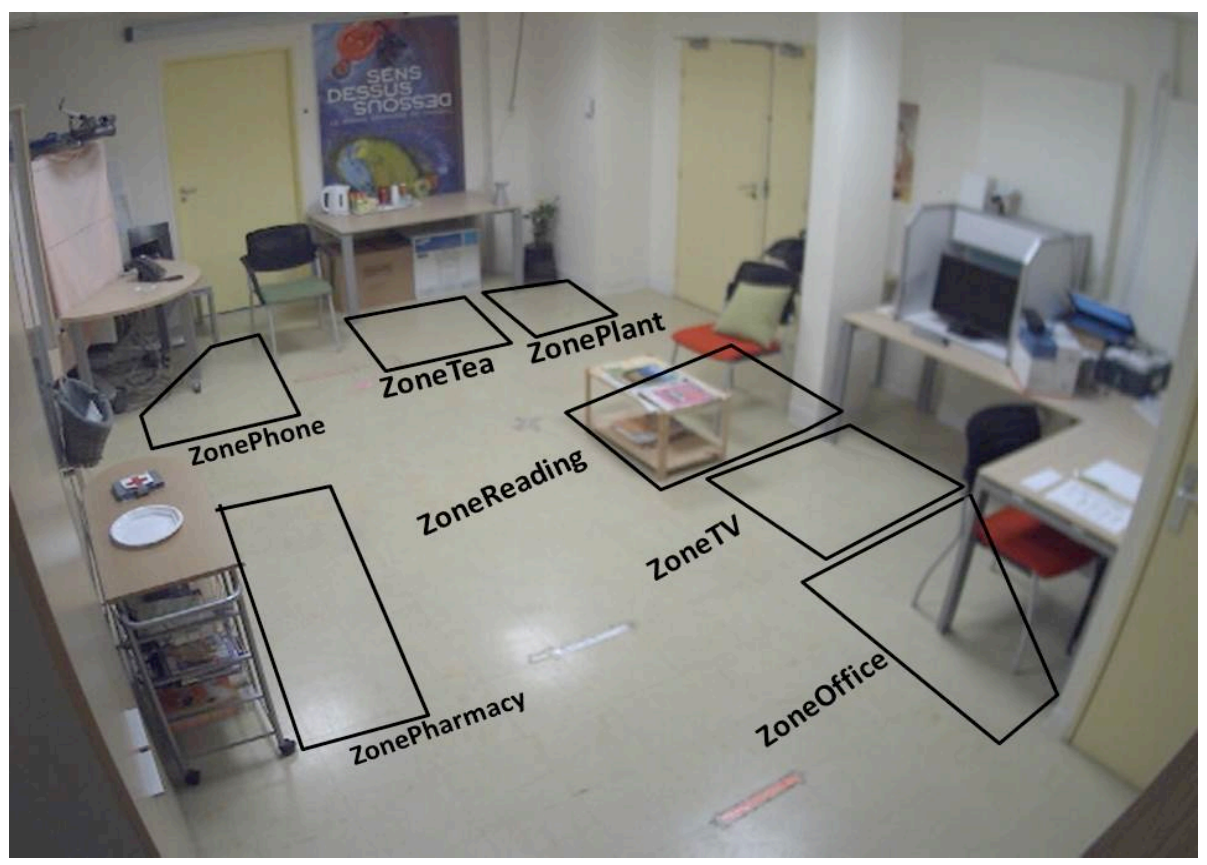

Figure 1. The experimental room for the IADL assessment. For the automatic activity detection the room was divided in different zones according to the designated IADL

According to the amount of carried out activities and rapidity, the best and worst performers were determined in each group. Next, we investigated if participants that performed well showed a difference in the parameters extracted from the automated video analyses compared to participants that did not perform as well on the assessment. This, in turn, could help establish diagnostic-specific profiles of IADL functioning. The results are presented in Fig. 2.

Moreover, the manually and automatically extracted video data parameter 'activity frequency' correlated significantly with neuropsychological test results namely the MMSE $(\mathrm{p}<0.01)$ and FABscore $(\mathrm{p}<0.05)$. The obtained correlation analyses results are presented in Table 4. Particularly, from the manually annotated parameters, the time spent to prepare the pillbox correlated 
significantly negatively with the MMSE scores $(\mathrm{p}<0.01)$, whereas the time spent to make a phone call correlated significantly negatively with the FAB scores $(\mathrm{p}<0.05)$. The mean frequency of the activity 'making tea' correlated significantly positively with the FAB scores ( $p$ $<0.05$ ). From the automatically extracted parameters, the detected time spent to prepare the pillbox $(\mathrm{p}<0.01)$ and to make the phone call $(\mathrm{p}<0.05)$ correlated significantly negatively with the MMSE scores. None of the extracted parameters correlated with the IADL-E scores.

Automatic video monitoring results: Experimental results

Table 5 presents the results of the evaluation of the AVMS with respect to its accuracy at detecting the number of activities of daily living annotated by domain experts while watching the experiment video. From all 10 proposed activities, 'Reading' was detected automatically with the highest precision of $91.30 \%$, followed by 'Preparing pillbox' with $90.24 \%$, and 'Making phone call' with $89.47 \%$.

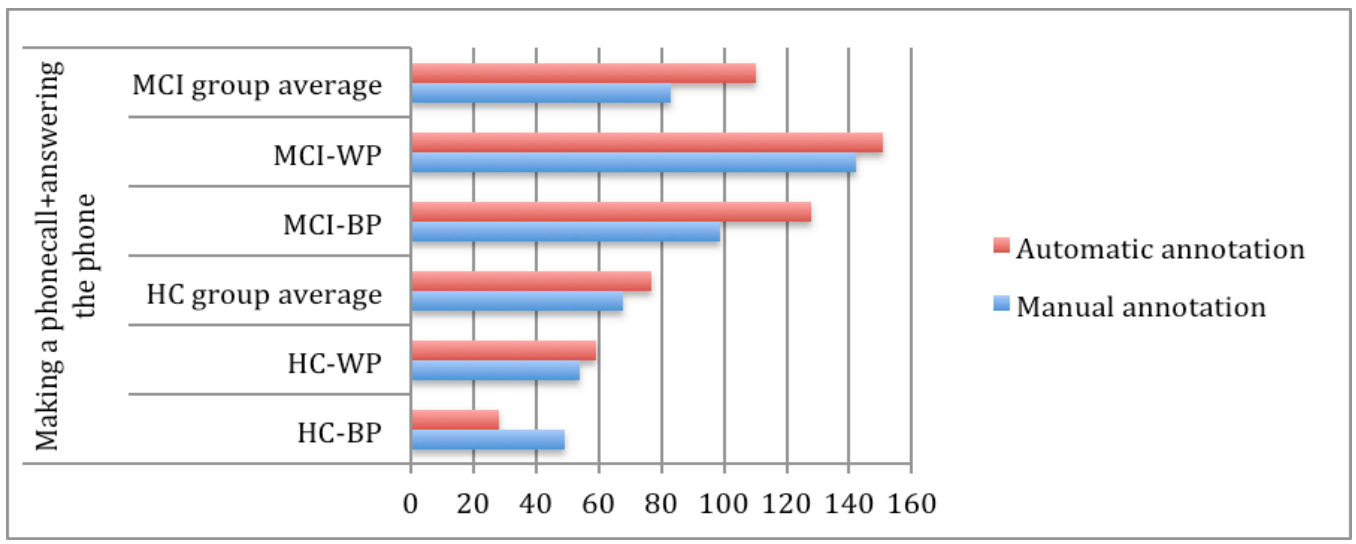



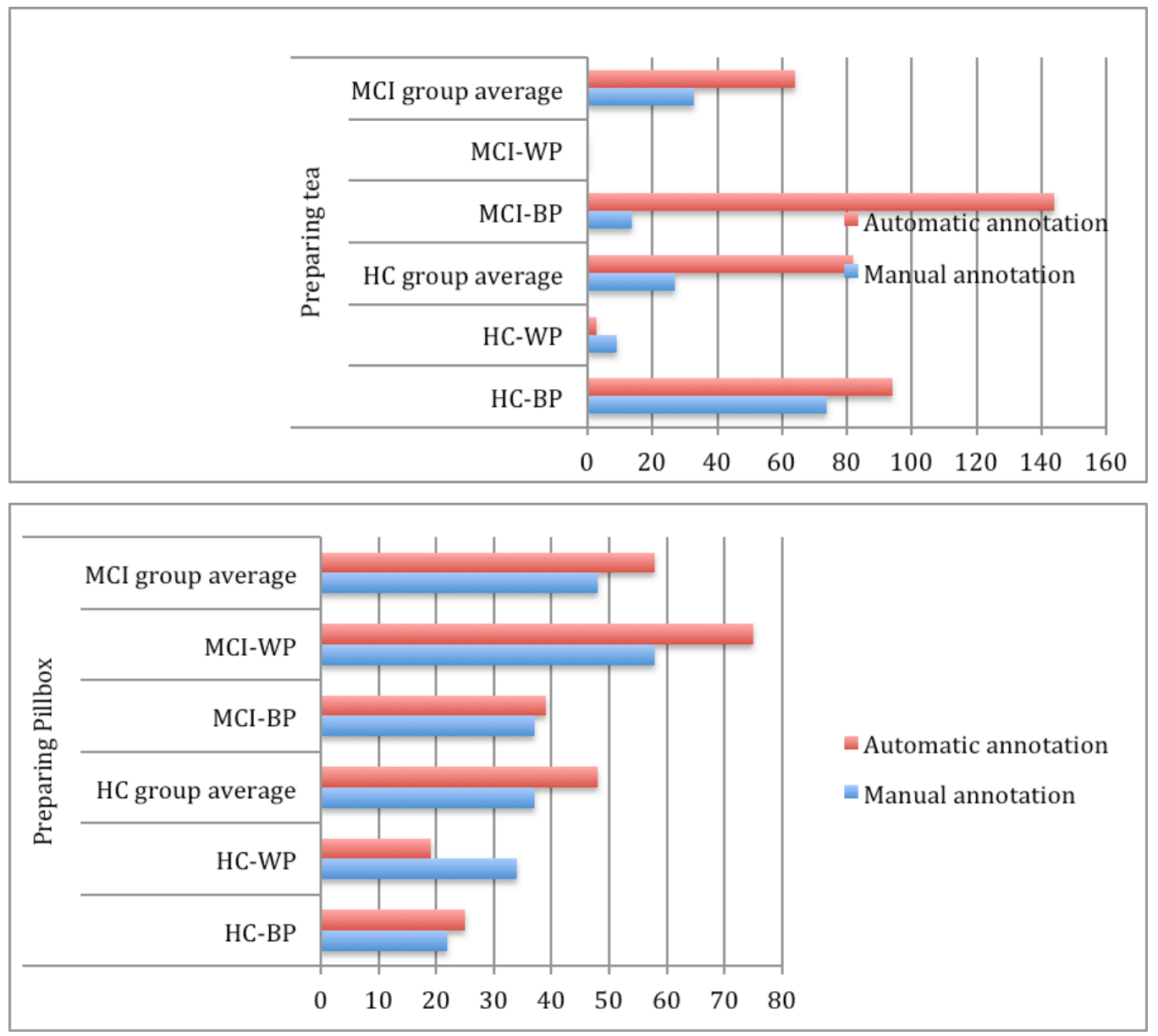

Figure 2. The average execution times for each activity in blue annotated manually and in red detected automatically. MCI: Mild Cognitive Impairment; WP: Worst performer, BP: Best performer, HC: Healthy control 


\section{DISCUSSION}

The presented study demonstrates the additional value of employing new technologies such as automatic video monitoring system in clinical practice for the assessment of (I)ADL in dementia patients.

The two main goals of the study were (1) to investigate if differences in IADL functioning can be detected between MCI and $\mathrm{HC}$ and (2) to compare between manual and automated assessments of IADL performances in contrast to standard paper scales.

The obtained results demonstrate that significant group differences between MCI and HC participants (even with just a small sample size) can be detected when using such techniques, and this when regular assessment tools such as the IADL-E questionnaire lack sensitivity to detect these group differences. A detection accuracy of up to $90 \%$ for the 'Preparing pillbox'activity has been achieved validating clearly the use of AVMS for evaluation and monitoring purposes. Furthermore, the correlation analyses demonstrated that extracted parameters, particularly execution times of activities, correlated significantly with neuropsychological tests results, namely the MMSE and FAB scores.

The study's results were consistent with those previously presented in [32], where a recall of 88.30 and a precision of 71.23 were demonstrated. Although our evaluation results were obtained from different patients and from a larger cohort, small differences were observed in precision index which is higher by $\sim 5 \%$, and in the recall index which is lower by $3 \%$. 


\section{Ianually annotated:}

ctivities frequency

ctivities completed correctly

utomatically extracted:

ctivity frequency

\section{Ianually annotated:}

'reparing Pillbox (f)

'reparing Pillbox time

Making tea (f)

Laking tea time

Phone call (f)

'hone call time

\section{utomatically extracted:}

'reparing Pillbox (f)

'reparing Pillbox time

laking tea (f)

laking tea time

'hone call (f)

hone call time (r)

$0.491 * *$

$\mathrm{p}=0.002$

$0.819 * *$

$\mathrm{p}=0.000$

$0.415^{* *}$

$\mathrm{p}=0.005$

0.055

$\mathrm{p}=239$

$-0.468 * *$

$\mathrm{p}=0.001$

0.270

$\mathrm{p}=0.083$

$-0.143$

$\mathrm{p}=0.222$

$-0.123$

$\mathrm{p}=0.128$

$-0.280 *$

$\mathrm{p}=0.044$

$-0.287^{*}$

$\mathrm{p}=0.043$

$-0.618 * *$

$\mathrm{p}=0.001$

0.223

$\mathrm{p}=0.60$

0.016

$\mathrm{p}=0.392$

$-0.248$

$\mathrm{p}=0.095$ (r)

0.394*

$\mathrm{p}=0.014$

0.660 **

$\mathrm{p}=0.000$

$0.273 *$

$\mathrm{p}=0.048$

0.299

$\mathrm{p}=0.063$

$-0.114$

$\mathrm{p}=0.409$

$0.363 *$

$\mathrm{p}=0.042$

0.053

$\mathrm{p}=0.343$

$-0.235$

$\mathrm{p}=0.084$

$-0.332 *$

$\mathrm{p}=0.041$

$-0.073$

$\mathrm{p}=0.295$

$-0.241$

$\mathrm{p}=0.340$

0.221

$\mathrm{p}=0.083$

$-0.101$

$\mathrm{p}=0.261$

0.077

$\mathrm{p}=0.330$ (r)

$-0.035$

$\mathrm{p}=0.834$

$-0.107$

$\mathrm{p}=0.522$

$-0.071$

$\mathrm{p}=0.337$

$-0.149$

$\mathrm{p}=0.127$

$-0.179$

$\mathrm{p}=0.211$

$-0.50$

$\mathrm{p}=0.391$

$-0.002$

$\mathrm{p}=0.396$

0.002

$\mathrm{p}=0.465$

$-0.145$

$\mathrm{p}=0.291$

0.125

$\mathrm{p}=0.222$

$-0.050$

$\mathrm{p}=0.128$

$-0.264$

$\mathrm{p}=0.051$

$-0.114$

$\mathrm{p}=0.197$

0.158

$\mathrm{p}=0.223$ 


$\begin{array}{lll}-0.373^{*} & -0.277^{*} & -0.054 \\ \mathrm{p}=0.002 & \mathrm{p}=0.049 & \mathrm{p}=0.451\end{array}$

Table 4. Correlation between automatic video parameters, manually annotated parameters and conventional cognitive assessments (Spearman's correlation coefficient)

These differences are a result of a trade-off between AVMS precision and recall performance due to a refinement of the event-modeling step. By opting for more strict constraints in such models, we make the system less prone to errors such as misleading evidence. For instance, instead of patients walking toward the plant to water it, they just stretch from the tea table to do so, as this table is just beside the plant. Activities where the AVMS presented lower precision refer to at least one of two factors: participants performing the activity far from the camera and/or noise from low-level vision components of the AVMS. For example, a few patients stopped close by or inside the activity zones for long periods to read the instructions sheet, which caused false-positive detections of the zone-related activities. In addition, noisy data from low-level vision components sometimes shifted the estimation of the position of participants from their actual location to an activity zone close by, mostly when the participants were far from the camera. For the described problems, possible solutions include

the adoption of a probabilistic framework to handle noise and event modeling uncertainty, and a multisensor approach for cases where the activities are mis-detected by a lack of view of the participants. 
Table 5. Activity/Event Detection Performance

\begin{tabular}{l|l|l}
\hline \hline Activity & Recall & Precision \\
\hline Phone call & 85.00 & 89.47 \\
\hline Watching TV & 83.33 & 73.77 \\
\hline Making tea & 80.90 & 80.00 \\
\hline Preparing Pillbox & 100.00 & 90.24 \\
\hline Watering Plant & 75.00 & 61.22 \\
\hline Reading & 75.00 & 91.30 \\
\hline Average Recognition. & $\mathbf{8 5 . 3 1}$ & $\mathbf{7 5 . 9 0}$ \\
\hline
\end{tabular}

N: 38, MCI: 19 / HC: 19

If we try to interpret the results, it is not surprising that MCI participants carried out fewer activities in general and took more time, especially for preparing the pillbox and the phone call, which was detected by the observer as well as by the automatic video analysis. Recent studies demonstrated that even in MCI patients, difficulties in the execution of complex IADL tasks, could be observed and linked to possible early impairment of executive function [8]. This is further in line with our finding of significant group differences in the studied population (see Table 2) on the FAB, a test that specifically measures levels of executive functioning. Interestingly, the preparing tea activity took longer for $\mathrm{HC}$ participants and can be explained by the fact that, for the most part, they correctly completed this activity (which takes at least a minimum of $60 \mathrm{~s}$ ), whereas MCI patients initiated this activity but did not always finish it completely. Therefore, their execution time was shorter but may serve as an indicator of poor task performance.

One major drawback of this study was that healthy control subjects were recruited through the Memory Clinic and therefore suffered in most cases from subjective memory complaints. However, according to classical assessment tools and diagnostic manual they were cognitively healthy. Thus it is debatable whether or not to classify 
them as healthy controls, as the MMSE and FAB mean scores for that group were relatively low. Furthermore, the study was only based on a small population size. This does not mean that the chosen parameters were not helpful indicators, and they should be validated with a larger population in the future, potentially combined with other ICT data such as actigraphy [37] or automatic speech analyses [38], given the fact that certain significant group differences could be observed. It can be further argued that the experimentwas conducted in an artificial laboratory environment and not in a complete natural setting such as a patient's home. This could have had increased the stress level of the participants and consequently an impact on their IADL performance. It is therefore desirable in the future to conduct this type of assessment in more naturalistic settings, but that may also represent a less controlled environment and therefore a bigger challenge from a technical point of view. Finally, the current study placed less emphasis on multi-tasking in IADL performances, but rather focused more on the simple execution of tasks sequentially. However, in real life, multi-tasking is of great importance and represents complex cognitive processing required for functional ability. It is important to mention that in the field of automatic video analysis, it is almost impossible to achieve $100 \%$ accuracy in the activity recognition, often caused as well by inaccurate manual annotations. The challenge is to define, for example, the beginning and the end of an activity, which represents a common problem in video analyses. Nevertheless, the activity detection by video analyses might be actually a much closer representation of the reality and the real events happening than annotations of a human observer because the latest can be influenced by various confounding factors such as fatigue, distraction, lack of concentration, etc.

The advantages of using such techniques are that the application in daily practice is easy and reproducible, and add an objective measure to the assessment of autonomy. Furthermore, this evaluation provides quicker results than manual annotations and could be even used as an 
outcome measure in clinical trials in order to evaluate the effect of certain treatments (pharmacological and non-pharmacological) on the functioning of IADLs of patients. Overall, the study showed in particular that manually annotated data gives a more accurate picture of a patient's status to date, and is better validated by traditional diagnostic and neuropsychological assessment tools. This means that qualitative assessments still seem to better correlate with conventional scoring than quantitative video extracted parameters. Until now, the obtained data still needs interpretation of an experienced clinician regarding the quality of the carried out activities. It should be emphasized that this cannot be replaced by technology and is not the objective of this research. However, in future studies, we aim for improvement in the activity detection with a larger group sample, in particular to improve the detection of the quality of activity execution, i.e., if an activity was carried out successfully and completely. 


\section{REFERENCES}

1. Reppermund S, Brodaty H, Crawford JD,KochanNA, Draper B, Slavin MJ, Trollor JN, Sachdev PS (2013) Impairment in instrumental activities of daily living with high cognitive demand is an early marker of mild cognitive impairment: The Sydney memory and ageing study. Psychol Med 43, 24372445.

2. Albert MS, DeKosky ST, Dickson D, Dubois B, Feldman HH, Fox NC, Gamst A, Holtzman DM, Jagust WJ, Petersen RC, Snyder PJ, Carrillo MC, Thies B, Phelps CH (2011) The diagnosis of mild cognitive impairment due to Alzheimer's disease: Recommendations from the National Institute on Aging-Alzheimer's Association workgroups on diagnostic guidelines for Alzheimer's disease. Alzheimers Dement 7, 270-279.

3. Artero S, Petersen R, Touchon J, Ritchie K (2006) Revised criteria for mild cognitive impairment: Validation within a longitudinal population study. Dement Geriatr Cogn Disord 22, 465-470.

4. Petersen RC, Smith GE, Waring SC, Ivnik RJ, Tangalos EG, Kokmen E (1999) Mild cognitive impairment: Clinical characterization and outcome. Arch Neurol 56, 303-308.

5. Morris JC, Cummings J (2005) Mild cognitive impairment (MCI) represents early-stage Alzheimer's disease. J Alzheimers Dis 7, 235-239; discussion 255-262.

6. Wadley VG, Okonkwo O, Crowe M, Ross-Meadows LA (2008) Mild cognitive impairment and everyday function: Evidence of reduced speed in performing instrumental activities of daily living. Am J Geriatr Psychiatry 16, 416-424.

7. Gold DA (2012) An examination of instrumental activities of daily living assessment in older adults and mild cognitive impairment. J Clin Exp Neuropsychol 34, 11-34. 
8. Marshall GA, Rentz DM, FreyMT, Locascio JJ, Johnson KA, Sperling RA, Alzheimer's Disease Neuroimaging I (2011) Executive function and instrumental activities of daily living in mild cognitive impairment and Alzheimer's disease. Alzheimers Dement 7, 300-308.

9. Burton CL, Strauss E, Bunce D, Hunter MA, Hultsch DF (2009) Functional abilities in older adults with mild cognitive impairment. Gerontology 55, 570-581.

10. Jefferson AL, Byerly LK, Vanderhill S, Lambe S, Wong S, OzonoffA, Karlawish JH (2008) Characterization of activities of daily living in individuals with mild cognitive impairment. Am J Geriatr Psychiatry 16, 375-383.

11. Sikkes SA, de Lange-de Klerk ES, Pijnenburg YA, Scheltens P, Uitdehaag BM (2009) A systematic review of Instrumental Activities of Daily Living scales in dementia: Room for improvement. J Neurol Neurosurg Psychiatry 80, 7-12.

12. Schmitter-Edgecombe M, McAlister C, Weakley A (2012) Naturalistic assessment of everyday functioning in individuals with mild cognitive impairment: The day-out task. Neuropsychology 26, 631-641.

13. Nelson AP, O'Connor MG (2008) Mild cognitive impairment: A neuropsychological perspective. CNS Spectr 13, 56-64.

14. Razani J, Casas R, Wong JT, Lu P, Alessi C, Josephson K (2007) Relationship between executive functioning and activities of daily living in patients with relatively mild dementia. Appl Neuropsychol 14, 208-214.

15. Dawadi PN, Cook DJ, Schmitter-Edgecombe M, Parsey C (2013) Automated assessment of cognitive health using smart home technologies. Technol Health Care 21, 323-343.

16. Sablier J, Stip E, Jacquet P, Giroux S, Pigot H, Franck N, Mobus G (2012) Ecological assessments of activities of daily living and personal experiences with Mobus, an assistive technology for cognition: A pilot study in schizophrenia. Assist Technol 24, 67-77. 
17. Okahashi S, Seki K, Nagano A, Luo Z, Kojima M, Futaki T (2013) A virtual shopping test for realistic assessment of cognitive function. J Neuroeng Rehabil 10, 59.

18. Werner P, Rabinowitz S, Klinger E, Korczyn AD, Josman N (2009) Use of the virtual action planning supermarket for the diagnosis of mild cognitive impairment: A preliminary study. Dement Geriatr Cogn Disord 27, 301-309.

19. Sacco G, Joumier V, Darmon N, Dechamps A, Derreumaux A, Lee JH, Piano J, Bordone N, Konig A, Teboul B, David R, Guerin O, Bremond F, Robert P (2012) Detection of activities of daily living impairment in Alzheimer's disease and mild cognitive impairment using information and communication technology. Clin Interv Aging 7, 539-549.

20. Romdhane R, Mulin E, Derreumeaux A, Zouba N, Piano J, Lee L, Leroi I, Mallea P, David R, Thonnat M, Bremond F, Robert PH (2012) Automatic video monitoring system for assessment of Alzheimer's disease symptoms. J Nutr Health Aging 16, 213-218.

21. Stone EE, Skubic M (2012) Capturing habitual, in-home gait parameter trends using an inexpensive depth camera. Conf Proc IEEE Eng Med Biol Soc 2012, 5106-5109.

22. Wang F, Stone E, DaiW, Banerjee T, Giger J, Krampe J, Rantz M, Skubic M (2009) Testing an in-home gait assessment tool for older adults. Conf Proc IEEE Eng Med Biol Soc 2009, 6147-6150.

23. Banerjee T, Keller JM, Skubic M (2012) Resident identification using kinect depth image data and fuzzy clustering techniques. Conf Proc IEEE Eng Med Biol Soc 2012, 5102- 5105.

24. Dubois B, SlachevskyA, Litvan I, Pillon B (2000) The FAB:A Frontal Assessment Battery at bedside. Neurology 55, 16211626. 
25. Folstein MF, Folstein SE, McHugh PR (1975) Mini-mental state. A practical method for grading the cognitive state of patients for the clinician. J Psychiatr Res 12, 189-198.

26. Lawton MP, Brody EM (1969) Assessment of older people: Self-maintaining and instrumental activities of daily living. Gerontologist 9, 179-186.

28. Mathuranath PS, George A, Cherian PJ, Mathew R, Sarma PS (2005) Instrumental activities of daily living scale for dementia screening in elderly people. Int Psychogeriatr 17, 461-474.

29. Montgomery SA, Asberg M (1979) A new depression scale designed to be sensitive to change. Br J Psychiatry 134, 382389.

30. Yesavage JA, Brink TL, Rose TL, Lum O, Huang V, AdeyM, Leirer VO (1982) Development and validation of a geriatric depression screening scale: A preliminary report. J Psychiatr Res 17, 37-49.

31. D'Arcy S (2008) Speech as a means of monitoring cognitive function of elderly subjects. Interspeech (Brisbane, Australia).

32. Crispim-Junior CF, Bathrinarayanan V, Fosty B, Konig A, Romdhane R, Thonnat M, Bremond F (2013) Evaluation of a monitoring system for event recognition of older people. 10th IEEE International Conference on Advanced Video and SignalBased Surveillance (Krakow, Poland).

33. Zouba N, Bremond F, Thonnat M (2010) An activity monitoring system for real elderly at home: Validation study. 7th IEEE International Conference on Advanced Video and Signal-Based Surveillance (Boston, USA).

34. $\mathrm{Vu} \mathrm{T}$, Bremond F, Thonnat M (2003) Automatic video interpretation:Anovel algorithm for temporal scenario recognition. The Eighteenth International Joint Conference on Artificial Intelligence (IJCAI'03) (Acapulco, Mexico). 
35. NghiemAT, Bremond F, Thonnat M (2009) Controlling background subtraction algorithms for robust object detection. 3rd International Conference on Imaging for Crime Detection and Prevention (London, UK), pp. 1-6.

36. Chau DP, Bremond F, Thonnat M (2011) A multi-feature tracking algorithm enabling adaptation to context variations. International Conference on Imaging for Crime Detection and Prevention.

37. Yakhia M, Konig A, van der Flier WM, Friedman L, Robert PH, David R (2014) Actigraphic motor activity in mild cognitive impairment patients carrying out short functional activity tasks: Comparison between mild cognitive impairment with and without depressive symptoms. J Alzheimers Dis 40, 869-875.

38. Satt A, Sorin A, Toledo-Ronen O, Barkan O, Kompatsiaris I, Kokonozi A, Tsolaki M (2013) Evaluation of speech-based protocol for detection of early-stage dementia. Interspeech (Lyon, France). 


\section{CHAPTER 6}

ECOLOGICAL ASSESSMENT OF AUTONOMY IN INSTRUMENTAL ACTIVITIES OF DAILY LIVING IN DEMENTIA PATIENTS BY THE MEAN OF AN AUTOMATIC VIDEO MONITORING SYSTEM

Frontiers in Aging Neuroscience 2015, 7:98.

Alexandra König, Carlos Fernando Crispim Junior, Alvaro Gomez Uria Covella, Francois Bremond, Alexandre Derreumaux, Gregory Bensadoun, Renaud David, Frans Verhey, Pauline Aalten, Philippe Robert 


\section{ABSTRACT}

Currently, the assessment of autonomy and functional ability involves clinical rating scales. However, scales are often limited in their ability to provide objective and sensitive information. By contrast, information and communication technologies may overcome these limitations by capturing more fully functional as well as cognitive disturbances associated with Alzheimer disease (AD). We investigated the quantitative assessment of autonomy in dementia patients based not only on gait analysis but also on the participant performance on instrumental activities of daily living (IADL) automatically recognized by a video event monitoring system (EMS). Three groups of participants (healthy controls, mild cognitive impairment, and $\mathrm{AD}$ patients) had to carry out a standardized scenario consisting of physical tasks (single and dual task) and several IADL such as preparing a pillbox or making a phone call while being recorded. After, video sensor data were processed by an EMS that automatically extracts kinematic parameters of the participants' gait and recognizes their carried out activities. These parameters were then used for the assessment of the participants' performance levels, here referred as autonomy. Autonomy assessment was approached as classification task using artificial intelligence methods that takes as input the parameters extracted by the EMS, here referred as behavioral profile. Activities were accurately recognized by the EMS with high precision. The most accurately recognized activities were "prepare medication" with $93 \%$ and "using phone" with $89 \%$ precision. The diagnostic group classifier obtained a precision of $73.46 \%$ when combining the analyses of physical tasks with IADL. In a further analysis, the created autonomy group classifier which obtained a precision of $83.67 \%$ when combining physical tasks and IADL. Results suggest that it is possible to quantitatively assess IADL functioning supported by an EMS and that even based on the extracted data the groups could be classified with high accuracy. This means that the use of such technologies may provide clinicians with diagnostic relevant information to improve autonomy assessment in real time decreasing observer biases. 


\section{INTRODUCTION}

One of the key features of Alzheimer's disease (AD) is impairment in daily functioning as well as executive dysfunction due to global pathological changes in frontal and posterior areas [1]. Recent studies show that in dementia patients, loss of functioning in Instrumental Activities of Daily Living (IADL) is strongly associated with faster cognitive decline [2] and in particular with poorer performances on executive function tasks [3-4] such as the Frontal Assessment Battery (FAB) [5] or the Trail Making Test (version B) [6]. Hence, it represents an early predictor for cognitive deterioration and possibly even for conversion from Mild Cognitive Impairment (MCI) to AD [7]. This is in line with older findings that show that declines in IADLs are influenced by cognitive functioning, and affected relatively early in the course of dementia [8] and in particular the executive component in IADL tasks that requires higher frontal lobe activation [9].

The assessment of functioning in IADL attracts gradually more attention in clinical research and should be included not only as a part of diagnostic evaluation in dementia but it would also be essential to evaluate efficacy in rehabilitation settings [10-11]. Characterizing impairment in IADL is controversial because no standard exists so far as to the practical or theoretical definition [12]. Furthermore, until now, the assessment of IADL is mostly limited to questionnaires and rely often on informants reports, such as the Disability Assessment for Dementia scale (DAD), or the IADL scale of Lawton and Brody [13] which suffer from biases and inaccuracies in informants' perceptions as well as the possibility that some older adults do not have an individual who can comment on their impact of cognitive impairment on routine activities. In general, existing functional assessments lack sufficient sensitivity to detect subtle functional changes or differences in behavior and therefore treatment effects [14]. This leads to an urgent need for better measures of functional changes in people with 
the earliest changes associated with AD in clinical trials [15]. Besides, just a few of the named tools capture the earliest functional deficits seen in preclinical AD. Growing recognition of the need for an more objective and direct measurement has led to some attempts to improve the assessments of IADL in clinical practice by developing new extensive informant-based computerized IADL questionnaire [16] or direct performance-based measures [17] which differ from the traditional informant-based or self-report questionnaires, such as the IADL Lawton scale, by observing directly in fact an individual enacting an IADL, like making a phone call or managing money.

Farina et al. (2010) developed such direct performance-based measure of patients with dementia, e.g. the functional living skills assessment (FLSA) [18]. This tool was conceived to detect functional impairment targeting high-order social abilities in everyday-life and IADL by a clinician's direct observation of the patient carrying out practical tasks or being verbally stimulated.

Nevertheless, those methods can be critized as well first, for being still strongly dependent on a human observer; secondly for removing the individual 's chosen routine and environmental cues that typically facilitate IADL. Finally, performance-based assessment can be often time-consuming [19] and represents a single evaluation data point compared with the multiple observations afforded by a questionnaire that comments on an individuals overall behavior through the last past weeks.

ICT and in particular automatic video analyses of patients carrying out various IADL could be an innovative assessment method [20] to help overcome those limitations in reducing the inter/intra-rater variability due to human interpretation and increase ecological value by removing completely the human observer from the assessment site. Such techniques and thus further, our proposed automatized videobased IADL assessment differs from these current tools by enabling 
the patients' performances and actions to be captured remotely in real time and real life situations and being accurately evaluated in order to provide the clinician with objective performance measures and a « second opinion » regarding the overall state of functionality of the patient.

In previous work, the use of such video sensor technology has been already demonstrated by König et al by showing significant correlations between manually as automatically extracted parameters and neuropsychological test scores as well as high accuracy rates for the detected activities (up to $89.47 \%$ ) [21]. In a next step, we would like to investigate the use of video analyses for a completely automatized autonomy assessment based on the extracted video features.

In this line, the objective of this study is to investigate the use of ICT and in particular video analyses in clinical practice for the assessment of autonomy in IADL in healthy elderly MCI and AD patients by demonstrating an accurate automatized autonomy assessment based simply on automatically extracted video features from gait and IADL performances.

\section{MATERIAL AND METHODS}

Study participants and clinical assessment

Participants aged 65 or older were recruited within the Dem@care protocol at the Nice Memory Research Center located at the Geriatric department of the University Hospital. The study was approved by the local Nice ethics committee and only participants with the capacity to consent to the study were included. Each participant gave informed consent before the first assessment. It was a non-randomized study involving 3 diagnosis groups of participants. 
The video data of 49 participants was exploitable from which 12 patients were diagnosed with $\mathrm{AD}, 23$ patients diagnosed with $\mathrm{MCI}$ and 14 healthy controls (HC). All diagnosis were made by a medical doctor from the Geriatric University Hospital.

For the AD group, the diagnosis was determined using the proposed diagnostic criteria from Dubois et al. [22] requiring the presence of a progressive episodic memory impairment and biomarker evidence. For the MCI group, patients were diagnosed using the Petersen clinical criteria [23] and only included with a mini-mental state examination (MMSE) [24] score higher than 24. Subjects were not included if they had a history of head trauma with loss of consciousness, psychotic or aberrant motor activity (tremor, rigidity, Parkinsonism) as defined by the Movement Disorder Society Unified Parkinson Disease Rating Scale [25] in order to control for any possible motor disorders influencing the ability to carry out IADLs. Furthermore, participants with a MMSE score below 16 were excluded in order to avoid that the participant suffers from experiencing this assessment as a major failure.

Each participant underwent a standardized neuropsychological assessment with a psychologist. In addition, medical, clinical and demographical information were collected. Global cognitive functioning was assessed using the MMSE (Mini Mental State Examination) [24]. Other cognitive functions were assessed, among others, with the Frontal assessment battery (FAB) [5] and the Free and Cued Selective Reminding Test [26-27]. Neuropsychiatric symptoms were assed using the Neuropsychiatric Inventory [28] and functional abilities were assessed using the IADL scale (IADL-E) [13] during a clinical interview with the caregiver if there was one available. 


\section{Clinical protocol}

The clinical protocol asked the participants to undertake first a set of physical tasks (Scenario 1) and secondly a set of typical IADLs (Scenario 2) followed by a free discussion period while being recorded by a set of sensors. Scenario 1 consisted of a single walking task and a dual task. The dual task involves walking while counting backwards from ' 305 '. These tasks intend to assess kinematic parameters of the participant via gait analysis (e.g., duration, number of steps, cadence, stride length). Scenario 2, also called the 'ecological assessment of IADLs', consisted of carrying out a set of daily living activities such as preparing a pillbox or writing a check within a timeframe of 15 minutes (see Table 1.) followed by a short discussion. The defined activities were based on commonly used IADL questionnaires and represent at once activities with high or low cognitive demand (in accordance with the Bayer Activities of Daily Living scale) [29-30]. The protocol was conducted in an observation room located in the Nice Research Memory Center, which was equipped with everyday objects for use in ADLs and IADLs, eg, an armchair, a table, a tea corner, a television, a personal computer, and a library. Color-depth sensors (Kinect ${ }^{\circledR}$, Microsoft $\mathbb{C}$ ) were installed to capture the activity of the participants during the assessment. The aim of this protocol is an ecological assessment based on a 'real time' performance, that determines to which extent the participant could undertake independently a list of daily activities within a timeframe of 15 minutes. All assessments were performed at the same time of the day, between $2 \mathrm{pm}$ and $3 \mathrm{pm}$. A clinician verified the performance of each participant in terms of the amount of initiated activities, correctly carried out activities as well as repetitions and omissions in order to define the quality of each task execution. Accordingly to this performance verification and based on previous work [31-33] participants were grouped (independently from their diagnosis group) into either 'good', 'intermediate' or 'poor' performer. 
Table 1. Design of Ecological assessment

\begin{tabular}{|c|c|c|}
\hline & $\begin{array}{l}\text { Part } 1 \\
\text { Guided Activities } \\
(5 \mathrm{~min})\end{array}$ & $\begin{array}{l}\text { Part } 2 \\
\text { Semi Guided Activities } \\
(30 \mathrm{~min})\end{array}$ \\
\hline 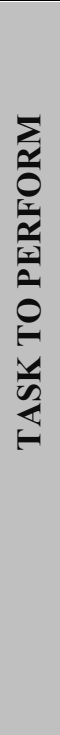 & $\begin{array}{l}\text { Mono/Dual directed tasks } \\
-\quad \text { Walking } \\
-\quad \text { Counting backwards } \\
\text { - } \quad \text { Both walking and counting backwards } \\
\text { Vocal directed tasks } \\
\text { - Sentence repeating task } \\
\text { - Articulation control task }\end{array}$ & $\begin{array}{l}\text { List of ADLs/IADLs to } \\
\text { organize and perform within } \\
\underline{\text { 15mn }} \\
\text { - Watering Plant } \\
\text { - } \quad \text { Preparing tea } \\
\text { - } \quad \text { Medication } \\
\quad \text { preparation } \\
\text { - } \quad \text { Managing finance } \\
\quad \text { (establishing account } \\
\text { balance, writing a } \\
\text { check) } \\
\text { - Watching TV } \\
\text { - Using Phone } \\
\quad \text { (answering, calling) } \\
\text { - } \quad \text { Reading Article and } \\
\quad \text { answering to questions }\end{array}$ \\
\hline 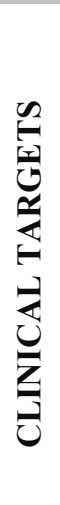 & $\begin{array}{l}\text { - } \quad \text { Motor abilities: balance disorders } \\
\text { Cognitive abilities: flexibility, shared } \\
\text { attention, psychomotricity coordination, } \\
\text { answer time to a stimulus, working memory }\end{array}$ & $\begin{array}{l}\text { Cognitive abilities: } \\
\text { flexibility, } \\
\text { planification, shared } \\
\text { attention, } \\
\text { psychomotricity } \\
\text { coordination, work } \\
\text { memory, time } \\
\text { estimation, answer } \\
\text { time to a stimulus } \\
\text { ADL/IADL } \\
\text { performance }\end{array}$ \\
\hline
\end{tabular}




\section{Data collection \& Processing}

Participants had their activity recorded using a color-depth sensor placed close to the ceiling of the ecological room to maximize its coverage of the room. Recorded data was posteriorly analyzed by an Event Monitoring System (EMS, see Figure 1) to automatically extract fine- to coarse-grained information about patient's performance (e.g., feet position, number of steps, the IADLs carried out). Using the automatically extracted information we estimate gait- and IADLrelated parameters to describe the participant performance in the clinical protocol. The estimated parameters were then used as input features for Naïve Bayes to classify the participants patient into the autonomy and dementia classes investigated in this work. Targeted autonomy classes were good, intermediate, and poor; and targeted cognitive status classes were Alzheimer's, MCI and healthy.

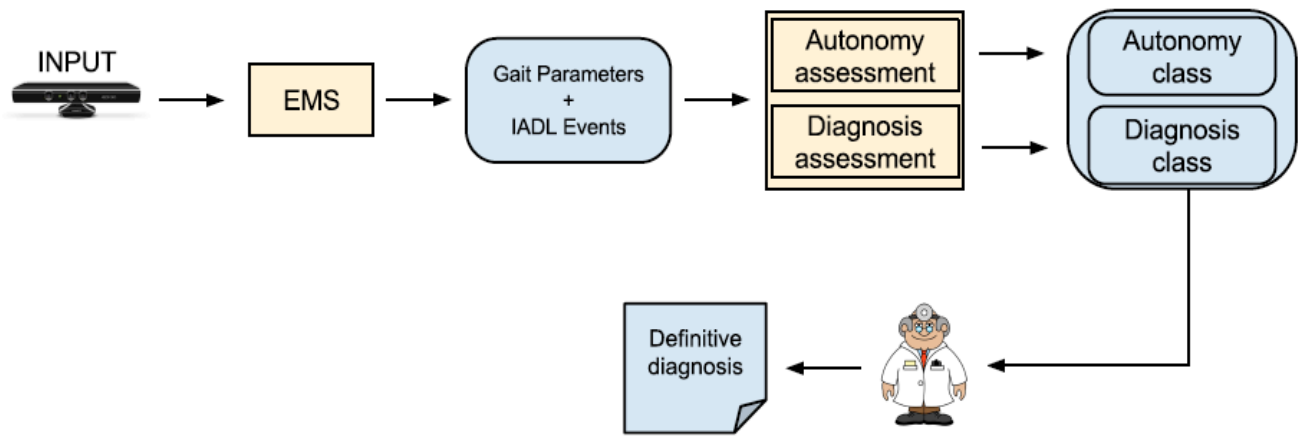

Figure 1. System Architecture; This figure shows the different steps from the system receiving the input to the definitive diagnosis. The EMS consists of four modules that will lead to the correct assessment based on extracted video features: People Detection, People Tracking, Gait Analysis and Event Recognition. The main outcome is based on 'Gait Parameters' and 'Instrumental Activities of Daily Living Events' which are processed with a feature selection method and a classifier for the Autonomy and Diagnosis assessment. 


\section{Event Monitoring System}

The event monitoring system is composed of four main modules: people detection, people tracking, gait analysis and event recognition. People detection step is performed by the background-subtraction algorithm proposed by Nghiem and Bremond [34]. The set of people detected in the scene is then tracked over the space and time by the algorithm of Chau et al. [35]. The output of these two modules is used as input for gait analysis and event recognition. The latter module is based on the work of Crispim-Junior et al. [36], where an constraintbased ontology language is employed to model daily living activities in terms of posture, motion and location patterns of the participant in the scene. An IADL model is generally defined based on a set of physical objects (e.g., detected people, room furniture and objects), a set of sub-events that model specific aspects of the targeted IADL, and constraints that establish rules sub-events and physical objects need to satisfy. Figure 2 presents an example of event model "Prepare Drink" using the ontology language. "Prepare Drink" event model is based on two sub-events (components): one event that verifies whether the person global position is located where the drinking objects are generally placed (named Person_in_zone_Drink), and a second subevent verifying whether the person displays the posture "bending" (named Person_bending). Given that both components are recognized by the system, to satistfy the first constraint in the model both subevents the person must be performing them at the same time (c1$>$ Interval AND c2->Interval). The second constraint establishes that the first sub-event must have being performed for at least 2 seconds already. Once both constraints are satisfied, the event starts to be recognized by the EMS. For more details on IADL modeling, please refer to the work of Crispim-Junior et al [36]. Figure 3 presents the monitored scene annotated with the semantic information used for event modeling and recognition. Left image displays the recognition of watering plant event. 


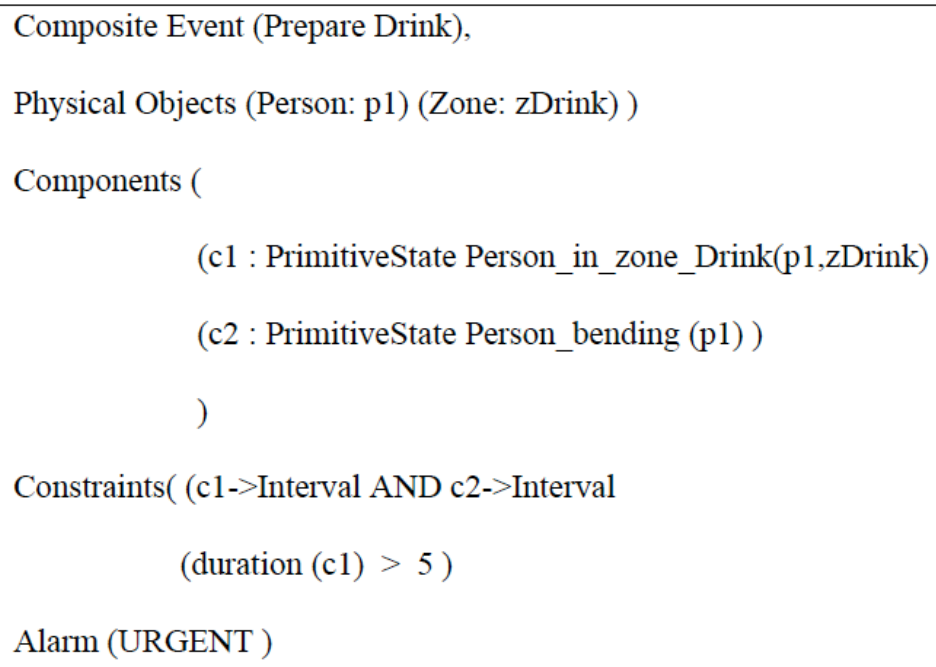

Figure 2. Event model for Preparing Drink Activity

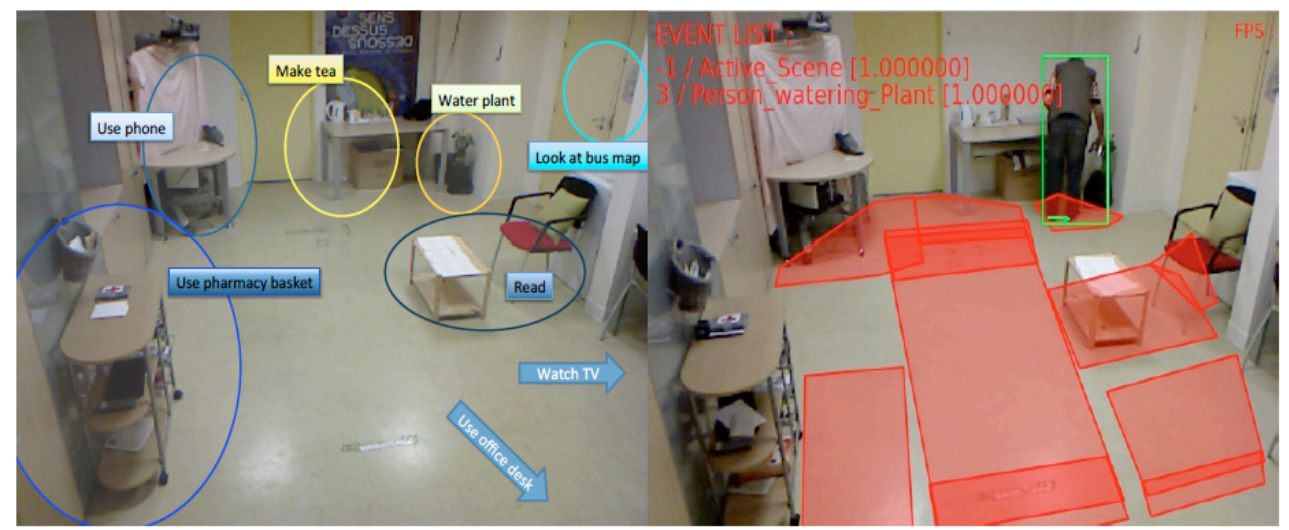

Figure 3. Event recognition based on Activity zones. The left image presents the contextual zones used to describe the scene semantics. The right image presents an example of output of the Automatic Video Monitoring System. 
The output of the EMS is the basis for the computation of the performance of the patients in the clinical protocol. From its output data (event report), we extract descriptors with different levels of granularity to appropriately describe the patient performance according to the complexity of the monitored activity. For gait analysis we estimate fine-grained features like stride length, distance travelled, average speed, and cadence for the period of time of the physical task events (e.g., Mono and Dual task events). For the IADLs we compute their frequency and duration, and the number of times the patient missed or repeated them. Activity repetition and omission are calculated with respect to the number of times the participants are expected to perform an activity given the instructions they received at the beginning of the experiment. The ensemble of data automatically computed by the system constituted the behavioral profile (or performance assessment) of the monitored participant.

\section{Autonomy Assessment and Dementia Diagnosis Classification}

Using the behavioral profile extracted by the EMS two Naïve Bayes models were trained to classify participants into the targeted cognitive status and autonomy level classes according to their performance in the clinical protocol. To learn and validate the classifiers' performance we employed a 20 -fold cross-validation scheme, where we partitioned the data set into 20 equal parts, and then perform model learning and validation 20 times. At each iteration, the cross-validation scheme retained one of the 20 -folds for validation and used the other 19 part for model learning. The reported model performance corresponds to the averaged performance of the models in the 20 validation folds.

To determine the best combination of parameters for dementia and autonomy classification we performed feature subset selection based on best first search and Naïve Bayes classifier [37-38]. Using the feature selection method we downsized the patient behavioral profile to the most relevant parameters for the classification of dementia and autonomy. It is worth mentioning that although the feature selection for both classification tasks (Autonomy and dementia diagnosis) 
started with the same global feature set, each task was free to choose the input-parameters that maximize its individual performance.

We have selected the Naïve Bayes classifiers due to its probabilistic nature, which quantifies the pertinence of a participant's performance for each class evaluated. Although this method assumes conditional independence among input-parameters, an assumption that proves to be unrealistic for most practical application, it tends to perform reasonably well compared to more sophisticate methods, like support vector machines [39-40], with the advantage of having a much smaller running time and requiring very little training data [41]. All classification experiments were performed using WEKA platform [42]. The implementation of Naïve Bayes in WEKA is based on the work of John and Langley [40].

\section{Statistical analyses}

In a separate step, next to the video data extraction analyses, the characteristics of all participants as well as the annotated performance results of the ecological assessment were analyzed in order to determine the different autonomy levels. Comparisons between the groups (e.g. HC subjects, MCI patients and AD group) good performer, mediocre and poor performer) were performed with MannWhitney tests for each outcome variable of the automatic video analyses. Differences were reported as significant if $\mathrm{p}<0.05$. Spearman's correlations were further performed to determine the association between the extracted video parameters and established assessment tools in particular for executive functioning, e.g. the FAB. 


\section{RESULTS}

\section{Population}

$14 \mathrm{HC}$ subjects (age $=74.1 \pm 6.62), 23 \mathrm{MCI}($ age $=77.6 \pm 6.17)$ and 12 AD subjects (age $=82 . \pm 8$ ) were included. Table 2 shows the clinical and demographic data of the participants. Significant intergroup differences in demographic factors were found for age between MCI and AD subjects as well as between $\mathrm{HC}$ and $\mathrm{AD}$ subjects $(p<.05)$. Further, significant differences were found between all groups for the MMSE score, with a mean of $28.4( \pm 1.1)$ for the HC group, $25.5( \pm 2.1)$ for the MCI group and $22.67 \pm 3.6$ for the AD group $(p<.05)$. Significant differences were found for FAB results between $\mathrm{HC}$ subjects with $16.3( \pm 1.1)$ and MCI subjects with $14( \pm 2.4)$, as well as between HC subjects and AD subjects with $12.33( \pm 3.1)(p<.05)$. The mean IADL scores did not differ between groups, with a mean IADL score of $7( \pm 1.2)$ for the HC group, 6.33 $( \pm 1.7)$ for the MCI group and $(6 \pm 1.8)$ for the AD group. 
Table 2a. Characteristics and group comparisons for HC, MCI and AD subjects. Group comparisons were made using Mann-Whitney U test $(\mathrm{p}<0.05)$

\begin{tabular}{|c|c|c|c|}
\hline Characteristics & $\begin{array}{l}\text { All subject } \\
N=49\end{array}$ & $\begin{array}{l}\text { Healthy group } \\
N=14\end{array}$ & $\begin{array}{l}\text { MCI group } \\
\mathrm{N}=23\end{array}$ \\
\hline Female, n (\%) & $26(53.1 \%)$ & $9(64.3 \%)$ & $10(43.5 \%)$ \\
\hline Age, years mean ST & $77.7 \pm 7.3 \dagger+$ & $74.1 \pm 6.6$ & $77.6 \pm 6.2$ \\
\hline \multicolumn{4}{|l|}{ Level of Education, n (\%) } \\
\hline Unknown & $0(0 \%)$ & $0(0 \%)$ & $0(0 \%)$ \\
\hline No formal education & $0(0 \%)$ & $0(0 \%)$ & $0(0 \%)$ \\
\hline Elementary school & $16(32.6 \%)$ & $2(14.3 \%)$ & $5(21.7 \%)$ \\
\hline Middle school & $9(18.4 \%)$ & $2(14.3 \%)$ & $6(26.1 \%)$ \\
\hline High school & $8(16.3 \%)$ & $4(28.6 \%)$ & $4(17.4 \%)$ \\
\hline Post-secondary education & $16(32.6 \%)$ & $6(42.9 \%)$ & $8(34.8 \%)$ \\
\hline MMSE, mean \pm SD & $25.6 \pm 3.1 *+\div$ & $28.4 \pm 1.1$ & $25.5 \pm 2.1$ \\
\hline FAB, mean \pm SD & $14.25 \pm 2.7^{*+}+$ & $16.3 \pm 1.1$ & $14 \pm 2.4$ \\
\hline FCSR Test \pm SD & $39.2 \pm 9.9^{*}+$ & $46.27 \pm 1.9$ & $38.19 \pm 7.2$ \\
\hline IADL-E, mean \pm SD & $6.4 \pm 1.3$ & $7 \pm 1.2$ & $6.33 \pm 1.7$ \\
\hline NPI total, mean \pm SD & $6.89 \pm 8.1 \dagger+$ & $3.54 \pm 2.8$ & $5.77 \pm 7.1$ \\
\hline \multicolumn{4}{|l|}{ Ecological Assessment results } \\
\hline Single Task time (in sec) & $11.92 \pm 3.1 \dagger \dagger$ & $10.79 \pm 1.31$ & $11.43 \pm 2.97$ \\
\hline $\begin{array}{l}\text { Dual Task time } \\
\text { IADLS: }\end{array}$ & $18.53 \pm 8.19+t$ & $14.79 \pm 4.26$ & $18.35 \pm 8.78$ \\
\hline Activities initiated & $9.16 \pm 3.27 * \dagger \dagger$ & $11.64 \pm 1.15$ & $9.39 \pm 2.46$ \\
\hline Activities completed & $6.65 \pm 3.66 *+t$ & $10.00 \pm 1.47$ & $6.57 \pm 3.27$ \\
\hline
\end{tabular}

Abbreviations: MCI: mild cognitive impairment, AD:Alzheimer's Disease, MMSE: Mini Mental State Examination, FAB: Frontal Assessment Battery, FCSR: Free and Cued Selective Reminding Test, IADL-E: Instrumental Activities of Daily Living for Elderly, NPI: Neuropsychiatric Inventory. Note. All values represent means and SD (except $\mathrm{n}$, gender, education and the classification results) $* P<.05$ for $\mathrm{HC}$ versus MCI, $\dagger P<.05$ for MCI versus $\mathrm{AD}, \ddagger P<.05$ for $\mathrm{HC}$ versus $\mathrm{AD}$ 
Table 2b. Intergroup comparison of scores and performance results from the Ecological assessment (Mann -Whitney U-test). P and Z values are presented for each group comparison

\begin{tabular}{|c|c|c|c|c|c|c|c|c|c|c|}
\hline Comparison & $\begin{array}{l}\text { Age } \\
Z / P\end{array}$ & $\begin{array}{l}\text { MMSE } \\
\mathbf{Z} / \mathbf{P}\end{array}$ & $\begin{array}{l}\text { FAB } \\
Z / P\end{array}$ & $\begin{array}{l}\text { FCSR } \\
\mathbf{Z} / \mathbf{P}\end{array}$ & $\begin{array}{l}\text { IADL } \\
\text { Z / P }\end{array}$ & $\begin{array}{l}\mathbf{N P I} \\
\mathrm{Z} / \mathrm{P}\end{array}$ & $\begin{array}{l}\text { Single } \\
\text { Task }\end{array}$ & $\begin{array}{l}\text { Dual } \\
\text { Task }\end{array}$ & $\mathbf{A I}$ & $\mathbf{A C}$ \\
\hline HC vs $M C I$ & $\begin{array}{l}-1.695 / \\
0.090\end{array}$ & $\begin{array}{l}-4.080 / \\
0.000\end{array}$ & $\begin{array}{l}-3.024 / \\
0.002\end{array}$ & $\begin{array}{l}-3.469 / \\
0.001\end{array}$ & $\begin{array}{l}-1.603 / \\
0.109\end{array}$ & $\begin{array}{l}-0.258 / \\
0.797\end{array}$ & $\begin{array}{l}-0.286 / \\
0.775\end{array}$ & $\begin{array}{l}-1.196 / \\
0.232\end{array}$ & $\begin{array}{l}-3.067 / \\
0.002\end{array}$ & $\begin{array}{l}-3.328 / \\
0.001\end{array}$ \\
\hline$M C I$ vs $A D$ & $\begin{array}{l}-2.036 / \\
0.042\end{array}$ & $\begin{array}{l}-2.432 / \\
0.015\end{array}$ & $\begin{array}{l}-1.363 / \\
0.173\end{array}$ & $\begin{array}{l}-1.024 / \\
0.306\end{array}$ & $\begin{array}{l}-0.656 / \\
0.512\end{array}$ & $\begin{array}{l}-2.228 / \\
0.026\end{array}$ & $\begin{array}{l}-2.134 / \\
0.033\end{array}$ & $\begin{array}{l}-2.003 / \\
0.045\end{array}$ & $\begin{array}{l}-2.837 / \\
0.005\end{array}$ & $\begin{array}{l}-3.093 / \\
0.002\end{array}$ \\
\hline$H C$ vs $A D$ & $\begin{array}{l}0.023 / \\
-2.267\end{array}$ & $\begin{array}{l}-4.261 / \\
0.000\end{array}$ & $\begin{array}{l}-3.838 / \\
0.000\end{array}$ & $\begin{array}{l}-2.654 / \\
0.008\end{array}$ & $\begin{array}{l}-1.476 / \\
0.140\end{array}$ & $\begin{array}{l}-2.433 / \\
0.015\end{array}$ & $\begin{array}{l}-2.492 / \\
0.013\end{array}$ & $\begin{array}{l}-2968 / \\
0.003\end{array}$ & $\begin{array}{l}-4.121 / \\
0.000\end{array}$ & $\begin{array}{l}-4.326 / \\
0.000\end{array}$ \\
\hline
\end{tabular}

Abbreviations: MCI: mild cognitive impairment, AD:Alzheimer's Disease, MMSE: Mini Mental State Examination, FAB: Frontal Assessment Battery, FCSR: Free and Cued Selective Reminding Test, IADL-E: Instrumental Activities of Daily Living for Elderly, NPI: Neuropsychiatric Inventory, AI: Activites initiated, AC: Activities completed. 


\section{Ecological assessment results}

The participants performed differently on the IADL scenario in terms of initiated and successfully completed activities in accordance with their cognitive status. Table $2 \mathrm{a}$ and $2 \mathrm{~b}$ present results of the intergroup comparison of the performance results in the ecological assessment. Significant group differences were found for the single and dual task between MCI and $\mathrm{AD}(p<.05)$ and for HC and $\mathrm{AD}(p<$ $.05)$. The amount of 'activities iniated' and 'activities completed'differed significantly between all three groups $(p<.05)$.

The parameter 'activities iniated' correlated significantly with neuropsychological test results namely the MMSE $(p<0.01)$, FAB score $(p<0.01), \operatorname{FCSR}(p<0.05)$ and the IADL-E score $(p<0.05)$. In the same line, the parameter 'activity completed' correlated significantly with the test results, MMSE $(p<0.01)$, FAB score $(p<$ $0.01), \operatorname{FCSR}(p<0.05)$ and the IADL-E score $(p<0.05)$. The obtained correlation analyses results are presented in Table 3 . None of the extracted parameters correlated with the NPI total scores.

Table 3. Correlation between IADL scenario performance and conventional cognitive assessments (Spearman's correlation coefficient)

\begin{tabular}{|c|c|c|c|c|c|}
\hline $\begin{array}{l}\text { deo analyses data } \\
\text { zarman correlation coefficient (r) / } \\
\text { ralues }\end{array}$ & MMSE & FAB & FCSR & NPI & IADL-E \\
\hline tivities initiated & $\begin{array}{l}0.650 * * \\
\mathrm{p}=0.000\end{array}$ & $\begin{array}{l}0.519 * * \\
\mathrm{p}=0.000\end{array}$ & $\begin{array}{l}0.380 * \\
\mathrm{p}=0.019\end{array}$ & $\begin{array}{l}-0.177 \\
p=0.234\end{array}$ & $\begin{array}{l}0.324 * \\
\mathrm{p}=0.030\end{array}$ \\
\hline tivities completed & $\begin{array}{l}0.685 * * \\
\mathrm{p}=0.000\end{array}$ & $\begin{array}{l}0.620 * * \\
\mathrm{p}=0.000\end{array}$ & $\begin{array}{l}0.356^{*} \\
p=0.028\end{array}$ & $\begin{array}{l}-0.266 \\
p=0.071\end{array}$ & $\begin{array}{l}0.334^{*} \\
\mathrm{p}=0.025\end{array}$ \\
\hline
\end{tabular}


After the performance analyses, the participants were classified based on their IADL performance. The cut-off scores between the classes have been based on the observation of the analyses of the participant's performances in terms of completely carried out activities, and on the cumulative frequencies of the completely carried out activities. These were divided in equal parts, as homogeneously as possible in terms of data coverage following the frequency curve as presented in Figure 2.

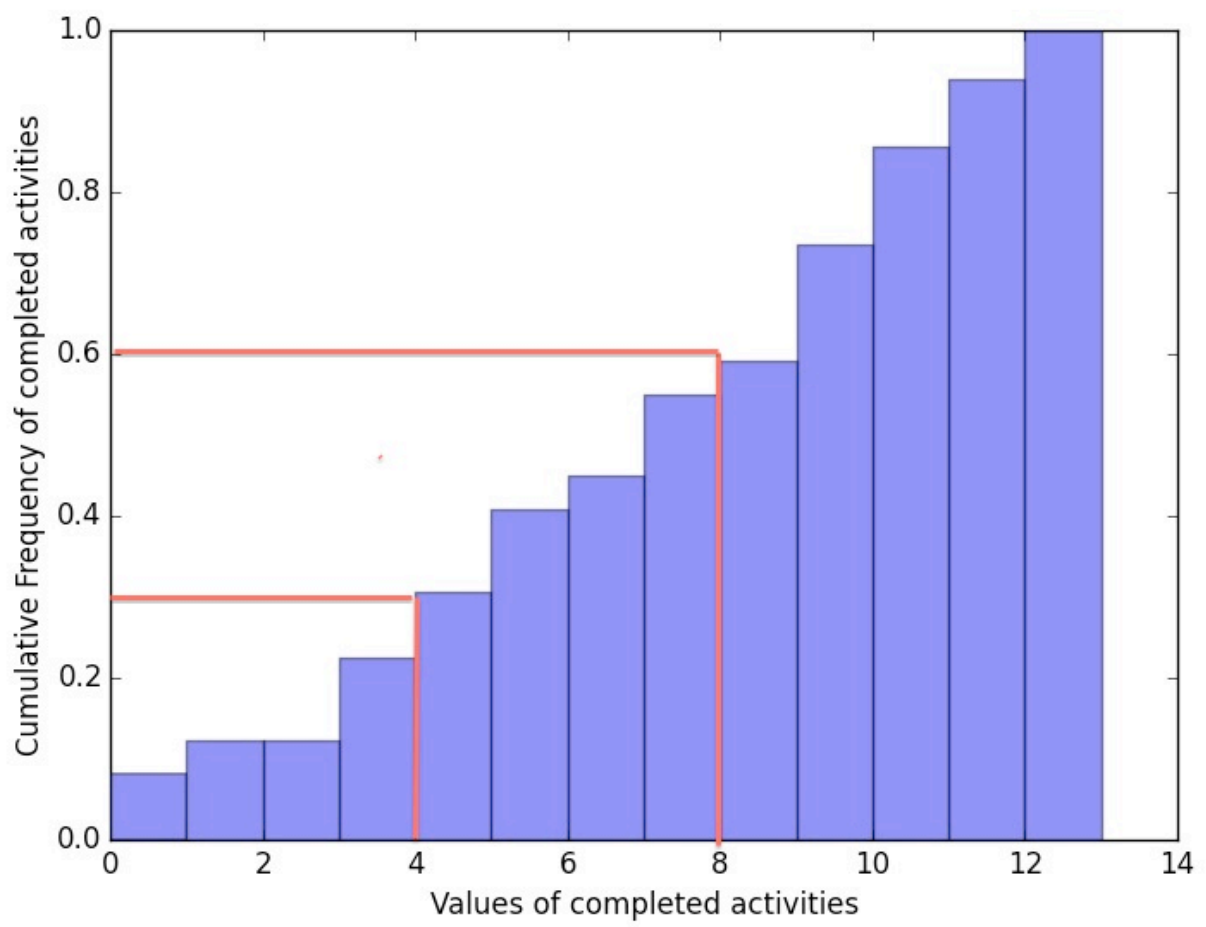

Figure 4. Cumulative frequency curve of completed carried out activities. The red lines indicate the cut-off scores between the autonomy classes which have been based on the the analyses of the participant's performances in terms of completely carried out activities, and on the cumulative frequencies of the completely carried out activities. These were divided in equal parts, as homogeneously as possible in terms of data coverage following the frequency curve. 
This division into three equal classes resulted in the following cut-off scores: From 13 to 8 completed activities was a good performance, meaning highly independent; from 7 to 4 completed activities was an intermediate performance; and below 4 completed activities was a poor performance, representing highly dependent in daily living activities. The grouping of the participants was done blinded from their diagnosis group in order to avoid classification baises, i.e. more likely to classify a $\mathrm{HC}$ as a 'good' performer. A HC subject could sometimes show a mediocre IADL performance on the assessment and in turn a MCI subject could show a good IADL performance. Taking into consideration that the objective of the assessment was to stage autonomy levels and not necessarily disease progression, even though they are associated, it was important to make that differentiation. Table 4 shows the classification results based on the participants IADL scenario performances with their diagnosis group, as well as their average amount of completely carried out activities. Twenty-two participants from which $13 \mathrm{HC}$ and 9 MCI subjects with an average of 10.04 correctly carried out activities were classified as good performer, 16 participants from which $1 \mathrm{HC}, 10 \mathrm{MCI}$ and $5 \mathrm{AD}$ subjects with an average of 5.5 correctly carried out activities were classified as intermediate performer and 11 participants from which 4 $\mathrm{MCI}$ and $7 \mathrm{AD}$ patients with an average of 1.5 correctly carried out activities were classified as poor performer. 
Table 4. Ecological Assessment results

\begin{tabular}{lccccl}
\hline & N & HC & MCI & AD & $\begin{array}{l}\text { Activites } \\
\text { completed } \\
\text { (in mean } \pm \text { SD) }\end{array}$ \\
\hline $\begin{array}{l}\text { Good } \\
\text { performance } \\
\begin{array}{l}\text { Intermediate } \\
\text { performance }\end{array}\end{array}$ & 22 & 13 & 9 & - & $10.04 \pm 1.4$ \\
$\begin{array}{l}\text { Poor } \\
\text { performance }\end{array}$ & 11 & 1 & 10 & 5 & $5.5 \pm 1.2$ \\
\hline
\end{tabular}

Validation of the Event Recognition System

Table 5 presents the results of the evaluation of the Event Video Monitoring System (EMS) with respect to its precision at detecting correctly the events of the clinical protocol (scenario 1: Single and Dual task and scenario 2: the number of activities of daily living) annotated by domain experts while watching the experiment video. 
Table 5. Activity/Event Detection Performance

\begin{tabular}{lll}
\hline Events & Recall $(\%)$ & $\begin{array}{l}\text { Precision } \\
(\%)\end{array}$ \\
\hline $\begin{array}{l}\text { Scenario 01 } \\
\text { Mono Task }\end{array}$ & 100.0 & 88.0 \\
Dual Task & 100.0 & 98.0 \\
$\begin{array}{l}\text { Scenario 02 } \\
\text { Searching Bus line }\end{array}$ & 58.0 & \\
Medication preparation & 87.0 & 62.5 \\
Watering Plant & 80.0 & 93.0 \\
Reading Article & 60.0 & 63.0 \\
Preparing Drink & 90.0 & 88.0 \\
Talk on Phone & 89.0 & 68.0 \\
\hline
\end{tabular}

Scenario 1, the single and dual task obtained the precision rates of $88 \%$ and $98 \%$. From all proposed activities, 'Medication preparation' was detected with the highest precision of $93 \%$ followed by 'Using the phone' with $89 \%$ and 'Reading an article with $88 \%$.

\section{Classification of participant cognitive status}

Table 6 presents the classification results for autonomy assessment and dementia diagnosis. The classification procedure was intrinsically based on the features automatically extracted from the physical tasks and IADLs performed by the participant during the clinical protocol. For comparison purposes we have also learned two classifiers based only on behavioral data of the physical task or IADL derived data. We hypothesized that combining the information from the two scenarios of the protocol increases the accuracy of the classification since they 
provide different but complementary information about a participant performance at daily living activities, e.g., motor and cognitive performances. For the three classifiers the data set is the same and contains 49 patients in total. The overall activities were correctly automatically detected with high sensitivity and precision results as previously described.

In the Autonomy classification task the following features were employed:

- Single Task Total Duration,

- Single Task Gap Duration,

- Single Task Standard Deviation Steps,

- Dual Task Gap Duration.

- Dual Task Max Steps,

- Person using PharmacyBasket Frequency of Event (frequency),

- Person using PharmacyBasket Duration of Event (seconds).

For the Diagnosis classification, the set of features was:

- Age,

- Single Task Average Steps,

- Single Task Speed Average from Centroid Information,

- Dual Task Max Steps,

- Dual Task Min Steps,

- Person reading inChairReadingTable Duration of Event (Frames),

The classifier for Dementia Diagnosis task obtained an accuracy of $61.22 \%$ when using only features based on IADL (Scenario 2), and of $75.51 \%$ when just extracting features from Physical Tasks (Scenario 1). The accuracy rate increased up to $73.46 \%$ when combining features from both scenarios. However, the higher recognition rates were found for the classifier learned for autonomy classification; 
based on simply the automatically extracted video features from Scenario 2, 77.55\% accuracy was obtained and 75\% accuracy for scenario 1 . The highest accuracy rate of $83.67 \%$ was obtained when combining directed tasks and IADLs.

Table 6. Classification results

\begin{tabular}{|l|l|l|l|}
\hline $\begin{array}{l}\text { Autonomy } \\
\text { assessment }\end{array}$ & \multicolumn{3}{|c|}{ Input Data } \\
\hline & $\begin{array}{l}|c| \\
\text { Performance }\end{array}$ & $\mathbf{0 1}$ & $\begin{array}{l}\text { Both } \\
\text { Scenarios }\end{array}$ \\
\hline $\begin{array}{l}\text { Correctly Classified } \\
\text { Instances }\end{array}$ & 37 & $38(77.551 \%)$ & 41 \\
\hline $\begin{array}{l}\text { Incorrectly Classified } \\
\text { Instances }\end{array}$ & $(75.51 \%)$ & $(83.6735 \%)$ \\
\hline
\end{tabular}

\begin{tabular}{|l|l|l|l|}
\hline $\begin{array}{l}\text { Diagnosis } \\
\text { assessment }\end{array}$ & \multicolumn{3}{|c|}{ Input Data } \\
\hline Performance & $\begin{array}{l}\text { Scenario } \\
\text { 01 }\end{array}$ & Scenario 02 & $\begin{array}{l}\text { Both } \\
\text { Scenarios }\end{array}$ \\
\hline $\begin{array}{l}\text { Correctly Classified } \\
\text { Instances }\end{array}$ & 36 & & 36 \\
\hline $\begin{array}{l}\text { Incorrectly Classified } \\
\text { Instances }\end{array}$ & $(73.4694 \%)$ & $30(61.2245 \%)$ & $(73.4694 \%)$ \\
\hline
\end{tabular}

\section{DISCUSSION}

The present study suggests that it is possible to assess autonomy in IADL functioning with the help of an an event monitoring system and that simply based on the extracted video features different autonomy levels can be classified highly accurately. The results obtained are significantly high for a correct assessment of autonomy but also cognitive status in terms of diagnosis. 
This means, that 'the proposed system' may become a very useful tool providing clinicians with diagnostic relevant information and improve autonomy assessment in AD or MCI patients in real time decreasing observer biases.

The results demonstrate further that gait analysis applied to IADL assessment may provide a reliable and precise methodology to assess patients functioning in daily life, which could be used at both diagnostic and rehabilitation level. All extracted elements of the clinical protocol, the kinetic parameters from the single and dual task, as well as the selected features from the IADL task, are important to take into consideration in the automatized analyses in order to assess and further predict accurately autonomy performance of patients. This means that in extractable gait features such as 'Single Task Standard Deviation Steps' and 'Dual Task Gap Duration' lies relevant information about a patient's capacity to perform IADLs and therefore his or her autonomy level. These features added up to the automatically detected lengths and frequencies of the to carry out activities result in a highly accurate autonomy classification rate of almost $84 \%$, allowing soon an almost fully automatized functional assessment in clinical practice. The work of Gillain et al. illustrates in the same manner that it may be possible to determine different cognitive profiles, and hence autonomy levels, by the measurement of gait parameters [43]. This confirms previous research findings that gait ability and cognitive functions are interrelated, and in particular executive functions and gait speed [44-47]. Gait impairment is already known to be a common characteristic of patients with MCI [48] and represents a risk factor for conversion to $\mathrm{AD}$ [49-50]. Therefore, changes in these motor functions may be useful in the early detection of dementia during preclinical stages and easily measurable by sensor technologies. 
Furthermore, significant correlations were found between the parameters of initiated and completed activities and most neuropsychological test results, particularly with MMSE and FAB scores showing that group differences even with just a small sample size could be detected when using such techniques, and this when regular assessment tools such as the IADL-E questionnaire lacked sensitivity to detect these group differences. Finally, high single activity detection rates, up to $93 \%$ for the 'Medication preparation' activity, could be achieved validating further the use of EMS for evaluation and monitoring purposes.

The study's results were consistent with previous work where with a sensitivity of $85.31 \%$ and a precision of $75.90 \%$ the overall activities were correctly automatically detected [31] although the present study was with a larger cohort and included as well AD patients.

Similar work, hence quantitative assessments of IADL performance, has been done using a different technique by Wadley et al. with the results that across timed IADL domains, MCI participants demonstrated accuracy comparable with cognitively normal participants but took significantly longer to complete the functional activities [51].

This suggests that slower speed in task execution could explain the differences found in the extracted features and thus, represent an important component and early marker of functional change already in MCI patient. A component that would not be clearly identified using traditional measurements of daily function, but could be easily spotted using the quantitative and unbiased EMS data. Likewise, Stucki et al. proved feasibility and reliability of a non-intrusive web-based sensor system for the recognition of Activities of Daily Living (ADL) and the estimation of a patient's self-dependency with high classification precision rates (up to 90\%) [52]. Bang et al. used multiple sensor fusion (pressure sensors, passive infrared sensors and worn 
accelerometers) for automatized ADL detection with achieved accuracy rates of up to $90 \%$ [53]. Nevertheless, these studies were carried out with a very small group sample of healthy and in average younger participants. Until now, the clinical assessment of functional changes in $\mathrm{AD}$ and MCI patients has traditionally relied on scales and questionnaires that are not always sensitive to the earliest functional changes. This leads to an important need to develop improved methods to measures these changes, ideally at the earliest stages. Therefore, recently research efforts have been placed on studies finding new innovative and more objective ways to measure functional and cognitive changes associated with $\mathrm{AD}$ [54-58].

The main interest of the present study was to demonstrate the practical application of the use of such a video monitoring system in clinical practice. Now, once the system's use has been validated by significant correlation with neuropsychological test scores, particularly for executive functioning, and highly accurate detection rates, it can be employed as a supportive assessment tool within clinical routine check-ups also on a rehabilitation level and even move on to more naturalistic environments such as nursing homes.

The systems' extracted information can provide the clinician with direct measurements (see the list of features) indicating, once interpreted, a certain level of autonomy performance, as well as with information about possible underlying mechanisms caused by decline in certain cognitive functioning, namely executive functions which are highly associated [59]. This technique has the advantage of leaving out the clinician, who represents often in assessments a potential stress factor, completely from the evaluation site, and thus increasing ecological validity by leaving the patient alone in a more naturalistic 'living-room alike' setting. The use of sensors for the measurement of behavioral patterns reduces important assessment biases often present in clinical practice and adds objective value to the assessment procedure. 
The objective on a long term is to provide a stable system that allows to monitor patients and their autonomy at home over a longer period. The within this study validated parameters can serve as indicators for illness progression, decline in IADL performance and hence, executive functions detectable with the help of new technologies much earlier, before somebody in the family would notice and send the patient to a specialist.

The limitation of this study resides firstly in the age and education differences among the groups; the AD population was older than the other groups, and the HC and MCI group had higher levels of education. This can be partly explained by the recruitment process and that generally in clinical practice it is quite difficult to recruit young AD patients. However, age and education level differences could have had an impact on the IADL and gait performances and should therefore being taken into consideration.

Therefore, in future studies it would be important to also focus on recruiting younger $\mathrm{AD}$ patients and participants with equal education levels in order to control for this variability. Secondly, the HC subjects were recruited through the Memory Centre which means that most of the HC participants came to the centre with a memory complaint even though in their neuropsychological tests they performed within normal ranges. It has to be taken into consideration that those participants may not be completely healthy and suffer from a higher risk to convert to MCI than people that do not consult the center for a memory complaint [60].

It has to be further underlined that even if participants were alone during the IADL assessment, the simple fact of knowing that they were recorded could have had an impact on their stresslevel and thus, their performance. 
Finally, it cannot be denied that the development of such a system and its analysis program was time-consuming and expensive. Engineers worked within the European FP7 Research Program Dem@care several years on improving the system's efficacity and detection precision. However, once its usabibility in clinical practice has been further demonstrated by validation studies, its integration in routine assessment procedures is feasible, installation of such system affordable (Kinect camera and a computer) for Memory Clinics and analyses can be provided in real-time. Nevertheless, more efforts in performance evaluation of such ICTs are needed to help the industry meet user needs and researchers in considering the available technologies for clinical practice. A solid economic model is a major issue: who will pay for assistive technology? Who will install and maintain ICTs at AD patients' homes? The cost-effectiveness balance for assistive technology remains a matter of debate.

To conclude, according to the recently published review of Snyder et al, research efforts have launched large prevention trials in AD and these efforts have further clearly demonstrated a need for better and more accurate measures of cognitive and functional changes in people already in the earliest stages of AD [61]. In the same line, the US Food and Drug Administration elevated the importance of cognitive and functional assessments in early stage clinical trials by proposing that even in the pre-symptomatic stages of the disease, approval will be contingent on demonstrating clinical meaningfulness.

Similarly, Laske et al. argued that there is an increasing need for additional noninvasive and/or cost-effective tools, allowing identification of subjects in the preclinical or early clinical stages of $\mathrm{AD}$ who could be suitable for further cognitive evaluation and dementia diagnostics [62]. Once examined in ongoing large trials, the implementation of such tools may facilitate early and potentially more effective therapeutic and preventative strategies for AD. All this points out, the need for improved cognitive and functional outcome measures 
for clinical studies of participants with preclinical $\mathrm{AD}$ and those diagnosed with MCI due to AD. With our study, we propose a new method of measuring objectively and accurately functional decline in patients from the earliest stages on with the support of the vision sensor technologies; a reliable method that could potentially, once validated through larger scale cohort studies, serve within clinical trial of new drug interventions as an endpoint measure to prove their effects on ADL function. Finally, the use of such systems could facilitate and support aging-in-place and improve medical care in general for these patients.

\section{Acknowledgments and sources of support}

This study was supported by grants from the FP7 Dem@care project, by the Innovation Alzheimer associations, by the STARS Team from the French Institute for Research in Computer Science and Automation (INRIA - Institut National de Recherche en Informatique et en Automatique, INRIA) in Sophia Antipolis, France, by the CoBTek (Cognition - Behaviour - Technology) Research Unit from the Nice Sophia-Antipolis University (UNS), the CMRR Nice team and by the platform patients of the Nice CHU member of the CIU-S. 


\section{REFERENCES}

1. Marshall, GA, Fairbanks, LA, Tekin, S, Vinters, HV, \& Cummings, JL. (2006). Neuropathologic correlates of activities of daily living in Alzheimer disease. Alzheimer Dis Assoc Disord, 20(1), 56-59.

2. Arrighi, HM, Gelinas, I, McLaughlin, TP, Buchanan, J, \& Gauthier, S. (2013). Longitudinal changes in functional disability in Alzheimer's disease patients. Int Psychogeriatr, 19.

3. Karzmark, P, Llanes, S, Tan, S, Deutsch, G, \& Zeifert, P. (2012). Comparison of the frontal systems behavior scale and neuropsychological tests of executive functioning in predicting instrumental activities of daily living. Appl Neuropsychol Adult, 19(2), 81-85.

4. Razani, J, Casas, R, Wong, JT, Lu, P, Alessi, C, \& Josephson, K. (2007). Relationship between executive functioning and activities of daily living in patients with relatively mild dementia. Appl Neuropsychol, 14(3), 208-214.

5. Dubois, B, Slachevsky, A, Litvan, I, Pillon, B. (2000). The FAB: a Frontal Assessment Battery at bedside. Neurology, 55(11), 1621-1626.

6. Tombaugh, TN. (2004). Trail Making Test A and B: normative data stratified by age and education. Arch Clin Neuropsychol, 19(2), 203-214.

7. Reppermund, S, Brodaty, H, Crawford, JD, Kochan, NA, Draper, B, Slavin, MJ, Sachdev, PS. (2013). Impairment in instrumental activities of daily living with high cognitive demand is an early marker of mild cognitive impairment: the Sydney Memory and Ageing Study. Psychol Med, 1-9.

8. Stern, Y, Hesdorffer, D, Sano, M, and Mayeux, R, Measurement and prediction of functional capacity in Alzheimer's disease. Neurology, 1990. 40(1): p. 8-14. 
9. Baddeley, A, Logie, R, Bressi, S, Della Sala, S, and Spinnler, H, Dementia and working memory. Q J Exp Psychol A, 1986. 38(4): p. 603-18.

10. Clare, L, Woods, RT, Moniz Cook, ED, Orrell, M, \& Spector, A. (2003). Cognitive rehabilitation and cognitive training for early-stage Alzheimer's disease and vascular dementia. Cochrane Database Syst Rev(4).

11. Cotelli, M, Calabria, M, \& Zanetti, O. (2006). Cognitive rehabilitation in Alzheimer's Disease.. Aging Clin Exp Res, 18(2), 141-143.

12. DeBettignies, BH, Mahurin, RK, \& Pirozzolo, FJ. (1990). Insight for impairment in independent living skills in Alzheimer's disease and multi-infarct dementia. J Clin Exp Neuropsychol, 12(2), 355-363.

13. Lawton, MP, \& Brody, EM. (1969). Assessment of older people: self-maintaining and instrumental activities of daily living. Gerontologist, 9(3), 179-186.

14. Gold, DA. (2012). An examination of instrumental activities of daily living assessment in older adults and mild cognitive impairment. J Clin Exp Neuropsychol, 34(1), 11-34.

15. Snyder, PJ, Kahle-Wrobleski, K., Brannan, S., Miller, D. S., Schindler, R. J., DeSanti, S., Ryan, J. M., Morrison, G., Grundman, M., Chandler, J., Caselli, R. J., Isaac, M., Bain, L., Carrillo, M. C. (2014). Assessing cognition and function in Alzheimer's disease clinical trials: Do we have the right tools? Alzheimers Dement, 10(6), 853-860.

16. Sikkes, SA, de Lange-de Klerk, ES, Pijnenburg, YA, Gillissen, F, Romkes, R, Knol, DL, Scheltens, P. (2012). A new informant-based questionnaire for instrumental activities of daily living in dementia. Alzheimers Dement, 8(6), 536-543.

17. Moore, DJ, Palmer, BW, Patterson, TL, \& Jeste, DV. (2007). A review of performance-based measures of functional living skills. J Psychiatr Res, 41(1-2), 97-118. 
18. Farina, E, Fioravanti, R, Pignatti, R, Alberoni, M, Mantovani, F, Manzoni, G, .Nemni, R. (2010). Functional living skills assessment: a standardized measure of high-order activities of daily living in patients with dementia. Eur J Phys Rehabil Med, 46(1), 73-80.

19. Sikkes, SA, de Lange-de Klerk, ES, Pijnenburg, YA, Scheltens, P, \& Uitdehaag, BM. (2009). A systematic review of Instrumental Activities of Daily Living scales in dementia: room for improvement. J Neurol Neurosurg Psychiatry, 80(1), 7-12.

20. Robert, PH, Konig, A, Andrieu, S, Bremond, F, Chemin, I, Chung, PC, Mallea, P. (2013). Recommendations for ICT Use in Alzheimer's Disease Assessment: Monaco CTAD Expert Meeting. J Nutr Health Aging, 17(8), 653-660.

21. König, A, Satt, A, Sorin, A, Hoory, R, Derreumaux, A, Manera, V, et al. (2015). Automatic speech analysis for the assessment of pre-demented and Alzheimer patients. Alzheimer's \& Dementia: Diagnosis, Assessment and Disease Monitoring, 1(1) 112-124.

22. Dubois, B, Feldman, HH, Jacova, C, Dekosky, ST, BarbergerGateau, P, Cummings, J, Delacourte, A, Galasko, D, Gauthier, S, Jicha, G, Meguro, K, O'Brien, J, Pasquier, F, Robert, P, Rossor, M, Salloway, S, Stern, Y, Visser, PJ, and Scheltens, P, Research criteria for the diagnosis of Alzheimer's disease: revising the NINCDS-ADRDA criteria. Lancet Neurol, 2007. 6(8): p. 734-46.

23. Petersen, RC, Smith, GE, Waring, SC, Ivnik, RJ, Tangalos, EG, \& Kokmen, E. (1999). Mild cognitive impairment: clinical characterization and outcome. Arch Neurol, 56(3), 303-308.

24. Folstein, M, Folstein, SE, McHugh, PR. (1975). "Mini-Mental State": A practical method for grading the cognitive state of patients for the clinician. J Psychiatr Res 121, 189-198. 
25. Fahn, S, Elton, RL (1987). UPDRS program members. Unified Parkinsons Disease Rating Scale. In N. M. H. I. Florham Park (Ed.), Recent developments in Parkinsons disease (pp. 153163): M.C. Fahn S, Goldstein M, Calne DB.

26. Buschke, H. (1984). Cued recall in amnesia. J Clin Neuropsychol, 6(4), 433-440.

27. Grober, E, Buschke, H. (1987). Genuine memory deficits in dementia. Developmental Neuropsycholy, 3, 13-36.

28. Cummings, J. (1997). The neuropsychiatric inventory: assessing psychopathology in dementia patients. Neurology, 48, 10-16.

29. Erzigkeit, H, Lehfeld, H, Pena-Casanova, J, Bieber, F, Yekrangi-Hartmann, C, Rupp, M, Hindmarch, I. (2001). The Bayer-Activities of Daily Living Scale (B-ADL): results from a validation study in three European countries. Dement Geriatr Cogn Disord, 12(5), 348-358.

30. Hindmarch, I, Lehfeld, H, de Jongh, P, \& Erzigkeit, H. (1998). The Bayer Activities of Daily Living Scale (B-ADL). Dement Geriatr Cogn Disord, 9 Suppl 2, 20-26.

31. Konig, A, Crispim Junior, CF, Derreumaux, A, Bensadoun, G, Petit, PD, Bremond, F, Robert, P. (2015). Validation of an automatic video monitoring system for the detection of instrumental activities of daily living in dementia patients. $\mathrm{J}$ Alzheimers Dis, 44(2), 675-685.

32. Romdhane, R, Mulin, E, Derreumeaux, A, Zouba, N, Piano, J, Lee, L, Robert, PH. (2012). Automatic video monitoring system for assessment of Alzheimer's disease symptoms. J Nutr Health Aging, 16(3), 213-218.

33. Sacco, G, Joumier, V, Darmon, N, Dechamps, A, Derreumaux, A, Lee, JH, Robert, P. (2012). Detection of activities of daily living impairment in Alzheimer's disease and mild cognitive impairment using information and communication technology. Clin Interv Aging, 7, 539-549. 
34. Nghiem, AT, Bremond, F. . (2014). Background subtraction in people detection framework for RGB-D cameras. Paper presented at the 11th IEEE International Conference on Advanced Video and Signal-Based Surveillance, AVSS Seoul, Korea.

35. Chau, DP, Bremond, F., Thonnat, M. (2011). A multi-feature tracking algorithm enabling adaptation to context variations. Paper presented at the International Conference on Imaging for Crime Detection and Prevention, ICDP London, UK.

36. Crispim-Junior, C, Bathrinarayanan, V., Fosty, B., Konig, A., Romdhane, R., Thonnat, M., Bremond, F. (2013). Evaluation of a Monitoring System for Event Recognition of Older People. Paper presented at the 10th IEEE International Conference on Advanced Video and Signal-Based Surveillance, AVSS, Krakow, Poland.

37. Hall, MA, Holmes, G., . (2003). Benchmarking attribute selection techniques for discrete class data mining. Paper presented at the IEEE Transactions on Knowledge and Data Engineering.

38. Kohavi, R, John, G.H. . (1997). Wrappers for feature subset selection. Silicon Graphics, Inc., 2011 N. Shoreline Boulevard, Mountain view, CA 94043, USA.

39. Huang, J, Lu, J., Ling, C.X. (2003). Comparing naive Bayes, decision trees, and SVM with AUC and accuracy. Paper presented at the Third IEEE International Conference on Data Mining (ICDM).

40. John, GH, Langley, P. (1995). Estimating continuous distributions in bayesian classifiers. Paper presented at the Eleventh Conference on Uncertainty in Artificial Intelligence, San Mateo.

41. Matwin, S, Sazonova, V. (2012). Direct Comparison Between Support Vector Machine and Multinomial Naive Bayes Algorithms for Medical Abstract Classification. Journal of the American Medical Informatics Association : JAMIA 19(5). 
42. Hall, M, Frank, E., Holmes, G., Pfahringer, B., Reutemann, P., Witten, I. (2009). The WEKA Data Mining Software: An Update. SIGKDD Explorations, 11(1).

43. Gillain, S, Warzee, E., Lekeu, F., Wojtasik, V., Maquet, D. Croisier, J.-L., Salmon, E., Petermans, J. (2009). The value of instrumental gait analysis in elderly healthy, MCI or Alzheimer's disease subjects and a comparison with other clinical tests used in single and dual-task conditions Annals of Physical and Rehabilitation Medicine, 52(6), 453-474.

44. Beauchet, O, Allali, G, Launay, C, Herrmann, FR, \& Annweiler, C. (2013). Gait variability at fast-pace walking speed: a biomarker of mild cognitive impairment? J Nutr Health Aging, 17(3), 235-239.

45. Doi, T, Makizako, H, Shimada, H, Park, H, Tsutsumimoto, K, Uemura, K, \& Suzuki, T. (2013). Brain activation during dualtask walking and executive function among older adults with mild cognitive impairment: a fNIRS study. Aging Clin Exp Res, 25(5), 539-544.

46. Doi, T, Shimada, H, Makizako, H, Tsutsumimoto, K, Uemura, K, Anan, Y, \& Suzuki, T. (2014). Cognitive function and gait speed under normal and dual-task walking among older adults with mild cognitive impairment. BMC Neurol, 14, 67.

47. Montero-Odasso, M, Bergman, H, Phillips, NA, Wong, CH, Sourial, N, \& Chertkow, H. (2009). Dual-tasking and gait in people with mild cognitive impairment. The effect of working memory. BMC Geriatr, 9, 41.

48. Allan, LM, Ballard, CG, Burn, DJ, \& Kenny, RA. (2005). Prevalence and severity of gait disorders in Alzheimer's and non-Alzheimer's dementias. J Am Geriatr Soc, 53(10), 16811687.

49. Buracchio, T, Dodge, HH, Howieson, D, Wasserman, D, \& Kaye, J. (2010). The trajectory of gait speed preceding mild cognitive impairment. Arch Neurol, 67(8), 980-986. 
50. Verghese, J, Wang, C, Lipton, RB, Holtzer, R, \& Xue, X. (2007). Quantitative gait dysfunction and risk of cognitive decline and dementia. J Neurol Neurosurg Psychiatry, 78(9), 929-935.

51. Wadley, VG, Okonkwo, O, Crowe, M, \& Ross-Meadows, LA. (2008). Mild cognitive impairment and everyday function: evidence of reduced speed in performing instrumental activities of daily living. Am J Geriatr Psychiatry, 16(5), 416424.

52. Stucki, RA, Urwyler, P, Rampa, L, Muri, R, Mosimann, UP, \& Nef, T. (2014). A web-based non-intrusive ambient system to measure and classify activities of daily living. J Med Internet Res, 16(7), e175.

53. Bang, S, Kim, M, Song, SK, \& Park, SJ. (2008). Toward real time detection of the basic living activity in home using a wearable sensor and smart home sensors. Conf Proc IEEE Eng Med Biol Soc, 2008, 5200-5203.

54. Goldberg, TE, Koppel, J, Keehlisen, L, Christen, E, DresesWerringloer, U, Conejero-Goldberg, C, Davies, P. (2010). Performance-based measures of everyday function in mild cognitive impairment. Am J Psychiatry, 167(7), 845-853.

55. López-de-Ipiña, K, Alonso, J.B., Barroso, N., Faundez-Zanuy, M., Ecay, M., Solé-Casals, J., Travieso,C.M., Estanga, A., Ezeiza, A. . (2012). New Approaches for Alzheimer's Disease Diagnosis Based on Automatic Spontaneous Speech Analysis and Emotional Temperature. Ambient Assisted Living and Home Care Lecture Notes in Computer Science 7657, 407414.

56. Vestal, L, Smith-Olinde, L, Hicks, G, Hutton, T, \& Hart, J, Jr. (2006). Efficacy of language assessment in Alzheimer's disease: comparing in-person examination and telemedicine. Clin Interv Aging, 1(4), 467-471. 
57. Yakhia, M, Konig, A, van der Flier, WM, Friedman, L, Robert, PH, \& David, R. (2014). Actigraphic motor activity in mild cognitive impairment patients carrying out short functional activity tasks: comparison between mild cognitive impairment with and without depressive symptoms. J Alzheimers Dis, 40(4), 869-875.

58. Zola, SM, Manzanares, CM, Clopton, P, Lah, JJ, \& Levey, AI. (2013). A behavioral task predicts conversion to mild cognitive impairment and Alzheimer's disease. Am J Alzheimers Dis Other Demen, 28(2), 179-184.

59. Marshall, GA, Rentz, DM, Frey, MT, Locascio, JJ, Johnson, KA, Sperling, RA, \& Alzheimer's Disease Neuroimaging, I. (2011). Executive function and instrumental activities of daily living in mild cognitive impairment and Alzheimer's disease. Alzheimers Dement, 7(3), 300-308.

60. Jacinto, AF, Brucki, SM, Porto, CS, Arruda Martins, M, \& Nitrini, R. (2014). Subjective memory complaints in the elderly: a sign of cognitive impairment? Clinics (Sao Paulo), 69(3), 194-197.

61. Snyder, PJ, Kahle-Wrobleski, K., Brannan, S., Miller, D. S., Schindler, R. J., DeSanti, S., Ryan, J. M., Morrison, G., Grundman, M., Chandler, J., Caselli, R. J., Isaac, M., Bain, L., Carrillo, M. C. (2014). Assessing cognition and function in Alzheimer's disease clinical trials: Do we have the right tools? Alzheimers Dement, 10(6), 853-860.

62. Laske, C, Sohrabi, HR, Frost, SM, Lopez-de-Ipina, K, Garrard, P, Buscema, M, . . . O'Bryant, SE. (2014). Innovative diagnostic tools for early detection of Alzheimer's disease. Alzheimers Dement. 


\section{CHAPTER 7}

\section{AUTOMATIC SPEECH ANALYSIS FOR THE ASSESSMENT OF PRE-DEMENTED AND ALZHEIMER PATIENTS}

Alzheimer's \& Dementia : Diagnosis, Assessment \& Disease Monitoring 1 (2015) 112-124

König, A., Satt, A., Sorin, A., Hoory, R., Toledo-Ronen, O., Derreumaux, A., Manera, V., Verhey, F., Aalten, P, Robert, P.H., David, R. 


\section{ABSTRACT}

\section{Background}

To evaluate the interest of using automatic speech analyses for the assessment of mild cognitive impairment (MCI) and early-stage Alzheimer's disease (AD).

\section{Methods}

Healthy elderly control (HC) subjects and patients with MCI or AD were recorded while performing several short cognitive vocal tasks. The voice recordings were processed, and the first vocal markers were extracted using speech signal processing techniques. Second, the vocal markers were tested to assess their "power" to distinguish among HC, $\mathrm{MCI}$, and AD. The second step included training automatic classifiers for detecting $\mathrm{MCI}$ and $\mathrm{AD}$, using machine learning methods and testing the detection accuracy.

\section{Results}

The classification accuracy of automatic audio analyses were as follows: between $\mathrm{HCs}$ and those with MCI, 79\% 6 5\%; between HCs and those with $\mathrm{AD}, 87 \% 63 \%$; and between those with MCI and those with $\mathrm{AD}, 80 \% 65 \%$, demonstrating its assessment utility.

\section{Conclusion}

Automatic speech analyses could be an additional objective assessment tool for elderly with cognitive decline. 


\section{INTRODUCTION}

Various types of dementia affect human speech and language [1] and disorders or irregularities in the language domain could be a strong predictor of disease progression [2,3]. Considering this association, reason exists to explore speech analysis as a method for early dementia diagnosis.

One avenue we investigated was the analysis of speech using software that takes as input the audio recording from a clinical consultation. Combined with other methods such as video monitoring [4] and actigraphy [5], the speech analysis tool has the potential to become a useful, noninvasive, and simple method for early dementia diagnosis [6]. These technologies enable rapid, accurate, and inexpensive monitoring over time. Noninvasive diagnosis methods will also reduce the burden on the healthcare system and improve the possibility of early dementia detection. Alzheimer's disease (AD) is diagnosed when it has reached the stage at which cognitive (i.e., episodic memory impairment) and neuropsychiatric symptoms interfere with social functioning or activities of daily living. In addition to the clinical criteria, Dubois et al [7] recently suggested that pathophysiologic biomarker evidence is also needed.

The dementia diagnosis is strongly based on clinical judgment, for which appropriate assessment instruments are of vital importance. Providing reliable additional methods to assess dementia progression in patients is of high interest, because the cognitive domains other than memory have been increasingly recognized as important outcome measures in clinical practice. Information and communication technology (ICT), in particular, automatic speech analysis, is important, because it enables the capture of patient performance and actions to accurately evaluate patients in real time. Using real life situations and applying less intrusive methods that do not require specialized personnel would also be advantageous Speech analyses 
have already been used in patients with dementia [8-10] and those with Parkinson's disease [11] to find potential vocal markers. Studies have shown that one consistently found language abnormality in early $\mathrm{AD}$ is anomia, or impaired word finding [12,13], leading to circumlocution that is evidenced in poor word list generation, in particular, for words in a given semantic category [14]. Patients with AD have difficulty accessing semantic information intentionally, which manifests itself in a manner that appears to reflect a general semantic deterioration [1].

This difficulty can affect the temporal cycles during spontaneous speech production (speech fluency) and therefore can be detectable in the hesitation and uttering of a patient [15]. Additional affected speech characteristics in patients with $\mathrm{AD}$ seem to be those related to articulation (speed in language processing) [16], prosody in terms of temporal and acoustic measures, which includes alterations in rhythm (ability to vary pitch level, pitch modulation, reduced or fluctuating rate of language output, frequent word finding pauses, a lack of initiative, and slowness) [17,18], and eventually, in later stages, phonologic fluency [19]. Some of these characteristic alterations could be detected by automatic analysis by extracting speech parameters from patients, for example, by performing cognitive vocal tasks or even recording free speech. Recently, Ahmed et al [2] tried to identify the features of speech that could be used to examine the longitudinal changes to profile impairment in patients with AD. Their study showed that progressive disruption in language integrity was detectable as early as the prodromal stage. Meilan et al [20] found that voiceless segments explained a significant portion of the variance in the overall scores obtained in the neuropsychological test. Lopez-deIpina et al [21] investigated the potential of applying artificial intelligence algorithms to patients' speech as a method to improve thediagnosis of $\mathrm{AD}$ and determine the degree of its severity, with promising results for early diagnosis and classification of patients with AD. Roark et al [22] studied different characteristics of spoken 
language that were automatically derived, such as pause frequency and duration. They demonstrated statistically significant differences between healthy subjects and subjects with mild cognitive impairment (MCI) for a number of measures. However, in these studies, the expected performance of an end-to-end voice-based dementia assessment system was not clearly demonstrated and was often limited by the sample size, method (i.e., manual transcriptions), and technologies.

The present study aimed to determine the value of automatic analyses of voice recordings during vocal tasks for the early diagnosis of AD. This was done through the Dem@Care project, a substudy of the European Community FP7 program. Within this project, ICTs are used for the assessment of patients with dementia in an ecological setting [23]. Specialized IBM speech researchers worked together in close collaboration with the clinical dementia researchers to develop a process to analyze automated speech recordings.

To detect dementia-related characteristics in human voice and speech patterns, a classifier was developed using a support vector machine to analyze the statistical properties of vocal features [24]. The classifier determined which features characterize different states of the disease. The main research objective was to determine whether automated speech and voice pattern analyses increases the accuracy, reliability, and affordability of AD early detection.

The present study analyzed voice recordings collected during cognitive vocal tasks performed by patients with AD, MCI, and healthy elderly controls (HCs). The tasks were used to determine the effectiveness of speech processing technologies to support dementia assessment. The primary objective of the study was to investigate whether a method based on automatic speech analyses can detect differences among $\mathrm{AD}, \mathrm{MCI}$, and $\mathrm{HC}$ subjects. Furthermore, we sought to determine which speech features are the most sensitive to the deterioration due to the disease. This would allow us to obtain a 
profile for the different populations to improve the differential diagnosis. The secondary objective was to evaluate which tasks are the most appropriate ones to allow the detection of differences in these speech features.

\section{METHODS}

\section{Participants}

Within the framework of the Dem@care project, speech recordings were conducted at the Memory Clinic in Nice, France. The Nice ethics committee approved the present study. Each participant gave informed consent before the first assessment. Participants aged 65 years or older were recruited through the Memory Clinic located at the geriatric department of the University Hospital.

\section{Clinical assessment}

The general cognitive status was assessed using neuropsychological tests, including the

- Mini-mental state examination (MMSE) [25]

- Five word test [26]

- Frontal assessment battery [27]

- Instrumental activities of daily living scale [28]

Additionally, neuropsychiatric symptoms were assessed using the neuropsychiatric inventory [29]. Apathy was assessed using the apathy inventory [30] and the apathy diagnostic criteria [31]. These tests were performed for potential postanalysis of the audio recordings investigating the effect of neuropsychiatric symptoms on the voice parameters. After the clinical assessment, the participants were categorized into 3 groups: HCs, who had complained about subjective memory problems but were diagnosed as cognitively healthy after the clinical consultation; patients with MCI; and patients who had been diagnosed with $\mathrm{AD}$. For the $\mathrm{AD}$ group, the diagnosis was determined using the National Institute of Neurological and Communicative 
Disorders and Stroke and the Alzheimer's Disease and Related Disorders Association criteria [32]. For the MCI group, diagnosis was conducted using the Petersen criteria [33]. Participants were excluded if they had any major audition or language problems or a history of head trauma, loss of consciousness, or psychotic or aberrant motor behavior.

\section{Recording protocol}

Each participant performed four spoken tasks during a regular consultation with a general practitioner while being recorded as a part of an ongoing research protocol. The tasks consisted of a counting backward task, a sentence repeating task, an image description task, and a verbal fluency task (Table 1). These tasks were chosen from the findings of previous studies [24].

The vocal tasks were recorded using an Audio Technica AT2020 USB Condenser Microphone (16-mm diaphragm, cardioid polar pattern, frequency response $20 \mathrm{~Hz}$ to $16.000 \mathrm{~Hz}$, Thomann $144 \mathrm{~dB}$ maximum sound pressure level) that was placed on a stand $10 \mathrm{~cm}$ from the participant. Each task was recorded entirely to extract specific vocal features, including pause length, verbal reaction time, and amount of silence. After recoding, the vocal features were extracted from each spoken task using both the open software tool Praat [34] and a set of purposefully developed signal processing tools. 
Table 1. The vocal tasks of the protocol

\begin{tabular}{|c|c|c|}
\hline \# & Task & Description \\
\hline 1 & Countdown & $\begin{array}{l}\text { Count backwards one by one from ' } 305 \text { ' down } \\
\text { to ' } 285 \text { ' without making a mistake }\end{array}$ \\
\hline 3 & $\begin{array}{l}\text { Picture } \\
\text { description }\end{array}$ & $\begin{array}{l}\text { Look at a picture and describe it as detailed as } \\
\text { you can in one minute }\end{array}$ \\
\hline 2 & $\begin{array}{l}\text { Sentence } \\
\text { repeating }\end{array}$ & $\begin{array}{l}\text { Repeat ten short sentences after the clinician } \\
\text { (one at a time); the first three are: }\end{array}$ \\
\hline & & $\begin{array}{l}\text { - "La montagne est enneigée en ce mois } \\
\text { - ce mars" } \\
\text { "Le chien a fait une longue promenade } \\
\text { - ce matin" } \\
\text { "Le Schtroumpf grognon est très } \\
\text { content aujourd'hui" }\end{array}$ \\
\hline 4 & $\begin{array}{l}\text { Semantic } \\
\text { fluency } \\
\text { (animals) }\end{array}$ & $\begin{array}{l}\text { Name as many animals as you can think of as } \\
\text { quickly as possible (one minute time). This } \\
\text { semantic fluency test is widely used in } \\
\text { neuropsychological assessments to evaluate } \\
\text { frontal lobe functions. }\end{array}$ \\
\hline
\end{tabular}

\section{Statistical analysis}

Demographic variables are presented as the median and interquartile range. Before analysis, the data were verified for normality, potential outliers, and missing values. Intergroup comparisons for continuous variables were performed using a nonparametric Mann-Whitney $U$ test, because the distribution of the data was not normal. Alpha error adjustments $(p<.05 / 3=.016)$ were performed using the Bonferroni correction method. Categorical testing for gender and education was calculated using the Fisher' exact test. All statistical analyses of the demographic and neuropsychological data were computed using SPSS, version 20.0, and are presented in detail in the subsequent sections. 


\section{Vocal features and analysis}

After recording, numerous vocal features were extracted from each spoken task. These features presumably covered the task-specific manifestation of dementia in the speech data. Some were similar to features described in previous studies [2,20,35-37] and others were novel. Because of the developing language-independent technology, speech recognition was not included, and only nonverbal features were targeted.

\section{Countdown and picture description}

In cognitive task 1 of the protocol, the participants were asked to count backward from " 305 " to " 285 " as fluently as they could. In cognitive task 2 , free speech was collected by asking the participants to describe a picture. Task 1 was therefore more cognitively demanding. The tasks were analyzed for the continuity of speech (i.e., longer contiguous voice segments and shorter silent segments were sought as speech features for both the countdown and the picture description tasks). We expected greater continuity for $\mathrm{HCs}$, lower continuity for those with MCI, and the lowest continuity for those with $\mathrm{AD}$. Some speech features were based on techniques reported in previous studies [2,35-38], and others were new. We derived continuity features from the length (duration) of the contiguous voice and silent segments and from the length of contiguous periodic and aperiodic segments. Voice or silence was detected using a voice activity detection algorithm, which is based on the energy envelop (intensity) of the recorded speech signal, as calculated using the Praat software [34]. Periodic versus aperiodic segments were detected using pitch contour (periodicity), calculated using the Praat software [34]. Figure 1 shows the voice and silence segments and the periodic and aperiodic segments of a typical spoken task recording. 
From that analysis we obtained four data types for each recording, reflecting each cognitive task (countdown or picture description):

- Voice segment length (in seconds)

- Silence segment length (in seconds)

- Periodic segment length (in seconds)

- Aperiodic segment length (in seconds)

For each set of the four data types (the set for the countdown and the set for the picture description), we calculated several vocal features:

- The mean of the durations (we expected longer durations of the voice and periodic segment lengths and shorter durations for the silence and aperiodic segment lengths): The comparison groups were the HC participants versus those with MCI and those with MCI versus those with AD

- The ratio mean of the durations (defined as the mean voice duration/mean silence duration, mean silence duration/mean voice duration, mean periodic duration/ mean aperiodic duration, and mean aperiodic duration/mean periodic duration, for the four data types [voice, silence, periodic, and aperiodic])

- The median of the durations and the ratio median of the durations (the same as for the mean and ratio mean but computing for the median instead)

- The standard deviation of the durations and the ratio standard deviation of the durations (similar to the mean and ratio mean)

- The sum of the durations, ratio sum of the durations (similar to the mean and ratio mean)

- Segment count

These features were derived from techniques introduced in a previous study [24], other than the ratio features, which are novel to the field of speech analysis. 


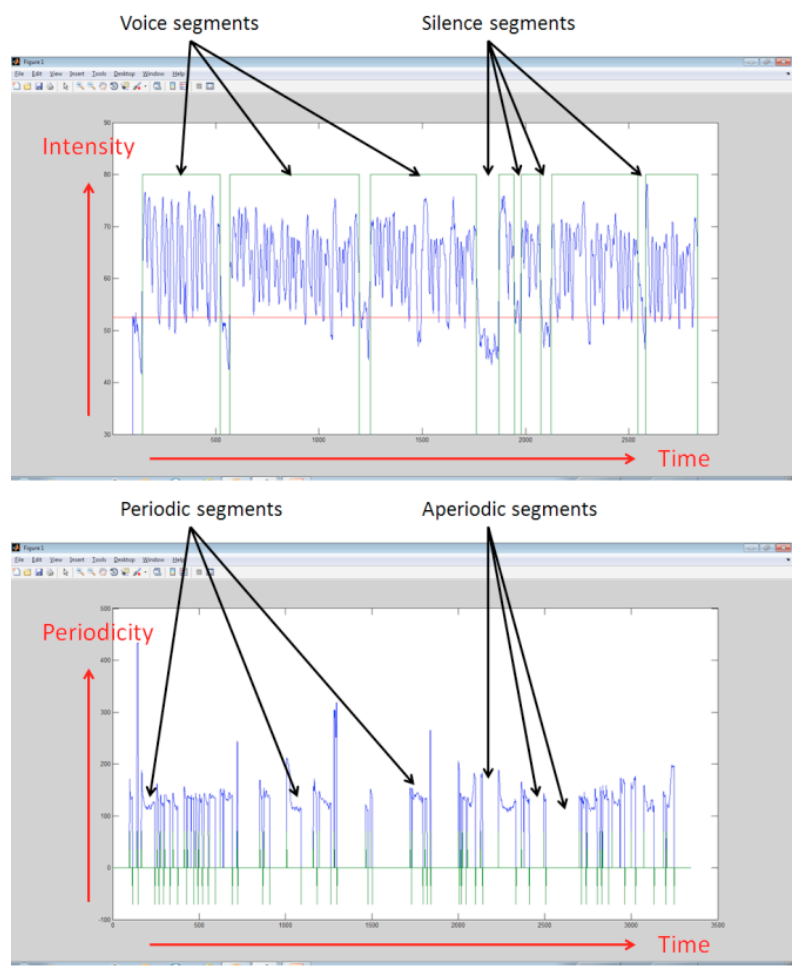

Figure 1: voice vs. silence segments, and periodic vs. aperiodic segments, of a typical spoken task recording. The horizontal axis designates time frames of 10 milliseconds; the vertical axis on the left side designates the signal intensity; the vertical axis on the right side designates the signal periodicity. Voice vs. silence, and periodic vs. aperiodic, are determined from the smoothed intensity and periodicity contours, respectively.

\section{Sentence repeating}

In cognitive task 3, the participants had to repeat a sequence of 10 sentences spoken by the clinician one at a time while being recorded. First, speaker separation was performed on the entire recording to detect the boundary points of the individual sentences. Next, a standardized signal processing technique (dynamic time warping) was used to evaluate the time alignment — calculating the alignment curve 
between pairs of corresponding waveforms (the sentence uttered by the clinician and the corresponding sentence repeated by the participant). Figure 2 shows the time alignment for two different cases. On the left side of Figure 2, a "successful" sentence repeating case is shown. The blue curve indicates a quite smooth and regular time alignment between the clinician's signal and the participant's repeated signal. This smooth and regular curve demonstrates that the repeated sentence followed the clinician's sentence closely. The linear and second-order approximations to the timealignment curve (green line and red curve, respectively) closely match the time-alignment curve. The close matching to the line and a smooth second-order curve are measures of the time alignment "regularity." We defined the firstand second-order irregularity measures as the squared error between the time alignment (blue) curve and its linear and second-order approximations (green and red), respectively.

In contrast, the right side of Figure 2 shows the case of a poorly repeated sentence. A good match between the clinician's signal and the participant's repeated signal was only partially found along parts of the sentence. The nearly horizontal part of the blue curve represents an "insertion" by the patient: it is a segment of the participant's speech for which no alignment was found with any part of the clinician's uttered sentence. The nearly vertical part of the blue curve represents a "deletion" by the patient: it is a segment of the clinician's speech for which no alignment was found with any part in the patient's repeated sentence. Also, on the right side, the time alignment curve (blue) is highly irregular, because it differs significantly from its linear and secondorder approximations (green and red, respectively).

We expected fewer insertions, fewer deletions, and less irregularity for the HC participants compared with those with $\mathrm{MCI}$ and between those with $\mathrm{MCI}$ and those with $\mathrm{AD}$. 
We defined the following vocal measures for each pair of corresponding sentences:

- Vocal reaction time (in seconds)

- Relative length (patient sentence duration/clinician sentence duration)

- Amount of silence (0 to 1 continuous scale)

- Amount of insertions (0 to 1 scale)

- Amount of deletions (0 to 1 scale)

- Irregularity - first order (arbitrary units)

- Irregularity—second order (arbitrary units)

We calculated the vocal features of the entire sentence repeating task for each patient to compute the mean and standard deviations of the vocal measures across the different sentence pairs. These features and the use of dynamic time warping to derive the vocal features from spoken cognitive tasks are also novel to the field of speech analysis.

\section{Semantic fluency}

In cognitive task 4, the participants were asked to name as many animals as they could within 1 minute. This semantic verbal fluency test is widely used in neuropsychological assessments to evaluate frontal lobe functions [39]. Figure 3 shows the positions (in time) of the individual words detected from a sample of a participant's recording of task 4. The word positions were estimated from the signal's intensity and periodicity using a peak detector. The signal intensity information was used to locate the peaks, and the periodicity information was used to reject the irrelevant peaks. The intensity and periodicity were calculated using the Praat software [34]. The vocal features for the semantic fluency task were defined as follows: the distances in time of the second, third, fourth, and until the ninth detected word positions from the first detected word position. 

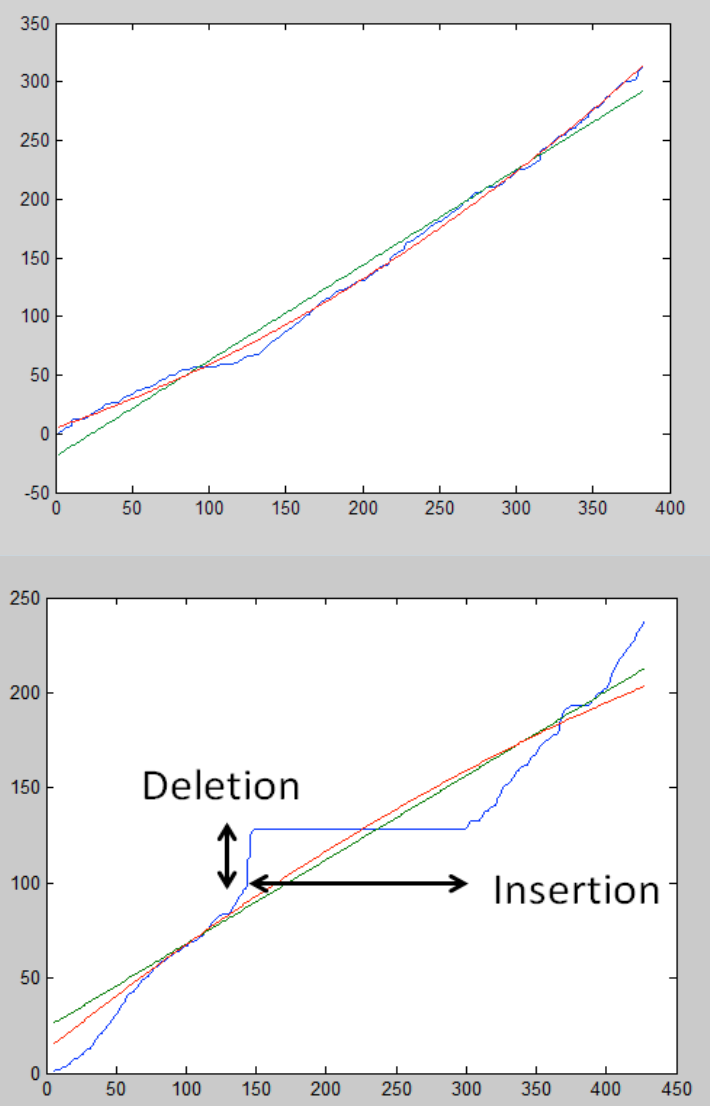

Figure 2: Time alignment between the clinician's sentence and the participant's repeated sentence. The horizontal axis the time of the participant's signal (in 10 millisecond frames); the vertical axis designates the time of the clinician's signal (in 10 millisecond frames). The blues curve shows the 'best' match (alignment) between the two signals; the green line and the red curve show the best linear and second-order approximations of the blue curve. 


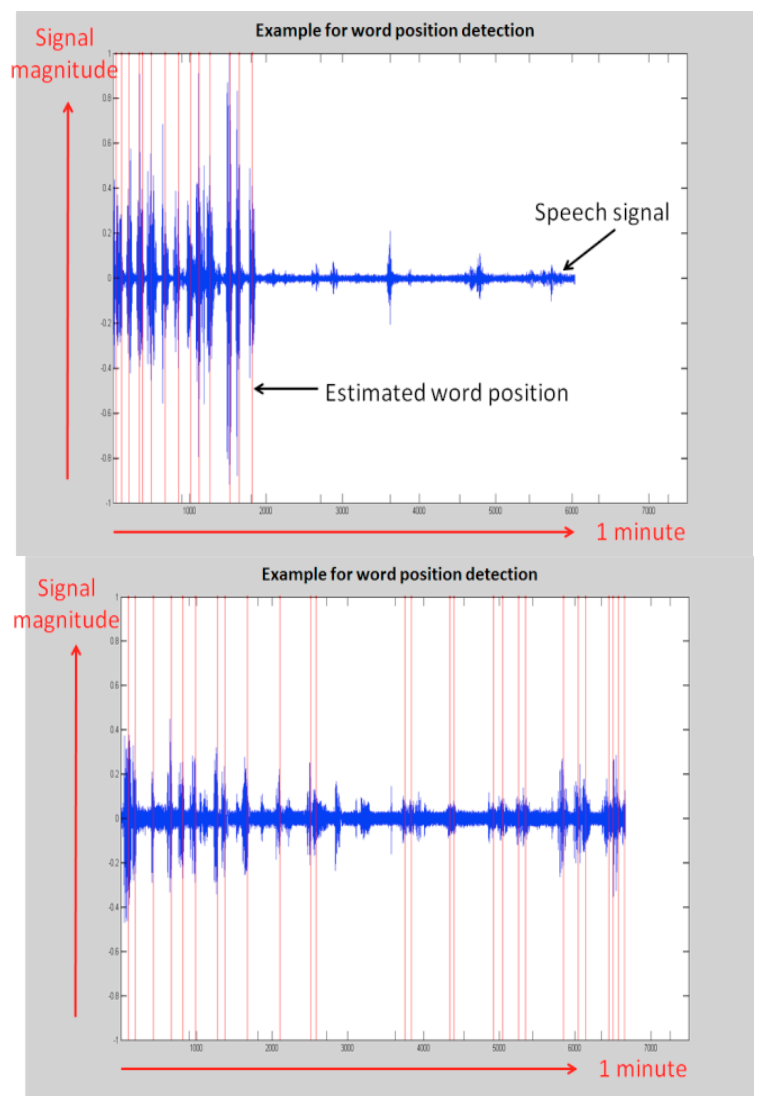

Figure 3: The time positions of the individual words along a one minute recording. On the left side: case of $\mathrm{HC}$, which demonstrates a faster rate of uttering words (assumed to be animal names), at least at the beginning of the task. On the right side, a case of $\mathrm{AD}$; it demonstrates a slower rate of uttering words at the beginning of the task.

\section{Classification procedure}

Before running a classifier, the feature selection procedure was implemented. The purpose of the feature selection procedure was to select the most meaningful vocal features and discard the "noisy" features that contribute less to the classification accuracy and might, in fact, reduce the accuracy if used. This procedure was tested to verify the outcomes. 
The feature selection techniques, known as wrapper or embedded methods [33], were found to perform poorly in terms of classification accuracy. This resulted fromthe limited size of the collected data; hence, the sparseness of the training feature vectors. The filter approach using the Mann-Whitney $U$ test was found to perform well using our data. Three different classification scenarios were evaluated, covering the three pairwise combinations of the three groups (HC, $\mathrm{MCI}$ and $\mathrm{AD}$ ):

- $\mathrm{HC}$ versus $\mathrm{AD}$ : detecting $\mathrm{AD}$ from the mixed $\mathrm{HC}$ and $\mathrm{AD}$ population

- $\mathrm{HC}$ versus MCI: detecting MCI from the mixed $\mathrm{HC}$ and MCI population

- $\mathrm{MCI}$ versus $\mathrm{AD}$ : detecting $\mathrm{AD}$ from the mixed $\mathrm{MCI}$ and $\mathrm{AD}$ population

For each classification scenario, an optimal subset of vocal features was selected. The P value of the Mann-Whitney U test was calculated for each vocal feature to estimate its "value" for distinguishing between the two classes associated with the scenario. The vocal features with a $\mathrm{P}$ value less than the threshold were selected for classification, and the remaining features were ignored. All the meaningful vocal features exhibited a property in which the feature values in one group tended to be greater than those in the other group. For example, the mean silence segment lengths tended to be smaller for the HC group than for the MCI group.We used the Mann-Whitney U statistical test, because it facilitated selecting the features when this property was present. The $P$ value selection thresholds, for the three scenarios, were chosen to retain about 22 to 23 vocal features in each scenario and to ignore the rest; this quantity was found to yield good (low) classification error. Figure 4 demonstrates the different distributions of the mean silence segment lengths across the three groups: $\mathrm{HC}, \mathrm{MCI}$, and $\mathrm{AD}$. After feature selection, classification accuracy was evaluated using the support vector machine classifier 
and random subsampling based cross-validation.We report the classification accuracy in terms of the equal error rate (EER), which is the point at which the rate of type I error (a error rate, false alarm rate) equals the rate of type II error ( $b$ error rate, misdetection rate). For each of the three classification scenarios, the following procedure was implemented:

1. We randomly divided the entire data set (in the form of vocal feature vectors, containing the selected features) into test/train subsets

2. Applied regularization to the training set

3. Trained a support vector machine classifier using the regularized train set

4. Normalized the (original, not the regularized) test set according to the parameters derived from the training set

5. Ran the normalized test data through the classifier to evaluate the EER for the current random selection of test versus the training sets

6. Repeated steps 1 through 5 with different random selections of the test versus training sets

7. Calculated the mean and standard error (SE) of the EER and divided them by the EER values that corresponded to the different random selections

The training set regularization in step 2 helped to remove the outliers and increase the classification accuracy. Steps 1 to 5 were repeated 300 times to obtain stable results. We evaluated the results in terms of the EER, which is the point at which the false alarm rate equals the misdetection rate. The EER is equivalent to the point of equal specificitysensitivity (specificity-sensitivity $=1$ - EER/100). 


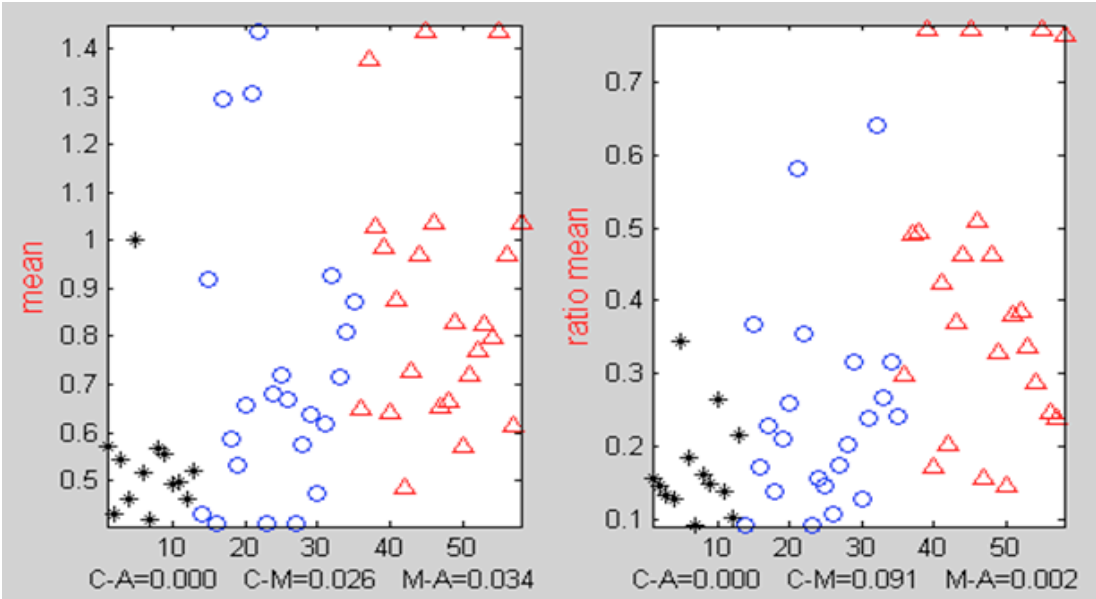

Figure 4: The distributions and the Mann-Whitney p-values of the silnce lengths. The horizontal axis designates the participant index. Different participants are designated as follows : HC by black asterisks, MCI by blue circles and $\mathrm{AD}$ by red triangles. It is seen that the values in each class tend to be higher (or lower) than in another class. Also shown the p-values for the three classification scenarios. It is also seen that ratio-mean (on the right side) helps distiguising between $\mathrm{MCI}$ and $\mathrm{AD}$ better than the plain arithmetic mean (on the left side).

\section{RESULTS}

\section{Participant characteristics}

Because the distribution of the data was nonparametric, the results are reported as the median and interquartile range. The characteristics of the HC group ( $\mathrm{n}=15$, age 72 years, interquartile range 60-79; MMSE 29 , interquartile range 29-30), MCI group ( $n=23$, age 73 years, interquartile range 67-79; MMSE 26, interquartile range 25-27), and AD group ( $\mathrm{n}=26$, age 80 years, interquartile range 71.75-86; MMSE 19 , interquartile range 16.75-21.25) are presented in Table 2. Categorical testing using Fisher's exact test showed no significant differences in education level among the three groups $(P<.05)$. However, if using $P<.1$, significant differences in the education 
levels were found between the HC and AD groups $(P=.062)$ and MCI and AD groups $(P=.059)$. Furthermore, after a error adjustments $(P<$ $.05 / 3=.016)$ using the Bonferroni correction method, the HC, MCI, and AD groups did not significantly differ in age. The three groups had significantly different scores on the MMSE, instrumental activities of daily living scale, verbal fluency, neuropsychiatric inventory, and apathy inventory $(P<.05)$. However, the frontal assessment battery score just differed between the MCI and AD groups and the $\mathrm{HC}$ and $\mathrm{AD}$ groups. The same results were obtained using the five word learning test. Using the apathy diagnostic criteria [31], a total of 20 participants had apathy (5 in the MCI and 15 in the $\mathrm{AD}$ group). The results in Table 3 were obtained using the crossvalidation procedure as described in the Methods section (section 2).These results reflect the average and SE of the EER values from 300 random selections of the test and train set.

\section{Vocal feature selection and analysis}

Comparing the HC and MCI groups, 23 features were selected (14 from the countdown task and 9 from the picture description task). Comparing the MCI and AD groups, 23 features were also selected (12 from the countdown task, 5 from the picture description task, and 6 from the verbal fluency task). Comparing the HC and AD groups, 22 features were selected (all from the countdown task). The selection $P$ value threshold, per classification scenario, was optimized to yield the highest average classification accuracy after cross-validation. The sentence repeating task was inferior than the other tasks in contributing to the classification accuracy. Thus, no features from that task were selected.

\section{Countdown and picture description}

The optimal features for both the countdown and picture description tasks were those that reflected speech continuity, showing longer contiguous voice segments and shorter silence segments and longer contiguous periodic segments and shorter aperiodic segments. 
According to the cognitive states, greater continuity would be expected for $\mathrm{HCs}$, lower continuity for those with $\mathrm{MCI}$, and the lowest for those with AD. Only a small subset of the continuity-reflecting vocal features significantly contributed to the classification accuracy. The ratio features were found to help, emphasizing the separation among the different groups (HC, MCI, and $\mathrm{AD}$ ), more than many other features.

\section{Sentence repeating}

The most relevant features we found were determined by comparing the pair of waveforms representing the sentence uttered by the clinician and the sentence repeated by the participant. The vocal reaction time was of little benefit for patient classification into the $\mathrm{HC}$, $\mathrm{MCI}$, and $\mathrm{AD}$ groups. Other features were more relevant. Although these vocal features were not selected using the Mann-Whitney U test, they can be useful when redesigning the recordings of the task. These features were powerful for some of the participants across all three groups. 
Table 2

Characteristics and comparisons for $\mathrm{HC}$, MCI, and AD groups

\begin{tabular}{|c|c|c|c|c|}
\hline Variable & All subjects $(n=64)$ & $\mathrm{HC}(\mathrm{n}=15)$ & MCI $(n=23)$ & $\mathrm{AD}(\mathrm{n}=26)$ \\
\hline \multicolumn{5}{|l|}{ Gender } \\
\hline Female & 34 & 9 & 12 & 13 \\
\hline Male & 30 & 6 & 11 & 13 \\
\hline Age (y) & $76(70-82)$ & $72(60-79)$ & $73(67-79)$ & $80(71.75-86)$ \\
\hline \multicolumn{5}{|l|}{ Education category } \\
\hline Primary & $18 / 64 *, \dagger$ & $2 / 15$ & $6 / 23$ & $10 / 26$ \\
\hline Secondary & $19 / 64 *, \dagger$ & $4 / 15$ & $4 / 23$ & $11 / 26$ \\
\hline College & $14 / 64 *, \dagger$ & $4 / 15$ & $7 / 23$ & $3 / 26$ \\
\hline University & $13 / 64 *, \dagger$ & $5 / 15$ & $6 / 23$ & $2 / 26$ \\
\hline MMSE & $25(19.25-28)^{\ddagger, \S . ศ}$ & $29(29-30)$ & $26(25-27)$ & $19(16.75-21.25)$ \\
\hline FAB & $15(12-17)^{5.9}$ & $17(16-18)$ & $15.5(14.75-17)$ & $11(9-13.75)$ \\
\hline IADL & $4(2-4)^{\S .9}$ & $4(4-4)$ & $4(3-4)$ & $2(1-3)$ \\
\hline 5 Word test & $9(7-10)^{\S, \Upsilon}$ & $10(10-10)$ & $9(9-10)$ & $7(4.25-8)$ \\
\hline Verbal fluency & $13(8.75-18)^{\ddagger, \S . \Upsilon}$ & $22.5(17.75-25)$ & $14(11-14)$ & $8.5(6.75-11)$ \\
\hline NPI total & $3(1-8)^{\ddagger, \S, \text { โ }}$ & $0(0-1.25)$ & $2(1-6)$ & $8(4-16)$ \\
\hline Apathy diagnostic & $20 / 64$ & $0 / 15$ & $5 / 23$ & $15 / 26$ \\
\hline Apathy inventory & $2(2-4)^{\ddagger, \S} \Phi$ & $0(0-0)$ & $2(0-3)$ & $4(2-6)$ \\
\hline
\end{tabular}

Abbreviations: AD, Alzheimer's disease; FAB, frontal assessment battery; HC, healthy elderly control; IADL, instrumental activities of daily living questionnaire; MCI, mild cognitive impairment; MMSE, mini-mental state examination; NPI, neuropsychiatric inventory.

NOTE. All values presented as median and interquartile range or number of subjects. Group comparisons were performed using the Mann-Whitney $U$ test $(P$

$<.05)$. Categorical testing for education was analyzed using Fischer's exact test.

$* P<.1$ for $\mathrm{MCI}$ versus $\mathrm{AD}$

${ }^{\dagger} P<.1$ for $\mathrm{HC}$ versus $\mathrm{AD}$.

${ }^{\ddagger} P<.05$ for $\mathrm{HC}$ versus MCI.

${ }^{8} P<.05$ for $\mathrm{MCI}$ versus $\mathrm{AD}$.

${ }^{\top} P<.05$ for $\mathrm{HC}$ versus AD. 


\section{Ecological assessment results}

The participants performed differently on the IADL scenario in terms of initiated and successfully completed activities in accordance with their cognitive status. Table $2 \mathrm{a}$ and $2 \mathrm{~b}$ present results of the intergroup comparison of the performance results in the ecological assessment. Significant group differences were found for the single and dual task between MCI and $\mathrm{AD}(p<.05)$ and for HC and $\mathrm{AD}(p<$ $.05)$. The amount of 'activities iniated' and 'activities completed'differed significantly between all three groups $(p<.05)$.

The parameter 'activities iniated' correlated significantly with neuropsychological test results namely the MMSE $(p<0.01)$, FAB score $(p<0.01), \operatorname{FCSR}(p<0.05)$ and the IADL-E score $(p<0.05)$. In the same line, the parameter 'activity completed' correlated significantly with the test results, MMSE $(p<0.01)$, FAB score $(p<$ $0.01), \operatorname{FCSR}(p<0.05)$ and the IADL-E score $(p<0.05)$. The obtained correlation analyses results are presented in Table 3 . None of the extracted parameters correlated with the NPI total scores.

Table 3. Correlation between IADL scenario performance and conventional cognitive assessments (Spearman's correlation coefficient)

\begin{tabular}{|c|c|c|c|c|c|}
\hline $\begin{array}{l}\text { deo analyses data } \\
\text { zarman correlation coefficient (r) / } \\
\text { ralues }\end{array}$ & MMSE & FAB & FCSR & NPI & IADL-E \\
\hline tivities initiated & $\begin{array}{l}0.650 * * \\
\mathrm{p}=0.000\end{array}$ & $\begin{array}{l}0.519 * * \\
\mathrm{p}=0.000\end{array}$ & $\begin{array}{l}0.380 * \\
\mathrm{p}=0.019\end{array}$ & $\begin{array}{l}-0.177 \\
p=0.234\end{array}$ & $\begin{array}{l}0.324^{*} \\
\mathrm{p}=0.030\end{array}$ \\
\hline tivities completed & $\begin{array}{l}0.685 * * \\
\mathrm{p}=0.000\end{array}$ & $\begin{array}{l}0.620 * * \\
\mathrm{p}=0.000\end{array}$ & $\begin{array}{l}0.356^{*} \\
p=0.028\end{array}$ & $\begin{array}{l}-0.266 \\
p=0.071\end{array}$ & $\begin{array}{l}0.334^{*} \\
p=0.025\end{array}$ \\
\hline
\end{tabular}


After the performance analyses, the participants were classified based on their IADL performance. The cut-off scores between the classes have been based on the observation of the analyses of the participant's performances in terms of completely carried out activities, and on the cumulative frequencies of the completely carried out activities. These were divided in equal parts, as homogeneously as possible in terms of data coverage following the frequency curve as presented in Figure 2.

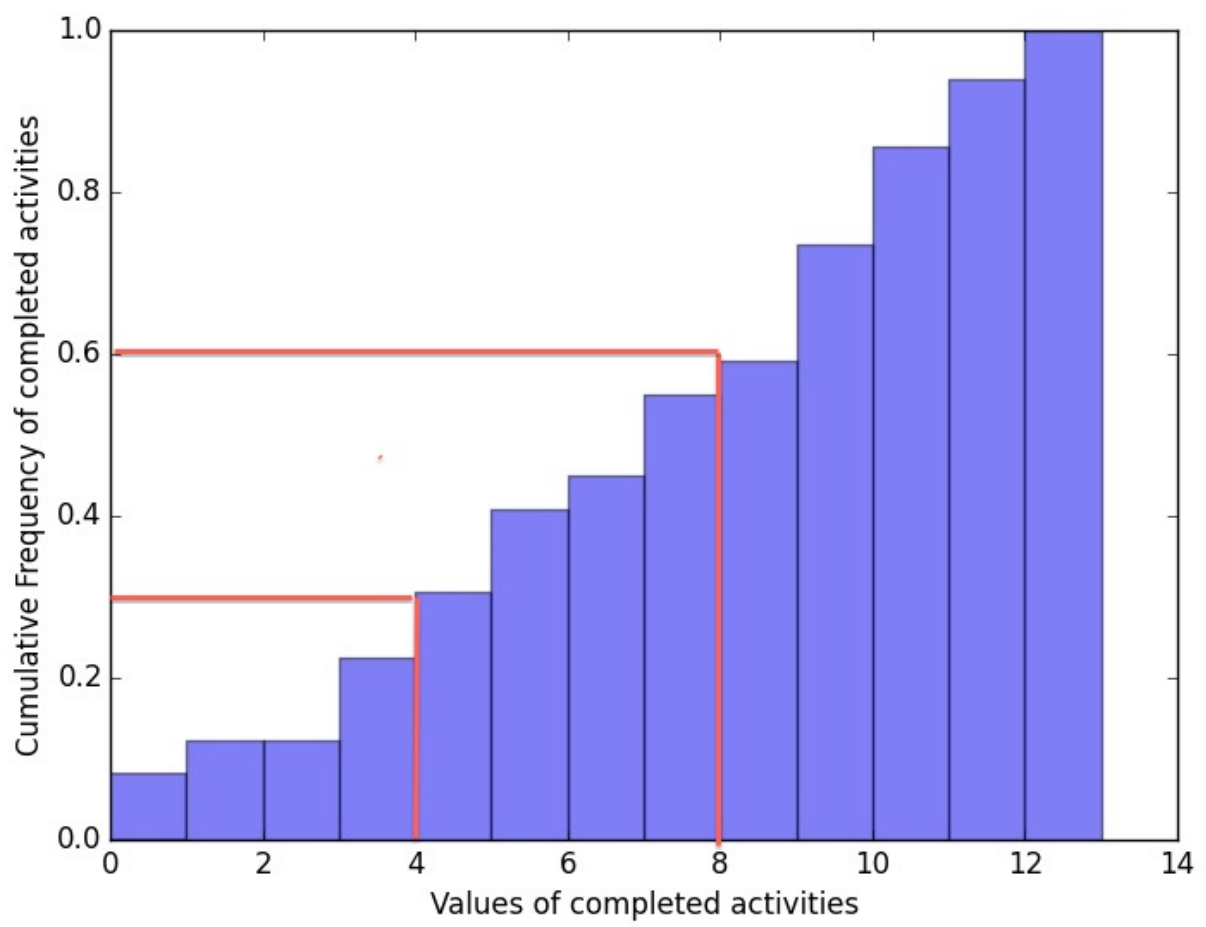

Figure 4. Cumulative frequency curve of completed carried out activities. The red lines indicate the cut-off scores between the autonomy classes which have been based on the the analyses of the participant's performances in terms of completely carried out activities, and on the cumulative frequencies of the completely carried out activities. These were divided in equal parts, as homogeneously as possible in terms of data coverage following the frequency curve. 
This division into three equal classes resulted in the following cut-off scores: From 13 to 8 completed activities was a good performance, meaning highly independent; from 7 to 4 completed activities was an intermediate performance; and below 4 completed activities was a poor performance, representing highly dependent in daily living activities. The grouping of the participants was done blinded from their diagnosis group in order to avoid classification baises, i.e. more likely to classify a $\mathrm{HC}$ as a 'good' performer. A HC subject could sometimes show a mediocre IADL performance on the assessment and in turn a MCI subject could show a good IADL performance. Taking into consideration that the objective of the assessment was to stage autonomy levels and not necessarily disease progression, even though they are associated, it was important to make that differentiation. Table 4 shows the classification results based on the participants IADL scenario performances with their diagnosis group, as well as their average amount of completely carried out activities. Twenty-two participants from which $13 \mathrm{HC}$ and 9 MCI subjects with an average of 10.04 correctly carried out activities were classified as good performer, 16 participants from which $1 \mathrm{HC}, 10 \mathrm{MCI}$ and $5 \mathrm{AD}$ subjects with an average of 5.5 correctly carried out activities were classified as intermediate performer and 11 participants from which 4 $\mathrm{MCI}$ and $7 \mathrm{AD}$ patients with an average of 1.5 correctly carried out activities were classified as poor performer. 
Table 4. Ecological Assessment results

\begin{tabular}{lccccl}
\hline & N & HC & MCI & AD & $\begin{array}{l}\text { Activites } \\
\text { completed } \\
\text { (in mean } \pm \text { SD) }\end{array}$ \\
\hline $\begin{array}{l}\text { Good } \\
\text { performance } \\
\begin{array}{l}\text { Intermediate } \\
\text { performance }\end{array}\end{array}$ & 22 & 13 & 9 & - & $10.04 \pm 1.4$ \\
$\begin{array}{l}\text { Poor } \\
\text { performance }\end{array}$ & 11 & 1 & 10 & 5 & $5.5 \pm 1.2$ \\
\hline
\end{tabular}

Validation of the Event Recognition System

Table 5 presents the results of the evaluation of the Event Video Monitoring System (EMS) with respect to its precision at detecting correctly the events of the clinical protocol (scenario 1: Single and Dual task and scenario 2: the number of activities of daily living) annotated by domain experts while watching the experiment video. 
Table 5. Activity/Event Detection Performance

\begin{tabular}{lll}
\hline Events & Recall $(\%)$ & $\begin{array}{l}\text { Precision } \\
(\%)\end{array}$ \\
\hline $\begin{array}{l}\text { Scenario 01 } \\
\text { Mono Task }\end{array}$ & 100.0 & 88.0 \\
Dual Task & 100.0 & 98.0 \\
$\begin{array}{l}\text { Scenario 02 } \\
\text { Searching Bus line }\end{array}$ & 58.0 & \\
Medication preparation & 87.0 & 62.5 \\
Watering Plant & 80.0 & 93.0 \\
Reading Article & 60.0 & 63.0 \\
Preparing Drink & 90.0 & 88.0 \\
Talk on Phone & 89.0 & 68.0 \\
\hline
\end{tabular}

Scenario 1, the single and dual task obtained the precision rates of $88 \%$ and $98 \%$. From all proposed activities, 'Medication preparation' was detected with the highest precision of $93 \%$ followed by 'Using the phone' with $89 \%$ and 'Reading an article with $88 \%$.

\section{Classification of participant cognitive status}

Table 6 presents the classification results for autonomy assessment and dementia diagnosis. The classification procedure was intrinsically based on the features automatically extracted from the physical tasks and IADLs performed by the participant during the clinical protocol. For comparison purposes we have also learned two classifiers based only on behavioral data of the physical task or IADL derived data. We hypothesized that combining the information from the two scenarios of the protocol increases the accuracy of the classification since they 
provide different but complementary information about a participant performance at daily living activities, e.g., motor and cognitive performances. For the three classifiers the data set is the same and contains 49 patients in total. The overall activities were correctly automatically detected with high sensitivity and precision results as previously described.

In the Autonomy classification task the following features were employed:

- Single Task Total Duration,

- Single Task Gap Duration,

- Single Task Standard Deviation Steps,

- Dual Task Gap Duration.

- Dual Task Max Steps,

- Person using PharmacyBasket Frequency of Event (frequency),

- Person using PharmacyBasket Duration of Event (seconds).

For the Diagnosis classification, the set of features was:

- Age,

- Single Task Average Steps,

- Single Task Speed Average from Centroid Information,

- Dual Task Max Steps,

- Dual Task Min Steps,

- Person reading inChairReadingTable Duration of Event (Frames),

The classifier for Dementia Diagnosis task obtained an accuracy of $61.22 \%$ when using only features based on IADL (Scenario 2), and of $75.51 \%$ when just extracting features from Physical Tasks (Scenario 1). The accuracy rate increased up to $73.46 \%$ when combining features from both scenarios. However, the higher recognition rates were found for the classifier learned for autonomy classification; 
based on simply the automatically extracted video features from Scenario 2, 77.55\% accuracy was obtained and 75\% accuracy for scenario 1 . The highest accuracy rate of $83.67 \%$ was obtained when combining directed tasks and IADLs.

Table 6. Classification results

\begin{tabular}{|l|l|l|l|}
\hline $\begin{array}{l}\text { Autonomy } \\
\text { assessment }\end{array}$ & \multicolumn{3}{|c|}{ Input Data } \\
\hline Performance & $\begin{array}{l}\text { Scenario } \\
\mathbf{0 1}\end{array}$ & Scenario 02 & $\begin{array}{l}\text { Both } \\
\text { Scenarios }\end{array}$ \\
\hline $\begin{array}{l}\text { Correctly Classified } \\
\text { Instances }\end{array}$ & 37 & $38(77.551 \%)$ & 41 \\
\hline $\begin{array}{l}\text { Incorrectly Classified } \\
\text { Instances }\end{array}$ & $(75.51 \%)$ & $(83.6735 \%)$ \\
\hline
\end{tabular}

\begin{tabular}{|l|l|l|l|}
\hline $\begin{array}{l}\text { Diagnosis } \\
\text { assessment }\end{array}$ & \multicolumn{3}{|c|}{ Input Data } \\
\hline Performance & $\begin{array}{l}\text { Scenario } \\
\text { 01 }\end{array}$ & Scenario 02 & $\begin{array}{l}\text { Both } \\
\text { Scenarios }\end{array}$ \\
\hline $\begin{array}{l}\text { Correctly Classified } \\
\text { Instances }\end{array}$ & 36 & & 36 \\
\hline $\begin{array}{l}\text { Incorrectly Classified } \\
\text { Instances }\end{array}$ & $(73.4694 \%)$ & $30(61.2245 \%)$ & $(73.4694 \%)$ \\
\hline
\end{tabular}

\section{DISCUSSION}

The present study suggests that it is possible to assess autonomy in IADL functioning with the help of an an event monitoring system and that simply based on the extracted video features different autonomy levels can be classified highly accurately. The results obtained are significantly high for a correct assessment of autonomy but also cognitive status in terms of diagnosis. 
This means, that 'the proposed system' may become a very useful tool providing clinicians with diagnostic relevant information and improve autonomy assessment in AD or MCI patients in real time decreasing observer biases.

The results demonstrate further that gait analysis applied to IADL assessment may provide a reliable and precise methodology to assess patients functioning in daily life, which could be used at both diagnostic and rehabilitation level. All extracted elements of the clinical protocol, the kinetic parameters from the single and dual task, as well as the selected features from the IADL task, are important to take into consideration in the automatized analyses in order to assess and further predict accurately autonomy performance of patients. This means that in extractable gait features such as 'Single Task Standard Deviation Steps' and 'Dual Task Gap Duration' lies relevant information about a patient's capacity to perform IADLs and therefore his or her autonomy level. These features added up to the automatically detected lengths and frequencies of the to carry out activities result in a highly accurate autonomy classification rate of almost $84 \%$, allowing soon an almost fully automatized functional assessment in clinical practice. The work of Gillain et al. illustrates in the same manner that it may be possible to determine different cognitive profiles, and hence autonomy levels, by the measurement of gait parameters [43]. This confirms previous research findings that gait ability and cognitive functions are interrelated, and in particular executive functions and gait speed [44-47]. Gait impairment is already known to be a common characteristic of patients with MCI [48] and represents a risk factor for conversion to $\mathrm{AD}$ [49-50]. Therefore, changes in these motor functions may be useful in the early detection of dementia during preclinical stages and easily measurable by sensor technologies. 
Furthermore, significant correlations were found between the parameters of initiated and completed activities and most neuropsychological test results, particularly with MMSE and FAB scores showing that group differences even with just a small sample size could be detected when using such techniques, and this when regular assessment tools such as the IADL-E questionnaire lacked sensitivity to detect these group differences. Finally, high single activity detection rates, up to $93 \%$ for the 'Medication preparation' activity, could be achieved validating further the use of EMS for evaluation and monitoring purposes.

The study's results were consistent with previous work where with a sensitivity of $85.31 \%$ and a precision of $75.90 \%$ the overall activities were correctly automatically detected [31] although the present study was with a larger cohort and included as well AD patients.

Similar work, hence quantitative assessments of IADL performance, has been done using a different technique by Wadley et al. with the results that across timed IADL domains, MCI participants demonstrated accuracy comparable with cognitively normal participants but took significantly longer to complete the functional activities [51].

This suggests that slower speed in task execution could explain the differences found in the extracted features and thus, represent an important component and early marker of functional change already in MCI patient. A component that would not be clearly identified using traditional measurements of daily function, but could be easily spotted using the quantitative and unbiased EMS data. Likewise, Stucki et al. proved feasibility and reliability of a non-intrusive web-based sensor system for the recognition of Activities of Daily Living (ADL) and the estimation of a patient's self-dependency with high classification precision rates (up to 90\%) [52]. Bang et al. used multiple sensor fusion (pressure sensors, passive infrared sensors and worn 
accelerometers) for automatized ADL detection with achieved accuracy rates of up to $90 \%$ [53]. Nevertheless, these studies were carried out with a very small group sample of healthy and in average younger participants. Until now, the clinical assessment of functional changes in $\mathrm{AD}$ and MCI patients has traditionally relied on scales and questionnaires that are not always sensitive to the earliest functional changes. This leads to an important need to develop improved methods to measures these changes, ideally at the earliest stages. Therefore, recently research efforts have been placed on studies finding new innovative and more objective ways to measure functional and cognitive changes associated with $\mathrm{AD}$ [54-58].

The main interest of the present study was to demonstrate the practical application of the use of such a video monitoring system in clinical practice. Now, once the system's use has been validated by significant correlation with neuropsychological test scores, particularly for executive functioning, and highly accurate detection rates, it can be employed as a supportive assessment tool within clinical routine check-ups also on a rehabilitation level and even move on to more naturalistic environments such as nursing homes.

The systems' extracted information can provide the clinician with direct measurements (see the list of features) indicating, once interpreted, a certain level of autonomy performance, as well as with information about possible underlying mechanisms caused by decline in certain cognitive functioning, namely executive functions which are highly associated [59]. This technique has the advantage of leaving out the clinician, who represents often in assessments a potential stress factor, completely from the evaluation site, and thus increasing ecological validity by leaving the patient alone in a more naturalistic 'living-room alike' setting. The use of sensors for the measurement of behavioral patterns reduces important assessment biases often present in clinical practice and adds objective value to the assessment procedure. 
The objective on a long term is to provide a stable system that allows to monitor patients and their autonomy at home over a longer period. The within this study validated parameters can serve as indicators for illness progression, decline in IADL performance and hence, executive functions detectable with the help of new technologies much earlier, before somebody in the family would notice and send the patient to a specialist.

The limitation of this study resides firstly in the age and education differences among the groups; the AD population was older than the other groups, and the HC and MCI group had higher levels of education. This can be partly explained by the recruitment process and that generally in clinical practice it is quite difficult to recruit young AD patients. However, age and education level differences could have had an impact on the IADL and gait performances and should therefore being taken into consideration.

Therefore, in future studies it would be important to also focus on recruiting younger $\mathrm{AD}$ patients and participants with equal education levels in order to control for this variability. Secondly, the HC subjects were recruited through the Memory Centre which means that most of the HC participants came to the centre with a memory complaint even though in their neuropsychological tests they performed within normal ranges. It has to be taken into consideration that those participants may not be completely healthy and suffer from a higher risk to convert to MCI than people that do not consult the center for a memory complaint [60].

It has to be further underlined that even if participants were alone during the IADL assessment, the simple fact of knowing that they were recorded could have had an impact on their stresslevel and thus, their performance. 
Finally, it cannot be denied that the development of such a system and its analysis program was time-consuming and expensive. Engineers worked within the European FP7 Research Program Dem@care several years on improving the system's efficacity and detection precision. However, once its usabibility in clinical practice has been further demonstrated by validation studies, its integration in routine assessment procedures is feasible, installation of such system affordable (Kinect camera and a computer) for Memory Clinics and analyses can be provided in real-time. Nevertheless, more efforts in performance evaluation of such ICTs are needed to help the industry meet user needs and researchers in considering the available technologies for clinical practice. A solid economic model is a major issue: who will pay for assistive technology? Who will install and maintain ICTs at AD patients' homes? The cost-effectiveness balance for assistive technology remains a matter of debate.

To conclude, according to the recently published review of Snyder et al, research efforts have launched large prevention trials in AD and these efforts have further clearly demonstrated a need for better and more accurate measures of cognitive and functional changes in people already in the earliest stages of AD [61]. In the same line, the US Food and Drug Administration elevated the importance of cognitive and functional assessments in early stage clinical trials by proposing that even in the pre-symptomatic stages of the disease, approval will be contingent on demonstrating clinical meaningfulness.

Similarly, Laske et al. argued that there is an increasing need for additional noninvasive and/or cost-effective tools, allowing identification of subjects in the preclinical or early clinical stages of $\mathrm{AD}$ who could be suitable for further cognitive evaluation and dementia diagnostics [62]. Once examined in ongoing large trials, the implementation of such tools may facilitate early and potentially more effective therapeutic and preventative strategies for AD. All this points out, the need for improved cognitive and functional outcome measures 
for clinical studies of participants with preclinical $\mathrm{AD}$ and those diagnosed with $\mathrm{MCI}$ due to $\mathrm{AD}$. With our study, we propose a new method of measuring objectively and accurately functional decline in patients from the earliest stages on with the support of the vision sensor technologies; a reliable method that could potentially, once validated through larger scale cohort studies, serve within clinical trial of new drug interventions as an endpoint measure to prove their effects on ADL function. Finally, the use of such systems could facilitate and support aging-in-place and improve medical care in general for these patients.

\section{Acknowledgments and sources of support}

This study was supported by grants from the FP7 Dem@care project, by the Innovation Alzheimer associations, by the STARS Team from the French Institute for Research in Computer Science and Automation (INRIA - Institut National de Recherche en Informatique et en Automatique, INRIA) in Sophia Antipolis, France, by the CoBTek (Cognition - Behaviour - Technology) Research Unit from the Nice Sophia-Antipolis University (UNS), the CMRR Nice team and by the platform patients of the Nice CHU member of the CIU-S. 


\section{REFERENCES}

1. Marshall, GA, Fairbanks, LA, Tekin, S, Vinters, HV, \& Cummings, JL. (2006). Neuropathologic correlates of activities of daily living in Alzheimer disease. Alzheimer Dis Assoc Disord, 20(1), 56-59.

2. Arrighi, HM, Gelinas, I, McLaughlin, TP, Buchanan, J, \& Gauthier, S. (2013). Longitudinal changes in functional disability in Alzheimer's disease patients. Int Psychogeriatr, 19.

3. Karzmark, P, Llanes, S, Tan, S, Deutsch, G, \& Zeifert, P. (2012). Comparison of the frontal systems behavior scale and neuropsychological tests of executive functioning in predicting instrumental activities of daily living. Appl Neuropsychol Adult, 19(2), 81-85.

4. Razani, J, Casas, R, Wong, JT, Lu, P, Alessi, C, \& Josephson, K. (2007). Relationship between executive functioning and activities of daily living in patients with relatively mild dementia. Appl Neuropsychol, 14(3), 208-214.

5. Dubois, B, Slachevsky, A, Litvan, I, Pillon, B. (2000). The FAB: a Frontal Assessment Battery at bedside. Neurology, 55(11), 1621-1626.

6. Tombaugh, TN. (2004). Trail Making Test A and B: normative data stratified by age and education. Arch Clin Neuropsychol, 19(2), 203-214.

7. Reppermund, S, Brodaty, H, Crawford, JD, Kochan, NA, Draper, B, Slavin, MJ, Sachdev, PS. (2013). Impairment in instrumental activities of daily living with high cognitive demand is an early marker of mild cognitive impairment: the Sydney Memory and Ageing Study. Psychol Med, 1-9.

8. Stern, Y, Hesdorffer, D, Sano, M, and Mayeux, R, Measurement and prediction of functional capacity in Alzheimer's disease. Neurology, 1990. 40(1): p. 8-14. 
9. Baddeley, A, Logie, R, Bressi, S, Della Sala, S, and Spinnler, H, Dementia and working memory. Q J Exp Psychol A, 1986. 38(4): p. 603-18.

10. Clare, L, Woods, RT, Moniz Cook, ED, Orrell, M, \& Spector, A. (2003). Cognitive rehabilitation and cognitive training for early-stage Alzheimer's disease and vascular dementia. Cochrane Database Syst Rev(4).

11. Cotelli, M, Calabria, M, \& Zanetti, O. (2006). Cognitive rehabilitation in Alzheimer's Disease.. Aging Clin Exp Res, 18(2), 141-143.

12. DeBettignies, BH, Mahurin, RK, \& Pirozzolo, FJ. (1990). Insight for impairment in independent living skills in Alzheimer's disease and multi-infarct dementia. J Clin Exp Neuropsychol, 12(2), 355-363.

13. Lawton, MP, \& Brody, EM. (1969). Assessment of older people: self-maintaining and instrumental activities of daily living. Gerontologist, 9(3), 179-186.

14. Gold, DA. (2012). An examination of instrumental activities of daily living assessment in older adults and mild cognitive impairment. J Clin Exp Neuropsychol, 34(1), 11-34.

15. Snyder, PJ, Kahle-Wrobleski, K., Brannan, S., Miller, D. S., Schindler, R. J., DeSanti, S., Ryan, J. M., Morrison, G., Grundman, M., Chandler, J., Caselli, R. J., Isaac, M., Bain, L., Carrillo, M. C. (2014). Assessing cognition and function in Alzheimer's disease clinical trials: Do we have the right tools? Alzheimers Dement, 10(6), 853-860.

16. Sikkes, SA, de Lange-de Klerk, ES, Pijnenburg, YA, Gillissen, F, Romkes, R, Knol, DL, Scheltens, P. (2012). A new informant-based questionnaire for instrumental activities of daily living in dementia. Alzheimers Dement, 8(6), 536-543.

17. Moore, DJ, Palmer, BW, Patterson, TL, \& Jeste, DV. (2007). A review of performance-based measures of functional living skills. J Psychiatr Res, 41(1-2), 97-118. 
18. Farina, E, Fioravanti, R, Pignatti, R, Alberoni, M, Mantovani, F, Manzoni, G, .Nemni, R. (2010). Functional living skills assessment: a standardized measure of high-order activities of daily living in patients with dementia. Eur J Phys Rehabil Med, 46(1), 73-80.

19. Sikkes, SA, de Lange-de Klerk, ES, Pijnenburg, YA, Scheltens, P, \& Uitdehaag, BM. (2009). A systematic review of Instrumental Activities of Daily Living scales in dementia: room for improvement. J Neurol Neurosurg Psychiatry, 80(1), 7-12.

20. Robert, PH, Konig, A, Andrieu, S, Bremond, F, Chemin, I, Chung, PC, Mallea, P. (2013). Recommendations for ICT Use in Alzheimer's Disease Assessment: Monaco CTAD Expert Meeting. J Nutr Health Aging, 17(8), 653-660.

21. König, A, Satt, A, Sorin, A, Hoory, R, Derreumaux, A, Manera, V, et al. (2015). Automatic speech analysis for the assessment of pre-demented and Alzheimer patients. Alzheimer's \& Dementia: Diagnosis, Assessment and Disease Monitoring, 1(1) 112-124.

22. Dubois, B, Feldman, HH, Jacova, C, Dekosky, ST, BarbergerGateau, P, Cummings, J, Delacourte, A, Galasko, D, Gauthier, S, Jicha, G, Meguro, K, O'Brien, J, Pasquier, F, Robert, P, Rossor, M, Salloway, S, Stern, Y, Visser, PJ, and Scheltens, P, Research criteria for the diagnosis of Alzheimer's disease: revising the NINCDS-ADRDA criteria. Lancet Neurol, 2007. 6(8): p. 734-46.

23. Petersen, RC, Smith, GE, Waring, SC, Ivnik, RJ, Tangalos, EG, \& Kokmen, E. (1999). Mild cognitive impairment: clinical characterization and outcome. Arch Neurol, 56(3), 303-308.

24. Folstein, M, Folstein, SE, McHugh, PR. (1975). "Mini-Mental State": A practical method for grading the cognitive state of patients for the clinician. J Psychiatr Res 121, 189-198. 
25. Fahn, S, Elton, RL (1987). UPDRS program members. Unified Parkinsons Disease Rating Scale. In N. M. H. I. Florham Park (Ed.), Recent developments in Parkinsons disease (pp. 153163): M.C. Fahn S, Goldstein M, Calne DB.

26. Buschke, H. (1984). Cued recall in amnesia. J Clin Neuropsychol, 6(4), 433-440.

27. Grober, E, Buschke, H. (1987). Genuine memory deficits in dementia. Developmental Neuropsycholy, 3, 13-36.

28. Cummings, J. (1997). The neuropsychiatric inventory: assessing psychopathology in dementia patients. Neurology, 48, 10-16.

29. Erzigkeit, H, Lehfeld, H, Pena-Casanova, J, Bieber, F, Yekrangi-Hartmann, C, Rupp, M, Hindmarch, I. (2001). The Bayer-Activities of Daily Living Scale (B-ADL): results from a validation study in three European countries. Dement Geriatr Cogn Disord, 12(5), 348-358.

30. Hindmarch, I, Lehfeld, H, de Jongh, P, \& Erzigkeit, H. (1998). The Bayer Activities of Daily Living Scale (B-ADL). Dement Geriatr Cogn Disord, 9 Suppl 2, 20-26.

31. Konig, A, Crispim Junior, CF, Derreumaux, A, Bensadoun, G, Petit, PD, Bremond, F, Robert, P. (2015). Validation of an automatic video monitoring system for the detection of instrumental activities of daily living in dementia patients. $\mathrm{J}$ Alzheimers Dis, 44(2), 675-685.

32. Romdhane, R, Mulin, E, Derreumeaux, A, Zouba, N, Piano, J, Lee, L, Robert, PH. (2012). Automatic video monitoring system for assessment of Alzheimer's disease symptoms. J Nutr Health Aging, 16(3), 213-218.

33. Sacco, G, Joumier, V, Darmon, N, Dechamps, A, Derreumaux, A, Lee, JH, Robert, P. (2012). Detection of activities of daily living impairment in Alzheimer's disease and mild cognitive impairment using information and communication technology. Clin Interv Aging, 7, 539-549. 
34. Nghiem, AT, Bremond, F. . (2014). Background subtraction in people detection framework for RGB-D cameras. Paper presented at the 11th IEEE International Conference on Advanced Video and Signal-Based Surveillance, AVSS Seoul, Korea.

35. Chau, DP, Bremond, F., Thonnat, M. (2011). A multi-feature tracking algorithm enabling adaptation to context variations. Paper presented at the International Conference on Imaging for Crime Detection and Prevention, ICDP London, UK.

36. Crispim-Junior, C, Bathrinarayanan, V., Fosty, B., Konig, A., Romdhane, R., Thonnat, M., Bremond, F. (2013). Evaluation of a Monitoring System for Event Recognition of Older People. Paper presented at the 10th IEEE International Conference on Advanced Video and Signal-Based Surveillance, AVSS, Krakow, Poland.

37. Hall, MA, Holmes, G., . (2003). Benchmarking attribute selection techniques for discrete class data mining. Paper presented at the IEEE Transactions on Knowledge and Data Engineering.

38. Kohavi, R, John, G.H. . (1997). Wrappers for feature subset selection. Silicon Graphics, Inc., 2011 N. Shoreline Boulevard, Mountain view, CA 94043, USA.

39. Huang, J, Lu, J., Ling, C.X. (2003). Comparing naive Bayes, decision trees, and SVM with AUC and accuracy. Paper presented at the Third IEEE International Conference on Data Mining (ICDM).

40. John, GH, Langley, P. (1995). Estimating continuous distributions in bayesian classifiers. Paper presented at the Eleventh Conference on Uncertainty in Artificial Intelligence, San Mateo.

41. Matwin, S, Sazonova, V. (2012). Direct Comparison Between Support Vector Machine and Multinomial Naive Bayes Algorithms for Medical Abstract Classification. Journal of the American Medical Informatics Association : JAMIA 19(5). 
42. Hall, M, Frank, E., Holmes, G., Pfahringer, B., Reutemann, P., Witten, I. (2009). The WEKA Data Mining Software: An Update. SIGKDD Explorations, 11(1).

43. Gillain, S, Warzee, E., Lekeu, F., Wojtasik, V., Maquet, D. Croisier, J.-L., Salmon, E., Petermans, J. (2009). The value of instrumental gait analysis in elderly healthy, MCI or Alzheimer's disease subjects and a comparison with other clinical tests used in single and dual-task conditions Annals of Physical and Rehabilitation Medicine, 52(6), 453-474.

44. Beauchet, O, Allali, G, Launay, C, Herrmann, FR, \& Annweiler, C. (2013). Gait variability at fast-pace walking speed: a biomarker of mild cognitive impairment? J Nutr Health Aging, 17(3), 235-239.

45. Doi, T, Makizako, H, Shimada, H, Park, H, Tsutsumimoto, K, Uemura, K, \& Suzuki, T. (2013). Brain activation during dualtask walking and executive function among older adults with mild cognitive impairment: a fNIRS study. Aging Clin Exp Res, 25(5), 539-544.

46. Doi, T, Shimada, H, Makizako, H, Tsutsumimoto, K, Uemura, K, Anan, Y, \& Suzuki, T. (2014). Cognitive function and gait speed under normal and dual-task walking among older adults with mild cognitive impairment. BMC Neurol, 14, 67.

47. Montero-Odasso, M, Bergman, H, Phillips, NA, Wong, CH, Sourial, N, \& Chertkow, H. (2009). Dual-tasking and gait in people with mild cognitive impairment. The effect of working memory. BMC Geriatr, 9, 41.

48. Allan, LM, Ballard, CG, Burn, DJ, \& Kenny, RA. (2005). Prevalence and severity of gait disorders in Alzheimer's and non-Alzheimer's dementias. J Am Geriatr Soc, 53(10), 16811687.

49. Buracchio, T, Dodge, HH, Howieson, D, Wasserman, D, \& Kaye, J. (2010). The trajectory of gait speed preceding mild cognitive impairment. Arch Neurol, 67(8), 980-986. 
50. Verghese, J, Wang, C, Lipton, RB, Holtzer, R, \& Xue, X. (2007). Quantitative gait dysfunction and risk of cognitive decline and dementia. J Neurol Neurosurg Psychiatry, 78(9), 929-935.

51. Wadley, VG, Okonkwo, O, Crowe, M, \& Ross-Meadows, LA. (2008). Mild cognitive impairment and everyday function: evidence of reduced speed in performing instrumental activities of daily living. Am J Geriatr Psychiatry, 16(5), 416424.

52. Stucki, RA, Urwyler, P, Rampa, L, Muri, R, Mosimann, UP, \& Nef, T. (2014). A web-based non-intrusive ambient system to measure and classify activities of daily living. J Med Internet Res, 16(7), e175.

53. Bang, S, Kim, M, Song, SK, \& Park, SJ. (2008). Toward real time detection of the basic living activity in home using a wearable sensor and smart home sensors. Conf Proc IEEE Eng Med Biol Soc, 2008, 5200-5203.

54. Goldberg, TE, Koppel, J, Keehlisen, L, Christen, E, DresesWerringloer, U, Conejero-Goldberg, C, Davies, P. (2010). Performance-based measures of everyday function in mild cognitive impairment. Am J Psychiatry, 167(7), 845-853.

55. López-de-Ipiña, K, Alonso, J.B., Barroso, N., Faundez-Zanuy, M., Ecay, M., Solé-Casals, J., Travieso,C.M., Estanga, A., Ezeiza, A. . (2012). New Approaches for Alzheimer's Disease Diagnosis Based on Automatic Spontaneous Speech Analysis and Emotional Temperature. Ambient Assisted Living and Home Care Lecture Notes in Computer Science 7657, 407414.

56. Vestal, L, Smith-Olinde, L, Hicks, G, Hutton, T, \& Hart, J, Jr. (2006). Efficacy of language assessment in Alzheimer's disease: comparing in-person examination and telemedicine. Clin Interv Aging, 1(4), 467-471. 
57. Yakhia, M, Konig, A, van der Flier, WM, Friedman, L, Robert, PH, \& David, R. (2014). Actigraphic motor activity in mild cognitive impairment patients carrying out short functional activity tasks: comparison between mild cognitive impairment with and without depressive symptoms. J Alzheimers Dis, 40(4), 869-875.

58. Zola, SM, Manzanares, CM, Clopton, P, Lah, JJ, \& Levey, AI. (2013). A behavioral task predicts conversion to mild cognitive impairment and Alzheimer's disease. Am J Alzheimers Dis Other Demen, 28(2), 179-184.

59. Marshall, GA, Rentz, DM, Frey, MT, Locascio, JJ, Johnson, KA, Sperling, RA, \& Alzheimer's Disease Neuroimaging, I. (2011). Executive function and instrumental activities of daily living in mild cognitive impairment and Alzheimer's disease. Alzheimers Dement, 7(3), 300-308.

60. Jacinto, AF, Brucki, SM, Porto, CS, Arruda Martins, M, \& Nitrini, R. (2014). Subjective memory complaints in the elderly: a sign of cognitive impairment? Clinics (Sao Paulo), 69(3), 194-197.

61. Snyder, PJ, Kahle-Wrobleski, K., Brannan, S., Miller, D. S., Schindler, R. J., DeSanti, S., Ryan, J. M., Morrison, G., Grundman, M., Chandler, J., Caselli, R. J., Isaac, M., Bain, L., Carrillo, M. C. (2014). Assessing cognition and function in Alzheimer's disease clinical trials: Do we have the right tools? Alzheimers Dement, 10(6), 853-860.

62. Laske, C, Sohrabi, HR, Frost, SM, Lopez-de-Ipina, K, Garrard, P, Buscema, M, . . . O'Bryant, SE. (2014). Innovative diagnostic tools for early detection of Alzheimer's disease. Alzheimers Dement. 


\section{CHAPTER 7}

\section{AUTOMATIC SPEECH ANALYSIS FOR THE ASSESSMENT OF PRE-DEMENTED AND ALZHEIMER PATIENTS}

Alzheimer's \& Dementia : Diagnosis, Assessment \& Disease Monitoring 1 (2015) 112-124

König, A., Satt, A., Sorin, A., Hoory, R., Toledo-Ronen, O., Derreumaux, A., Manera, V., Verhey, F., Aalten, P, Robert, P.H., David, R. 


\section{ABSTRACT}

\section{Background}

To evaluate the interest of using automatic speech analyses for the assessment of mild cognitive impairment (MCI) and early-stage Alzheimer's disease (AD).

\section{Methods}

Healthy elderly control (HC) subjects and patients with MCI or AD were recorded while performing several short cognitive vocal tasks. The voice recordings were processed, and the first vocal markers were extracted using speech signal processing techniques. Second, the vocal markers were tested to assess their "power" to distinguish among HC, $\mathrm{MCI}$, and AD. The second step included training automatic classifiers for detecting $\mathrm{MCI}$ and $\mathrm{AD}$, using machine learning methods and testing the detection accuracy.

\section{Results}

The classification accuracy of automatic audio analyses were as follows: between $\mathrm{HCs}$ and those with MCI, 79\% 6 5\%; between HCs and those with $\mathrm{AD}, 87 \% 63 \%$; and between those with MCI and those with $\mathrm{AD}, 80 \% 65 \%$, demonstrating its assessment utility.

\section{Conclusion}

Automatic speech analyses could be an additional objective assessment tool for elderly with cognitive decline. 


\section{INTRODUCTION}

Various types of dementia affect human speech and language [1] and disorders or irregularities in the language domain could be a strong predictor of disease progression [2,3]. Considering this association, reason exists to explore speech analysis as a method for early dementia diagnosis.

One avenue we investigated was the analysis of speech using software that takes as input the audio recording from a clinical consultation. Combined with other methods such as video monitoring [4] and actigraphy [5], the speech analysis tool has the potential to become a useful, noninvasive, and simple method for early dementia diagnosis [6]. These technologies enable rapid, accurate, and inexpensive monitoring over time. Noninvasive diagnosis methods will also reduce the burden on the healthcare system and improve the possibility of early dementia detection. Alzheimer's disease (AD) is diagnosed when it has reached the stage at which cognitive (i.e., episodic memory impairment) and neuropsychiatric symptoms interfere with social functioning or activities of daily living. In addition to the clinical criteria, Dubois et al [7] recently suggested that pathophysiologic biomarker evidence is also needed.

The dementia diagnosis is strongly based on clinical judgment, for which appropriate assessment instruments are of vital importance. Providing reliable additional methods to assess dementia progression in patients is of high interest, because the cognitive domains other than memory have been increasingly recognized as important outcome measures in clinical practice. Information and communication technology (ICT), in particular, automatic speech analysis, is important, because it enables the capture of patient performance and actions to accurately evaluate patients in real time. Using real life situations and applying less intrusive methods that do not require specialized personnel would also be advantageous Speech analyses 
have already been used in patients with dementia [8-10] and those with Parkinson's disease [11] to find potential vocal markers. Studies have shown that one consistently found language abnormality in early $\mathrm{AD}$ is anomia, or impaired word finding [12,13], leading to circumlocution that is evidenced in poor word list generation, in particular, for words in a given semantic category [14]. Patients with AD have difficulty accessing semantic information intentionally, which manifests itself in a manner that appears to reflect a general semantic deterioration [1].

This difficulty can affect the temporal cycles during spontaneous speech production (speech fluency) and therefore can be detectable in the hesitation and uttering of a patient [15]. Additional affected speech characteristics in patients with $\mathrm{AD}$ seem to be those related to articulation (speed in language processing) [16], prosody in terms of temporal and acoustic measures, which includes alterations in rhythm (ability to vary pitch level, pitch modulation, reduced or fluctuating rate of language output, frequent word finding pauses, a lack of initiative, and slowness) [17,18], and eventually, in later stages, phonologic fluency [19]. Some of these characteristic alterations could be detected by automatic analysis by extracting speech parameters from patients, for example, by performing cognitive vocal tasks or even recording free speech. Recently, Ahmed et al [2] tried to identify the features of speech that could be used to examine the longitudinal changes to profile impairment in patients with AD. Their study showed that progressive disruption in language integrity was detectable as early as the prodromal stage. Meilan et al [20] found that voiceless segments explained a significant portion of the variance in the overall scores obtained in the neuropsychological test. Lopez-deIpina et al [21] investigated the potential of applying artificial intelligence algorithms to patients' speech as a method to improve thediagnosis of $\mathrm{AD}$ and determine the degree of its severity, with promising results for early diagnosis and classification of patients with AD. Roark et al [22] studied different characteristics of spoken 
language that were automatically derived, such as pause frequency and duration. They demonstrated statistically significant differences between healthy subjects and subjects with mild cognitive impairment (MCI) for a number of measures. However, in these studies, the expected performance of an end-to-end voice-based dementia assessment system was not clearly demonstrated and was often limited by the sample size, method (i.e., manual transcriptions), and technologies.

The present study aimed to determine the value of automatic analyses of voice recordings during vocal tasks for the early diagnosis of AD. This was done through the Dem@Care project, a substudy of the European Community FP7 program. Within this project, ICTs are used for the assessment of patients with dementia in an ecological setting [23]. Specialized IBM speech researchers worked together in close collaboration with the clinical dementia researchers to develop a process to analyze automated speech recordings.

To detect dementia-related characteristics in human voice and speech patterns, a classifier was developed using a support vector machine to analyze the statistical properties of vocal features [24]. The classifier determined which features characterize different states of the disease. The main research objective was to determine whether automated speech and voice pattern analyses increases the accuracy, reliability, and affordability of AD early detection.

The present study analyzed voice recordings collected during cognitive vocal tasks performed by patients with AD, MCI, and healthy elderly controls (HCs). The tasks were used to determine the effectiveness of speech processing technologies to support dementia assessment. The primary objective of the study was to investigate whether a method based on automatic speech analyses can detect differences among $\mathrm{AD}, \mathrm{MCI}$, and $\mathrm{HC}$ subjects. Furthermore, we sought to determine which speech features are the most sensitive to the deterioration due to the disease. This would allow us to obtain a 
profile for the different populations to improve the differential diagnosis. The secondary objective was to evaluate which tasks are the most appropriate ones to allow the detection of differences in these speech features.

\section{METHODS}

\section{Participants}

Within the framework of the Dem@care project, speech recordings were conducted at the Memory Clinic in Nice, France. The Nice ethics committee approved the present study. Each participant gave informed consent before the first assessment. Participants aged 65 years or older were recruited through the Memory Clinic located at the geriatric department of the University Hospital.

\section{Clinical assessment}

The general cognitive status was assessed using neuropsychological tests, including the

- Mini-mental state examination (MMSE) [25]

- $\quad$ Five word test [26]

- Frontal assessment battery [27]

- Instrumental activities of daily living scale [28]

Additionally, neuropsychiatric symptoms were assessed using the neuropsychiatric inventory [29]. Apathy was assessed using the apathy inventory [30] and the apathy diagnostic criteria [31]. These tests were performed for potential postanalysis of the audio recordings investigating the effect of neuropsychiatric symptoms on the voice parameters. After the clinical assessment, the participants were categorized into 3 groups: HCs, who had complained about subjective memory problems but were diagnosed as cognitively healthy after the clinical consultation; patients with MCI; and patients who had been diagnosed with $\mathrm{AD}$. For the $\mathrm{AD}$ group, the diagnosis was determined using the National Institute of Neurological and Communicative 
Disorders and Stroke and the Alzheimer's Disease and Related Disorders Association criteria [32]. For the MCI group, diagnosis was conducted using the Petersen criteria [33]. Participants were excluded if they had any major audition or language problems or a history of head trauma, loss of consciousness, or psychotic or aberrant motor behavior.

\section{Recording protocol}

Each participant performed four spoken tasks during a regular consultation with a general practitioner while being recorded as a part of an ongoing research protocol. The tasks consisted of a counting backward task, a sentence repeating task, an image description task, and a verbal fluency task (Table 1). These tasks were chosen from the findings of previous studies [24].

The vocal tasks were recorded using an Audio Technica AT2020 USB Condenser Microphone (16-mm diaphragm, cardioid polar pattern, frequency response $20 \mathrm{~Hz}$ to $16.000 \mathrm{~Hz}$, Thomann $144 \mathrm{~dB}$ maximum sound pressure level) that was placed on a stand $10 \mathrm{~cm}$ from the participant. Each task was recorded entirely to extract specific vocal features, including pause length, verbal reaction time, and amount of silence. After recoding, the vocal features were extracted from each spoken task using both the open software tool Praat [34] and a set of purposefully developed signal processing tools. 
Table 1. The vocal tasks of the protocol

\begin{tabular}{|c|c|c|}
\hline \# & Task & Description \\
\hline 1 & Countdown & $\begin{array}{l}\text { Count backwards one by one from ' } 305 \text { ' down } \\
\text { to ' } 285 \text { ' without making a mistake }\end{array}$ \\
\hline 3 & $\begin{array}{l}\text { Picture } \\
\text { description }\end{array}$ & $\begin{array}{l}\text { Look at a picture and describe it as detailed as } \\
\text { you can in one minute }\end{array}$ \\
\hline 2 & $\begin{array}{l}\text { Sentence } \\
\text { repeating }\end{array}$ & $\begin{array}{l}\text { Repeat ten short sentences after the clinician } \\
\text { (one at a time); the first three are: }\end{array}$ \\
\hline & & $\begin{array}{l}\text { - "La montagne est enneigée en ce mois } \\
\text { - ce mars" } \\
\text { "Le chien a fait une longue promenade } \\
\text { - ce matin" } \\
\text { "Le Schtroumpf grognon est très } \\
\text { content aujourd'hui" }\end{array}$ \\
\hline 4 & $\begin{array}{l}\text { Semantic } \\
\text { fluency } \\
\text { (animals) }\end{array}$ & $\begin{array}{l}\text { Name as many animals as you can think of as } \\
\text { quickly as possible (one minute time). This } \\
\text { semantic fluency test is widely used in } \\
\text { neuropsychological assessments to evaluate } \\
\text { frontal lobe functions. }\end{array}$ \\
\hline
\end{tabular}

\section{Statistical analysis}

Demographic variables are presented as the median and interquartile range. Before analysis, the data were verified for normality, potential outliers, and missing values. Intergroup comparisons for continuous variables were performed using a nonparametric Mann-Whitney U test, because the distribution of the data was not normal. Alpha error adjustments $(\mathrm{p}<.05 / 3=.016)$ were performed using the Bonferroni correction method. Categorical testing for gender and education was calculated using the Fisher' exact test. All statistical analyses of the demographic and neuropsychological data were computed using SPSS, version 20.0, and are presented in detail in the subsequent sections. 


\section{Vocal features and analysis}

After recording, numerous vocal features were extracted from each spoken task. These features presumably covered the task-specific manifestation of dementia in the speech data. Some were similar to features described in previous studies [2,20,35-37] and others were novel. Because of the developing language-independent technology, speech recognition was not included, and only nonverbal features were targeted.

\section{Countdown and picture description}

In cognitive task 1 of the protocol, the participants were asked to count backward from " 305 " to " 285 " as fluently as they could. In cognitive task 2 , free speech was collected by asking the participants to describe a picture. Task 1 was therefore more cognitively demanding. The tasks were analyzed for the continuity of speech (i.e., longer contiguous voice segments and shorter silent segments were sought as speech features for both the countdown and the picture description tasks). We expected greater continuity for $\mathrm{HCs}$, lower continuity for those with MCI, and the lowest continuity for those with $\mathrm{AD}$. Some speech features were based on techniques reported in previous studies [2,35-38], and others were new. We derived continuity features from the length (duration) of the contiguous voice and silent segments and from the length of contiguous periodic and aperiodic segments. Voice or silence was detected using a voice activity detection algorithm, which is based on the energy envelop (intensity) of the recorded speech signal, as calculated using the Praat software [34]. Periodic versus aperiodic segments were detected using pitch contour (periodicity), calculated using the Praat software [34]. Figure 1 shows the voice and silence segments and the periodic and aperiodic segments of a typical spoken task recording. 
From that analysis we obtained four data types for each recording, reflecting each cognitive task (countdown or picture description):

- Voice segment length (in seconds)

- Silence segment length (in seconds)

- Periodic segment length (in seconds)

- Aperiodic segment length (in seconds)

For each set of the four data types (the set for the countdown and the set for the picture description), we calculated several vocal features:

- The mean of the durations (we expected longer durations of the voice and periodic segment lengths and shorter durations for the silence and aperiodic segment lengths): The comparison groups were the HC participants versus those with MCI and those with MCI versus those with AD

- The ratio mean of the durations (defined as the mean voice duration/mean silence duration, mean silence duration/mean voice duration, mean periodic duration/ mean aperiodic duration, and mean aperiodic duration/mean periodic duration, for the four data types [voice, silence, periodic, and aperiodic])

- The median of the durations and the ratio median of the durations (the same as for the mean and ratio mean but computing for the median instead)

- The standard deviation of the durations and the ratio standard deviation of the durations (similar to the mean and ratio mean)

- The sum of the durations, ratio sum of the durations (similar to the mean and ratio mean)

- Segment count

These features were derived from techniques introduced in a previous study [24], other than the ratio features, which are novel to the field of speech analysis. 


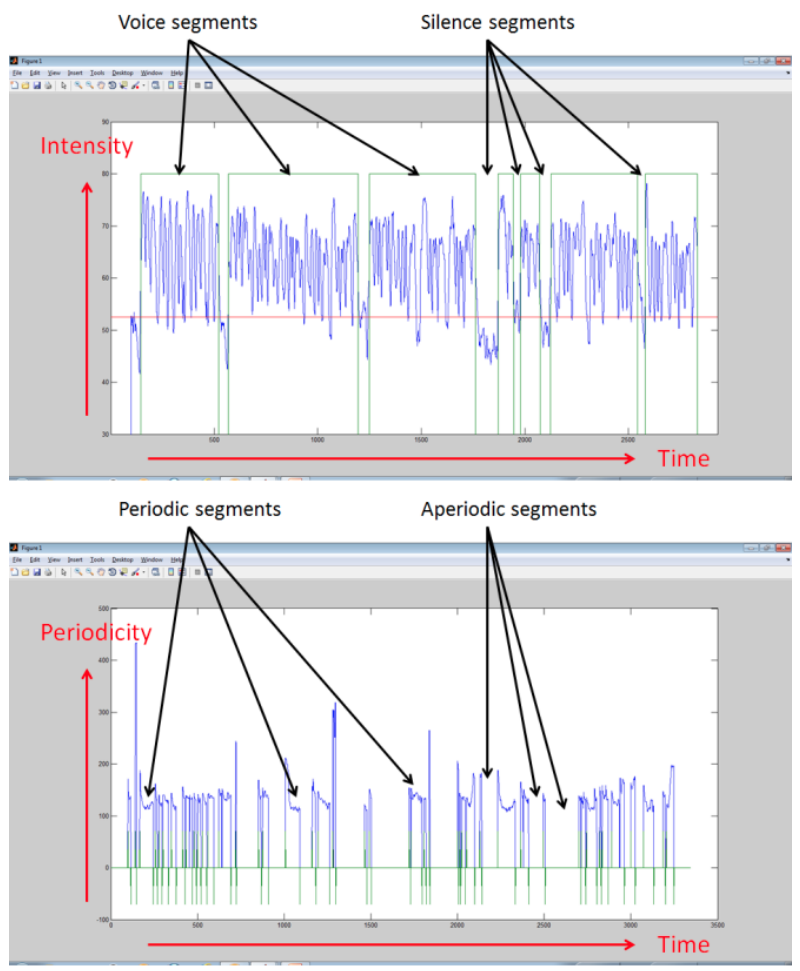

Figure 1: voice vs. silence segments, and periodic vs. aperiodic segments, of a typical spoken task recording. The horizontal axis designates time frames of 10 milliseconds; the vertical axis on the left side designates the signal intensity; the vertical axis on the right side designates the signal periodicity. Voice vs. silence, and periodic vs. aperiodic, are determined from the smoothed intensity and periodicity contours, respectively.

\section{Sentence repeating}

In cognitive task 3 , the participants had to repeat a sequence of 10 sentences spoken by the clinician one at a time while being recorded. First, speaker separation was performed on the entire recording to detect the boundary points of the individual sentences. Next, a standardized signal processing technique (dynamic time warping) was used to evaluate the time alignment — calculating the alignment curve 
between pairs of corresponding waveforms (the sentence uttered by the clinician and the corresponding sentence repeated by the participant). Figure 2 shows the time alignment for two different cases. On the left side of Figure 2, a "successful" sentence repeating case is shown. The blue curve indicates a quite smooth and regular time alignment between the clinician's signal and the participant's repeated signal. This smooth and regular curve demonstrates that the repeated sentence followed the clinician's sentence closely. The linear and second-order approximations to the timealignment curve (green line and red curve, respectively) closely match the time-alignment curve. The close matching to the line and a smooth second-order curve are measures of the time alignment "regularity." We defined the firstand second-order irregularity measures as the squared error between the time alignment (blue) curve and its linear and second-order approximations (green and red), respectively.

In contrast, the right side of Figure 2 shows the case of a poorly repeated sentence. A good match between the clinician's signal and the participant's repeated signal was only partially found along parts of the sentence. The nearly horizontal part of the blue curve represents an "insertion" by the patient: it is a segment of the participant's speech for which no alignment was found with any part of the clinician's uttered sentence. The nearly vertical part of the blue curve represents a "deletion" by the patient: it is a segment of the clinician's speech for which no alignment was found with any part in the patient's repeated sentence. Also, on the right side, the time alignment curve (blue) is highly irregular, because it differs significantly from its linear and secondorder approximations (green and red, respectively).

We expected fewer insertions, fewer deletions, and less irregularity for the HC participants compared with those with $\mathrm{MCI}$ and between those with $\mathrm{MCI}$ and those with $\mathrm{AD}$. 
We defined the following vocal measures for each pair of corresponding sentences:

- Vocal reaction time (in seconds)

- Relative length (patient sentence duration/clinician sentence duration)

- Amount of silence (0 to 1 continuous scale)

- Amount of insertions (0 to 1 scale)

- Amount of deletions (0 to 1 scale)

- Irregularity - first order (arbitrary units)

- Irregularity—second order (arbitrary units)

We calculated the vocal features of the entire sentence repeating task for each patient to compute the mean and standard deviations of the vocal measures across the different sentence pairs. These features and the use of dynamic time warping to derive the vocal features from spoken cognitive tasks are also novel to the field of speech analysis.

\section{Semantic fluency}

In cognitive task 4, the participants were asked to name as many animals as they could within 1 minute. This semantic verbal fluency test is widely used in neuropsychological assessments to evaluate frontal lobe functions [39]. Figure 3 shows the positions (in time) of the individual words detected from a sample of a participant's recording of task 4 . The word positions were estimated from the signal's intensity and periodicity using a peak detector. The signal intensity information was used to locate the peaks, and the periodicity information was used to reject the irrelevant peaks. The intensity and periodicity were calculated using the Praat software [34]. The vocal features for the semantic fluency task were defined as follows: the distances in time of the second, third, fourth, and until the ninth detected word positions from the first detected word position. 


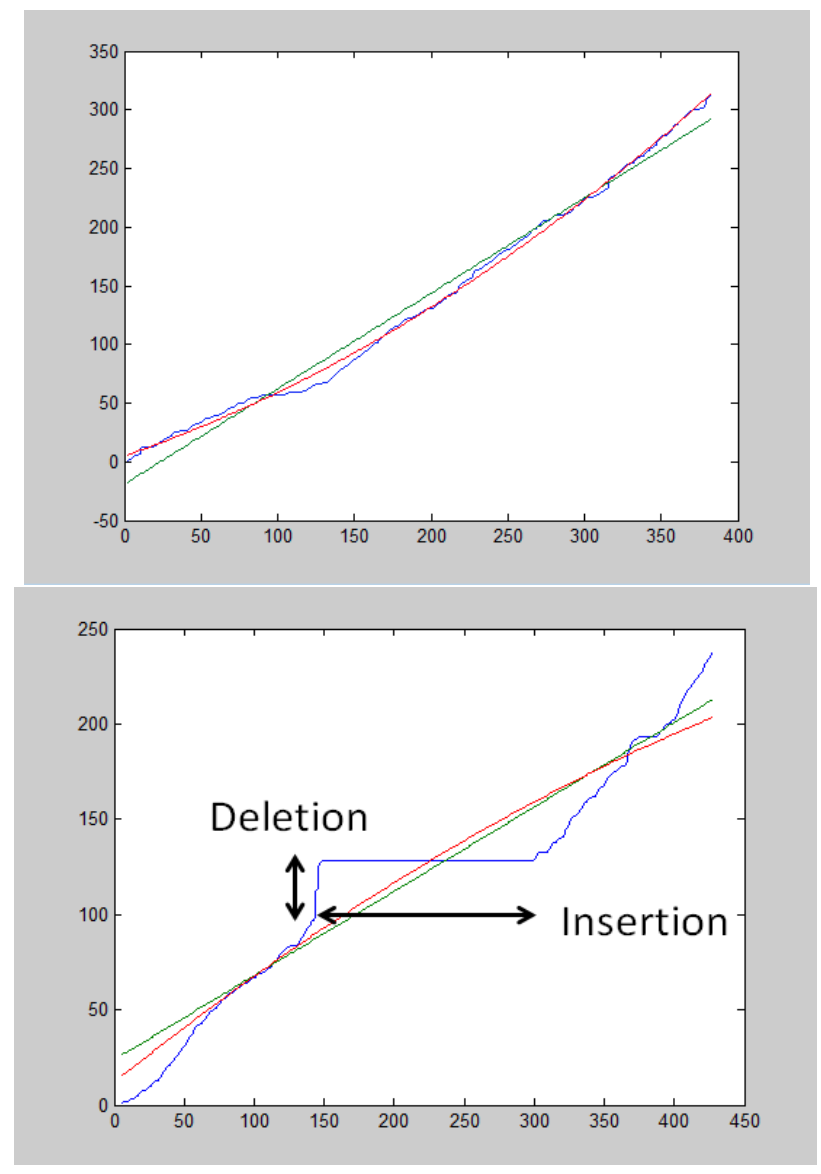

Figure 2: Time alignment between the clinician's sentence and the participant's repeated sentence. The horizontal axis the time of the participant's signal (in 10 millisecond frames); the vertical axis designates the time of the clinician's signal (in 10 millisecond frames). The blues curve shows the 'best' match (alignment) between the two signals; the green line and the red curve show the best linear and second-order approximations of the blue curve. 


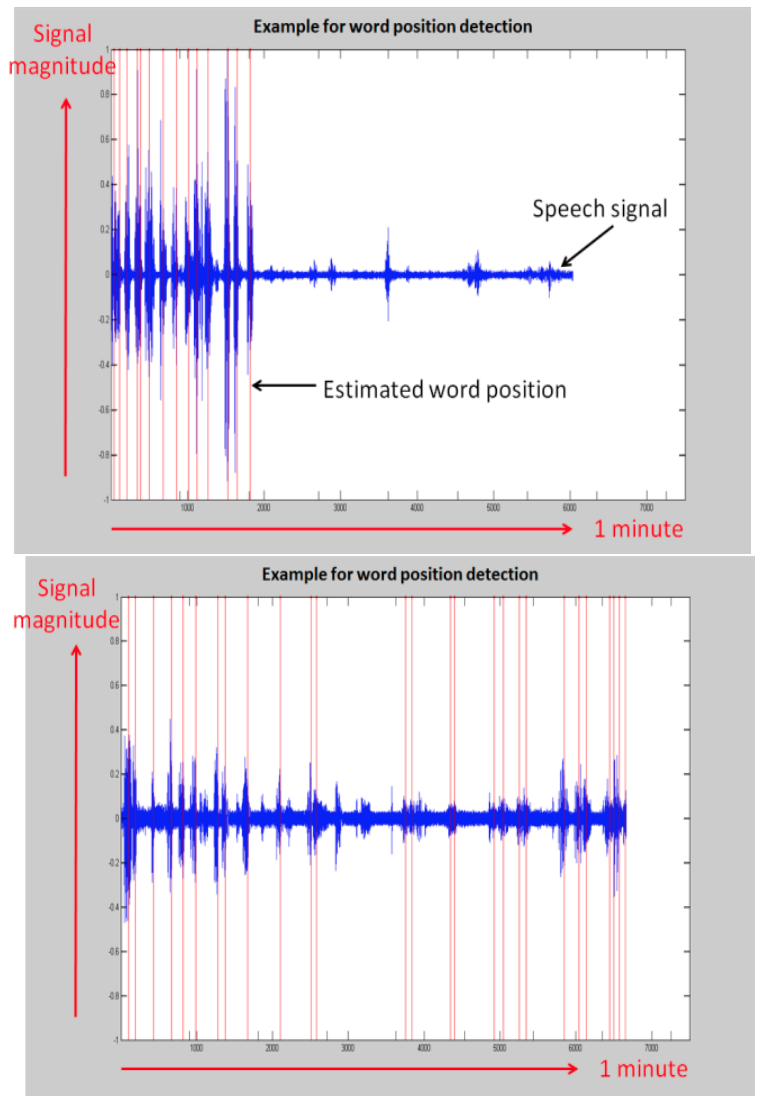

Figure 3: The time positions of the individual words along a one minute recording. On the left side: case of $\mathrm{HC}$, which demonstrates a faster rate of uttering words (assumed to be animal names), at least at the beginning of the task. On the right side, a case of $\mathrm{AD}$; it demonstrates a slower rate of uttering words at the beginning of the task.

\section{Classification procedure}

Before running a classifier, the feature selection procedure was implemented. The purpose of the feature selection procedure was to select the most meaningful vocal features and discard the "noisy" features that contribute less to the classification accuracy and might, in fact, reduce the accuracy if used. This procedure was tested to verify the outcomes. 
The feature selection techniques, known as wrapper or embedded methods [33], were found to perform poorly in terms of classification accuracy. This resulted fromthe limited size of the collected data; hence, the sparseness of the training feature vectors. The filter approach using the Mann-Whitney $U$ test was found to perform well using our data. Three different classification scenarios were evaluated, covering the three pairwise combinations of the three groups (HC, $\mathrm{MCI}$ and $\mathrm{AD})$ :

- $\mathrm{HC}$ versus $\mathrm{AD}$ : detecting $\mathrm{AD}$ from the mixed $\mathrm{HC}$ and $\mathrm{AD}$ population

- $\mathrm{HC}$ versus MCI: detecting MCI from the mixed $\mathrm{HC}$ and MCI population

- $\mathrm{MCI}$ versus $\mathrm{AD}$ : detecting $\mathrm{AD}$ from the mixed $\mathrm{MCI}$ and $\mathrm{AD}$ population

For each classification scenario, an optimal subset of vocal features was selected. The P value of the Mann-Whitney U test was calculated for each vocal feature to estimate its "value" for distinguishing between the two classes associated with the scenario. The vocal features with a $\mathrm{P}$ value less than the threshold were selected for classification, and the remaining features were ignored. All the meaningful vocal features exhibited a property in which the feature values in one group tended to be greater than those in the other group. For example, the mean silence segment lengths tended to be smaller for the HC group than for the MCI group.We used the Mann-Whitney U statistical test, because it facilitated selecting the features when this property was present. The $P$ value selection thresholds, for the three scenarios, were chosen to retain about 22 to 23 vocal features in each scenario and to ignore the rest; this quantity was found to yield good (low) classification error. Figure 4 demonstrates the different distributions of the mean silence segment lengths across the three groups: $\mathrm{HC}, \mathrm{MCI}$, and $\mathrm{AD}$. After feature selection, classification accuracy was evaluated using the support vector machine classifier 
and random subsampling based cross-validation.We report the classification accuracy in terms of the equal error rate (EER), which is the point at which the rate of type I error (a error rate, false alarm rate) equals the rate of type II error ( $b$ error rate, misdetection rate). For each of the three classification scenarios, the following procedure was implemented:

1. We randomly divided the entire data set (in the form of vocal feature vectors, containing the selected features) into test/train subsets

2. Applied regularization to the training set

3. Trained a support vector machine classifier using the regularized train set

4. Normalized the (original, not the regularized) test set according to the parameters derived from the training set

5. Ran the normalized test data through the classifier to evaluate the EER for the current random selection of test versus the training sets

6. Repeated steps 1 through 5 with different random selections of the test versus training sets

7. Calculated the mean and standard error (SE) of the EER and divided them by the EER values that corresponded to the different random selections

The training set regularization in step 2 helped to remove the outliers and increase the classification accuracy. Steps 1 to 5 were repeated 300 times to obtain stable results. We evaluated the results in terms of the EER, which is the point at which the false alarm rate equals the misdetection rate. The EER is equivalent to the point of equal specificitysensitivity (specificity-sensitivity $=1$ - EER/100). 


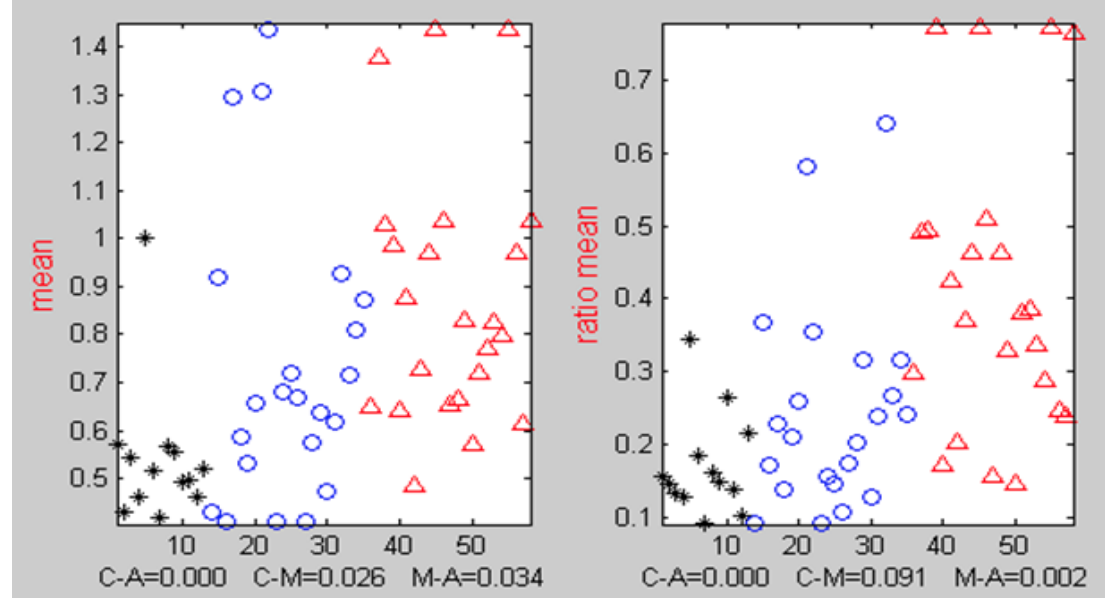

Figure 4: The distributions and the Mann-Whitney p-values of the silnce lengths. The horizontal axis designates the participant index. Different participants are designated as follows : HC by black asterisks, MCI by blue circles and $\mathrm{AD}$ by red triangles. It is seen that the values in each class tend to be higher (or lower) than in another class. Also shown the p-values for the three classification scenarios. It is also seen that ratio-mean (on the right side) helps distiguising between MCI and $\mathrm{AD}$ better than the plain arithmetic mean (on the left side).

\section{RESULTS}

\section{Participant characteristics}

Because the distribution of the data was nonparametric, the results are reported as the median and interquartile range. The characteristics of the HC group ( $\mathrm{n}=15$, age 72 years, interquartile range 60-79; MMSE 29 , interquartile range 29-30), MCI group ( $n=23$, age 73 years, interquartile range 67-79; MMSE 26, interquartile range 25-27), and AD group ( $\mathrm{n}=26$, age 80 years, interquartile range 71.75-86; MMSE 19 , interquartile range 16.75-21.25) are presented in Table 2. Categorical testing using Fisher's exact test showed no significant differences in education level among the three groups $(P<.05)$. However, if using $P<.1$, significant differences in the education 
levels were found between the HC and AD groups $(P=.062)$ and MCI and AD groups $(P=.059)$. Furthermore, after a error adjustments $(P<$ $.05 / 3=.016)$ using the Bonferroni correction method, the HC, MCI, and AD groups did not significantly differ in age. The three groups had significantly different scores on the MMSE, instrumental activities of daily living scale, verbal fluency, neuropsychiatric inventory, and apathy inventory $(P<.05)$. However, the frontal assessment battery score just differed between the MCI and AD groups and the $\mathrm{HC}$ and $\mathrm{AD}$ groups. The same results were obtained using the five word learning test. Using the apathy diagnostic criteria [31], a total of 20 participants had apathy (5 in the MCI and 15 in the $\mathrm{AD}$ group). The results in Table 3 were obtained using the crossvalidation procedure as described in the Methods section (section 2).These results reflect the average and SE of the EER values from 300 random selections of the test and train set.

\section{Vocal feature selection and analysis}

Comparing the HC and MCI groups, 23 features were selected (14 from the countdown task and 9 from the picture description task). Comparing the MCI and AD groups, 23 features were also selected (12 from the countdown task, 5 from the picture description task, and 6 from the verbal fluency task). Comparing the HC and AD groups, 22 features were selected (all from the countdown task). The selection $P$ value threshold, per classification scenario, was optimized to yield the highest average classification accuracy after cross-validation. The sentence repeating task was inferior than the other tasks in contributing to the classification accuracy. Thus, no features from that task were selected.

\section{Countdown and picture description}

The optimal features for both the countdown and picture description tasks were those that reflected speech continuity, showing longer contiguous voice segments and shorter silence segments and longer contiguous periodic segments and shorter aperiodic segments. 
According to the cognitive states, greater continuity would be expected for HCs, lower continuity for those with MCI, and the lowest for those with AD. Only a small subset of the continuity-reflecting vocal features significantly contributed to the classification accuracy. The ratio features were found to help, emphasizing the separation among the different groups ( $\mathrm{HC}, \mathrm{MCI}$, and $\mathrm{AD}$ ), more than many other features.

\section{Sentence repeating}

The most relevant features we found were determined by comparing the pair of waveforms representing the sentence uttered by the clinician and the sentence repeated by the participant. The vocal reaction time was of little benefit for patient classification into the $\mathrm{HC}$, $\mathrm{MCI}$, and AD groups. Other features were more relevant. Although these vocal features were not selected using the Mann-Whitney U test, they can be useful when redesigning the recordings of the task. These features were powerful for some of the participants across all three groups. 
Table 2

Characteristics and comparisons for $\mathrm{HC}, \mathrm{MCI}$, and $\mathrm{AD}$ groups

\begin{tabular}{|c|c|c|c|c|}
\hline Variable & All subjects $(n=64)$ & $\mathrm{HC}(\mathrm{n}=15)$ & $\operatorname{MCI}(n=23)$ & $\mathrm{AD}(\mathrm{n}=26)$ \\
\hline \multicolumn{5}{|l|}{ Gender } \\
\hline Female & 34 & 9 & 12 & 13 \\
\hline Male & 30 & 6 & 11 & 13 \\
\hline Age (y) & $76(70-82)$ & $72(60-79)$ & $73(67-79)$ & $80(71.75-86)$ \\
\hline \multicolumn{5}{|l|}{ Education category } \\
\hline Primary & $18 / 64 *, \dagger$ & $2 / 15$ & $6 / 23$ & $10 / 26$ \\
\hline Secondary & $19 / 64 *, \dagger$ & $4 / 15$ & $4 / 23$ & $11 / 26$ \\
\hline College & $14 / 64 *, \dagger$ & $4 / 15$ & $7 / 23$ & $3 / 26$ \\
\hline University & $13 / 64 *, \dagger$ & $5 / 15$ & $6 / 23$ & $2 / 26$ \\
\hline MMSE & $25(19.25-28)^{\ddagger, \S .9}$ & $29(29-30)$ & $26(25-27)$ & $19(16.75-21.25)$ \\
\hline FAB & $15(12-17)^{5,9}$ & $17(16-18)$ & $15.5(14.75-17)$ & $11(9-13.75)$ \\
\hline IADL & $4(2-4)^{\S}$ & $4(4-4)$ & $4(3-4)$ & $2(1-3)$ \\
\hline 5 Word test & $9(7-10)^{\S, \Upsilon}$ & $10(10-10)$ & $9(9-10)$ & $7(4.25-8)$ \\
\hline Verbal fluency & $13(8.75-18)^{ \pm . \S .9}$ & $22.5(17.75-25)$ & $14(11-14)$ & $8.5(6.75-11)$ \\
\hline NPI total & $3(1-8)^{\ddagger \S \S}$ & $0(0-1.25)$ & $2(1-6)$ & $8(4-16)$ \\
\hline Apathy diagnostic & $20 / 64$ & $0 / 15$ & $5 / 23$ & $15 / 26$ \\
\hline Apathy inventory & $2(2-4)^{\ddagger, \S}$ ฯ & $0(0-0)$ & $2(0-3)$ & $4(2-6)$ \\
\hline
\end{tabular}

Abbreviations: AD, Alzheimer's disease; FAB, frontal assessment battery; HC, healthy elderly control; IADL, instrumental activities of daily living questionnaire; MCI, mild cognitive impairment; MMSE, mini-mental state examination; NPI, neuropsychiatric inventory.

NOTE. All values presented as median and interquartile range or number of subjects. Group comparisons were performed using the Mann-Whitney $U$ test $(P$

$<.05)$. Categorical testing for education was analyzed using Fischer's exact test.

$* P<.1$ for $\mathrm{MCI}$ versus $\mathrm{AD}$

${ }^{\dagger} P<.1$ for $\mathrm{HC}$ versus $\mathrm{AD}$.

${ }^{\ddagger} P<.05$ for $\mathrm{HC}$ versus MCI.

${ }^{\S} P<.05$ for $\mathrm{MCI}$ versus $\mathrm{AD}$.

${ }^{\top} P<.05$ for $\mathrm{HC}$ versus AD. 


\section{Semantic fluency}

From the many features we examined, the greatest contribution to the classification accuracy was obtained from the positions (in time) of the individual words at the first part of the task. The vocal features determined from the voice and silence segment durations, as described for tasks 1 and 2, were also useful for improving the classification accuracy. This task was particularly useful for distinguishing between those with $\mathrm{MCI}$ and those with $\mathrm{AD}$ and greatly improved the classification accuracy. Its contribution to separating the $\mathrm{HC}$ and MCI groups was not significant.

Table 3. Classification accuracy results of voice based analyses

\begin{tabular}{lccc}
\hline $\begin{array}{l}\text { Classification } \\
\text { results based } \\
\text { on audio } \\
\text { analyses }\end{array}$ & Scenario & $\begin{array}{c}\text { Equal Error } \\
\text { Rate }\end{array}$ & $\begin{array}{c}\text { Equal } \\
\text { Specificity- } \\
\text { Sensitivity }\end{array}$ \\
\hline & HC vs. MCI & $21 \pm 5 \%$ & $0.79 \pm$ \\
& HC vs. AD & $13 \pm 3 \%$ & 0.05 \\
& MCI vs. AD & $20 \pm 5 \%$ & $0.87 \pm$ \\
& & & 0.03 \\
& & & $0.80 \pm$ \\
\hline
\end{tabular}

Abbreviations : HC, control subjects ; $\mathrm{MCI}$, mild cognitive impairment ; AD, Alzheimer's disease ;

\section{Classification procedure}

The classification accuracy is presented in Table 3 in terms of the EER, corresponding to the point at which the false alarm rate equaled the misdetection rate. For the classification scenario of $\mathrm{HC}$ versus MCI, the EER was $20 \% \pm 5 \%$ (SE). This corresponded to an equal specificity-sensitivity result of $0.80 \pm 0.05$ (SE). For the classification scenario of $\mathrm{HC}$ versus $\mathrm{AD}$, the EER was only $13 \% \pm 3 \%$ (SE), 206 
corresponding to a specificity-sensitivity of $0.87 \pm 0.03$ (SE). For the classification scenario of MCI versus $\mathrm{AD}$, the EER was $19 \% \pm 5 \%$ (SE), corresponding to a specificity-sensitivity of $0.81 \pm 0.05(\mathrm{SE})$.

Figure 5 depicts the receiver operating characteristics curves- the alpha error rate (false alarm rate) against the beta-error rate (misdetection rate) - for the three classification scenarios. The blue curves show the individual receiver operating characteristic curves for the different test/train set selections during the cross-validation procedure. The red curve shows the average receiver operating characteristic curve, and the point of the EER is highlighted with a red circle.

These results were further investigated statistically to evaluate whether they would generalize to new unseen data with the same statistical properties. The classifier's generalization error consists of three components [40]: (1) the classifier bias (reported in Table 3 as the mean EER); (2) the classifier variance (reported in Table 3 as the SE of the EER), and (3) the classifier generalization measure, which relates to the dependency between the test and train data across different random selections of test/train sets. The third component was very small compared with the mean EER and its SE. This implies that the reported classifier performance would generalize to a new unseen data set of the same statistical type. 

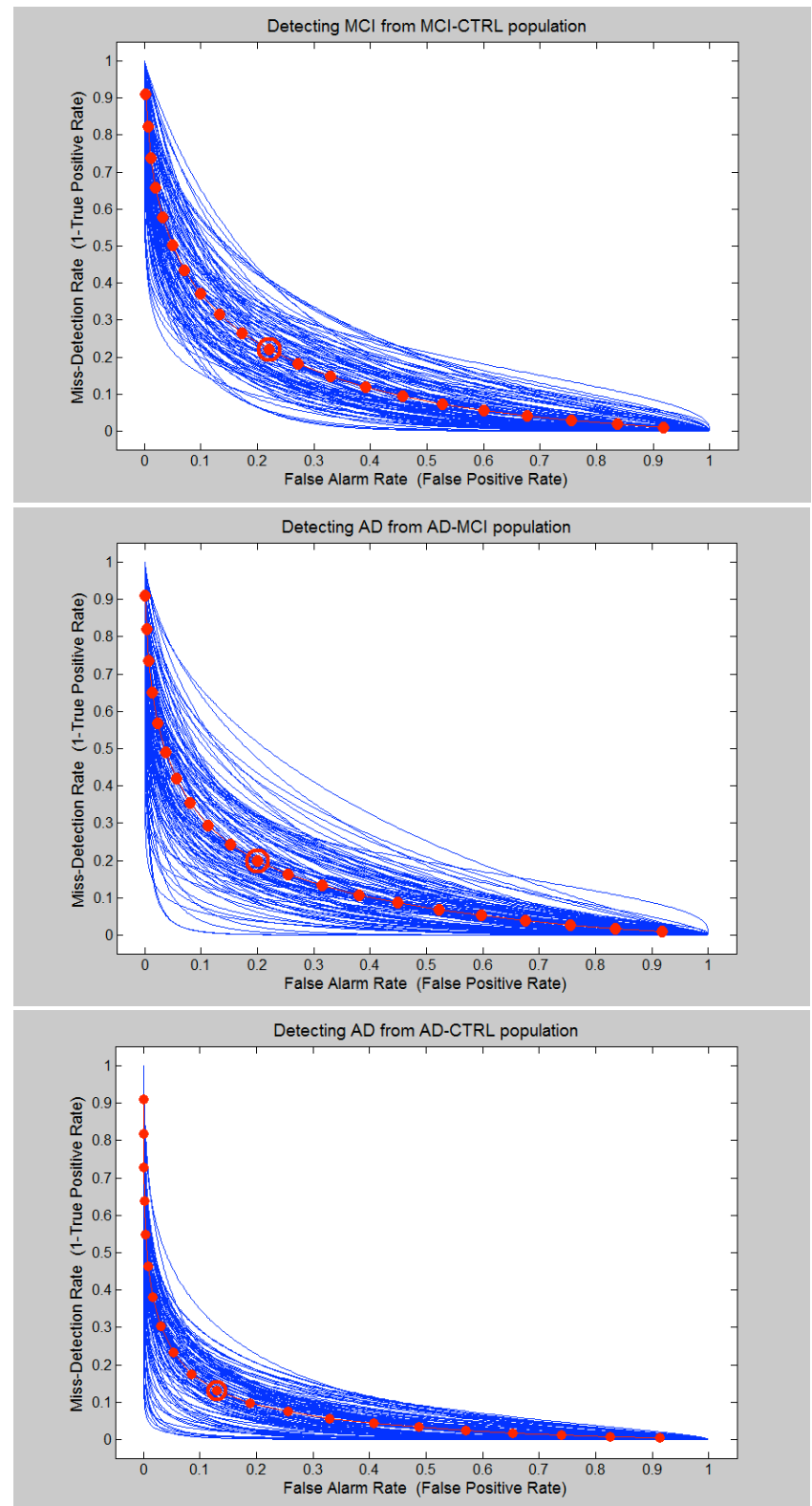

Figure 5. shows plots of the false alarm error probability (horizontal axis) vs. the misdetection error probability (vertical axis). It is one minus the standard ROC curve. 


\section{DISCUSSION}

Speech, as the main channel of human communication, has great potential to monitor people with dementia, because speech and language characteristics could represent behavioral markers of dementia variants [41].

The present study has demonstrated that speech processing technology could be a valuable supportive method for clinicians responding to the need for additional objective and automated tools to enable assessment of very early-stage dementia. High classification accuracy, $\leq 81 \%$, has been achieved, which can possibly be generalized to new unseen data with the same statistical properties. Assessing the voice and unvoiced segments tended to show the best discrimination results between the groups. However, certain features, namely the ratio features, were more informative than were the others for classification, depending on the vocal task.

The extracted vocal features that were significant to this classification were novel in the context of a dementia assessment from speech, such as the comparison of the sentence uttered by the clinician to that uttered by the patient. These were the ratio features in the countdown and picture description tasks, all the features were based on the time alignment in sentence repeating and the word location detection in semantic fluency.

Generally, the chosen vocal tasks, such as the countdown task, were appropriate and cognitively challenging. This provided the automatic speech processing technology with sufficient information to classify the participants into their diagnostic groups with precise accuracy. Good vocal tasks were optimized to find a balance between being challenging enough to detect the cognitive decline in those with early $\mathrm{AD}$ and MCI but not so challenging the HC subjects would fail, masking the differences among the populations. The countdown task 
is an example of such a balance. Verbal fluency represented a good balance for distinguishing between $\mathrm{AD}$ and $\mathrm{MCI}$, but not between $\mathrm{MCI}$ and HC. Finally, the sentence repeating task requires reworking to provide that balance, perhaps by using a different spoken content to become a significant contributor to the classification process. These observations demonstrate that the applicability of the cognitive tasks is a main factor for the speech detection software to function effectively.

The present study analyzed the differences in vocal features shown by patients with $\mathrm{AD}$ compared with those with $\mathrm{MCI}$ and $\mathrm{HCs}$ to determine whether these differences represent the characteristics of disease progression. The diagnostic utility of speech measures has been previously demonstrated by Canning et al [9], who reported $88 \%$ sensitivity and $96 \%$ specificity for $\mathrm{AD} / \mathrm{HC}$ discrimination for the category fluency. However, the results of the present study have illustrated the ability of automatic speech analyses of recorded vocal tasks to discriminate among $\mathrm{HC}, \mathrm{MCI}$, and $\mathrm{AD}$ groups. The participants in each diagnostic group performed differently on each vocal task. These differences in vocal features were not perceptible to the ear of a clinician most of the time; however, they were detectable by the developed speech analysis algorithm. Our results are in line with the findings from Gayraud et al [42], who showed that patients with $\mathrm{AD}$ differ from controls in their process of discourse production, displaying more frequent silent pauses outside the syntactic boundaries, which might be a marker of planning difficulties. Meilan et al [20] found that the increase in voiceless segments in a patient's speech is a sign that explains more than $34 \%$ of the variance in scores obtained for a specific language and memory test. Thus, this increase could be related to $\mathrm{AD}$ and to some extent to the cognitive impairments associated with it. Similar to our results, they also found that the speech of patients with AD seemed characterized by a greater proportion and number of voice breaks [38]. Furthermore, Roark et al [37] demonstrated that using multiple complementary spoken language measures can help in the early detection of MCI, underlining 
that effective automatic vocal feature extraction of audio recordings is possible such that significant differences in the feature mean values between HC and MCI can be obtained. Similarly, Lopez-de-Ipina et al [21] and Singh and Cuerden [43] reported new approaches for dementia evaluation using automatic speech analysis. Singh and Cuerden [43] reported that the mean duration of pauses, standardized phonation time, and verbal rates are useful features for discriminating between $\mathrm{HC}$ and MCI.

The results of the present study could have several explanations. As reported in the review by Taler and Phillips [44], the commonly found language deficits in those with $\mathrm{MCI}$ and $\mathrm{AD}$, shown clinically by alterations in speech production, could possibly be generated by deterioration of semantic knowledge. Certain studies have demonstrated that the pause rate in reading and spontaneous speech correlates with cognitive impairment in elderly individuals [35,37]. The hypothesis is that the number and duration of pauses indicate the cognitive load experienced by the person trying to continue the logical train of thought. D'Arcy [35] measured the pause rate on clinical and telephone speech recordings using very simplistic methods for pauses and breathing detection. These results imply that the more cognitively demanding the task, the more difficult the speech production for the patient reflected in longer pause and breathing rates, which seems in line with our results. The symptoms that seem to define the language of patients with $\mathrm{AD}$ could stem from the presence of atrophy in the medial temporal lobe that might be present from the prodromal phase of the disease [15]. Hence, abnormalities in the expression of vocal features such as voiced/unvoiced segment frequency, periodicity, amplitude, and so forth might represent the direct characteristic consequences of such neurophysiologic changes. These prosodic variables can provide insight about the cognitive processes such as language planning, speech production and word naming, the access to lexicosematic memory, and the structural organization of semantic memory [15]. 
Early detection of these potential vocal markers could allow earlier treatment interventions that will possibly modify the progression of the disease before extensive and irreversible brain damage occurs. The existence of simple voice analysis programs could facilitate the oral language assessment in the specific parameters sought, even with specific technology for doing so. Thus, we would have to define the briefest language stimuli that best bring to light the variables that discriminate phonologic change, such as the counting down task.

One major advantage of the use of such techniques is the possibility to assess a patient's state in an unobtrusive, less stressful, and more natural method. For example, by recording the patient during a regular consultation or in an open discussion (e.g., during a telephone conversation), the use can be imagined in many different contexts and situations, possibly with a direct visualized output to provide immediate feedback to the patient.

To date, the most commonly used outcome measure in clinical AD trials has been the performance on cognitive tests. Nevertheless, it might be debatable whether commonly used screening tools are sensitive enough to detect small subtle changes, either deterioration or amelioration, in a patient's state [45] within a shorter period. As dementia research has progressed, the findings have demonstrated that the disease does not just affect cognition, but also other functions, such as motor [46], vision [47], and speech [38], possibly even from the early stages. Thus, the results of the present study indicate we should consider other assessment methods in addition to the currently used methods. This would enable clinicians to cover the full spectrum of dementia when evaluating a patient, maximizing the detection capacities of sensitive changes in behavior. This could be of particular interest for pharmacologic dementia research and to monitor a patient's disease progression. 
The present study was performed in French; however, nonverbal vocal features were assessed. Also, considering that similar results that were obtained from a previous proof-of-concept study [24], performed in Greek, we have concluded that multiple languages can be supported, optionally with the requirement for per-language classifier retraining.

In the present study, the word content of speech was intentionally not used to aim for a language-independent solution that would be easily deployable. Tools to support classification and statistical analysis in the case of limited in-size and sparse data were described. The small sample size represents the major drawback of the present study. Another limitation was the age differences among the groups and the choice of the vocal tasks. It can be argued that counting backward or repeating sentences are not very natural tasks and therefore would be strongly influenced by a patient's stress level. The different tasks also required different levels of cognitive effort. For instance, counting backward is cognitively more demanding than describing a picture; thus, these differences could partly explain the high sensitivity of the voice analyses. Furthermore, we did not recruit HC participants from the general elderly population. Instead, rather we limited the HC group to those who had presented for clinical consultation and had subjective complaints. Although this choice limited the HC population size, it reflects the expected scenario in which our technology is likely to be useful: those already experiencing some (subjective) level of cognitive or functional issues, although less than the level of clinical MCI. Finally, it would be very challenging to recruit younger patients with $\mathrm{AD}$ to agematch them with those with MCI, because they represent a very small population using our memory clinic.

Finally, a relatively high number of patients with apathy were recruited, which could also have influenced the results. In the followon study, this aspect will be analyzed in more depth to investigate the effect of apathy and other relevant factors on the voice analysis results. In future work, we aim to extend the research scope, collecting 
data on a wider scale using a newly developed application that ensures a standardized recording scenario and adding new spoken cognitive tasks that aremore challenging, such as describing a positive memory. Special attention will be paid to the calibration of the audio measurements used to achieve a meaningful characterization of the status and progress of the person with dementia.We expect the newcognitive tasks to increase the classification accuracy even further.

\section{RESEARCH IN CONTEXT}

1. Systematic review: From the findings of previous studies and data reviews, we noted that various types of dementia and MCI manifest as irregularities in human speech and language, even from the very early stages. Thus, they could represent strong predictors for disease presence and progression. However, until now, only a few studies have investigated the potential utility of using automatic speech analysis for the assessment and detection of early-stage AD and MCI.

2. Interpretation: The obtained group classification accuracy of the automatic audio analyses, which were based on vocal features extracted from recorded vocal cognitive tasks, was relatively high at up to $87 \% 63 \%$. This demonstrates the value of such techniques for accurate automatic differentiation among HC, MCI, and AD.

3. Future directions: Additional studies are needed with larger population sizes to improve the classification accuracy and to investigate new and improved vocal tasks, signal processing tools, and pattern recognition tools. 


\section{Acknowledgments}

This study was supported by grants from the FP7 Dem@care project (grant 288199), the Innovation Alzheimer Associations, the IBM Speech Laboratory in Haifa, Israel, the Cognition Behaviour Technology Research Unit from the Nice Sophia-Antipolis University (UNS), the Memory Resource and Research Centre Nice team, and by the platform patients of the Nice CHU member of the CIU-S. 


\section{REFERENCES}

1. Braaten AJ, Parsons TD, McCue R, Sellers A, Burns WJ. Neurocognitive differential diagnosis of dementing diseases: Alzheimer's dementia, vascular dementia, frontotemporal dementia, and major depressive disorder. Int J Neurosci 2006;1 16:1271-93.

2. Ahmed S, Haigh AM, de Jager CA, Garrard P. Connected speech as a marker of disease progression in autopsy-proven Alzheimer's disease. Brain 2013; 136(Pt 12):3727-37.

3. Forbes KE, Venneri A, Shanks MF. Distinct patterns of spontaneous speech deterioration: An early predictor of Alzheimer's disease. Brain Cogn 2002; 48:356-61.

4. Sacco G, Joumier V, Darmon N, Dechamps A, Derreumaux A, Lee JH, et al. Detection of activities of daily living impairment in Alzheimer's disease and mild cognitive impairment using information and communication technology. Clin Interv Aging 2012; 7: 539-49.

5. Yakhia M, Konig A, van der Flier WM, Friedman L, Robert $\mathrm{PH}$, David R. Actigraphic motor activity in mild cognitive impairment patients carrying out short functional activity tasks: Comparison between mild cognitive impairment with and without depressive symptoms. J Alzheimers Dis 2014; 40:86975.

6. Lopez-de-Ipina K, Alonso JB, Travieso CM, Sole-Casals J, Egiraun H, Faundez-Zanuy M, et al. On the selection of noninvasive methods based on speech analysis oriented to automatic Alzheimer disease diagnosis. Sensors (Basel) 2013; 13:6730-45.

7. Dubois B, Feldman HH, Jacova C, Hampel H, Molinuevo JL, Blennow $\mathrm{K}$, et al. Advancing research diagnostic criteria for Alzheimer's disease: The IWG-2 criteria. Lancet Neurol 2014; 13: 614-29. 
8. Bucks RS, Singh S, Cuerden JM, Wilcock GK. Analysis of spontaneous, conversational speech in dementia of Alzheimer type: Evaluation of an objective technique for analysing lexical performance. Aphasiology 2000; 14:71-91.

9. Canning SJ, Leach L, Stuss D, Ngo L, Black SE. Diagnostic utility of abbreviated fluency measures in Alzheimer disease and vascular dementia. Neurology 2004; 62:556-62.

10. Forbes-McKay KE, Venneri A. Detecting subtle spontaneous language decline in early Alzheimer's disease with a picture description task. Neurol Sci 2005; 26:243-54.

11. Tsanas A, Little MA, McSharry PE, Spielman J, Ramig LO. Novel speech signal processing algorithms for high-accuracy classification of Parkinson's disease. IEEE Trans Biomed Eng 2012; 59:1264-71.

12. Barr A, Brandt J.Word-list generation deficits in dementia. J Clin Exp Neuropsychol 1996; 18:810-22.

13. Reilly J, Peelle JE, Antonucci SM, Grossman M. Anomia as a marker of distinct semantic memory impairments in Alzheimer's disease and semantic dementia. Neuropsychology 2011; 25:413-26.

14. Mendez MF, Cummings JL. Dementia: A Clinical Approach. 3rd ed. Boston: Butterworth-Heinemann; 2003.

15. Hoffmann I, Nemeth D, Dye CD, Pakaski M, Irinyi T, Kalman J. Temporal parameters of spontaneous speech in Alzheimer's disease. Int J Speech Lang Pathol 2010; 12:29-34.

16. Cummings JL, Benson DF. Dementia: A Clinical Approach. 2nd ed. Boston: Butterworth-Heinmann; 1992.

17. Horley K, Reid A, Burnham D. Emotional prosody perception and production in dementia of the Alzheimer's type. J Speech Lang Hear Res 2010; 53:1132-46.

18. Martinez-Sanchez F, Garcia Meilan JJ, Perez E, Carro J, Arana JM. Expressive prosodic patterns in individuals with Alzheimer's disease. Psicothema 2012; 24:16-21. 
19. Henry JD, Crawford JR, Phillips LH. Verbal fluency performance in dementia of the Alzheimer's type: A metaanalysis. Neuropsychologia 2004; 42:1212-22.

20. Meilan JJ, Martinez-Sanchez F, Carro J, Sanchez JA, Perez E. Acoustic markers associated with impairment in language processing in Alzheimer's disease. Span J Psychol 2012; 15:487-94.

21. Lopez-de-Ipi na KA, Alonso JB, Sol_e-Casals J, Barroso N, Faundez M, Ecay-Torres M, et al. A new approach for Alzheimer's disease diagnosis based on automatic spontaneous speech analysis and emotional temperature. Ambient Assist Living Home Care 2012; 7657:407-14.

22. Roark B, Mitchell M, Hosom JP, Hollingshead K, Kaye J. Spoken language derived measures for detecting mild cognitive impairment. IEEE Trans Audio Speech Lang Process 2011; 19:2081-90.

23. Dementia Ambient Care: Multi-Sensing Monitoring for Intelligent Remote Management and Decision Support. Available at: http:// www.demcare.eu/. Accessed March 20, 2015.

24. Satt A, Sorin A, Toledo-Ronen O, Barkan O, Kompatsiaris I, Kokonozi A, et al. Evaluation of speech-based protocol for detection of early-stage dementia. In: Bimbot $\mathrm{F}$, Cerisara C, Fougeron C, Gravier G, Lamel L, Pellegrino F, et al (eds): INTERSPEECH. Presented at the 14th Annual Conference of the International Speech Communication Association, Lyon, France, August 25-29, 2013; ISCA, 2013:1692-1696.

25. Folstein MF, Folstein SE, McHugh PR. "Mini-mental state": A practical method for grading the cognitive state of patients for the clinician. J Psychiatr Res 1975; 12:189-98. 
26. Robert PH, Schuck S, Dubois B, Lepine JP, Gallarda T, Olie JP, et al. Validation of the Short Cognitive Battery (B2C): Value in screening for Alzheimer's disease and depressive disorders in psychiatric practice. Encephale 2003; 29(3 Pt 1):266-72.

27. Dubois B, Slachevsky A, Litvan I, Pillon B. The FAB: A frontal assessment battery at bedside. Neurology 2000; 55:1621-6.

28. Mathuranath PS, George A, Cherian PJ, Mathew R, Sarma PS. Instrumental activities of daily living scale for dementia screening in elderly people. Int Psychogeriatr 2005;17:461-74.

29. Cummings JL, Mega MS, Gray K, Rosemberg-Thompson S, Gornbein T. The neuropsychiatric inventory: Comprehensive assessment of psychopathology in dementia. Neurology 1994; 44:2308-14.

30. Robert PH, Clairet S, Benoit M, Koutaich J, Bertogliati C, Tible O, et al. The apathy inventory: Assessment of apathy and awareness in Alzheimer's disease, Parkinson's disease and mild cognitive impairment. Int $\mathrm{J}$ Geriatr Psychiatry 2002;17:1099-105.

31. Mulin E, Leone E, Dujardin K, Delliaux M, Leentjens A, Nobili F, et al. Diagnostic criteria for apathy in clinical practice. Int J Geriatr Psychiatry 2011;26:158-65.

32. McKhann G, Drachman D, Folstein M, Katzman R, Price D, Stadlan EM. Clinical diagnosis of Alzheimer's disease: Report of the NINCDS-ADRDAWork Group under the auspices of Department of Health and Human Services Task Force on Alzheimer's Disease. Neurology 1984; 34:939-44.

33. Petersen RC, Smith GE, Waring SC, Ivnik RJ, Tangalos EG, Kokmen E. Mild cognitive impairment: Clinical characterization and outcome. Arch Neurol 1999; 56:303-8.

34. Boersma $\mathrm{P}$ and Weenink D. Praat: doing phonetics by computer. Available at: www.fon.hum.uva.nl/praat. Accessed May 15, 2013. 
35. D'Arcy S, Rapcan V, P_enard N, Morris ME, Reilly RB, Robertson IH. Speech as a means of monitoring cognitive function of elderly subjects. In: INTERSPEECH. Presented at the Ninth Annual Conference of the International Speech Communication Association, Brisbane, Australia, September 22-26, 2008.

36. Rapcan V. The use of telephone speech recordings for assessment and monitoring of cognitive function in elderly people. In: INTERSPEECH. Presented at the 10th Annual Conference of the International Speech Communication Association, Brighton, United Kingdom, September 6-10, 2009.

37. Roark B. Automatically derived spoken language markers for detecting mild cognitive impairment. Presented at the Second International Conference on Technology and Aging (ICTA), Toronto, Canada, 2007.

38. Meilan JJ, Martinez-Sanchez F, Carro J, Lopez DE, MillianMorell L, Arana JM. Speech in Alzheimer's disease: Can temporal and acoustic parameters discriminate dementia? Dement Geriatr Cogn Disord 2014; 37:327-34.

39. Monsch AU, Bondi MW, Butters N, Salmon DP, Katzman R, Thal LJ. Comparisons of verbal fluency tasks in the detection of dementia of the Alzheimer type. Arch Neurol 1992; 9:12538.

40. Bengio Y. No unbiased estimator of the variance of K-fold cross-validation. J Machine Learn Res 2004; 5:1089-105.

41. Forbes-McKaya K, Shanksa MF, Venneria A. Profiling spontaneous speech decline in Alzheimer's disease: A longitudinal study. Acta Neuropsychiatr 2013; 25:320-7.

42. Gayraud F, Lee HR, Barkat-Defradas M. Syntactic and lexical context of pauses and hesitations in the discourse of Alzheimer patients and healthy elderly subjects. Clin Linguist Phon 2011; 25:198-209. 
43. Singh SB, Bucks RS, Cuerden J. Evaluation of an objective technique for analysing temporal variables in patients with Alzheimer's spontaneous speech. Aphasiology 2001; 15:57183.

44. Taler V, Phillips NA. Language performance in Alzheimer's disease and mild cognitive impairment: A comparative review. J Clin Exp Neuropsychol 2008; 30:501-56.

45. Velayudhan L, Ryu SH, Raczek M, Philpot M, Lindesay J, Critchfield M, et al. Review of brief cognitive tests for patients with suspected dementia. Int Psychogeriatr 2014; 26:1-16.

46. Kuhlmei A, Walther B, Becker T, Muller U, Nikolaus $T$. Actigraphic daytime activity is reduced in patients with cognitive impairment and apathy. Eur Psychiatry 2013; 28:947.

47. Verheij S, Muilwijk D, Pel JJ, van der Cammen TJ, MattaceRaso FU, van der Steen J. Visuomotor impairment in earlystage Alzheimer's disease: Changes in relative timing of eye and hand movements. J Alzheimers Dis 2012;30:131-43. 
222 


\section{PART III}

\section{CONCLUSION AND FUTURE}

IMPLICATIONS 
224 


\section{CHAPTER 8}

\section{THE ROLE OF INFORMATION AND COMMUNICATION TECHNOLOGIES IN CLINICAL TRIALS WITH PATIENTS WITH ALZHEIMER'S DISEASE AND RELATED DISORDERS}

Frontiers in Aging Neuroscience, 2015, 7:110

Alexandra König, Guillaume Sacco, Gregory Bensadoun, Francois Bremond, Renaud David, Frans Verhey, Pauline Aalten, Philippe Robert, Valeria Marena 


\begin{abstract}
Clinical trials conducted to test the efficacy of treatments for Alzheimer's disease (AD) has so far given mostly negative results. It has been proposed that the inclusion of patients in the late stages of the disease, together with the low sensitivity of the classical outcome measures (e.g., dementia conversion rate) may be partially responsible for these findings.
\end{abstract}

In order to progress in the validation of treatments for $\mathrm{AD}$, better outcome measures for cognitive and functional changes are needed in the early stages of the disease. Therefore, we face an increasing need for additional population-based screening with simpler and timelier adapted, non-invasive and cost-effective tools allowing early identification of subjects in preclinical stages of $\mathrm{AD}$ and monitoring of the disease progression and treatment effects over time.

In the present opinion paper we suggest that new Information and Communication Technologies (ICT) - such as automated speech and video analysis techniques and wearable accelerometers - may be successfully employed in clinical trials to improve the functional and cognitive assessment of these patients, thus contributing to an earlier $\mathrm{AD}$ diagnosis and providing additional ecological and objective endpoint measurements. 


\section{Introduction}

In the last decades, many promising disease-modifying treatments for Alzheimer's disease (AD) have been proposed. However, clinical trials conducted on the treatments' efficacy have not lead to any important breakthroughs. There is a growing consensus that this can, at least partially, being explained by methodological difficulties, including the inclusion of participants that are already in the later stages of the disease progression, and the selection of outcome measures - such as dementia conversion rate - which are not sensitive enough [1].

Most of the current assessment tools have been accused to be artificial, and to lack ecological validity [2]. Furthermore, test results can show variability depending on many factors, such as the patient's emotional state, and may therefore not always fully reflect a patient's capacities and the complexity of the disease, leading to delayed diagnosis [3].

Based on the Monaco CTAD expert meeting in 2012, Robert and colleagues (2013) [2] highlighted that new Information and Communication Technologies (ICT) - such as video and audio analysis techniques, computerized testing and actigraphy - may represent promising new tools to improve the functional and cognitive assessment of patients with $\mathrm{AD}$ and related disorders (see also König et al., 2014, for a recent review of studies employing ICT in this domain) [4]. However, these new technologies are still not widely employed in clinical trials for assessment purposes. In November 2014, the association Innovation Alzheimer organized a workshop with stakeholders in the field (e.g., psychiatrist, neurologists, geriatricians, psychologists, researchers, engineers and patients). The aim was to gather recommendations for the use of ICT in the different stages of clinical trials. These recommendations are available online on the website of the Association Innovation Alzheimer (http://www.innovation-alzheimer.fr/homepage/). 
Based on these recommendations, in the present opinion paper, we will highlight how ICT may be employed in clinical trials involving patients with $\mathrm{AD}$ and related disorders to improve patient's assessment and the admissibility to participate in clinical trials.

\section{The current use of ICT in clinical trials}

ICT is now widely employed in several stages of clinical trials. For instance, top pharmaceutical companies and Contract Research Organizations routinely adopt E-trainings for investigators. Patients' recruitment can take advantage of the wide employ of Electronic Health Records storing health related data [5], and E-recruitment methods employing social media and the Internet to advertise clinical trials are also starting to emerge. Similarly, data entry is now facilitated by electronic Case Report Forms, which are employed in almost the totality of the clinical trials leaded by pharmaceutical companies [6]. However, ICT is still not consistently used in clinical trials at the assessment stage.

ClinicalTrials.gov - a registry and results database of publicly and privately supported clinical studies of human participants conducted around the world - contains at present (January 2015) more than 2500 clinical trials involving participants with Mild Cognitive Impairment (MCI), AD or other dementia types. We performed a keyword-based search on these trials focusing on automated audio and video analysis techniques, actigraphy and computerized testing. Only 16 pharmaceutical trials employing ICT for assessment purposes were retrieved: 6 employing accelerometers and 10 employing computerized testing. No study employing automated audio or video analysis techniques was found. While it is certainly possible that these numbers represent an underestimate, they suggest that more work should be done to bring the clinical domain closer to the frontiers of the clinical research. 


\section{ICT for assessment in clinical research}

The design of ICT solutions for the health domain is a complex process which requires the close collaboration of different stakeholders (see Figure 1). Recent evidence suggests that ICT can play a crucial role in the assessment of AD and related disorders, both in terms of providing additional information for an earlier and more accurate diagnosis, and in terms of monitoring of the disease progression [2]. For instance, it has been shown that automatic speech analysis techniques - which are analyses of verbal communication through computerized speech recognition interfaces - can represent a non-invasive and cheap method to gather information about verbal communication impairments, which are very common in patients with MCI and in the early stages of AD [7]. These techniques are useful for automating the analysis of clinical and neuropsychological tests employed to assess linguistic abilities (such as verbal fluency and sentence repetition tests). But even more importantly, they can provide additional information that cannot be gathered in a clinical setting, such as utterance duration, filler typology, and analysis of voiced and voiceless segments. Recently, we showed that the vocal markers extracted from speech signal processing techniques differed significantly among healthy elderly participants, MCI and early AD patients with an accuracy of higher than $80 \%$ [8].

Similar observations apply to automatic video-analysis techniques [9-11]. These techniques have proven to be useful for fall detection and to improve home safety [12], but recently they started to be adopted also for assessment purposes. For instance, in the FP7 project Dem@Care (www.demcare.eu) video-analysis techniques are employed to provide objective measures to assess functional impairments in activities of daily living in elderly people and patients with MCI and AD. In the classical clinical settings, autonomy in activities such as taking their medications, or handling their own finances are assessed through self-reports and informant-based questionnaires, which do not offer accurate, 
reproducible, objective, and ecological measures of functional performance. Using non-invasive 2D video recordings combined with video signal analysis, Konig et al. (2015; in press) [13] showed that activities of daily living can be accurately detected and recognized by automated activity recognition algorithms, as suggested by results highly consistent with the clinician's evaluation. Furthermore, video analysis allowed obtaining finer-grade measures such as the time spent on each activity, which could not be captured in the classical clinical evaluation. Syrali et al. (2015) [14] investigated if early signs of cognitive decline could be monitored by computer memory games with the results that healthy elderly subjects achieving lower scores in the memory game have increased level of atrophy in the temporal brain structures and showed a decreased performance in the Paired Associates Learning (PAL) test. Thus, computer games may be useful tools in early screening for cognitive decline. Similarly, online questionnaires tapping risk and protective factors in different health domains (e.g., diet, physical and cognitive activity, social engagement), such as those developed in the FP7 project InMINDD (http://www.inmindd.eu/), are starting to be employed to assess brain health and to screen for participants at risk of developing dementia.

A final example is represented by actigraphy, which is frequently used to monitor motor activity and rest-activity rhythms [15], and it has been proposed as an observer-independent evaluation method in different disorders, including dementia [16]. Specifically, its utility as an assessment tool in $\mathrm{AD}$ and related disorders has been proven to assess neuropsychiatric symptoms such as agitation [17-18], depression [19] and apathy [20]. See Konig et al. (2014) [4] for recent reviews on the use of actigraphy for assessment in patients with $\mathrm{AD}$ and related disorders. 


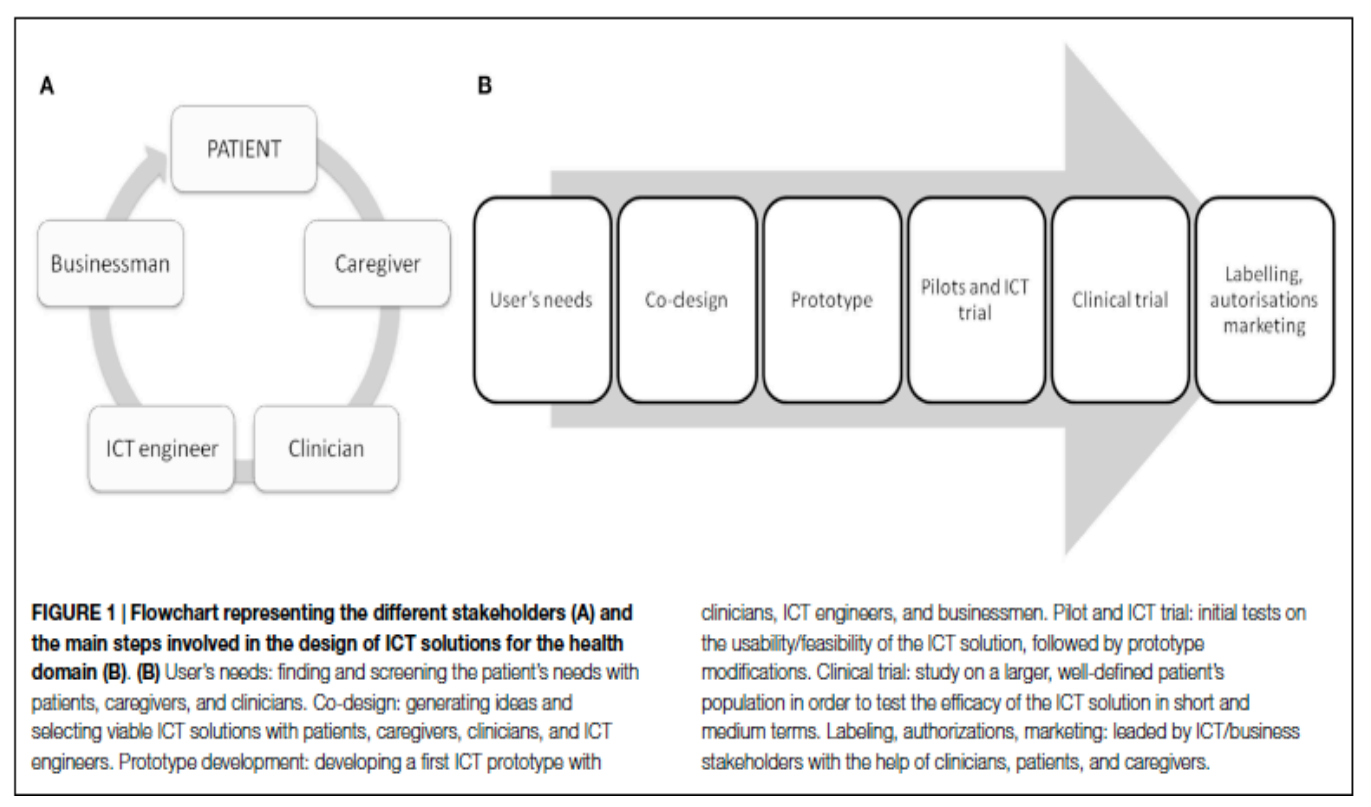

\section{Why should ICT be employed more consistently in clinical trials?}

As detailed above, ICT-based techniques may represent non-invasive, objective and inexpensive solutions to detect early cognitive and functional decline in patients with $\mathrm{AD}$. Clinical interventional trials may take advantage of these solutions in several ways. First, ICT may contribute to determine the admissibility of participation in clinical trials at earlier stages of the disease, when treatment is supposed to be more effective. Patient's performance scores on one assessment may fluctuate as a function of daily rhythms, fatigue, emotion, stress, and many other state-dependent factors. Due to this variance, certain difficulties present in the earliest stages of $\mathrm{AD}$ and related disorders may be undetectable during the classical assessment. ICT may be of great interest in this respect, because they enable the patients' performance to be captured and accurately evaluated in real time and real life situations, even at the patient's home [2]. Second, ICT may help in providing a more timely conversion diagnosis, thus improving the sensitivity of outcome measures based on conversion rate as end- 
point of the intervention. Similarly, by allowing easy and non-invasive continuous monitoring of the patient over time, ICT can help assessing subtle changes in behavioral, cognitive and functional patterns, and thus contribute to the definition of outcome measures finer than dementia progresion or neuropsychological test scores. Finally, ICT may provide an interesting solution for remote assessment. One of the challenges faced by big cohort clinical studies is that there is a consistent drop-out rate, at least partially due to the fact that patients need to go to a clinic for the assessments and follow-ups. ICT solutions combined with safe data transfer methods may reduce drastically the number of required visits, thus reducing the drop-out rate and the costs/time associated with the clinical trial.

An interesting example of how ICT could be employed in clinical trials is represented by the assessment of agitation. Agitation represents one of the most frequent neuropsychiatric symptoms in patients with dementia, and one of the most challenging symptoms to manage for primary caregivers [21]. Following the Agitation Definition Work Group provisional consensus definition [22], agitation in patients with cognitive disorders is defined by A) the presence of criteria for a cognitive impairment or dementia syndrome, and $\mathrm{B}$ ) the presence at least one of the following behaviors associated with observed or inferred evidence of emotional distress for a minimum of two weeks, which represent a change from the patient's usual behavior: (a) Excessive motor activity; (b) Verbal aggression; (c) Physical aggression.

As for cognition, pharmacological solutions for agitation have given so far disappointing results [23]. However, recently a new promising treatment has been released and tested, and showed preliminary efficacy evidence in larger cohort trials [24-25]. ICT could play a key role in assessing agitation in patients with $\mathrm{AD}$, and to test the new treatment efficacy. For instance, accelerometers could be employed to measure objectively the presence of abnormal motor activity. Speech 
analyses that extract automatically vocal features of recorded speech could be employed to assess verbal aggression in a more subtle and objective way. Finally, automated video analysis and activity recognition techniques may be useful to quantify the appearance of certain activities and movement sequences that underline physical aggression.

\section{Conclusions and future research directions}

In order to progress in the validation of the treatments for $\mathrm{AD}$, better outcome measures for cognitive and functional changes are acutely needed in the earliest stages of the pathology [26]. The clinical assessment of cognitive and functional changes in $\mathrm{AD}$ has traditionally relied on cognitive screening tests that are not always sensitive to the earliest cognitive, functional and behavioral changes important to detect for effective preventive interventions [26], are possibly subject to variations in the clinical interpretation, and are not always good predictor of the progression from MCI to AD [27]. Furthermore, current diagnostic measures can be invasive (CSF analyses), expensive (neuroimaging), time-consuming (neuropsychological assessment) and are often available only in specialized clinics, which leads to reduced accessibility as frontline screening tool for AD and related disorders [29]. Therefore, we face an increasing need for additional population-based screening and follow-up instruments with simpler and timelier adapted, non-invasive and cost-effective tools allowing early identification of subjects in preclinical stages of AD.

Here, we highlighted how new tools involving ICT may represent an optimal solution to most of these challenges. However, in order to successfully integrate ICT measurements into clinical trials, some work has still to be done [2;29]. Specifically, the use of such technologies should be validated in larger cohorts to demonstrate their clinical meaningfulness by correlating with available clinical 
diagnostics and biomarkers and thus receive recognition in the clinical scientific and medical world. Importantly. In addition, the use of ICT in clinical trials needs to be validated by Health authorities and policy makers. On the technological side, work in terms of system development and sensors integration has to be carried out to allow a reliable and complete assessment of a patient by merging information coming from different sensors into easily understandable feedback. The immediate and accurate visualization of the recorded data is of great importance to facilitate an easy use in clinical practice and to provide feedback to patients and their caregivers.

\section{Acknowledgments and sources of support}

This study and the 2014 workshop were supported by grants from the FP7 Dem@care project, the FP7 VERVE project and the Innovation Alzheimer associations. 


\section{REFERENCES}

1. Aisen, PS, Gauthier, S, Ferris, SH, Saumier, D, Haine, D, Garceau, D, et al. (2011). Tramiprosate in mild-to-moderate Alzheimer's disease - a randomized, double-blind, placebocontrolled, multi-centre study (the Alphase Study). Arch Med Sci, 7(1), 102-111.

2. Robert, PH, Konig, A., Andrieu, S., Bremond, F., Chemin, I., Chung, P. C., Dartigues, J. F., Dubois, B., Feutren, G., Guillemaud, R., Kenisberg, P. A., Nave, S., Vellas, B., Verhey, F., Yesavage, J., Mallea, P. (2013). Recommendations for ICT Use in Alzheimer's Disease Assessment: Monaco CTAD Expert Meeting. J Nutr Health Aging, 17(8), 653-660.

3. Sampaio, C. (2007). Clinical relevance on Alzheimer's disease endpoints. J. Nutr. Health Aging 11, 316-317.

4. Konig, A., Aalten, P., Verhey, F., Bensadoun, G., Petit, P. D., Robert, P., et al. (2014). A review of current information and communication technologies: can they be used to assess apathy? Int. J. Geriatr. Psychiatry 29, 345-358. doi:10.1002/gps. 4017

5. Hsiao, CJ, \& Hing, E. (2014). Use and characteristics of electronic health record systems among office-based physician practices: United States, 2001-2013. NCHS Data Brief(143), 1-8.

6. Kuchinke, W, Ohmann, C, Yang, Q, Salas, N, Lauritsen, J, Gueyffier, F, et al. (2010). Heterogeneity prevails: the state of clinical trial data management in Europe - results of a survey of ECRIN centres. Trials, 11, 79.

7. Satt, A, Sorin,A.,Toledo-Ronen, O., Barkan, O., Kompatsiaris, I., Kokonozi, A., Tsolaki, M. (2013). Evaluation of SpeechBased Protocol for Detection of Early-Stage Dementia. Paper presented at the INTERSPEECH, Lyon, France. 
8. König, A, Satt, A, Sorin, A, Hoory, R, Derreumaux, A, Manera, V, et al. (2015). Automatic speech analysis for the assessment of pre-demented and Alzheimer patients. Alzheimer's \& Dementia: Diagnosis, Assessment and Disease Monitoring, 1(1) 112-124.

9. Romdhane, R, Mulin, E, Derreumeaux, A, Zouba, N, Piano, J, Lee, L, et al. (2012). Automatic video monitoring system for assessment of Alzheimer's disease symptoms. J Nutr Health Aging, 16(3), 213-218.

10. Sacco, G, Joumier, V, Darmon, N, Dechamps, A, Derreumaux, A, Lee, JH, et al. (2012). Detection of activities of daily living impairment in Alzheimer's disease and mild cognitive impairment using information and communication technology. Clin Interv Aging, 7, 539-549.

11. Konig, A, Crispim Junior, CF, Derreumaux, A, Bensadoun, G, Petit, PD, Bremond, F, et al. (2015). Validation of an automatic video monitoring system for the detection of instrumental activities of daily living in dementia patients. $\mathrm{J}$ Alzheimers Dis, 44(2), 675-685.

12. Robinovitch, SN, Feldman, F., Yang, Y., Schonnop, R., Leung, P. M., Sarraf, T., Sims-Gould, J., Loughin, M. (2013). Video capture of the circumstances of falls in elderly people residing in long-term care: an observational study. Lancet, 381(9860), 47-54.

13. König, A., Crispim Junior, C., Gomez Uria Covella, A., Bremond, F., Derreumaux, A., Bensadoun, G., et al. (2015a). Ecological assessment of autonomy in instru- mental activities of daily living in dementia patients by the means of an auto- matic video monitoring system. Front. Aging Neurosci. 7:98. doi:10.3389/fnagi. 2015.00098 
14. Siraly, E, Szabo, A, Szita, B, Kovacs, V, Fodor, Z, Marosi, C, Salacz, P, Hidasi, Z, Maros, V, Hanak, P, Csibri, E, and Csukly, $\mathrm{G}$, Monitoring the early signs of cognitive decline in elderly by computer games: an MRI study. PLoS One, 2015. 10(2): p. e0117918.

15. Hatfield, C. F., Herbert, J., van Someren, E. J., Hodges, J. R., and Hastings, M. H. (2004). Disrupted daily activity/rest cycles in relation to daily cortisol rhythms of home-dwelling patients with early Alzheimer's dementia. Brain 127(Pt 5), 1061-1074. doi:10.1093/brain/awh129awh129

16. Yakhia, M, Konig, A, van der Flier, WM, Friedman, L, Robert, PH, \& David, R. (2014). Actigraphic Motor Activity in Mild Cognitive Impairment Patients Carrying Out Short Functional Activity Tasks: Comparison between Mild Cognitive Impairment with and without Depressive Symptoms. J Alzheimers Dis.

17. Nagels, G, Engelborghs, S, Vloeberghs, E, Van Dam, D, Pickut, BA, \& De Deyn, PP. (2006). Actigraphic measurement of agitated behaviour in dementia. Int J Geriatr Psychiatry, 21(4), 388-393.

18. Mahlberg, R, \& Walther, S. (2007). Actigraphy in agitated patients with dementia. Monitoring treatment outcomes. Z Gerontol Geriatr, 40(3), 178-184.

19. Volkers, AC, Tulen, JH, van den Broek, WW, Bruijn, JA, Passchier, J, \& Pepplinkhuizen, L. (2003). Motor activity and autonomic cardiac functioning in major depressive disorder. J Affect Disord, 76(1-3), 23-30.

20. David, R, Mulin, E, Friedman, L, Le Duff, F, Cygankiewicz, E, Deschaux, O, et al. (2012). Decreased daytime motor activity associated with apathy in Alzheimer disease: an actigraphic study. Am J Geriatr Psychiatry, 20(9), 806-814.

21. Okura, T, \& Langa, KM. (2011). Caregiver burden and neuropsychiatric symptoms in older adults with cognitive impairment: the Aging, Demographics, and Memory Study (ADAMS). Alzheimer Dis Assoc Disord, 25(2), 116-121. 
22. Cummings, J, Mintzer, J, Brodaty, H, Sano, M, Banerjee, S, Devanand, DP, et al. (2015). Agitation in cognitive disorders: International Psychogeriatric Association provisional consensus clinical and research definition. Int Psychogeriatr, 27(1), 7-17.

23. Soto, M, Andrieu, S, Nourhashemi, F, Ousset, PJ, Ballard, C, Robert, P, et al. (2014). Medication development for agitation and aggression in Alzheimer disease: review and discussion of recent randomized clinical trial design. Int Psychogeriatr, 1-17.

24. Cummings, J, Lyketsos, C, Tariot, P, et al. (2014). Dextromethorphan/quinidine (AVP-923) Efficacy and Safety for Treatment of Agitation in Alzheimer's Disease (AD): Results from a Phase 2 Study. In: (poster) 2014 American Neurological Association (ANA) $139^{\text {th }}$ Annual Meeting, October 10-12, 1014, Baltimore, USA.

25. Siffert, J. (2014). Phase 2 of AVP-923 (dextromethorphan/quinidine) for treatment of agitation in Alzheimer's disease: topline results and considerations for future research.In: (presentation) E.U./U.S. Task Force Meeting on Alzheimer's Trials: Outcome measures during the $7^{\text {th }}$ Annual Meeting of Clinical Trials in Alzheimer's Disease Meeting, November, 20-22, 2014, Philadelphia, USA

26. Snyder, PJ, Kahle-Wrobleski, K., Brannan, S., Miller, D. S., Schindler, R. J., DeSanti, S., Ryan, J. M., Morrison, G., Grundman, M., Chandler, J., Caselli, R. J., Isaac, M., Bain, L., Carrillo, M. C. (2014). Assessing cognition and function in Alzheimer's disease clinical trials: Do we have the right tools? Alzheimers Dement, 10(6), 853-860.

27. Schmand, B, Eikelenboom, P, van Gool, WA, \& Alzheimer's Disease Neuroimaging, I. (2012). Value of diagnostic tests to predict conversion to Alzheimer's disease in young and old patients with amnestic mild cognitive impairment. J Alzheimers Dis, 29(3), 641-648. 
28. Laske, C, Sohrabi, HR, Frost, SM, Lopez-de-Ipina, K, Garrard, P, Buscema, M, et al. (2014). Innovative diagnostic tools for early detection of Alzheimer's disease. Alzheimers Dement.

29. Robert, PH, Konig, A, Amieva, H, Andrieu, S, Bremond, F, Bullock, R, et al. (2014). Recommendations for the use of Serious Games in people with Alzheimer's Disease, related disorders and frailty. Front Aging Neurosci, 6, 54. 


\section{CHAPTER 9}

\section{RECOMMENDATIONS FOR THE USE OF SERIOUS GAMES IN PEOPLE WITH ALZHEIMER'S DISEASE, RELATED DISORDERS AND FRAILTY}

Frontiers in Aging in Neuroscience, 2014; 6:54.

Philippe H.Robert, Alexandra König, Hélene Amieva, Sandrine Andrieu, François Bremond, Roger Bullock, Mathieu Ceccaldi, Bruno Dubois, Serge Gauthier, Paul-Ariel Kenigsberg, Stéphane Nave, Jean M. Orgogozo, Julie Piano, Michel Benoit, Jacques Touchon, Bruno Vellas, Jerome Yesavage, Valeria Manera 


\section{ABSTRACT}

Alzheimer's disease and other related disorders (ADRD) represent a major challenge for health care systems within the aging population. It is therefore important to develop better instruments to assess the disease severity and progression, as well as to improve its treatment, stimulation, and rehabilitation. This is the underlying idea for the development of Serious Games (SG). These are digital applications specially adapted for purposes other than entertaining; such as rehabilitation, training and education. Recently, there has been an increase of interest in the use of SG targeting patients with ADRD. However, this field is completely uncharted, and the clinical, ethical, economic and research impact of the employment of SG in these target populations has never been systematically addressed. The aim of this paper is to systematically analyze the Strengths, Weaknesses, Opportunities, and Threats (SWOT) of employing SG with patients with ADRD in order to provide practical recommendations for the development and use of SG in these populations. These analyses and recommendations were gathered, commented on and validated during a 2-round workshop in the context of the 2013 Clinical Trial of Alzheimer's Disease (CTAD) conference, and endorsed by stakeholders in the field. The results revealed that SG may offer very useful tools for professionals involved in the care of patients suffering from ADRD. However, more interdisciplinary work should be done in order to create SG specifically targeting these populations. Furthermore, in order to acquire more academic and professional credibility and acceptance, it will be necessary to invest more in research targeting efficacy and feasibility. Finally, the emerging ethical challenges should be considered a priority. 


\section{INTRODUCTION}

Due to the increasing average lifespan, the occurrence of neurodegenerative disorders such as dementia has risen by unprecedented levels, thus engendering high socio-economic costs. Alzheimer's disease (AD) is the most common type of dementia, and affects one in eight aged 65 and older [1]. Prevalence studies estimate that the number of people affected will reach 81.1 million worldwide by 2040 [2]. As a consequence, the early detection and the treatment of $\mathrm{AD}$ and related disorders (ADRD) are considered as research priorities [3].

In the last decades there has been a growing interest in employ- ing Information and Communication Technologies (ICT) to help assess and evaluate patients' functional impairments, as well as to help and support patients in everyday activities [4]. Concerning clinical assessment, ICT play an important role allowing the development of new methods to evaluate more objectively behavioral and functional deficits [5]. This is important for clinical activity, as well as for research purposes [6]. But beyond being important for assessment, ICT can also play a key role in the patients' treatment, stimulation, and rehabilitation. This is the underlying idea for the development of Serious Games (SG), which are digital appli- cations specialized for purposes other than entertaining, such as training and educating, informing, communicating, market- ing, leading societal/ideological impact on specific subjects, or enhancing user's aptitudes or cognitive/physical functions.

The elderly population (above 50 years) represents now a considerable portion of digital gamers (e.g., 14\% in Germany BIU, 2011 and 29\% in USA ESA, 2011), which is predicted to increase. For this reason, SG may represent a low-barrier, moti- vating, sustainable and relatively cheap method to improve, or at least delay the onset of impairments in selected social, sensory- motor, and emotional functions [7]. Recently, some studies have started to investigate the effectiveness of SG in people with ADRD [8], but the field is still 
completely uncharted, and the clinical, ethical, economic, and research impact of the employment of SG in these target populations has never been rigorously addressed and discussed.

The purpose of the present methods paper is to put together recommendations for the development and use of SG in patients with ADRD and frailty gathered from stakeholders in the field, and to analyze systematically the Strengths, Weaknesses, Opportunities and Threats (SWOT) of employing SG with these patients. We will now briefly describe the target population and review the results of the few studies that addressed the employ- ment of SG in that area, before describing in more detail the aims of the present work.

\section{ADRD AND FRAILTY}

$\mathrm{AD}$ is a neuro-degenerative disorder where memory functions are primarily affected at the early stages of the disease [9]. Persons with $\mathrm{AD}$ generally deteriorate progressively through multiple stages over several years. Despite some discrep- ancies, there is a growing consensus in subdividing the course of AD into three stages: (1) a preclinical/asymptomatic stage, only revealed by biomarker evidence; (2) a predementia phase, charac- terized by the impairment in memory or other cognitive domains not negatively affecting social and/or occupational functioning (also known as Mild Cognitive Impairment, MCI) (3) a dementia phase, in which cognitive disturbances significantly interfere with the capacity of independent living [10]. At this stage, cognitive symptoms are often associated to behavioral and psychological symptoms such as apathy or agitation [11]. MCI is defined as a cognitive decline greater than expected for an individual's age, but which does not interfere notably with activities of daily life [12-13]. Some people with MCI remain stable or return to a normal state over time, but more than half progress to dementia within 5 years. Therefore, MCI can be regarded as a risk state for dementia and its early identification could offer opportunities for preventative interventions [14]. 
Another concept that has recently attracted the attention of researchers and clinicians is that of frailty, defined as a multi- dimensional geriatric syndrome characterized by increased vul- nerability to stressors as a result of reduced capacity of different physiological systems [15]. Traditionally, the concept of frailty has focused principally on the physical domain [16]. Recent work has started to study more deeply the cognitive impairment due to physical frailty, and lead to the definition of cognitive frailty, defined by the simultaneous pres- ence of both physical frailty and cognitive impairment without the presence of a concomitant neurological disease [15]. Cognitive frailty is viewed as a potential precursor of neurodegenerative processes with good potential for reversibility, and thus is the ideal target of early interventions.

\section{STATE OF THE ART: THE USE OF SERIOUS GAMES WITH PEOPLE WITH ADRD}

There is evidence that SG can successfully be employed to train physical and cognitive abilities in elderly people [17-18]. Recently, some studies have started to investigate the effectiveness of SG in people with $\mathrm{AD}, \mathrm{MCI}$, and related disor- ders. McCallum and Boletsis (2013) [8] performed a literature review of the experimental studies conducted to date on the use of SG in neurodegenerative disorders. In summary, the results of the 15 reported studies suggest that: (1) physical games (or exergames, i.e., games that promote physical fitness) can positively affect several health areas of the players with mild AD and MCI, such as balance and gait [19], and voluntary motor control [20]; (2) cognitive games (i.e., games which target cognitive improvement) can improve a number of cognitive functions, such as attention and memory [21-23] and visuo-spatial abilities [24] ; (3) both physical and cognitive games can have a positive impact on social and emotional functions, for instance they can improve the mood and increase positive affect and sociability $[22 ; 25 ; 24]$ and reduce depression [26]. Very few studies investigated the effects of the use of 
games for social/emotional health (which encourage the players to link with their friends and/or improve their social and emotional life) in dementia, but the results are encouraging [25].

Despite these promising results, a number of studies showed that elderly people and people with ADRD have problems in using many of the SG currently available on the market. Their difficulties include problems in getting familiar with the game technology and embarrassment about using the tools designed for the game $[27 ; 20]$. Furthermore, certain games were considered too demand- ing or even risky for elderly people [28]. These difficulties derive from the fact that most of the SG cur- rently employed have been developed for entertainment purposes (e.g., the Nintendo Wii Fit, Wii Sports, and Big Brain Academy) and with a "typical healthy user" in mind.

To overcome this problem, SG targeting specifically ADRD are starting to emerge [29-31], along with guide- lines ensuring their usability among the targeted populations [32-33]. However, these recommendations are still very sparse.

\section{AIMS OF THE PRESENT WORK}

As outlined in the previous paragraphs, there is an increasing interest in employing SG with patients with frailty and ADRD, and a general feeling that these cutting-edge applications may open new avenues for clinical treatment and experimental inves- tigation of important issues. However, the field is completely uncharted. Strong evidence concerning the effectiveness of SG as clinical tools is still missing, together with a consensus on how, when and for what purposes SG should be employed. Furthermore, the ethical, social, and economic consequences of the employment of SG in these clinical populations have never been systematically investigated. As the topic is very new and relatively few scientific papers have been published so far, we believe that it would benefit from a structured dialog and dis- cussion between different stakeholders: including people working in the health 
domain (e.g., clinicians, neuropsychologists, geri- atricians, etc.), people working on ICT (e.g., engineers and SG designers), people working in the business domain (e.g., prod- uct marketing, business development), as well as patients and their caregivers (e.g., people working on nursing homes, family caregivers, etc.).

Starting from these considerations, we organized a two-round workshop (IA workshop) with stakeholders in the field with the aims of (a) analyzing systematically the employment of SG in frailty and ADRD (SWOT analysis), and (b) gathering recom- mendations for the development and use of SG targeting these populations.

\section{METHODS}

\section{WORKSHOP STRATEGY}

The analyses and recommendations reported in the present paper were collected and discussed during the workshop "Innovation Alzheimer 2013" (IA workshop 2013), organized by the CoBTek (CognitionBehavior-Technology) Research Unit of the University of NiceSophia Antipolis (UNS) in Nice, France. CoBTek's main mission is to use ICT, particu- larly imaging and video analytic techniques to: (1) Improve diagnostics and treatment of behavioral and cognitive symptoms in ADRD (2) Develop new strategies in order to prevent, help and assist elderly people (3) Improve autonomy in the elderly.

The IA workshop 2013 had a two-step design (two rounds plus a web survey).

\section{FIRST ROUND}

The first round took place in Nice on November 7th, 2013, and involved 50 participants including health care professionals and family association representatives $(n=25)$, ICT engineers $(n=10)$, representatives of companies involved in ICT, and economi- cal experts $(n=15)$. It started with a 3 -h plenary session, where recent 
works employing SG in elderly people and people with ADRD were presented. The aim was to ensure that participants coming from different backgrounds were familiar with terms such ADRD, frailty, and SG. After the plenary session, participants were divided in three 2-h parallel sessions:

\section{SWOT analysis session}

Participants (2 groups of 4 participants) were presented with items concerning SWOT of SG in ADRD deriving from a former literature review, and asked to prioritize them, as well as to gen- erate new ideas. The list of items proposed to the participants, as well as the new items that were proposed during the session, are reported in the Results section.

\section{Serious Game design session}

Two groups of 4 participants worked separately to design a SG targeting patients suffering from ADRD.

\section{Recommendation session}

One group of 34 participants worked to generate practical recommendations for the development and use of SG in ADRD. Why, Where, When, What, and How questions were used as a guide- line to structure the session. The list of the 6 questions asked to the participants is reported in Table 1, and included two gen- eral questions and four questions focused on the use of SG in patients with ADRD. First, participants were presented with the questions, and asked to respond to them through a brainstorming carried out in small groups. After the brainstorming, participants were presented with a list of responses to each question, and were asked to rate the importance of each item on a $0-3$ scale $(0=$ not important at all/not adapted at all; $1=$ not very important/not very adapted; $2=$ important/adapted; $3=$ very important/very adapted). 
After voting, participants were presented with a list of practical recommendations for the development of SG adapted to peo- ple with ADRD that emerged from a previous literature review, and were asked to comment them and to generate new ideas. The complete list of items proposed to the participants is reported in the Results section.

At the end of the three parallel sessions, all participants were involved in a 1-h plenary discussion, where all the groups' works were presented and commented.

Table 1 | Questions for recommendation session.

\section{General questions}

SG for whom? i.e., what should be the target population for SG?

SG for what? i.e., Why is it interesting to use the SG?

\section{Questions focused on dementia-related disorders}

Why should SG be employed with patients with ADRD? What is the clinical target?

When (how frequently) should SG be used in patients with ADRD?

Where should SG be used for patients with ADRD

Whom should patients with ADRD play SG with?

\section{WEB SURVEY}

Based on the results collected from the recommendation session during the first round, a web survey was proposed to all CNR members, representatives of the French Memory centers, and members of the European FP7 project VERVE. 30 experts com- pleted the survey, including health care professionals $(\mathrm{N}=17)$, representatives of companies involved in ICT and economical experts $(n=6)$, ICT engineers $(n=1)$, and researchers $(N=6)$. Participants were presented 
with the same list of questions and items used during the first round, and asked to rate the importance of each item on a $0-3$ scale $(0=$ not important at all/not adapted at all; $1=$ not very important/not very adapted; 2 = important/adapted; 3 = very important/very adapted).

\section{SECOND ROUND}

The second round took place on November 15th during the 6th edition of Clinical Trials on Alzheimer's Disease (CTAD) conference held in San Diego (November 14-16th, 2013). The Consensus Group included 10 clinicians (geriatricians, epidemi- ologists, neurologists, psychiatrists, psychologists), 1 ICT engi- neer, and 1 representative from the pharmacological industry.

The week of the second round participants received a first draft of the recommendations. During the second round, the CoBTeK team presented the preliminary results collected during the first round and the web survey, and asked for comment on these results within a group discussion, which was audio recorded. The objective was to validate the manuscript draft, and to collect new and/or different ideas coming from international experts.

\section{RESULTS}

\section{SWOT ANALYSIS}

Participants of the SWOT analysis session (round 1) were pre- sented with items concerning SWOT of the use of SG in people with ADRD based a literature review [34], and asked to comment and prioritize the items, as well as to gen- erate new ideas. The reported results (summarized in Table 2) include the findings that emerged from the SWOT analysis session of round 1, commented on and integrated by all the partici- pants of the first round during the general discussion, and by the participants of the consensus group during the second round. 


\section{Strengths}

Interface adapted to the user. In the context of SG it is possi- ble to create game interfaces adapted to the users' capacities and interests. Motivation is a crucial aspect for the success of rehabil- itation programs, but differs from one person to another [35]. One of the advantages of SG is that it is possi- ble to generate games with different story-plots (e.g., cooking, travelling), but targeting the same ability (e.g., physical activity and executive functions). Furthermore, each SG can be poten- tially individualized. For example users may be able to generate personalized avatars, and the game can incorporate pictures or videos of familiar objects and environments. Adaptation is impor- tant also when it comes to the users' impairments. For instance, people with visual problems may receive auditory cues instead of visual cues, and people with memory problems may be prompted with repeated instructional cues. Taking into account the users' impairments is particularly important when targeting people with dementia-related disorders.

Gaming factors to enhance motivation, positive mood and improve assessment. SG have a playful character, which is sup- posed to enhance motivation and to improve the users' mood; an aspect which is particularly important when targeting clinical populations. Gaming factors can also improve assessment abili- ties. Plato said, "You can discover more about a person in an hour of play than in a year of conversation." Observing and quantify- ing a person's behavior when participating in a SG may provide information even more reliable than those acquired with tradi- tional performance assessments, because the person engaged in a gaming task is less focused on the fact of being "tested," which is usually reported as very stressful [36].

Independent practice and self-assessment. SG, due to their "light" interfaces, their playful aspect and interactivity, and their high level of immersion (for the VR-based SG) can be employed for selfassessment and home-based skill practice. These are com- mon 
components of most rehabilitation programs, considered crucial to promote activity automation, and generalization of the learned skills to every-day behavior. The possibility to carry out an autonomous activity can also lead to mood improvements and self-esteem enhancement. Furthermore, the home-based and independent practice would contribute to reduce the costs sus- tained by insurances and by the public healthcare system.

Safe testing and training environment. When developing eco- logical assessment and rehabilitation instruments, it is necessary to consider safety risks (for instance, the risks due to driving errors, but also the risks of burning oneself with a hot pan). SG represent an optimal solution to this problem, minimizing these kinds of risks.

Promoting social bonding. Social isolation and lack of social interactions are often reported as crucial problems by elderly peo- ple and people with dementia-related disorders [37]. SG may play a role in promoting social interactions. For instance, there are SG that can be played by multiple players physically co-present, or in groups. Some multi-player SG can be played online by people connected from remote locations. In this case the social interaction is more limited; even if some preliminary studies suggest that participants (undergraduate stu- dents) perceive the interactions developed during online SG as good quality social interactions [38], the prevalence and extent of social activities in online group games are intrinsically different from real world social interactions [39].

Enhanced ecological validity. Traditional clinical (nonpharmacological) rehabilitation methods have been criticized for their limited ecological validity [40]. The same concern applies to diagnostic laboratory testing. An important strength of SG, especially of those based on VR, is that they can offer rehabilitation environments which simulate real life environments and activities. 
Table 2 | Summary of a SWOT analysis of the use of SG in ADRD.

\begin{tabular}{|c|c|}
\hline Strengths & Weaknesses \\
\hline $\begin{array}{l}\text { Interface adapted to the user } \\
\text { Gaming factors to enhance motivation, positive mood and improve } \\
\text { assessment } \\
\text { Independent practice and self-assessment } \\
\text { Safe testing and training environment } \\
\text { Promoting social bonding } \\
\text { Enhanced ecological validity } \\
\text { Control of stimulus delivery } \\
\text { Cuing stimuli for error-free learning } \\
\text { Performance analysis in real time } \\
\text { Real-time feedback delivery } \\
\text { Promoting learning processes } \\
\text { Low-cost, duplicable environments }\end{array}$ & $\begin{array}{l}\text { Interface challenges } \\
\quad \text { Non-naturalistic interactions } \\
\text { Wires and displays } \\
\text { Immature engineering process } \\
\text { Expensive equipment } \\
\text { Poor platform compatibility } \\
\text { Software difficult to use } \\
\text { Lack of generalization } \\
\text { Addiction } \\
\text { Side effects }\end{array}$ \\
\hline Opportunities & Threats \\
\hline $\begin{array}{l}\text { Emerging advances in technology } \\
\text { Real time data analysis } \\
\text { Gaming industry drivers } \\
\text { Intuitive appeal to the public } \\
\text { New professions } \\
\text { Closeness between scientific, technical, and } \\
\text { clinical communities } \\
\text { SG as research instruments } \\
\text { Telerehabilitation } \\
\text { Big market }\end{array}$ & $\begin{array}{l}\text { Ethical challenges } \\
\text { Poor integration with the clinical practice } \\
\text { Lack of assessment methodology } \\
\text { Lack of feasibility and efficacy studies } \\
\text { Lack of regulation } \\
\text { Lack of business model } \\
\text { Too few costbenefit proofs } \\
\text { Technological vs. clinical tool } \\
\text { Aftereffects } \\
\text { The perception that the technological tools will eliminate the need for } \\
\text { the clinician } \\
\text { Unrealistic expectations } \\
\text { Academic and professional acceptance } \\
\text { Technophobia }\end{array}$ \\
\hline
\end{tabular}

Promoting learning processes. When thinking about elderly peo- ple and people with dementia, there is a tendency to focus on rehabilitation and recovery of lost functions. However, neuroplasticity can also be improved by learning new things and activities, and by promoting positive affect and stress reduction [41]. SG can be easily employed for this purpose. The employment of ICT when playing a SG represents a learn- ing opportunity and challenge for elderly people and people with dementia-related disorders. Furthermore, SG has been shown to be able to improve mood and to decrease stress [42].

Low-cost duplicable environments. Contrary to traditional rehabilitation methods that usually rely on costly physical mock-ups owned by specialized centers, SG offer the capacity to produce and distribute cheap and identical "standardized" environments. 
Within such digital rehabilitation scenarios, normative data can be accumulated for performance comparisons needed for diag- nostics, research and for training purposes.

\section{Weaknesses}

Interface challenge I: non-naturalistic interactions. Current SG platforms are still limited in the degree to which they allow users to naturalistically interact with them. Progress has been made, but it is necessary to invest more in usability testing, especially when designing SG for elderly and fragile people. Many elderly people are not used to interacting with high-tech interfaces, and the initial approach with SG may cause them a high cognitive and affective load, which may significantly slow down the learning curve. It is necessary to avoid any extra, non-automatic cognitive effort that could represent a distraction for the patient, and thus limit the assessment and rehabilitation processes.

The interface challenge 2: wires and displays. In order to use SG on ordinary PC/laptops or televisions, it is often necessary for the user to connect a number of cables and modify the setups. This may be too difficult for non-expert users, especially for elderly, and fragile people.

Immature engineering process. Building, testing, and maintain- ing a rehabilitation system based on SG is a very complex process, and there is a lack of a standard methodology. Developers must integrate disparate knowledge in both engineering and rehabilita- tion that include sub-areas such as tracking, displays, interaction, computer graphics, simulation, human factors, biokinesiology, cognitive psychology, and so forth. 
Expensive equipments. To be effective, some VR-based SG need fully immersive projection displays (i.e., CAVE, Powerwalls, Immersadesks), which are very expensive, and thus not easy to install where the assessment/rehabilitation programs usually take place (hospitals, day clinics, etc.).

Poor platform compatibility. Most of SG are not inter-operable, and the applications are not written in a simple and reconfig- urable manner. This represents an important problem, especially because the target places where the SG should be used (e.g., hospitals, nursing homes) are equipped with disparate (often not regularly updated) systems. Furthermore, many SG applications require a fast and reliable internet connection, which is sometimes not available, or not optimized.

Software difficult to use. Healthcare professionals are not programmers. Consequently, in order to maximize the usability and usefulness of rehabilitation program based on SG, great care needs to be placed on building an intuitive front-end interface. Similarly, the applications used to visualize performance results should be intuitive and easy to use. These remarks also apply to home-based SG managed directly by the patients and their caregivers.

Lack of generalization. Although SG try to promote ecological interactions and to create naturalistic environments, it is difficult to generalize the skills learned during SG to the real life context. For instance, learning to recognize other peoples' emotions from facial expressions in a SG does not guarantee that the user will actually demonstrate an improved ability to recognize emotions via facial expressions in a real social interaction context. 
Addiction. Like many digital games, SG could cause addiction [43]. Even if SG have mainly training purposes (e.g., enhancing memory and attention), people may spend too much time playing, and reduce the amount of time they dedicate to other activities (e.g., physical activity, hygiene, etc.).

Side effects. Side effects can be observed especially in the VR- based SG [44]. Cybersickness is a form of motion sickness with symptoms reported to include nausea, vomiting, eyestrain, disorientation, ataxia, and vertigo. After effects may also include symptoms such as disturbed locomotion, changes in postural control, perceptual-motor disturbances, flashbacks, drowsiness, fatigue, and generally lowered arousal. When using simpler SG (not VR-based), after effects may include headaches due to prolonged fixation of the display. In order to obtain usable and safe SG for fragile people, it is necessary to adapt them to the specific patients' deficits and problems.

\section{Opportunities}

Emerging advances in technology. Progress in the Graphics/Video Integration brings more visual realism to $\mathrm{SG}$, representing an important component for developing effective rehabilitation programs. Another positive development is the trend toward wireless technology, which reduces the need for complex wire configurations. Similarly, due to the increase of demands in the consumer market, display devices are becoming cheaper. For VR-based SG, autostereoscopy makes stereo viewing possible without the need to wear any special equipment (i.e., polarized or active shutter-type glasses), a feature that can enhance the overall usability of VR systems. 
Real-time data analysis. One of the strengths of rehabilitation programs based on SG is the possibility to collect and analyze performance data in real-time, and to provide the user with rapid performance feedback. This is possible in the context of cogni- tive tasks (e.g., providing results of memory or attention based games), but as well in the domain of motor tasks, thanks to the emergence of realtime motion analysis coupled with direct acquisition of motion data.

Gaming industry drivers. The recent growth in the interactive gaming-industry area, and its interest in the domain of health and ageing, will continue to drive the development of products tar- geting specific populations, such as people with dementia-related disorders.

Intuitive appeal to the public. The general public is very attracted to the idea of using SG with therapeutic or prevention targets. This interest is increased by the attention devoted to this domain by the media.

New professions. In order to create, develop, test and sell SG targeting specific populations, such as people with dementia-related disorders, it is necessary to rely on multi-disciplinary teams including people with different backgrounds and abilities, such as engineers, healthcare professionals, and businessmen. This process will lead to the creation of new professions (e.g., engineers with a deeper knowledge of specific health-related issues), and will represent an economical opportunity to create new job positions.

Closeness between scientific, technical, and clinical communi- ties. The interdisciplinary work between the communities of researchers, engineers and clinicians that focus on SG for reha- bilitation purposes are becoming more frequent.

SG as research instruments. SG can improve our knowledge of brain functioning. For instance, they can be easily used in association with brain imaging techniques, as they allow to interact in complex 
environments almost without moving (e.g., using a joystick). This feature of SG explains the increase of funding dedicated to projects that try to integrate the use of SG in domains such as neuropsychology and behavioral neu- roscience. SG may also be employed as motivating factors to facilitate participants' recruitment, and to reduce the incidence of drop-outs.

Telerehabilitation. Due to the flexibility of the Internet, the idea of delivering rehabilitation and therapy to patients in remote loca- tions has been a popular topic. The application of SG within a telerehabilitation format is the next logical step, allowing a therapist to check the utilization and progress of patients, or to manually modify the game parameters. Similarly, this would allow technicians to perform maintenance operations without the need to go to the users' home.

Big market. The number of people with dementia-related dis- orders is very high and destined to increase, and thus the tools developed to assess and rehabilitate dementia-related impair- ments are potentially addressing a large number of users. This makes the market interesting for high-tech companies, as well as for insurance companies.

\section{Threats}

Ethical challenges. Professionals must carefully consider and address incumbent ethical threats concerning the use of SG with fragile people, and the fact that the immersion in an environ- ment too realistic may sometimes cause more problems than benefits. Also, questions concerning the disclosure of private per- sonal information in the domain of internet-based SG should be addressed carefully.

Poor integration with the clinical practice. Although SG can be employed as clinical tools, they are poorly integrated in standard clinical and neuropsychological practice. In order to be effective, SG should be used only after a standard clinical and neuropsy- chological 
assessment of patient's deficits and abilities has been performed. This standardized evaluation (independent of the evaluation provided by SG) should be used to decide which SG should be employed with a specific patient, and with which level of difficulty.

Lack of assessment methodology. The field lacks standard methodologies to verify the effectiveness and efficacy of the use of SG. In order to understand if SG achieve the participants objectives, it is necessary to establish rigorous methods to assess the users' performance improvements, based on the methods used for clinical assessment. Clinicians and therapists should be involved directly in the assessment stage, especially during feasibility studies.

Lack of feasibility and efficacy studies. The interest in employ- ing SG with patients with ADRD emerged only recently [8], and as a consequence the field is completely uncharted. Rigorous feasibility and efficacy stud- ies will be necessary to develop a better understanding of the physical, psychological, and social effects and consequences of employing SG in these populations, and to predict and anticipate possible adverse consequences.

Lack of regulation. The field lacks regulations concerning the development, marketing and use of SG with sensitive popu- lations, such as people with dementia-related disorders. It is extremely important to create standard rules for companies and institutions that create, test, sell and use SG, in order to guarantee that SG are safe, useful, and respect ethical principles. This lack of regulations is responsible for some false promises made in the past through media advertisement. 
Lack of business model. Most SG are designed with the aim to create a prototype, and not a product for the market. As a con- sequence, the business model behind SG is not clear (e.g., should SG be free for the final user? who should pay for them, and for their cost of development? how should copyright issues be man- aged?). This lack can delay investments that game industries and companies working on ICT would devote to SG applications.

Too few cost/benefit proofs. The field lacks definitive cost/benefit analyses. Such analyses must spell out both the clinical and economic benefits of SG, weighed against the costs for using them over already-existing traditional methods.

Technological vs. clinical tools. SG are often considered by the general public as interesting and engaging technological tools. However, SG targeting assessment and rehabilitation of dementiarelated disorders should be considered primarily as clinical tools, and thus employed with the same care and cautions that apply to all clinical instruments.

Side effects. As discussed in the "Weaknesses" section, side effects (such as cybersickness, perceptual-motor disturbances, drowsi- ness, fatigue, and headaches) may occur in users after using SG applications. If these aftereffects are not understood and man- aged properly, there is the possibility that a developer, clinician, researcher, or supporting institution could be held responsible for them.

The perception that the technological tools will eliminate the need for the clinician. This issue belongs to the more general problem of using technology-based instruments in the health sec- tor. Although supporters of new technologies point out that SG are simply tools that extend the therapist's expertise, there still exists a view in some clinical quarters that any technology serves to subvert the clinical relationship. 
Unrealistic expectations. First-time SG users often experience unrealistic expectations, mostly based on overhyped media representations. This can lead to some disappointment when starting to use SG.

Poor academic and professional acceptance. SG are viewed by many researchers and clinicians as expensive toys gain- ing no scientific and clinical credibility. The perception of SG in therapy and rehabilitation contexts is slowly start- ing to change, and SG are gradually being accepted as tools providing new treatment options. This perception change is partly due to the increased number of articles published in mainstream journals, along with conferences dedicated to this topic. However, there is still a consistent part of the scien- tific community that derides the idea of using SG for scientific and clinical purposes. Controlled clinical trials will be neces- sary to evaluate the effectiveness of SG targeting dementia- related disorders, and to increase the academic and professional acceptance.

Technophobia. The fear or dislike of ICT is still common in many elderly people, as well as in some of their family caregivers and healthcare professionals. This can make it difficult to employ SG as assessment and rehabilitation tools for some of the present generation of elderly people.

Serious Game design. Participants working on the SG design ses- sion of the first round were asked to provide a definition of SG, and proposed the following: "A SG is a solution that combines entertainment and motivation to facilitate learning and social bonding in the context of an activity." Furthermore, they dis- cussed about two SG currently under development at the CoBtek research unit: "Panic at the Nursing Home" devoted to the train- ing of nursing home professional staff, and "battle ship" (http:// www.azagame.fr/) devoted to the physical and cognitive train- ing of patients with ADRD. Finally, participants were asked to generate ideas for a SG adapted to people with ADRD. They proposed the following games: (1) a cultural 
game taking place in a museum, where players can navigate different collections of artifacts, and in each location they are asked questions and play games to train their memory and executive functions; (2) a social quiz game (similar to the board game "Trivial Pursuit") to be played by people with ADRD together with young people, with the aim of training memory, and promote inter-generational bonding.

Recommendations. Participants in the recommendation session of round 1 were asked to:

- Respond to 6 questions (see Table 1); after a brainstorming with a free response format, participants were presented with a list of items for each question, and asked to rate the importance of each item on a 0-3 scale (see Methods). ${ }^{\circ}$ Comment and discuss practical recommendations for the development and use of SG in people with ADRD.

\section{QUESTIONS}

The results of the questions (mean scores of the ratings assigned to each item, collapsed across participants from round 1 and from the online survey) are reported in Figure 1. The additional ele- ments emerged during the brainstorming of round 1, and the additional comments provided by participants of round 2 are reported below.

\section{Generals questions}

- SG for whom? i.e.,what should be the target population for SG?

Based on a literature review [8]., and on the authors' clinical expertise, participants were asked to rate if SG are adapted to the following categories of target people: AD (dementia stage), MCI, people with frailty, family caregivers and health professionals.

The results of the ratings showed that SG are considered between "adapted" and "very adapted" to: people with MCI, people with frailty 
syndrome, and family and professional care- givers. The highest score was assigned to the use of SG for people with MCI. SG were rated between "not very adapted" and "adapted" to people with AD and other dementia-related disorders. The experts in round 2 agreed that most of the SG cur- rently available on the market are not very adapted to $\mathrm{AD}$ and dementia-related disorders, but suggested that designing SG for these target populations, though challenging, should be consid- ered a priority. Furthermore, they highlighted that professional caregivers should be sensitized to the opportunity to use SG for dementia-related disorders. SG may also be employed as an engagement tool to train caregivers and provide them with more "active" dementia-related information, as opposed to the tradi- tional standard training methods. The additional categories of target populations proposed during the brainstorming of round 1 included: all people; people with handicap, people suffering with phobias, autism, eating disorders, sleep disorders, depres- sion, apathy, behavioral disturbances, chronic illnesses, people with reduced autonomy, people alone, and isolated, and old/new friends of people with impairments.

- SG for what? i.e., Why is it interesting to use the $S G$ ?

Participants were asked to rate if SG are adapted for the follow- ing purposes: to stimulate, assess and rehabilitate the patients, and to train caregivers and healthcare professionals. The results of the ratings showed that SG are considered between "adapted" and "very adapted" for patient stimulation, assessment, and reha- bilitation and for the training of caregivers and healthcare pro- fessionals. The highest score was assigned to the use of SG for patients' stimulation. 
The additional categories proposed during the brainstorming of round 1 included: for everything, to have fun, to share and communicate, to help to address fears and pho- bias, to train in using new technologies, to help to accomplish everyday tasks, to educate, to improve the sense of self-efficacy, to work, for prevention purposes, and to reduce the cost of healthcare for the society, social security, and associations.

\section{Questions focused on $A D$, related disorders, and frailty}

- Why should SG be employed with patients with ADRD? What is the clinical target?

Participants were asked to rate whether SG are important to target AD patients: agitation, apathy, physical activity, cognitive impairment, impaired/reduced social interaction, and reduced functionality in activities of daily living. These categories were selected as they represent some of the most common symptoms of dementia, occurring in up to $90 \%$ of people with ADRD [45]. As the terms "agitation," "apathy," and "functionality in activities of daily living" are terms that can be employed with different meanings in different clinical populations, we will briefly clarify their meaning in the context of ADRD.

Agitation is a neuropsychiatric symptom defined as "inap- propriate verbal, vocal, or motor activity that is not judged by an outside observer to result directly from the needs or confu- sion of the agitated individual" [46]. Confusion, discomfort, and unmet needs may underscore agita- tion, but the outward behavioral expression is usually the result of a need not being addressed [47] as well as an attempt to overcome passivity [48]. Those unmeet needs, often present in AD patients, particularly institutional- ized, are addressed quite successfully by non-pharmacological interventions such as music therapy [49-50] and physical activity [51-52] and thus agitation should be susceptible to improvement through the use of SG. 
Apathy is one of the most common neuropsychiatric symp- toms of $\mathrm{AD}$, occurring in almost $65 \%$ of dementia patients $[2 ; 5]$ being associated with a higher degree of global functional impairment [53] and therefore loss of autonomy in activities of daily living [54-56]. Marin (1991) defined it as a lack of motivation, interest, emotion, or feeling [57]. Recently, Robert et al. (2009) proposed a consensus definition in terms of a set of diagnostic criteria for apathy in Alzheimer's dis- ease (AD) [58]. According to those criteria, an apathy diagnosis should meet the following requirements: first, the core feature of apathy, diminished motivation, must be present for at least 4 weeks; sec- ond two of the three dimensions of apathy (reduced goal-directed behavior, goal-directed cognitive activity, and emotions) must be present; third there should be identifiable functional impairments attributable to apathy. Most recent models consider apathy particularly in terms of an "absence of responsiveness to stim- uli as demonstrated by lack of self-initiated action" [59-60]. Due to their playful nature, SG may be particularly adapted to target apathy deficits.

Finally, impairment in functionality in activities of daily liv- ing represents a major diagnostic requirement for AD [61]. Several studies have investigated the link between cognitive functioning and daily functioning, both necessary to live autonomously. Cognitive domains such as memory, executive functioning, visuospatial functions, and object perception have all been found to correlate with activities of daily living impairment [62-66]. Those activities can be divided into basic activities of daily living such as self-maintenance skills, and Instrumental activities of daily living (IADL) such as preparing a meal and handling finances [67]. Complex IADL activities are sensitive to cognitive decline in early stages of $\mathrm{AD}$, whereas basic activities remains preserved until later and more severe stages of the disease [68-71]. SG could be employed to train those activities, in order to promote a longer 


\section{AD (dementia) \\ $\mathrm{MCl}$ \\ P. with fragility \\ Family caregivers \\ Healthcare prof.}
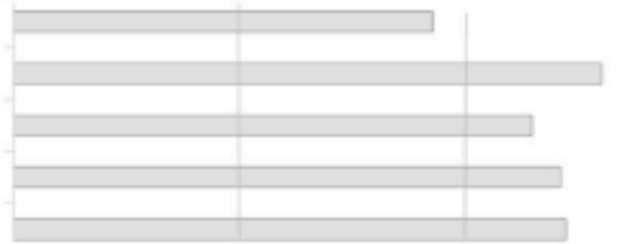

SG for WHAT?

Stimulation

Assessment

Rehabilitation

Train caregivers

Train health prof.

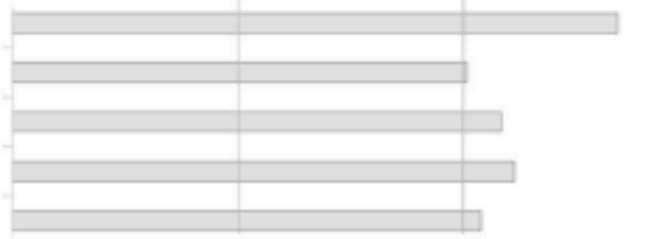

\section{What is the target?}

Agitation

Apathy

Physical activity

Cognitive impair.

Social Interaction

sunct. daily living

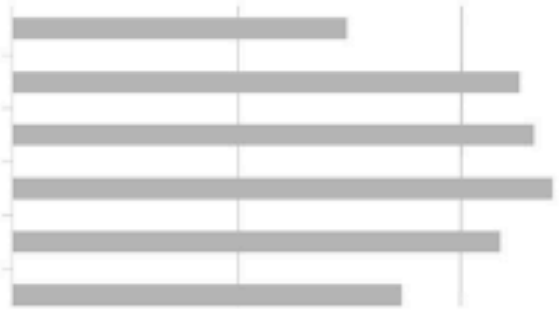

\section{When?}

Everyday

Once a week

On request

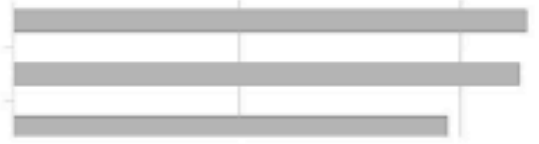

\section{Where?}

Home

Hospital

Day center

Nursing Home

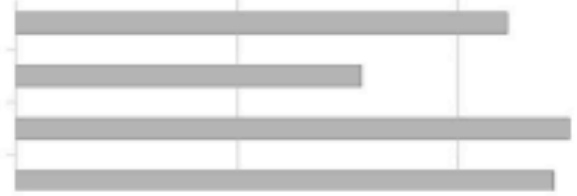

With whom?

Alone

Therapist

Family careg.

Professional careg.

Robot

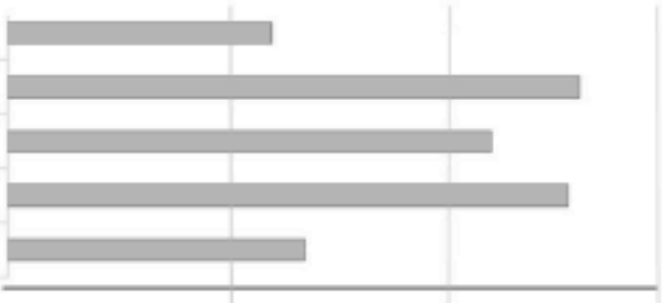

Not adapted at all

Not very

Adapted

FIGURE 1 | Results of the recommendation questions. Mean ratings provided by participants of round 1 of the recommendation session and participants of the online survey to the two general questions (light gray) and the four questions focused on ADRD (dark gray). Rating scale: $0 \_3$ scale 
independent life at home. The results of the ratings showed that SG are considered between "important" and "very important" to target apathy, motor activity, cognitive impairments, and diminished social interaction, with the highest score assigned to cognitive impair- ment. SG were rated between "not very important" and "impor- tant" to target agitation and reduced functionality in activities of daily living. The experts during round 2 suggested that SG could be further employed to target agitation. As seen above, very often agitation in people with dementia-related disorders is caused by the desire to overcome passitivity [48]. SG may represent an interesting and fun activity that could be possibly linked to an intervention: for instance, showing old pic- tures, or listening to well-known songs may have a calming effect.

The experts also suggested that SG may be employed in order to improve patients' functionality in activities of daily living, espe- cially for patients with $\mathrm{MCI}$ and patients in the $\mathrm{AD}$ pre-clinical stages. Importantly, SG should target depression and anxiety in $\mathrm{AD}$ and dementia-related disorders. Finally, the experts advised that SG should start to target a single ability/problem (e.g., the fear of falling down) and then extend progressively to other abil- ities (e.g., memory). The additional categories proposed during the brainstorming of round 1 includes: to create an intergenera- tional link, to improve mood, to combine different targets (e.g., physical + cognitive activity), to teach new abilities, to give per- sonalized information on therapeutic goals, to help the patient to orient (knowing the time and day, etc.), to improve sleep and eating disorders, to promote cultural aspects.

\section{- When (how frequently) should SG be used in patients with ADRD?}

Participants were asked to rate if SG are adapted to be used everyday, once a week, and on request. The results of the ratings showed that SG are considered between "adapted" and "very adapted" to be used every day, once a week, and on request, with the highest score assigned to the use of SG every day. 
The additional categories proposed during the brainstorming of round 1 included: frequently and regularly.

- Where should SG be used for patients with ADRD?

Participants were asked to rate if SG are adapted to be used at home, at the hospital, in the day centers and at the nursing homes. The results of the ratings showed that SG are considered between "adapted" and "very adapted" to be used at home, in the nursing homes, and in the day centers, with the highest score assigned to the use of SG in day centers. SG were rated between "not very adapted" and "adapted" to be used at the hospital. An additional category proposed during the brainstorming of round 1 was: in the waiting rooms

- Whom should patients with ADRD play SG with?

Participants were asked to rate whether SG are adapted to be used by the patient alone, and by the patient together with a therapist, a family caregiver, a professional caregiver, and a robot. The results of the ratings showed that SG are considered between "adapted" and "very adapted" to be used with a therapist, a professional caregiver and a family caregiver, with the highest score assigned to the use of SG with the therapist. SG were rated between "not very adapted" and "adapted" to be used alone and with a robot. The experts in round 2 added that SG could be played by the patient alone in the preclinical stages and the early clinical stages, to decrease the time, burden and effort the caregiver dedicates to the patient. The additional categories proposed during the brainstorming of round 1 included: in a group, with nurses.

\section{PRACTICAL RECOMMENDATIONS FOR THE DEVELOPMENT OF SG TARGETING ADRD}

Participants of the recommendation session of the first round were also presented with a list of recommendations for the devel- opment of 
SG targeting ADRD gathered from a literature review of the field [3233]. These recommendations are reported below, together with the comments and integrations provided by the participants of the recommendation session (first round), and the additional comments provided during the second round.

Based on literature review, in order to be used for assessment and rehabilitation purposes of dementia — related disorders, SG should:

1. Keeptrackofthepatient'scognitiveabilities. Thegameshould produce an in-game estimation of the patient's cognitive abil- ities. This would allow the clinician, caregiver and patient to assess the impact of the game on cognitive performance, and could be used to adapt the level of game difficulty to the actual performance achieved.

2. Determine an appropriate number of steps for the challenge. Each challenge should be completed in a correct number of steps. A high enough number of steps would correctly train the cognitive abilities of the patients. However, too many steps could overload them and lower the benefits of the game.

3. Keep the player in his "flow zone." Flow represents the feeling of complete and energized focus in an activity, with a high level of enjoyment and fulfillment. Maintaining flow will make the game more enjoyable, improving the learning experience.

4. Promote naturalistic interactions. Employing naturalistic interactions should allow a significant reduction of the learn- ing time, and thus optimize the effects of the game experience.

5. Use user-friendly interface for home-based exercises. Design choices should be made in a way to facilitate home-based rehabilitation training. 
6. Take advantage of the multimodal aspect. It is important to train sensory and motor modalities at the same time. When possible, multisensory interactions should be introduced both as input and output.

7. Take into account the impairments of the users. It is cru- cial to consider that ageing and dementia have important effects on the sensory, motor, and cognitive system. Patients with dementia can suffer from visual and hearing problems, and have troubles with many aspects of memory (e.g., work- ing memory, semantic memory, episodic memory, prospective memory). Furthermore, they can show a decline in the pro- cessing speed, have impairments in some executive functions (such as reasoning) and visuo-spatial abilities, and show some motor impairments. SG should take these impairments into account, for instance, keep the visual scenes as simple as possi- ble, provide instructions, and cues repeatedly and at the right time (possibly using different modalities, e.g., auditory and visual cues), minimize actions requiring a fast response and requiring complicated movements, and so on [33].

The participants of the first round of the IA workshop con- firmed that all the recommendations reported above are rel- evant for the application of SG to people with ADRD. In addition, the following recommendation emerged:

8. Take into account the social and cultural background of the user. To promote ecological interactions, it is necessary to sit- uate the game in the correct physical place (e.g., a city well known to the user) and cultural environment.

\section{DISCUSSION AND FUTURE RESEARCH DIRECTIONS}

The recommendations and analyses reported in the present paper have been carried out by and for healthcare professionals, patient, and family associations' representatives, engineers, and compa- nies involved in the development of SG. Even if the overestimated 
expectations, frequently presented by the media, are far from being achieved, our SWOT analysis showed that SG can be con- sidered as useful tools for professionals involved in the care of patients suffering from ADRD. However, more interdisciplinary work should be done in order to create SG specifically target- ing these populations. The employment of SG in the domain of rehabilitation of ADRD is still in an early phase of develop- ment, characterized by some early encouraging research results. The many listed strengths provide a justification for continu- ing in this direction. Weaknesses do exist (in particular limi- tations concerning the difficulty that patients experience while using SG interfaces), as well as some threats, but none are terminal, especially when addressed in collaboration with the different partners involved in the development of SG for rehabilitation. In order to acquire more academic and professional credibility and acceptance, the field of SG would need to invest more in research. Specifically, researchers need to start collect- ing incremental data over numerous small-scale studies to test and evolve usability, usefulness, and access of SG targeting peo- ple with dementia-related disorders. At the same time, ethical, professional, and cost/benefit issues need to be considered and addressed.

The field will need to face a number of challenges, which will benefit from the multidisciplinary collaboration between engi- neers, researchers, clinicians, healthcare professionals, patients, and family caregivers. For instance, it would be important for the companies and manufactures involved in the design and commer- cialization of SG to work closely not only with people in the ICT domain, but also with people coming from the health domain and with researchers. National and international agencies (such as the CNR in France-Centre national de reference en Santé) aiming to facilitate the communication and exchange between scientific community and private companies, may play a major role in driving this interdisciplinary exchange. 
The recommendations gathered during the IA workshop addressed several abilities and deficits that SG may target in peo- ple with ADRD, as well as different ways to employ SG based on the patients' impairments, and may be used as guidelines to design SG specifically adapted to people suffering from these dis- orders. A limitation of the present work is that the participants of the IA workshop were asked to provide recommendations con- cerning the development and use of SG for people with frailty and ADRD, but we did not specify at which stage of the disease progression. As neuro-degenerative diseases are characterized by different stages of impairment, future investigations should bet- ter clarify which recommendations are adapted to the different disease stages.

\section{ACKNOWLEDGMENTS}

The IA Workshop was supported by the Innovation Alzheimer association, The Centre National de Référence Santé à domi- cile et autonomie (CNR Santé) and by grants from the FP7 European Commission Seventh Framework Programme VERVE project, the Fondation Jean Louis Noisiez, the foun- dation Dream It, and COVEA. A special acknowledgment to all the participants of the IA Workshop: HEALTH domain (Gregory Bens-Sadoun, Pierre Bonhomme, Renaud David, Nathalie Fernandez, Sarah Gomez, Françoise Gugonis, Cathrine Colle, Serge Colson, Liliane Imbert, Salome Nicaise, Pierre David Petit, Jessica Roth, Guillaume Sacco, Elisa Saltarin, Karim Tifratene), TECHNOLOGY domain (Alexandre Derreumaux, Baptiste Fosty, Consuelo Granata, Rachid Guerchouche, Michael Lixon, Carol O'Sullivan), BUSINESS-ECONOMY domain (Laure Chantepy, Philippe Caton, Isabelle Corradi-Paumier, Cécile Cridelich, Frederic Couriol, Pierre Foulon, Jean François Herbert, Romain Le Cozannet, Patrick Malléa, Céline Jacquet Mercier, Françoise Salle-Tourne, Joseph Sfeir) 


\section{REFERENCES}

1. Alzheimer's Disease International. (2011). World Alzheimer Report 2011. The Benefits of Early Diagnosis and Intervention. Executive Summary. London: Alzheimer's Disease International. Available online at: http:/www.alz. co.uk/research/WorldAlzheimerReport2011ExecutiveSummary .pdf. (Accessed: February 08, 2012).

2. Ferri, C. P., Prince, M., Brayne, C., Brodaty, H., Fratiglioni, L., Ganguli, M., et al. (2005). Global prevalence of dementia: a Delphi consensus study. Lancet 366, 2112-2117.

3. Ballard, C., Gauthier, S., Corbett, A., Brayne, C., Aarsland, D., and Jones, E. (2011). Alzheimer's disease. Lancet 377, 10191031.

4. Wichers, M., Simons, C. J., Kramer, I. M., Hartmann, J. A., Lothmann, C., Myin- Germeys, I., et al. (2011). Momentary assessment technology as a tool to help patients with depression help themselves. Acta Psychiatr. Scand. 124, 262272.

5. König, A., Aalten, P., Verhey, F., Bensadoun, G., Petit, P. D., Robert, P., et al. (2014). A review of current information and communication technologies: can they be used to assess apathy? Int. J. Geriatr. Psychiatry 29, 345-358.

6. Robert, P. H., König, A., Andrieu, S., Bremond, F., Chemin, I., Chung, P. C., et al. (2013). Recommendations for ICT use in Alzheimer's Disease assess- ment: Monaco CTAD expert meeting. J. Nutr. Health Aging 17, 653-660.

7. McCallum, S. (2012). "Gamification and serious games for personalized health," in pHealth 2012, eds B. Blobel, P. Pharow, and F. Sousa (Amsterdam: IOS Press BV), 85-96. 
8. McCallum, S., and Boletsis, C. (2013). "Dementia Games: a literature review of dementia-related Serious Games," in Serious Games Development and Applications - Lecture Notes in Computer Science, Vol. 8101, eds M. Ma, M. F. Oliveira, S. Petersen, and J. B. Hauge (Berlin; Heidelberg: Springer Publishing), 15-27.

9. Agüero-Torres, H., Fragtiglioni, L. and Windblad, B. (1998). Natural history of Alzheimer's disease and other dementias: review of the literature in the light of the findings from the Kungsholmen project. Int. J. Geriatric Psychiatry 13, 755-766.

10. Dubois, B., Feldman, H. H., Jacova, C., Cummings, J. L., Dekosky, S. T., Barberger- Gateau, P., et al. (2010). Revising the definition of Alzheimer's disease: a new lexicon. Lancet Neurol. 9, 1118-1127.

11. Aalten, P., de Vugt, M. E., Lousberg, R., Korten, E., Jaspers, N., Senden, B., et al. (2003). Behavioral problems in dementia: a factor analysis of the neuropsychiatric inventory. Dement. Geriatr. Cogn. Disord. 15, 99-105.

12. Petersen, R. C., Smith, G. E., Waring, S. C., Ivnik, R. J., Tangalos, E. G., and Kokmen, E. (1999). Mild cognitive impairment: clinical characterization and outcome. Arch. Neurol. 56, 303-308.

13. Gauthier, S., Reisberg, B., Zaudig, M., Petersen, R. C., Ritchie, K., Broich, K., et al. (2006). Mild cognitive impairment. Lancet 367, 1262-1270.

14. Albert, M. S., DeKosky, S. T., Dickson, D., Dubois, B., Feldman, H. H., Fox, N. C., et al. (2011). The diagnosis of mild cognitive impairment due to Alzheimer's disease: recommendations from the National Institute on AgingAlzheimer's Association workgroups on diagnostic guidelines for Alzheimer's disease. Alzheimers Dement 7, 270-279. 
15. Kelaiditi, E., Cesari, M., Canevelli, M., Abellan Van Kan, G., Ousset, P. G., Gillette- Guyonnet, S., et al. (2013). Cognitive frailty: rational and definition from an (I.A.N.A./I.A.G.G.) international consensus group. J. Nutr. Health Aging 17, 726734.

16. Fried, L. P., Tangen, C. M., Walston, J., Newman, A. B., Hirsch, C., Gottdiener, J., et al. (2001). Frailty in older adults: evidence for a phenotype. J. Gerontol. A Biol. Sci. Med. Sci. $56,146-156$.

17. Anguera, J. A., Boccanfuso, J., Rintoul, J. L., Al-Hashimi, O., Faraji, F., Janowich, J., et al. (2013). Video game training enhances cognitive control in older adults. Nature 501, 97-102.

18. Wiemeyer, J., and Kliem, A. (2012). Serious games in prevention and rehabilita- tion - a new panacea for elderly people? Eur. Rev. Aging Phys. Activ. 9, 41-50.

19. Padala, K. P., Padala, P. R., Malloy, T. R., Geske, J. A., Dubbert, P. M., Dennis, R. A., et al. (2012). Wii-fit for improving gait and balance in an assisted living facility: a pilot study. J. Aging Res. 2012, 1-6.

20. Legouverneur, G., Pino, M., Boulay, M., and Rigaud, A. (2011). Wii sports, a usability study with MCI and Alzheimer's patients. Alzheimer's Dementia 7, S500-S501.

21. Stavros, Z., Fotini, K., and Magda, T. (2010). "Computer based cognitive training for patients with mild cognitive impairment (mci)," in Proceedings of the 3rd International Conference on Pervasive Technologies Related to Assistive Environments, PETRA '10 (Petras, Rhodes Island: ACM), 1-3.

22. Weybright, E., Dattilo, J., and Rusch, F. (2010). Effects of an interactive video game (Nintendo Wii) on older women with Mild Cognitive Impairment. Ther. Recreation J. 44, 271-287.

23. Rosen, A. C., Sugiura, L., Kramer, J. H., Whit_eld-Gabrieli, S., and Gabrieli, J. D. (2011). Cognitive training changes hippocampal function in mild cognitive impairment: a pilot study. J. Alzheimers Dis. 26, 349-357. 
24. Yamaguchi, H., Maki, Y., and Takahashi, K. (2011). Rehabilitation for demen- tia using enjoyable video-sports games. Int. Psychogeriatr. 23, 674-676.

25. Boyle, P. A., Malloy, P. F., Salloway, S., Cahn-Weiner, D. A., Cohen, R., and Cummings, J. L. (2003). Executive dysfunction and apathy predict functional impairment in Alzheimer disease. Am. J. Geriatr. Psychiatry, 11, 214-221.

26 Férnandez-Calvo, B., Rodriguez-Pérez, R., Contador, I., Rubio-Santorum, A., and Ramos, F. (2011). Efficacy of cognitive training programs based on new software technologies in patients with Alzheimer- Type dementia. Psicothema 23, 44-50.

27. Wollersheim, D., Merkes, M., Shields, N., Liamputtong, P., Wallis, L., Reynols, F., et al. (2010). Physical and psychosocial effects of Wii video game use among older women. Int. J. Emerging Tech. Soc. 8, 85-98.

28. Sohnsmeyer, J., Gilbrich, H., and Weisser, B. (2010). Effect of a six-week interven- tion with an activity-promoting video game on isometric muscle strength in elderly subjects. Int. J. Comp. Sci. Sport 9, 75-79.

29. Benveniste, S., Jouvelot, P., and Péquignot, R. (2010). "The MINWii Project: Renarcissization of patients suffering from Alzheimer's Disease through video game-based music therapy," in 9th International Conference on Entertainment Computing (ICEC 2010), (Coex Séoul, Corée), 8-11.

30. Nor Wan Shamsuddin, S., Lesk, V., and Ugail, H. (2011). Virtual environment design guidelines for elderly people in early detection of dementia. World Acad. Sci. Eng. Technol. 59, 751-755.

31. Tarnanas, I., Schlee, W., Tsolaki, M., Müri, R., Mosimann, U., and Nef, T. (2013). Ecological validity of virtual reality daily living activities screen- ing for early dementia: longitudinal study. JMIR Serious Games 1, e1. 
32. Bouchard, B., Imbeault, F., Bouzouane, A., and Menelas, B. A. J. (2012). "Developing SG specifically adapted to people suffering from Alzheimer," in Proceedings of the Third International Conference on Serious Games Development and Applications, (Berlin, Heidelberg: Springer-Verlag), 243-254.

33. Fua, K. C., Gupta, S., Pautler, D., and Farber, I. (2013). "Designing serious games for elders," in Foundations of Digital Games Proceedings (Chania, Crete), 291-297.

34. Rizzo, A. A., and Kim, G. J. (2005) A SWOT Analysis of the field of VR rehabilitation and therapy. Presence Teleope. Virtual Environ. 14, 119-146.

35. Leone, E., Piano, J., Deudon, A., Alain, B., Wargnier, A. M., Balard, P., et al. (2012). "What are you interested in?"-A survey on 601 nursing homes residents activities interests. Adv. Aging Res. 1, 13-21.

36. Cassady, J. C., and Johnson, R. E. (2002). Cognitive test anxiety and academic performance. Contemp. Ed. Psychol. 27, 270-295.

37. Cattan, M., White, M., Bond, J., and Learmouth, A. (2005). Preventing social isolation and loneliness among older people: a systematic review of health pro- motion interventions. Ageing Soc. 25, 41-67.

38. Mansour, S., and El-Said, M. (2008). "The impact of multiplayers serious games on the social interaction among online students versus face-to-face students," in 7th WSEAS International Conference on Applied Computer and Applied Computational Science (Hangzhou), 772-778.

39. Ducheneaut, N., Yee, N., Nickell, E., and Moore, R. J. (2006). "Alone together?: exploring the social dynamics of massively multiplayer online games," in Proceedings of the SIGCHI Conference on Human Factors in Computing Systems (Montreal), 407-416. 
40. Chaytor, N., and Schmitter-Edgecombe M. (2003). The ecological validity of neu- ropsychological tests: a review of the literature on everyday cognitive skills. Neuropsychol. Rev. 13, 181-197.

41. Davidson, R. J., and McEwen, B. S. (2012). Social influences on neuroplasticity: stress and interventions to promote wellbeing. Nat. Neurosci. 15, 689-695.

42. Russoniello, C. V., O'Brien, K., and Parks, J. M. (2009). The effectiveness of casual video games in improving mood and decreasing stress. J. CyberTher. Rehabil. 2, 53-66.

43. Griffiths, M. D., and Davies, M. N. O. (2002). Excessive online computer gam- ing: implications for education. J. Computer Assisted Learn. 18, 379-380.

44. Cobb, S. V. G., Nichols, S., Ramsey, A., and Wilson, J. R. (1999). Virtual reality-induced symptoms and effects. Presence 8, 169-186.

45. Cerejeira, J., Lagarto, L., and Mukaetova-Ladinska, E. B. (2012). Behavioral and psychological symptoms of dementia. Front. Neurol. 3:73.

46. Cohen-Mansfield, J., Marx, M. S., Dakheel-Ali, M., Regier, N. G., Thein, K., and Freedman, L. (2010). Can agitated behavior of nursing home residents with dementia be prevented with the use of standardized stimuli? J. Am. Geriatr. Soc. 58, 14591464.

47. Cohen-Mansfield, J. (1999). Measurement of inappropriate behavior associated with dementia. J. Gerontol. Nurs. 25, 4251.

48. Yu, F., Kolanowski, A. M., and Litaker, M. (2006). The association of physical function with agitation and passivity in nursing home residents with dementia. J. Gerontol. Nurs. 32, 30-36. 
49. Gerdner, L. (2000). Effects of individualized versus classical "relax- ation" music on the frequency of agitation in elderly persons with Alzheimer's disease and related disorders. Int. Psychogeriatr. 12, 49-65.

50. Remington, R. (2000). Calming music and hand massage. Nurs. Res. 51, 17-323. Rizzo, A. A., and Kim, G. J. (2005). A SWOT Analysis of the field of VR reha- bilitation and therapy. Presence Teleoper. Virtual Environ. 14, 119-146.

51. Alessi, C., Yoon, E., Schnelle, J., Al-Samarrai, N. R., and Cruise, P. A. (1999). A randomised trial of a combined physical activity and environment intervention in nursing home residents: do sleep and agitation improve? J. Am. Geriatr Soc. 47, 784-791.

52. Buettner, L. L., and Fitzsimmons, S. (2002). AD-venture program: therapeu- tic biking for the treatment of depression in long-term care residents with dementia. Am. J. Alzheimers. Dis. Other Demen. 17, 121-127.

53. Doron, M., Bastian, T., Maire, A., Dugas, J., Perrin, E., Gris, F., et al. (2013). Estimation of physical activity monitored during the day-to-day life by an autonomous wearable device (SVELTE project). Conf. Proc. IEEE Eng. Med. Biol. Soc. 2013, 4629-4632.

54. Boyle, P. A., Malloy, P. F., Salloway, S., Cahn-Weiner, D. A., Cohen, R., and Cummings, J. L. (2003). Executive dysfunction and apathy predict functional impairment in Alzheimer disease. Am. J. Geriatr. Psychiatry, 11, 214-221.

55. Scarpini, E., Scheltens, P., and Feldman, H. (2003). Treatment of Alzheimer's disease: current status and new perspectives. Lancet Neurol. 2, 539-547.

56. Lechowski, L., Benoit, M., Chassagne, P., Vedel, I., Tortrat, D., Teillet, L., et al. (2009). Persistent apathy in Alzheimer's disease as an independent factor of rapid functional decline: the REAL longitudinal cohort study. Int. J. Geriatr. Psychiatry 24, 341-346. 
57. Marin, R. S. (1991). Apathy: a neuropsychiatric syndrome. J. Neuropsychiatry Clin. Neurosci. 3, 243-554.

58. Robert, P., Onyike, C. U., Leentjens, A. F. G., Dujardin, K., Aalten, P., Starkstein,S., et al. (2009). Proposed Diagnostic Criteria for Apathy in Alzheimer's Disease and other Neuropsychiatric Disorders. Eur. Psychiatry 24, 98-104.

59. Andersen, C. K., Wittrup-Jensen, K. U., Lolk, A., Andersen, K., and Kragh- Sorensen, P. (2004). Ability to perform activities of daily living is the main factor affecting quality of life in patients with dementia. Health Qual. Life Outcomes 2, 52.

60. Levy, R. (2012). Apathy: a pathology of goal-directed behaviour. A new concept of the clinic and pathophysiology of apathy. Rev. Neurol. (Paris) 168, 585-597.

61. American Psychiatric Association. (1994). Diagnostic and Statistical Manual of Mental Disorders, 4th Edn. Washington, DC: American Psychiatric Association.

62. Perry, R. J., and Hodges, J. R. (2000). Relationship between functional and neu- ropsychological performance in early Alzheimer disease. Alzheimer Dis. Assoc. Disord. 14, 1-10.

63. Glosser, G., Gallo, J., Duda, N., de Vries, J. J., Clark, C. M., and Grossman, M. (2002). Visual perceptual functions predict instrumental activities of daily liv- ing in patients with dementia. Neuropsychiatry Neuropsychol. Behav. Neurol. 15, 198-206.

64. Plehn, K., Marcopulos, B. A., and McLain, C. A. (2004). The relationship between neuropsychological test performance, social functioning, and instrumental activities of daily living in a sample of rural older adults. Clin. Neuropsychol. 18, 101113.

65. Jefferson, A. L., Barakat, L. P., Giovannetti, T., Paul, R. H., and Glosser, G. (2006). Object perception impairments predict instrumental activities of daily living dependence in Alzheimer's disease. J. Clin. Exp. Neuropsychol. 28, 884-897. 
66. Tomaszewski Farias, S., Cahn-Weiner, D. A., Harvey, D. J., Reed, B. R., Mungas, D., Kramer, J. H., et al. (2009). Longitudinal changes in memory and exec- utive functioning are associated with longitudinal change in instrumental activities of daily living in older adults. Clin. Neuropsychol. 23, 446-461.

67. Lawton, M. P., and Brody, E. M. (1969). Assessment of older people: self- maintaining and instrumental activities of daily living. Gerontologist 9, 179-186.

68. Stern, Y., Hesdorffer, D., Sano, M., and Mayeux, R. (1990). Measurement and pre- diction of functional capacity in Alzheimer's disease. Neurology 40, 8-14.

69. Barberger-Gateau, P., Rainville, C., Letenneur, L., and Dartigues, J. F. (2000). A hierarchical model of domains of disablement in the elderly: a longitudinal approach. Disabil. Rehabil. 22, 308-317.

70. Wilms, H. U., Kanowski, S., and Baltes, M. M. (2000). Limitations in activities of daily living: towards a better understanding of subthreshold mental disorders in old age. Compr. Psychiatry 41(2 Suppl. 1), 19-25.

71. Peres, K., Chrysostome, V., Fabrigoule, C., Orgogozo, J. M., Dartigues, J. F., and Barberger-Gateau, P. (2006). Restriction in complex activities of daily living in MCI: impact on outcome. Neurology 67, 461-466. 
282 


\section{CHAPTER 10}

GENERAL DISCUSSION 


\section{GENERAL DISCUSSION}

With rising health-care costs, clinicians are shifting towards disease interception, which means moving from a 'diagnose and treat' to a 'predict and pre-empt' approach [1]. In this model, pre-emption, i.e. intervening early enough in the disease process to prevent serious effects of the disease associated with progression, becomes a critical component of managing chronic diseases such as $\mathrm{AD}$, and thus underlines the importance of considering new assessment tools for early detection.

The aim of this thesis is to investigate whether ICT can contribute to the clinical assessment of cognitive, behavioral and functional changes in patients with $\mathrm{AD}$ and related disorders, particularly in their early stages. For this purpose, part I of the thesis reviewed the use of ICT for assessment in clinical practice, particularly for the case of apathy. It also defined basic recommendations concerning the development and the use of ICT for AD and related disorders. In part II, different sensor-based assessment methods were studied. Finally, part III, considered the use of ICT within clinical trials for endpoint measures and follow-up. Recommendations were likewise proposed and presented for the use of ICT-based Serious Games as a potential early intervention tool for patients. This chapter is divided into the following sections; first, the current situation of clinical assessment and trials are briefly described pointing to the current need for the development of additional new tools. Secondly, new assessment tools involving ICT are presented by means of the different performed sensor-based validation studies. Finally, the methodological considerations of the thesis in terms of strengths and weaknesses are discussed as well as the implications of the obtained study findings for future research. 


\section{Assessment in clinical practice}

Most of the neuropsychological syndromes and thus cognitive measures were defined during the late nineteenth and early twentieth century (aphasia, alexia, apraxia, etc.) [2]. However, with the rapidly growing presence of technologies, living conditions have extremely changed during the last century, that those classical syndromes might need to be reconsidered, and eventually, new constructs could be proposed.

Writing no longer means using a pencil and paper, but a computer or a smartphone. Numerical abilities have changed drastically; instead of writing numbers down and applying certain mathematical rules, we more often require the ability to use a pocket calculator. In order to memorize information, we rely on smart devices [2]. Today, a major source of knowledge of other people's faces is through television or Internet; and of voices is through the telephone and intensive exposure to these medias can be observed over the past decades [2]. We can hypothesize that the new technological conditions are going to change the brain organization of cognitive functions, and thus these changes should be taken into consideration in their clinical assessments. Maybe it is time to re-analyse and re-interpret the classical neuropsychological syndromes and develop new assessment methods, and this, in particular within clinical trial designs, involving currently available technologies, which would be more in accordance with the actual century living conditions.

\section{Assessment in clinical trials}

Definitions of different cognitive functions form diagnostic measures for pathologies such as AD and related disorders. These definitions are consequently used as endpoint measurements within clinical trials. When it comes to clinical trials in $\mathrm{AD}$, it has been stated that better outcome measures for cognitive and functional changes are acutely needed in the earliest stage [3]. The clinical assessment of cognitive and functional changes in AD within clinical trials has traditionally relied on cognitive screening tests that are not always sensitive to the 
earliest changes that are important though to detect for effective preventive interventions [3]. For example, Schmand et al. demonstrated that the diagnostic yield of different techniques for example in predicting conversion from MCI to $\mathrm{AD}$ is rather moderate [4]. Furthermore, Laske et al. states in his recently published review that current diagnostic measures are invasive (CSF analyses), expensive (neuroimaging), time-consuming (neuropsychological assessment) and limited to special clinics which leads to reduced accessibility as frontline screening tool for dementia and related symptoms [5]. Therefore, we face an increasing need for additional population-based screening with simpler and timelier adapted, noninvasive and cost-effective tools allowing early identification of subjects in preclinical stages of AD. In order to adress this need, this thesis explored a range of new techniques and tools to expand assessment methods with, as presented in chapter 4-7, positive results in terms of high detection and classification rates, further demonstrating that this is a worthwhile area of research to pursue. The following sections discuss the intracacies of what was achieved and what needs to be considered in future rounds of research.

\section{New assessment tools involving ICT}

For the clinical assessment, a key issue in the design of trials is the lack of sensitivity of the employed assessment tools for the detection of subtle but relevant changes in patients at the very early stages of the disease, and thus at highest risk [6-20]. Several studies demonstrate that abnormalities in gait and walking performance [6-9], as well as in speech production [10-14] or in visuospatial [15-17] and IADL functions [18-20] can be observed in patients in presymptomatic stages. These observations are also associated with a higher risk of decline in cognition [21-22]. With the help of certain technologies, such as movement sensors (accelerometer), automatic speech analyses, or automatic video analyses, these abnormalities can be easily detected and were the once studied in this thesis. 
In Chapter 4, motor activity was assessed using an ambulatory actigraphy in MCI subjects who were carrying out short functional activity tasks. In addition, the influence of depressive symptoms on motor activity was investigated, because it may be associated [23] and thus detectable by actigraphy. We found that MCI subjects had significantly reduced mean motor activity while carrying out directed and semi-directed functional activities, compared to healthy control subjects. No difference was found in motor activity between MCI subjects with or without depression. However, actigraphic measurement of motor activity during the evaluation of IADLs and motor tasks is potentially an objective tool for detecting early changes in MCI.

Generally, detecting cognitive and functional decline, and thus the admissibility for participation in clinical trials, requires prospective testing over a longer period, but a patient's performance scores at an assessment may fluctuate as a function of daily rhythms, fatigue, emotion, stress, and many other state-dependent influences. Due to this variance, certain difficulties present in the earliest stages of dementia may be undetectable during the assessment, and their exploration through neuroimaging becomes feasible only for patients having more obvious deficits. We need measurements that represent cognitive performances derived from brief but repeated long term assessments and which may allow more stable characterizations of cognitive changes very early in the course of dementia as well as provide more objective and hence accurate information concerning the appearance of abnormal behavioral patterns in daily life activities which are highly linked with cognitive performance [19]. As a result, ICT may be of great interest if because they enable the patients' performances and actions to be captured accurately and remotely and over longer periods, in real time, and in real life situations [24]. Chapter 2 and 3 of the thesis summarized the current state of ICT use in clinical practice and proposed basic recommendations concerning 
the development and the use of ICT for AD and related disorders based on an expert panel during the ICT and Mental Health workshop (at the CTAD meeting held in Monaco on the 30th of October 2012). To summarize, special attention should be given to ICT solutions that provide personalized information and more objective assessment that indirectly help people with $\mathrm{AD}$ and their caregivers to better understand changes and fluctuations in behavior, and provide help with their daily living activities. One of the obvious results of this ICT workshop was to allow the interaction between ICT engineers and health professionals. For clinicians it is important to establish the exact type of indicators that are clinically relevant and that can provide useful information in daily practice. Secondly, for ICT engineers, the challenge is to adapt the constraints of the technology to the needs of the clinician. The adopted approach tries to emphasize the clinician's user needs. In the next step, more attention should be paid to the user needs from patient / caregiver and to tool designs considering end user perspectives. It is of great importance that patients and caregivers are engaged in the assessment process and able to give feedback on the feasibility and tolerability of the ICT sensors.

The present thesis has provided substantial evidence that the use of ICTin clinical practice has additional value for the assessment of patients. In Chapter 5, we first explored the use of a video monitoring system for automatic event recognition for the assessment of instrumental activities of daily living (IADL) in dementia patients carrying out a standardized scenario consisting of several IADLs such as making a phone call while they were recorded by $2 \mathrm{D}$ video cameras. The comparison between our automated activity detection and the direct observation annotation obtained results with a hight sensitivity and precision rates. However, no significant differences were found between the groups according to the IADL scale suggesting that ICT might, in certain cases, be a more sensitive tool to detect fine changes in behavioral functioning than classical assessment tools. 
In Chapter 6, we further investigated the possibility of a fully automatized quantitative assessment of autonomy levels in dementia patients based on merging extracted features not only from the participants' performance on IADL but also from gait analysis recognized by the same video monitoring system. In this study, we added the aspect of physical tasks (single and dual task) and thus automatic gait analysis to the previous IADL assessment in order to increase the precision accuracy rates and thus improve the staging of autonomy level. The resulting analyses and calculated autonomy group classifier obtained even a higher result than the previous study with a precision rate of $83.67 \%$. These findings suggest that it is possible to quantitatively assess IADL functioning supported by an EMS and that even based on the extracted data the groups could be classified highly accurately. This means that the use of such video analysis technologies, provide reliable and precise methodologies to assess patients functioning in daily life, which could be used at both diagnostic and rehabilitation levels. This is in line with previous work of Sacco et al. and Romdhane et al. [25-26]. Both studies demonstrated that video analyses was a novel tool coming from the ICT world for the assessment of functional impairment in AD and MCI patients. My research confirmed that these are no longer novel tools to be experimented with, but tools that should be invested in and implemented for specific clinical purposes, namely the objective assessment of autonomy and functional impairment in IADL.

Additionally, ICT may be a means to cope with the increasing number of patients with chronic diseases in our aging society. As indicated by Eghdam et al. [27] for individuals with chronic illness affecting cognitive capacities either directly (eg, dementia) or indirectly (eg, diabetes), ICT has become a fundamental part in their daily lives by providing a wide range of useful services and tools to use at home, work, or anywhere else [28]. Over the last few years, research has focused on the development and use of various sensors to monitor activities of the elderly as well as of AD patients. These include 
cameras and microphones for activity recognition [29] embedded sensors [30] or sensors placed on the body [31] as described in several publications of this thesis.

In Chapter 7, we evaluated the interest of using automatic speech analyses, for the assessment of mild MCI and early-stage AD patients performing several short cognitive vocal tasks while being recorded. Their voice recordings were processed, and the first vocal markers were extracted using speech signal processing techniques and thereafter tested to assess their "power" to distinguish among healthy subjects, MCI, and AD patients. After training of automatic classifiers to detect $\mathrm{MCI}$ and $\mathrm{AD}$, using machine learning methods and testing the detection accuracy, we demonstrated a classification accuracy of about $80 \%$ for healthy subjects vs. MCI and MCI vs. AD, and $87 \%$ for healthy subjects vs. AD, all percentages shown to generalize. This provides evidence that automatic speech analyses, similiar analytics that evaluated as well the speeches of Ronald Reagon, could be an additional objective assessment tool for elderly with cognitive decline, particularly at the early stages.

This proposed tool might provide the clinician with additional information at an earlier stage about the course of cognitive decline and appearance and disappearance of symptoms that may allow a better understanding of underlying mechanisms responsible for these behavioral changes. Considering the recent emerges of several large prevention treatment trials (e.g. DIAN-TU study [32]; or A4 Study [33]), research efforts should be placed on characterizing certain markers for the earliest stages of the disease for large-scale screenings in the general population. Within the fraiming, new instruments able to detect fine changes - often impossible to detect by the human eye or ear - in the patient's usual behavior are needed. 


\section{Current ICT use in clinical trials}

The work presented in this thesis provides evidence suggesting that ICT can play a crucial role in the assessment of $\mathrm{AD}$ and related disorders, both in terms of providing additional information for an earlier and more accurate diagnosis and in terms of monitoring of the disease progression as outlined in Chapter 3 [24]. For instance, as shown in Chapter 7 automatic speech analysis techniques, such as the analysis of verbal communication through computerized speech recognition interfaces, can represent a non-invasive and cheap method to gather information about verbal communication impairments. These sorts of impairments are very common in patients with MCI and who are in the early stages of $\mathrm{AD}$ [34]. These techniques are useful for automating the analysis of clinical and neuropsychological tests used to assess linguistic abilities (such as verbal fluency and sentence repetition tests). More importantly, automatic speech analysis can provide additional information, such as utterance duration, filler typology, and analysis of voiced and voiceless segments, that cannot be gathered in a clinical setting. In our study, presented in Chapter 7, we used automatic speech analysis to analyze the performance of healthy elderly participants, MCI and early AD patients while performing several short vocal cognitive tasks, including verbal fluency, picture description and counting backward. It showed that the vocal markers extracted from speech signal processing techniques differed significantly among the three categories of participants.

Despite these promising results in the research domain, these sorts of new technologies are still not commonly used in clinical trials. ClinicalTrials.gov - a registry and results database of publicly and privately supported clinical studies of human participants conducted around the world - contains at present more than 950 clinical trials involving participants with MCI, AD or other dementia types. In Chapter 8, we performed a keyword-based search on these trials, and we were able to find only one clinical trial employing automated speech analysis techniques, five employing automatic video analysis 
techniques, 20 employing actigraphy and 15 employing computerized testing for assessment. While it is certainly possible that these numbers are a slight underestimate, they suggest that more work should be done to bring the clinical domain closer to the frontiers of clinical research.

A weakness of our studies was that it was limited to a reduced number of outcome measures, including apathy and IADL functioning. However, the findings may be generalizable and ICT-based assessments can be of great value also for other neuropsychiatric or cognitive domains being related to, for example, motor activity like agitation.

Agitation represents an important treatment target in clinical trials in dementia patients. Firstly, it is one of the most frequent neuropsychiatric symptoms present in dementia patients, as well as one of the most 'difficult' symptoms to manage for primary caregivers [35]. Secondly, a new promising treatment has been released and tested, and has shown preliminary efficacy evidence in larger cohort trials [36,37]. The International Psychogeriatric Association (IPA) formed an Agitation Definition Work Group (ADWG) to develop a provisional consensus definition of agitation in patients with cognitive disorders [38]. The definition consists of the presence, next to cognitive impairment as criteria, a change from the patient's usual behavior in terms of either excessive motor activity. This would be easily detectable with the use of an accelerometer, as presented in our study in Chapter 3 or the presence of verbal aggression, detectable with the use of automatic speech analyses, as employed in our study in Chapter 7, or the appearance of physical aggression, measurable with the help of automatized video analyses and activity and movement recognition, as used in our studies in Chapter 4 and 5. As for cognition, pharmacological solutions for agitation have given so far disappointing results up until now [39]. ICT could play a key role in assessing agitation in patients with $\mathrm{AD}$, and to test the new treatment 
efficacy. In addition, clinical trials are limited by the use of 'classical' assessment. For example the Neuropsychiatric Inventory (NPI) is a widely used assessment tool for clinical trials, but is likely unable to deliver a parallel performance in terms of discriminating between different disorders [40]. Behavioral and mood disturbances vary in all patients and do not necessarily progress uniformly. Heterogeneity of presentation and variability of progression make it challenging to track changes, and thus limits the assessment of responsiveness to change for behavioral scales in longitudinal studies. This limitation that could be overcome by adding sensor-based ICT solutions to the assessment procedure.

\section{Methodological considerations}

\section{Strengths}

The work performed for this thesis was interdisciplinary and involved clinicians (psychologists, psychiatrists, geriatrists, nurses, etc), engineers (technicians, computer scientist, video analysts, speech analysts, etc.) as well as patients and their caregivers. The involvement of patients and their caregivers were particularly of great importance for the assessment of the acceptability, usability, and effectiveness of the employed technologies as well as the feasibility of the clinical protocols. The active participation of these different parties in the development and the design of the sensors and their usage represents a major strength of the thesis and aimed to maximize clinical validity stimulating a more successful implementation into other clinical settings.

The approaches of the different sensor studies (Chapter 4-7) were novel applied to this clinical context and thus, innovative delivering new avenues for clinical assessment and research. The studies were based on gathering data from different sensors, in combination with audio, actigraphy and video data, while participants were performing 
our clinical protocol with a main focus on the assessment of the functioning in IADL and data from conventional clinical assessments. Furthermore, physical and vocal tasks were administered providing additional information about the patients' cognitive state.

Within this thesis, the overall efficacy and impact of different technologies related to the Dem@Care system, including clinical considerations, factors related to enhanced quality of life for people with dementia, and their caregivers were considered with a focus on clinicians as final end-users due to the defined study targets 'assessment and monitoring'.

The studies performed (Chapters 4-7) covered a broad spectrum of domains related to $\mathrm{AD}$ such as cognition, behavior and functionality. This allowed us to demonstrate the different possibilities of ICT application in clinical practice for assessment purposes. As outlined in Chapters 2 and 3, the technological devices are not specific to their assessment target. For example actigraphy could be used to detect apathy as well as agitation in patients.

All studies have been designed by clinicians and performed in clinical settings with patients at different stages of cognitive decline in order to test and evaluate the sensor's usefulness under 'natural circumstances' and to insure its feasibility and acceptability. Replicating such a real-world set-up, increases the likelihood of successful clinical implementation when operationalizing our methods.

\section{Limitations}

Our studies had several limitations. Given the design of the performed clinical studies, and the recrutment process through the Memory Clinic in Nice, France, the studies risked suffering from selection biaises of the participants. We did not recruit healthy participants from the general elderly population. Instead, rather we limited the healthy 
group to those who had presented for clinical consultation and had subjective complaints. Although this choice limited the healthy population size, it reflects the expected scenario in which our technology is likely to be useful: those already experiencing some (subjective) level of cognitive or functional issues, although less than the level of clinical MCI.

Generally, ICT allows continuous monitoring of disease and symptom development over a longer period and even at a patient's home, thus his natural environment. In this respect, the present studies as described in this thesis are limited by the fact that they were based on ICT assessments in a clinical environment, which of course is just a substitute for the actual situations at patients' home. However, within the Dem@care projects, new studies have already started implememting ICT devices in nursing homes and even patients' homes in order to increase ecological validity.

The reliability of the functioning of the technological devices and the data collection within our studies represent another important limitation and needs therefore to be underlined. The technological equipment did not always work 'smoothly', i.e. lack of synchronization of sensor recordings, missing data, multiple folders etc. due partly due to multiple changes of versions and computers, which caused scattered and sparse data. Unfortunately, this has an impact on clinicians' view and attitude towards ICT and decreases their motivation and willigness to integrate ICT use in their daily routine assessments.

Afterall, in the world of ICT, devices and sensors are developping so fast, that it requires a lot of work and time to keep continoulsy updating softwares and programs which may be the reason for the lack of ICT use so far for clinical assesment and therefore the lack of existing gold-standards. 
Each commercialized device comes with its own software and analyses program which is not compatible with other ones, and thus prevent the merging of data coming from different sensor models/types. This puts a major barrier on the progress of large scale validation studies involving ICT.

Finally, it cannot be denied that the development of such a system and its analysis program was time-consuming and expensive. Engineers worked within the European FP7 Research Program Dem@care several years on improving the system's efficacity and detection precision. However, once its usabibility in clinical practice has been further demonstrated by validation studies, its integration in routine assessment procedures is feasible, installation of such system affordable (Kinect camera and a computer) for Memory Clinics and analyses can be provided in real-time. Nevertheless, more efforts in performance evaluation of such ICTs are needed to help the industry meet user needs and researchers in considering the available technologies for clinical practice. A solid economic model is a major issue: who will pay for assistive technology? Who will install and maintain ICTs at AD patients' homes? The cost-effectiveness balance for assistive technology remains a matter of debate.

\section{FUTURE DIRECTIONS}

In order to integrate ICT measurements into large clinical cohort trials, some research still has to be done, namely the validation of the use of such technologies in larger cohorts to demonstrate clinical meaningfulness and thus, receive recognition in the clinical scientific and medical world. This could eventually lead to a change of attitude in general practitioners and research investigators towards more willingness for using ICT in routine assessment procedures. The 'demystification' of ICT usage by showing that it is actually easy and simple to use, could facilitate its gradual integration in the users work routine and increase acceptability. 
On the technological side, work needs to be done on system development and sensor integration. The goal is for these to work in concert with each other to allow a reliable and complete assessment of a patient by merging information coming from different sensors into easily understandable feedback. The immediate and accurate visualization of the recorded data is of great importance in order to facilitate an easy use in clinical practice and allow support for feedback to patients and their caregivers. Another challenge represents the fusion of data coming from different sensors for meaningful automatized interpretation of detected behaviors for a more complete assessment of a patient's cognitive and functional status as well as the storage and transfer of big data.

Reliability of these ICTs is hard to achieve. Several initiatives have been organized to establish recommendations for ICT use in AD [24]. Some clinical studies on long duration have shown the difficulties in identifying strong benefits of using ICTs for people with AD. More efforts in performance and evaluation of ICTs are needed to help industry meet user needs and researchers (in particular pharmaceutical) in considering the available technologies for clinical trials. A solid economic model is a major issue: who will pay for assistive technology? Who will install and maintain ICTs at AD patients' homes? The cost-effectiveness balance for assistive technology remains a matter of debate.

We do have to ask the question, why many projects like Dem@care seem to develop sensor-based systems for assessment and monitoring of patients but remain 'stand alone models?' This means that these types of systems are rarely being released on the market or commercialized and successfully integrated and applied in clinical practice or clinical trials. 
What are the major barriers to scaling such systems? It may be the associated costs, the required effort, the fear of replacing somebody's work with a machine, the lack of confidence in the technology itself. In the future, these potential explanations should be further investigated in order to meet better the user's needs and overcome this obstacle.

Finally, it is worthwhile underlining that ICT can serve not only as an assessment tool but as well as an intervention tool as it was described and discussed in Chapter 9. Serious games, adapted to people with dementia, may constitute an important tool to maintain autonomy [41]. By providing pleasurable activities and that enable individual empowerment, these games are a way to enter the homes of people with dementia through technology, to structure collaborative care knowledge related to $\mathrm{AD}$, and to educate $\mathrm{AD}$ stakeholders cope with critical situations in patient everyday life. Establishing links between behavioral disorders and their causes could help a personal or virtual coach in proposing corrective actions and lifestyle training. The role of technology in improving sensory impairments, facilitating activities of daily living, and providing pleasure is still underexplored.

\section{CONCLUSION}

Implementing new tools that are able to detect fine and subtle changes in behavioral, cognitive and functional patterns, may allow earlier diagnosis, even at the point when memory functions are still intact. This could lead to earlier, and thus potentially more effective prevention and treatment of $\mathrm{AD}$. In this sense, the aim of this thesis was to investigate the possibility of using technologies for assessment purposes. The results of the studies in this thesis led to propose the implementation of their use for outcome measurements within clinical trials in $\mathrm{AD}$ and related disorders. 
ICTs can indeed provide useful information for assessing specific domains of AD patient's life, and hence address the current need to use innovative measures that demonstrate clinically meaningful cognitive, behavioral and functional outcomes. In addition, it is proposed to consider the use of ICT in the design of clinical trials.

It is important to underline, that not one composite measurement alone can cover the entire spectrum of $\mathrm{AD}$, from early to late stages. However, in combination with already existing clinical assessments and biomarkers, ICT can provide additional diagnostic relevant information that are captured in a more reliable and objective manner and therefore complete the evaluation of a patient's cognitive and functional status. 


\section{REFERENCES}

1. Insel, T., "From Prevention to Preemption: A Paradigm Shift in Psychiatry”. Psychiatric Times, 2008.

2. Ardila, A. (2013). A new neuropsychology for the XXI century. Arch Clin Neuropsychol, 28(8), 751-762.

3. Snyder, PJ, Kahle-Wrobleski, K., Brannan, S., Miller, D. S., Schindler, R. J., DeSanti, S., Ryan, J. M., Morrison, G., Grundman, M., Chandler, J., Caselli, R. J., Isaac, M., Bain, L., Carrillo, M. C. (2014). Assessing cognition and function in Alzheimer's disease clinical trials: Do we have the right tools? Alzheimers Dement, 10(6), 853-860.

4. Schmand, B, Eikelenboom, P, van Gool, WA, \& Alzheimer's Disease Neuroimaging, I. (2012). Value of diagnostic tests to predict conversion to Alzheimer's disease in young and old patients with amnestic mild cognitive impairment. J Alzheimers Dis, 29(3), 641-648.

5. Laske, C, Sohrabi, HR, Frost, SM, Lopez-de-Ipina, K, Garrard, P, Buscema, M, et al. (2014). Innovative diagnostic tools for early detection of Alzheimer's disease. Alzheimers Dement.

6. Beauchet, O, Allali, G, Launay, C, Herrmann, FR, \& Annweiler, C. (2013). Gait variability at fast-pace walking speed: a biomarker of mild cognitive impairment? J Nutr Health Aging, 17(3), 235-239.

7. Dodge, HH, Mattek, NC, Austin, D, Hayes, TL, \& Kaye, JA. (2012). In-home walking speeds and variability trajectories associated with mild cognitive impairment. Neurology, 78(24), 1946-1952.

8. Doi, T, Shimada, H, Makizako, H, Tsutsumimoto, K, Uemura, K, Anan, Y, \& Suzuki, T. (2014). Cognitive function and gait speed under normal and dual-task walking among older adults with mild cognitive impairment. BMC Neurol, 14, 67 
9. Montero-Odasso, M, Bergman, H, Phillips, NA, Wong, CH, Sourial, N, \& Chertkow, H. (2009). Dual-tasking and gait in people with mild cognitive impairment. The effect of working memory. BMC Geriatr, 9, 41.

10. Forbes-McKay, KE, \& Venneri, A. (2005). Detecting subtle spontaneous language decline in early Alzheimer's disease with a picture description task. Neurol Sci, 26(4), 243-254.

11. Hoffmann, I, Nemeth, D, Dye, CD, Pakaski, M, Irinyi, T, \& Kalman, J. (2010). Temporal parameters of spontaneous speech in Alzheimer's disease. Int J Speech Lang Pathol, 12(1), 29-34.

12. López-de-Ipiña, K, Alonso, J.B., Barroso, N., Faundez-Zanuy, M., Ecay, M., Solé-Casals, J., Travieso,C.M., Estanga, A., Ezeiza, A. . (2012). New Approaches for Alzheimer's Disease Diagnosis Based on Automatic Spontaneous Speech Analysis and Emotional Temperature. Ambient Assisted Living and Home Care Lecture Notes in Computer Science 7657, 407-414

13. Meilan, JJ, Martinez-Sanchez, F, Carro, J, Lopez, DE, MillianMorell, L, \& Arana, JM. (2014). Speech in Alzheimer's Disease: Can Temporal and Acoustic Parameters Discriminate Dementia? Dement Geriatr Cogn Disord, 37(5-6), 327-334.

14. Satt, A. (2013). Evaluation of Speech-Based Protocol for Detection of Early-Stage Dementia. Paper presented at the INTERSPEECH, Lyon, France.

15. Jacobs, HI, Van Boxtel, MP, Heinecke, A, Gronenschild, EH, Backes, WH, Ramakers, IH, Verhey, FR. (2012). Functional integration of parietal lobe activity in early Alzheimer disease. Neurology, 78(5), 352-360.

16. Tippett, WJ, Sergio, LE, \& Black, SE. (2012). Compromised visually guided motor control in individuals with Alzheimer's disease: can reliable distinctions be observed? J Clin Neurosci, 19(5). 
17. Verheij, S, Muilwijk, D, Pel, JJ, van der Cammen, TJ, Mattace-Raso, FU, \& van der Steen, J. (2012). Visuomotor impairment in early-stage Alzheimer's disease: changes in relative timing of eye and hand movements. J Alzheimers Dis, 30(1), 131-143.

18. Marshall, GA, Rentz, DM, Frey, MT, Locascio, JJ, Johnson, KA, Sperling, RA, \& Alzheimer's Disease Neuroimaging, I. (2011). Executive function and instrumental activities of daily living in mild cognitive impairment and Alzheimer's disease. Alzheimers Dement, 7(3), 300-308.

19. Reppermund, S, Brodaty, H, Crawford, JD, Kochan, NA, Draper, B, Slavin, MJ, . Sachdev, PS. (2013). Impairment in instrumental activities of daily living with high cognitive demand is an early marker of mild cognitive impairment: the Sydney memory and ageing study. Psychol Med, 43(11), 24372445.

20. Wadley, VG, Okonkwo, O, Crowe, M, \& Ross-Meadows, LA. (2008). Mild cognitive impairment and everyday function: evidence of reduced speed in performing instrumental activities of daily living. Am J Geriatr Psychiatry, 16(5), 416424.

21. Forbes KE, Venneri A, Shanks MF. Distinct patterns of spontaneous speech deterioration: An early predictor of Alzheimer's disease. Brain Cogn 2002; 48:356-61.

22. Marquis, S, Moore, MM, Howieson, DB, Sexton, G, Payami, H, Kaye, JA, and Camicioli, R, Independent predictors of cognitive decline in healthy elderly persons. Arch Neurol, 2002. 59(4): p. 601-6.

23. Vital TM, Hernandez SS, Stein AM, Garuffi M, Corazza DI, de Andrade LP, Costa JL, Stella F (2012) Depressive symptoms and level of physical activity in patients with Alzheimer's disease. Geriatr Gerontol Int 12, 637-642. 
24. Robert, PH, Konig, A., Andrieu, S., Bremond, F., Chemin, I., Chung, P. C., Dartigues, J. F., Dubois, B., Feutren, G., Guillemaud, R., Kenisberg, P. A., Nave, S., Vellas, B., Verhey, F., Yesavage, J., Mallea, P. (2013). Recommendations for ICT Use in Alzheimer's Disease Assessment: Monaco CTAD Expert Meeting. J Nutr Health Aging, 17(8), 653-660.

25. Sacco, G, Joumier, V, Darmon, N, Dechamps, A, Derreumaux, A, Lee, JH, et al. (2012). Detection of activities of daily living impairment in Alzheimer's disease and mild cognitive impairment using information and communication technology. Clin Interv Aging, 7, 539-549.

26. Romdhane, R, Mulin, E, Derreumeaux, A, Zouba, N, Piano, J, Lee, L, et al. (2012). Automatic video monitoring system for assessment of Alzheimer's disease symptoms. J Nutr Health Aging, 16(3), 213-218.

27. Eghdam, A, Scholl, J, Bartfai, A, and Koch, S, Information and communication technology to support self-management of patients with mild acquired cognitive impairments: systematic review. J Med Internet Res, 2012. 14(6): p. e159.

28. Meijer, W.J. and P.L. Ragetlie, Empowering the patient with ICTtools: the unfulfilled promise. Stud Health Technol Inform, 2007. 127: p. 199-218.

29. Clarkson, B.S.N., Pentland, A. , Auditory context awareness via wearable computing, in The Perceptual User Interfaces Workshop, P.o. PUI'98, Editor 1998. p. p. p. 37-42.

30. Wang, S., Common sense based joint training of human activity recognizers, in The 20th IEEE International Joint Conference on Artificial Intelligence P.o.I. 2007, Editor 2007. p. p. p. 2237- 42.

31. Foerster, F. and J. Fahrenberg, Motion pattern and posture: correctly assessed by calibrated accelerometers. Behav Res Methods Instrum Comput, 2000. 32(3): p. 450-7. 
32. Mills, SM, Mallmann, J, Santacruz, AM, Fuqua, A, Carril, M, Aisen, PS, Althage, MC, Belyew, S, Benzinger, TL, Brooks, WS, Buckles, VD, PR, Snider, J, Snyder, P, Sperling, RA, Stewart, C, Thomas, RG, Xiong, C, and Bateman, RJ, Preclinical trials in autosomal dominant AD: implementation of the DIAN-TU trial. Rev Neurol (Paris), 2013. 169(10): p. 737-43.

33. Sperling, RA, Rentz, DM, Johnson, KA, Karlawish, J, Donohue, M, Salmon, DP, and Aisen, P, The A4 study: stopping AD before symptoms begin? Sci Transl Med, 2014. 6(228): p. $228 \mathrm{fs} 13$.

34. König, A, Satt, A, Sorin, A, Hoory, R, Derreumaux, A, Manera, V, et al., Automatic speech analysis for the assessment of pre-demented and Alzheimer patients. Alzheimer's \& Dementia: Diagnosis, Assessment and Disease Monitoring, 2015. 1(1) 112-124.

35. Okura, T, \& Langa, KM. (2011). Caregiver burden and neuropsychiatric symptoms in older adults with cognitive impairment: the Aging, Demographics, and Memory Study (ADAMS). Alzheimer Dis Assoc Disord, 25(2), 116-121.

36. Siffert, J. (2014). Phase 2 of AVP-923 (dextromethorphan/quinidine) for treatment of agitation in Alzheimer's disease: topline results and considerations for future research.In: (presentation) E.U./U.S. Task Force Meeting on Alzheimer's Trials: Outcome measures during the $7^{\text {th }}$ Annual Meeting of Clinical Trials in Alzheimer's Disease Meeting, November, 20-22, 2014, Philadelphia, USA.

37. Cummings, J, Lyketsos, C, Tariot, P, et al. (2014). Dextromethorphan/quinidine (AVP-923) Efficacy and Safety for Treatment of Agitation in Alzheimer's Disease (AD): Results from a Phase 2 Study. In: (poster) 2014 American Neurological Association (ANA) $139^{\text {th }}$ Annual Meeting, October 10-12, 1014, Baltimore, USA. 
38. Cummings, J, Mintzer, J, Brodaty, H, Sano, M, Banerjee, S, Devanand, DP, Gauthier, S, Howard, R, Lanctot, K, Lyketsos, CG, Peskind, E, Porsteinsson, AP, Reich, E, Sampaio, C, Steffens, D, Wortmann, M, and Zhong, K, Agitation in cognitive disorders: International Psychogeriatric Association provisional consensus clinical and research definition. Int Psychogeriatr, 2015. 27(1): p. 7-17.

39. Soto, M, Andrieu, S, Nourhashemi, F, Ousset, PJ, Ballard, C, Robert, P, et al. (2014). Medication development for agitation and aggression in Alzheimer disease: review and discussion of recent randomized clinical trial design. Int Psychogeriatr, 1-17.

40. Lai, CK. (2014). The merits and problems of Neuropsychiatric Inventory as an assessment tool in people with dementia and other neurological disorders. Clin Interv Aging, 9, 1051-1061.

41. Robert, PH, Konig, A, Amieva, H, Andrieu, S, Bremond, F, Bullock, R, et al. (2014). Recommendations for the use of Serious Games in people with Alzheimer's Disease, related disorders and frailty. Front Aging Neurosci, 6, 54. 
306 


\section{SUMMARY}

The occurrence of neurodegenerative disorders such as dementia has risen by unprecedented levels in part due to increases in average lifespan, thus engendering high socio-economic costs. Alzheimer's Disease (AD) is the most common type of dementia and represents a central health problem in Western society, recognized mainly as a cognitive disorder where memory functions are primarily affected in the early stages of the disease. Diagnosis of AD has to be made mainly by the assessment of clinical features. Lately, emphasis is placed more and more on early diagnosis and detection of cognitive decline and related symptoms so that patients can benefit sufficiently from effective treatment and access to information, advice and support. At the same time, clinical assessments of cognitive and functional changes in $\mathrm{AD}$ have traditionally relied on cognitive neuropsychological screening tests, which can be biased by the clinician's subjectivity and are not always sensitive to the earliest disease-related changes. In addition, the role of biomarkers has received increasing interest as early markers for $\mathrm{AD}$, but involve invasive (eg, lumbar puncture), time-consuming (neuropsychological assessment) or expensive (PET) hospital-based procedures. Detecting early changes before clinical AD symptoms develop is crucial for the development and eventual success of therapeutic interventions. Better measures for cognitive, functional and behavioral changes are therefore needed in the early stages of the disease. Assessment methods involving simple, noninvasive and more accessible cost-effective tools are greatly required. For these reasons, information and communication technology (ICT), such as movement sensors and imaging and video processing, could be of interest because they enable the patients' performances and actions to be captured objectively, in real time, and in real life situations. The use of these types of ICT may allow early identification of subjects in preclinical stages of $\mathrm{AD}$ as well as monitoring of the disease's progression and treatment effects over time. 
The general aim of this thesis was to investigate the potential contribution of ICT use for clinical assessment of cognitive, behavioral and functional changes in patients with $\mathrm{AD}$ and related disorders. In particular, focus was on the early stages of cognitive decline in order to allow earlier access to preventative intervention such as tailored cognitive and physical training through serious games. For this purpose, the use of different sensors including actigraphy, video analyses and speech analyses, were investigated in clinical practice.

The thesis consists of three parts: first a review of ICT use for the specific case of apathy assessment and recommendations for ICT use for clinical assessment. In part II, different sensor-based studies are presented followed by part III, addressing the conclusion to consider the use of ICT within clinical trials for endpoint measures and followup. Finally, proposed recommendations are presented for the use of ICT-based Serious Games as a potential early intervention tool for patients.

In Chapter 2, an overview was given of current assessment tools for apathy in clinical practice and new approaches to assessment methods with the help ICT for which with a narrative literature review was conducted. The results suggest that there is evidence that apart from the currently used assessment methods for apathy, new ICT approaches could provide clinicians with valuable additional information for an earlier detection and therefore more accurate diagnosis of apathy. However, there are no ICT techniques specifically designed for the assessment of apathy, but nevertheless several techniques seem to be promising and deserve more study.

In Chapter 3, basic recommendations have been provided concerning the development and the use of ICT for $\mathrm{AD}$ and related disorders. During an ICT and Mental Health workshop an expert panel consisting of clinicians (geriatrician, neurologist, psychiatrist, 
psychologist), ICT engineers, representatives from the industry and patient association, was set up to prepare the first recommendations for the use of ICT in dementia research. The recommendations were divided into three sections corresponding to 1) clinical targets of interest for the use of ICT, 2) the conditions, the type of sensors and the outputs (scores) that could be used and obtained, 3) finally the last section concerns specifically the use of ICT within clinical trials.

In Chapter 4, we assessed motor activity in Mild Cognitive Impairment (MCI) and healthy control subjects (HC) carrying out short functional activity tasks using ambulatory actigraphy. Secondly, the influence of depressive symptoms on motor activity was investigated. We found that MCI subjects had significantly reduced mean motor activity while carrying out directed and semi-directed activities, compared to healthy control subjects. However, no difference was found in motor activity between MCI subjects with or without depression. Together, these results indicate that actigraphic measurement of motor activity during the evaluation of instrumental activities of daily living (IADL) and motor tasks is a potential objective tool in detecting early changes in MCI. Depressive symptoms seem not to be associated with motor activity in MCI subjects.

In Chapter 5, we investigated the use of a video monitoring system for automatic event recognition for the assessment of IADL in 19 healthy subjects and 19 MCI patients who had to carry out a standardized scenario consisting of several IADLs such as making a phone call while they were recorded by 2D video cameras. After the recording session, data was processed by a platform of video signal analysis in order to extract kinematic parameters detecting activities undertaken by the participant. We compared our automated activity quality prediction as well as cognitive health prediction with direct observation annotation and neuropsychological assessment scores. With a sensitivity of $85.31 \%$ and a precision of $75.90 \%$, the overall 
activities were correctly automatically detected. Activity frequency differed significantly between MCI and HC participants $(\mathrm{p}<0.05)$. In all activities, differences in the execution time could be identified in the manually and automatically extracted data. We obtained statistically significant correlations between manually as automatically extracted parameters and neuropsychological test scores $(p<0.05)$. However, no significant differences were found between the groups according to the IADL scale. The results suggest that it is possible to assess IADL functioning with the help of an automatic video monitoring system and that even based on the extracted data, significant group differences can be obtained.

In Chapter 6, we investigated the quantitative assessment of autonomy in dementia patients based not only on gait analysis but also on the participant performance on IADL automatically recognized by a video event monitoring system (EMS). Three groups of participants (healthy controls, MCI, and AD patients) had to carry out a standardized scenario consisting of physical tasks (single and dual task) and several IADL such as preparing a pillbox or making a phone call while being recorded. Video sensor data were processed by an EMS that automatically extracts kinematic parameters of the participants' gait and recognizes their carried out activities. These parameters were then used for the assessment of the participants' performance levels, here referred as autonomy. Autonomy assessment was approached as classification task using artificial intelligence methods that takes as input the parameters extracted by the EMS, here referred as behavioral profile. Activities were accurately recognized by the EMS with high precision. The most accurately recognized activities were "prepare medication" with $93 \%$ and "using phone" with $89 \%$ precision. The diagnostic group classifier obtained a precision of $73.46 \%$ when combining the analyses of physical tasks with IADL. 
In a further analysis, the created autonomy group classifier obtained a precision of $83.67 \%$ when combining physical tasks and IADL. Results suggest that it is possible to quantitatively assess IADL functioning supported by an EMS and that even based on the extracted data the groups could be classified with high accuracy.

In Chapter 7, we evaluated the interest of using automatic speech analyses for the assessment of MCI and early-stage AD. For this, $\mathrm{HC}$ subjects and patients with $\mathrm{MCI}$ or $\mathrm{AD}$ were recorded while performing several short cognitive vocal tasks. The voice recordings were processed, and the first vocal markers were extracted using speech signal processing techniques. Second, the vocal markers were tested to assess their "power" to distinguish among HC, MCI, and AD. The second step included training automatic classifiers for detecting MCI and AD, using machine learning methods and testing the detection accuracy. We obtained classification accuracy of automatic audio analyses as follows: between $\mathrm{HCs}$ and those with MCI, 79\%, between $\mathrm{HCs}$ and those with $\mathrm{AD}, 87 \%$ and between those with MCI and those with $\mathrm{AD}, 80 \%$, demonstrating its assessment utility. Thus, automatic speech analyses could be an additional objective assessment tool for elderly with cognitive decline.

In Chapter 8, an opinion paper was presented suggesting that new ICT - such as automated speech and video analysis techniques and wearable accelerometers - may be successfully employed in clinical trials to improve the functional and cognitive assessment of these patients, thus contributing to an earlier $\mathrm{AD}$ diagnosis and providing additional ecological and objective end-point measurements.

In Chapter 9, we systematically analyzed the Strengths, Weaknesses, Opportunities, and Threats (SWOT) of employing Serious Games (SG) with patients with Alzheimer's disease and other related disorders (ADRD) in order to provide practical 
recommendations for the development and use of SG in these populations. These analyses and recommendations were gathered, commented on and validated during a 2-round workshop in the context of the 2013 Clinical Trial of Alzheimer's Disease (CTAD) conference, and endorsed by stakeholders in the field. The results revealed that SG may offer very useful tools for professionals involved in the care of patients suffering from ADRD. However, more interdisciplinary work should be done in order to create SG specifically targeting these populations. Furthermore, in order to acquire more academic and professional credibility and acceptance, it will be necessary to invest more in research targeting efficacy and feasibility. Finally, the emerging ethical challenges should be considered a priority.

In Chapter 10, we provided a general discussion of our findings; its implications for clinical practice and $\mathrm{AD}$ trials, recommendations for future use of ICT, methodological considerations and recommendations for future research. Furthermore, the last chapter includes a summary of the findings, a description of knowledge valorisation, a list of author affiliations, list of publications, information about the author and acknowledgements. 


\section{KNOWLEDGE VALORIZATION}

The goal of this valorisation chapter is to describe how the knowledge resulting from the research in this dissertation can be made valuable for clinical and social use. This dissertation investigated the use of Information and Communication Technologies (ICT) for the assessment of patients with Alzheimer's disease (AD) and related disorders.

\section{Societal Relevance}

With the prevalence of aging population the risk for cognitive impairment leading to dementia is increasing many folds. The health systems are struggling to live up to the challenge of effective care delivery and management of dementia primarily due to the support cost and the absence of a disease modifying treatment. The number of people living with dementia in 2011 was estimated in 35.6 million, and is expected to nearly double every 20 years, to 65.7 million in 2030 and115.4 million in 2050. For these reasons, early detection, treatment and management of dementia are now considered as a research priority. There is a pressing need for innovative research that will enhance quality care for people with dementia, decrease caregiver burden and reduce care costs. Some key challenges in dementia care are to assist the person to maintain its mobility and stimulate physical exercise as well as sustain communication and connection to family, caregivers and the environment through a personalized and customizable program. All these challenges require beforehand to be able to monitor and evaluate precisely and accurately the patient's behavior and symptoms remotely and continuously.

Currently, the inadequacy of existing methods combined with biased evaluations, points to a need for objective and systematic assessment tools and researchers aim to provide novel solutions. Clinical expertise and literature review indicates that ICT are not yet able to provide a direct diagnosis of $\mathrm{AD}$ and related disorders, but can supply additional 
information for the assessment of specific domains (behavior, cognition, activity of daily living). This information can contribute with other clinical and biological data to earlier diagnosis of $\mathrm{AD}$ and related disorders. Several studies using ICT in the assessment of different domains show potential benefits of using ICT in clinical practice. It could help identifying earlier individuals that are more likely to develop dementia, clinicians can provide earlier timely care, treatment (pharmacological as non-pharmacological) and support, which will in turn reduce health care costs. Namely, drug research focuses at the moment to target patients at the very early stages of the disease when memory functions are still preserved. This means that the use of ICT could have a direct beneficial effect on the selection of people for the enrolment in clinical trials in the broader population, leading ultimately to a reduction of the total burden for society.

As soon as evaluation tools are available the results should be connected to assessment tools that will determine if the patient requires an assistance system that can provide help and coaching in a personalized way. ICT may be a solution in addressing these challenges by first providing evaluation and monitoring tools, with more objective and more frequent measurements that furthermore can be obtained in almost all contexts. Especially the use of assistance devices in the care of people with dementia may combine the assessment and the assistance dimensions and offers intriguing possibilities to address some of the care needs.

\section{Target Audience}

The results of the present thesis are relevant to various stakeholders who are involved in dealing with dementia and related disorders as well as its consequences.

First, the outcome of the different studies are of high interest for clinicians working in memory clinics since we tried to demonstrate the additional value of ICT use in clinical practice for routine assessments 
and this without increasing necessarily workload. The automatically detected events may serve as clinical decision support for diagnosis and could even further guide the appropriate selection of intervention. Patient's behavioral, cognitive and functional status can be assessed objectively without the presence of the typical observer's biases. The results of this thesis will aid clinicians improving the accuracy of diagnosis and thus, prognosis by increasing knowledge about early indicators of developing progressing towards dementia pathology. As a result, they can better inform patients and their families about risks and what specific actions need to be taken.

\section{Products}

The main product of this thesis is the proposal of novel solutions for the holistic management of dementia that exploit both medical knowledge and the latest advances in ICT. Specifically, multi-parametric remote monitoring and individual-tailored analysis of physiological, behavioral and lifestyle sensor-based measurements have, throughout the project 'Dem@care', shown to be obtainable, and on a long term will be integrated in a complete remote care system. This will include a loop for people with dementia and their informal caregivers that: a) monitors and assesses their health status by integrating a multiplicity of body, wearable and static sensors, $b$ ) enables time evolving context-sensitive profiling to support reactive and proactive care, c) provides personalised supportive feedback. Furthermore, a professional loop that: a) provides objective observations regarding the health progression of the person with dementia and medication effectiveness, b) warns professionals about unfavourable trends, c) supports preventive care decision making and updating of care plans for the person with dementia.

To meet these goals, the project capitalised upon continuous advances in pervasive computing and sensor technologies to power a multiparametric monitoring framework that will sustain context-aware, personalised and adaptive feedback mechanisms for the remote 
management of people with dementia. The studies performed for this thesis validated mainly the interest of using such a system in dementia care, thus underlining the importance of exploiting and even commercializing the project's outcome. To allow for the comprehensive assessment of a person's condition and enable the early identification of alarming and potentially hazardous behaviour patterns, as well as prolong independent living for patient who are still at early stages of the disease. Through the combination of the multisensorial processing technologies and advanced knowledge and reasoning methodologies the results of this thesis provide a uniquely comprehensive and personalised solution for dealing with issues related to dementia also outside a hospital. This is expected to have very positive repercussions on a personal level for the person with dementia, on a societal level for medical professionals and informal caregivers, but also on an economic and technological level. Notably, being confronted with an ageing population, and the ensuing socio-economic costs that it entails, Europe's health system has been forced to undergo radical changes, strongly promoting more preventative care, and directing efforts to provide treatment and care at home rather than in the hospital. In line with this shift, a holistic, integrated solution is proposed, taking into consideration medical, behavioral and cognitive aspects, to allow people with dementia to retain their current standing in society, avoiding unnecessary hospitalization, significantly reducing the cost on the health system, and the burdens on their caregivers and themselves.

\section{Innovation}

The different studies performed for this thesis, were highly innovative and among the first ones that tried to demonstrate the use of ICT-based tools for clinical assessment purposes of dementia patients. The aim was to validate the sensor measurements by associations with classical assessment instruments and accordingly promote a holistic solution for the remote management of people with dementia. Advantage was taken of recent progress in multi-sensor technologies, knowledge and reasoning 
methodologies, while placing emphasis on proactive and personalised management of wellness and independent living, rather than the mere reactive management of dementia related symptoms. From the early beginning on of the project, patients were involved in the co-design process of the multiple sensor-based system.

Physiological sensors were deployed to provide measurements that are pertinent to chronic health issues related with dementia, and to activity characteristics that can be indicative of its progression, augmenting the data currently used to evaluate a person's condition.

Audio sensing for cognitive state detection were investigated, focusing on the investigation of new lines of research with regards to the correlation between vocal characteristics and stages of dementia. Speaker identification and audio segmentation strategies were improved, to deal with the challenging problem of recognizing the voice of the person of interest in the presence of background noise or in the midst of other speakers.

Several advances in challenging problems in visual sensing were made to serve the goals and purposes of the Dem@Care system. Video data collected from wearable and static sensors were calibrated and fused to take advantage of their complementary nature. This lead to improved daily activity recognition performance, thanks to additional localisation information that provides context to the other camera data. Person detection and tracking methods were developed that make use of contextual scene information for accurate person localisation and tracking.

A comprehensive view of the patient's lifestyle, behavioral patterns and daily activities was studied for accurate diagnosis, and for correlating observed behaviours with the different stages of dementia. This will significantly advance the typical clinical workflow for dealing with dementia, which currently involves very subjective and incomplete means of recording, such as questionnaires and diaries. 


\section{Valorization process}

Generally, in order to exploit our findings for clinical practice, and integrate ICT measurements into large clinical cohort trials, some research still has to be done. The first step is validation of the use of such technologies in larger cohorts to demonstrate clinical meaningfulness and thus, receive recognition in the clinical scientific and medical world. This could eventually lead to a change of attitude in general practitioners and research investigators towards more willingness for using ICT in routine assessment procedures.

Moreover, the 'de-mystification' of ICT usage by showing that it is actually easy and simple to use, could facilitate its gradual integration in the users work routine and increase acceptability.

On the technological side, work needs to be done on system development and sensor integration. The goal is for these to work in concert with each other to allow a reliable and complete assessment of a patient by merging information coming from different sensors into easily understandable feedback. The immediate and accurate visualization of the recorded data is of great importance in order to facilitate an easy use in clinical practice and allow support for feedback to patients and their caregivers. Another challenge represents the fusion of data coming from different sensors for meaningful automatized interpretation of detected behaviors for a more complete assessment of a patient's cognitive and functional status as well as the storage and transfer of big data.

Reliability of these ICTs is hard to achieve. Several initiatives have been organized to establish recommendations for ICT use in AD, as also being described in the present thesis. Some clinical studies on long duration have shown the difficulties in identifying strong benefits of using ICTs for people with AD. More efforts in performance and evaluation of ICTs are needed to help industry meet user needs and researchers (in particular pharmaceutical) in considering the available 
technologies for clinical trials. A solid economic model is a major issue: who will pay for assistive technology? Who will install and maintain ICTs at AD patients' homes? The cost-effectiveness balance for assistive technology remains an important matter of debate.

We do have to ask the question, why many projects like Dem@care seem to develop sensor-based systems for assessment and monitoring of patients but remain 'stand alone models?' This means that these types of systems are rarely being released on the market or commercialized and successfully integrated and applied in clinical practice or clinical trials. What are the major barriers to scaling such systems? It may be the associated costs, the required effort, fear of replacing somebody's work with a machine, the lack of confidence in the technology itself. In the future, these potential explanations should be further investigated in order to meet better the user's needs and overcome these obstacles.

Nevertheless, the present thesis represent a first step in a new direction by showing the potential benefits and promises of ICT use in a clinical context and therefore its utility to help maintain or even improve the current quality of care for people with dementia. 


\section{Author Affiliations}

Pauline Aalten, PhD

School for Mental Health and Neuroscience, Alzheimer Center Limburg, Maastricht University Medical Center, Maastricht, The Netherlands

Hélene Amieva, PhD

Centre INSERM U897-Epidemiology-Biostatistics, University of Bordeaux, ISPED, Bordeaux, France

Sandrine Andrieu, M.D, PhD

Inserm, UMR1027, F-31000 Toulouse;

Université de Toulouse III, UMR1027; CHU de Toulouse, Service d'épidémiologie et santé publique, F-31000 Toulouse, France

Gregory Bensadoun, $M S c$

CoBTeK Cognition Behaviour Technology EA 7276, research center Edmond and Lily Safra, Nice Sophia-Antipolis University, Nice, France

François Bremond, $P h D$

Institut national de recherche en informatique et en automatique (INRIA) STARS Research Team - Sophia Antipolis, France

Roger Bullock, $M D, P h D$

Kingshill Research Centre, Victoria Hospital, Swindon, UK.

Carlos Fernando Crispim Junior, PhD

Institut national de recherche en informatique et en automatique (INRIA) STARS Research Team - Sophia Antipolis, France

Mathieu Ceccaldi, MD, PhD

Centre de Mémoire de Ressources et de Recherche, CHU de Marseille, France 
Isabelle Chemin

Association Chemin des sens, Grasse, France

Pau-Choo Chung, PhD

National Cheng Kung University, Taiwan

Jean-François Dartigues, $M D, P h D$

Centre de Recherche Inserm, University Victor Segalen Bordeaux 2, Bordeaux, France

Renaud David, $M D, P h D$

Memory Center, Claude Pompidou Institut, Department of Geriatrics, University Hospital of Nice, France

Alexandre Derreumaux

CoBTeK Cognition Behaviour Technology EA 7276, research center Edmond and Lily Safra, Nice Sophia-Antipolis University, Nice, France

Bruno Dubois, $M D, P h D$

CMRR CHU de Paris, IM2A, INSERM, UMR-S 975 (ICM), Hôpital La Salpêtrière, Université Pierre et Marie Curie-Paris, Franc

Feutren, G,

Global Development, Novartis Pharma AG, Basle, Switzerland

Wiesje van der Flier, PhD

Alzheimer Center \& Department of Neurology, Neuroscience Campus Amsterdam,

VU University Medical Center, Amsterdam, The Netherlands

\section{Lea Friedman}

Department of Psychiatry, Stanford University, Palo Alto CA, USA

Mental Illness Research, Education, and Clinical Center (MIRECC), VA Palo Alto Health Care System, Palo Alto CA, USA 
Serge Gauthier, $M D, P h D$

Department of Departments of Psychiatry, Neurology \& Neurosurgery, Medicine

McGill University

McGill Centre for Studies in Aging, Verdun, Quebec, Canada

Alvaro Gomez Uria, MSc

Institut national de recherche en informatique et en automatique (INRIA)

- STARS Research Team - Sophia Antipolis, France

Régis Guillemaud

Electronique et Système pour la Santé DTBS -CEA, Grenoble, France

Ron Hoory, PhD

IBM Research, Speech Lab, Haifa, Israel

Paul-Ariel Kenigsberg, MBA

Fondation Médéric Alzheimer, Paris, France

Laura Klaming, $P h D$

Philips Research, Eindhoven, The Netherlands

Stéphane Nave, $P h D$

pRED, Neuroscience, Roche, Basel, Switzerland

Jean M. Orgogozo

Centre de Mémoire de Ressources et de Recherche, CHU de Bordeaux, Bordeaux, France

Pierre-David Petit, PhD

CoBTeK Cognition Behaviour Technology EA 7276, research center Edmond and Lily Safra, Nice Sophia-Antipolis University, Nice, France

Marten Pijl, PhD

Philips Research, Eindhoven, The Netherlands 
Julie Piano, MSc

CoBTeK Cognition Behaviour Technology EA 7276, research center Edmond and Lily Safra, Nice Sophia-Antipolis University, Nice, France Memory Center, Claude Pompidou Institut, Department of Geriatrics, University Hospital of Nice, France

Michel Benoit, $M D, P h D$

Memory Center, Claude Pompidou Institut, Department of Geriatrics, University Hospital of Nice, France

Clinique de Psychiatrie et de Psychologie Médicale - Pole des Neurosciences Cliniques

Hôpital Pasteur - CHU de Nice, Nice, France

Philippe H.Robert, $M D$, PhD

CoBTeK Cognition Behaviour Technology EA 7276, research center Edmond and Lily Safra, Nice Sophia-Antipolis University, Nice, France Memory Center, Claude Pompidou Institut, Department of Geriatrics, University Hospital of Nice, Nice, France.

Guillaume Sacco, MD

CoBTeK Cognition Behaviour Technology EA 7276, research center Edmond and Lily Safra, Nice Sophia-Antipolis University, Nice, France Rehabilitation Unit, Department of Geriatrics, University Hospital of Nice, Cimiez Hospital, Nice, France

Centre d'Innovation et d'Usages en Santé (CIU-S), University Hospital of Nice, Cimiez Hospital, Nice, France

Aharon Satt, PhD

IBM Research, Speech Lab, Haifa, Israel

Alexander Sorin, $P h D$

IBM Research, Speech Lab, Haifa, Israel 
Orith Toledo-Ronen, PhD

IBM Research, Speech Lab, Haifa, Israel

Jacques Touchon, $M D, P h D$

Center for Memory Resources and Research CMRR, CHU de Montpellier, Faculté de médecine de Montpellier, France

Bruno Vellas, $M D, P h D$

INSERM UMR 1027, Gerontopole, CHU Toulouse, Université de Toulouse, France

Frans R.J. Verhey, $M D, P h D$

School for Mental Health and Neuroscience, Alzheimer Center Limburg, Maastricht University Medical Center, Maastricht, The Netherlands

Jerome Yesavage, $M D, P h D$

Palo Alto Veterans Affairs Health Care System, Palo Alto, CA, USA

Department of Psychiatry and Behavioral Sciences, Stanford University School of Medicine, Stanford University, Stanford, CA, USA

Patrick Malléa

Centre National de Référence Santé à domicile et autonomie (CNR Santé), Nice, France

Valeria Manera, $P h D$

CoBTeK Cognition Behaviour Technology EA 7276, research center Edmond and Lily Safra, Nice Sophia-Antipolis University, Nice, France

Maya Yakhia, MSc

CoBTeK Cognition Behaviour Technology EA 7276, research center Edmond and Lily Safra, Nice Sophia-Antipolis University, Nice, France Alzheimer Center \& Department of Neurology, Neuroscience Campus Amsterdam,

VU University Medical Center, Amsterdam, The Netherlands 


\section{Publications}

\section{International peer reviewed journals}

König A, Sacco G, Bensadoun G, Bremond F, David R, Verhey F, Aalten P, Robert P and Manera V (2015) The role of information and communication technologies in clinical trials with patients with Alzheimer's disease and related disorders. Front. Aging Neurosci. 7:110. doi: 10.3389/fnagi.2015.00110

König A, Crispim-Junior CF, Covella AGU, Bremond F, Derreumaux A, Bensadoun G, David R, Verhey F, Aalten P and Robert P (2015) Ecological assessment of autonomy in instrumental activities of daily living in dementia patients by the means of an automatic video monitoring system. Front. Aging Neurosci. 7:98. doi: 10.3389/fnagi.2015.00098

Ben-Sadoun , G, Petit , P.D. , Colson, S.S. , König, A. , Robert, P. , Aerobic activity an environmental enrichment: Perspective for Alzheimer's patient. Science \& Sports, 2015, 1-12.

J. Bourgeois, M. Laye, J. Lemaire, E. Leone, A. Deudon, N. Darmon, C. Giaume, V. Lafont, S. Brink-Jensen, A. Dechamps, A. König, P. Robert. Relearning of activities of daily living: a comparison of the effectiveness of three learning methods in patients with dementia of the Alzheimer type. Journal of Nutrition, Health and Aging. January, 2015. (in press)

Alexandra König, Carlos fernando Crispim Junior, Alexandre Derreumaux, Gregory Bensadoun, Pierre-David Petit, François Bremond, Renaud David, Frans Verhey, Pauline Aalten, Philippe Robert. Validation of an automatic video monitoring system for the detection of Instrumental Activities of Daily Living in dementia patients, Journal of Alzheimer's disease, 2015; 44(2):675-85. doi: 10.3233/JAD-141767 
Alexandra König, Aharon Satt; Alexander Sorin; Ron Hoory; Alexandre Derreumaux; Valeria Manera; Renaud David; Frans Verhey; Pauline Aalten; Philippe Robert, Automatic speech analysis for the assessment of pre-demented and Alzheimer patients. Alzheimer's \& Dementia: Diagnosis, Assessment and Disease Monitoring, 2015 1(1) : 112-124.

Robert P, König A, Amieva H, Andrieu S, Bremond F, Bullock R, Ceccaldi M, Dubois B, Gauthier S, Kenigsberg P, Nave S, Orgogozo J, Piano J, Benoit M, Touchon J, Vellas B, Yesavage J and Manera V. Recommendations for the use of Serious Games in people with Alzheimer's Disease, related disorders and frailty. Front. Aging Neurosci, 2014. 8:54. doi: 10.3389/fnagi.2014.00054

Konig, A, Aalten, P, Verhey, F, Bensadoun, G, Petit, PD, Robert, P, and David, R, A review of current information and communication technologies: can they be used to assess apathy? Int J Geriatr Psychiatry, 2013. 29(4):345-58. doi: 10.1002/gps.4017. Epub 2013 Sep 5.

Robert, PH, Konig, A, Andrieu, S, Bremond, F, Chemin, I, Chung, PC, Dartigues, JF, Dubois, B, Feutren, G, Guillemaud, R, Kenisberg, PA, Nave, S, Vellas, B, Verhey, F, Yesavage, J, and Mallea, P, Recommendations for ICT Use in Alzheimer's Disease Assessment: Monaco CTAD Expert Meeting. J Nutr Health Aging, 2013. 17(8): p. 653-60. doi: 10.1007/s12603-013-0046-3.

Yakhia, M, König, A, van der Flier, WM, Friedman, L, Robert, PH, David, R Actigraphic Motor Activity in Mild Cognitive Impairment Patients Carrying Out Short Functional Activity Tasks: Comparison between Mild Cognitive Impairment with and without Depressive Symptoms. Journal of Alzheimer's Disease, 2014 ;40(4):869-75. doi: 10.3233/JAD-131691. 
C.F. Crispim-Junior, V. Bathrinarayanan, B. Fosty, A. Konig, R. Romdhane, M. Thonnat and F. Bremond. Evaluation of a Monitoring System for Event Recognition of Older People. In Proceedings of the 10th IEEE International Conference on Advanced Video and SignalBased Surveillance 2013, AVSS 2013, Krakow, Poland, August 27-30, 2013. Link: 10.1109/AVSS.2013.6636634

Sacco, G., V. Joumier, N. Darmon, A. Dechamps, A. Derreumaux, J.H. Lee, J. Piano, N. Bordone, A. Konig, B. Teboul, R. David, O. Guerin, F. Bremond, and P. Robert, Detection of activities of daily living impairment in Alzheimer's disease and mild cognitive impairment using information and communication technology. Clin Interv Aging, 2012. 7: p. 539-49. doi: 10.2147/CIA.S36297

\section{Book chapters}

«Pourquoi les nouvelles technologies peuvent être utiles pour la fragilité » Philippe Robert, Patrick Malléa, Valeria Manera, Alexandra König, Renaud David in Livre Blanc Fragilité, Conférence sur la fragilité du sujet âgé, prévention de la dépendance, rencontres scientifiques sur la sarcopénie, Paris, Mars 2015

«Apport des nouvelles technologies pour l'évaluation et la prise en charge de la maladie Alzheimer» par P. Robert, P.-D. Petit, G. Bensadoun, A. Konig, F. Bremond in «Maladie d'Alzheimer et Communication » de Touchon, J., Gabelle, A., Burn, V., Echanges en réadaptation, SAURAMPS MEDICAL, EMPR-entretien de medecine physique et de readaptation, Montpellier-Nimes, ISBN 13 : 9782840238720 
„Apathie“ and „Gérontechnologie“ par A. König, R. David, A. Derreumaux, G. Sacco in „Alzheimer et états comportementaux Symptômes psychologiques et comportementaux des démences" de R. David, DUNOD, CPNLF, Congrès de psychiatrie et de neurologie de langue française, ISBN 978-2-10-071302-

\section{Abstracts}

Alexandra König (France/Netherlands). The use of ICT for the assessment of people with dementia and mild cognitive impairment within the Dem@care project. Oral presentation at the Alzheimer Europe Conference 2015, 2-4 September, Ljubljana, Slovenia.

König, A., Crispim-Junior, C., Bremond, F., Karakostas, A. Tsolaki, M. \& Robert, PH. Functional Assessment of Patients with Dementia and Mild Cognitive Impairment with the Help of a Multiple Sensor System. Oral presentation at the Alzheimer's Association International Conference (AAIC) 2015, July 18-23, Washington, USA.

König, A. The use of ICT for the assessment of pre-demented and demented patients within the Dem@care project. Oral presentation at the 9th Panhellenic Interdisciplinary Conference on Alzheimer's Disease and Related Disorders in combination with the 1st Mediterranean Conference on Neurodegenerative Diseases 2015, 14-17 May, Thessaloniki, Greece.

König, A, Crispim Junior, C, Covella, AGU, Bremond, F, Derreumaux, A, Bensadoun, G, David, R, Aalten, A, Verhey, F, Robert, P. Ecological assessment of autonomy in Instrumental Activities of Daily Living using an automatic video monitoring system. Presented at the 12th international Conference on Alzheimer's \& Parkinson's Disease (AD/PD) 2015, Nice, France. 
König, A., Satt, A., Sorin, A., Toledo-Ronen, O., Hoory, R., Derreumaux, A., David, R., Verhey, F., Aalten, P., Robert, P.H. Automatic Speech Analysis for the assessment of pre-demented and Alzheimer Patients. Presented at the 12th international Conference on Alzheimer's \& Parkinson's Disease (AD/PD) 2015, Nice, France.

Conference Paper: Aharon Satt, Ron Hoory, Alexandra König, Pauline Aalten, Philippe H Robert. Speech-Based Automatic and Robust Detection of Very Early Dementia. In Proceedings of the INTERSPEECH Conference 2014, September 14-18, 2014, Singapore. DOI: $10.13140 / 2.1 .1258 .8805$

König, A, Dem@care project. Invited Keynote speacker at the Preconference „Dementia \& Technology“ at the Alzheimer’s Association International Conference (AAIC) 2014, July, 2014, Copenhagen, Denmark.

König, A., Satt, A., Sorin, A., Toledo-Ronen, O, Hoory, R., Derreumaux, A., David, R., Verhey, F., Aalten, P., Robert, P.H. The Dem@Care project speech recording and automatic analysis for the assessment of Alzheimer disease and related disorders. Presented at the Alzheimer's Association International Conference (AAIC) 2014, 12-17 July, 2014, Copenhagen, Denmark.

König, A, Aalten, P, Verhey, F, David, R, Robert, PH. Use of ICT for the assessment of dementia patients. Presented at the 9th World Conference of Gerontechnology (ISG 2014) June 18-21, 2014, in Taipei, Taiwan (Oral presentation), Gerontechnology 2014; 13 (2): 81-82; doi: 10.4017/gt.2014.13.02.054.00 
König, A, Crispim Junior, C, Derreumaux, A, Bensadoun, B, Petit, PD, Bremond, F, David, D, Verhey, F, Aalten, P, Robert, PH. The use of automatic video analyses for the assessment of Instrumental Activities of Daily Living in dementia patients. Presented at the 13th International Geneva/Springfield Symposium on Advances in Alzheimer Therapy, March 26-29, 2014 in Geneva, Switzerland.

Prof Philippe Robert and Alexandra KONIG; "ICT Stimulation \& Aging - Defining recommendations".Innovation Alzheimer (IA) Workshop 2013: November $15^{\text {th }}$ during the 6th edition of Clinical Trials on Alzheimer's Disease (CTAD) conference held in San Diego (November $14^{\text {th }}-16^{\text {th }}, 2013$ ). Organized by CoBTek (Cognition Behaviour - Technology) Research Unit of the University of Nice Sophia Antipolis

Alexandra König Oral presentation , Use of ICT for the assessment of activity of daily living“ by within the Symposium " ICT in Dementia: from assessment to stimulation" by Philippe Robert at the 20th International World Congress of Gerontology and Geriatrics (IAGG), 23th-26th June 2013, Seoul, Korea

König, A., Assessment of behavioral symptoms in dementia patients with the help of ICT. Poster presentation at European Psychiatry Congress (EPA) 2013, 6-9 April in Nice, France.

A. Konig, G. Sacco, R. David, F. Bremond. Evaluation des comportements et des activités de la vie quotidenne grâce aux nouvelles technologies. Presented at the IX Journée de la fédération des CMRR (Memory Clinic) du sud de la France, 2013 in Nice, France. 
König, A. Validation of ICT tools for the assessment of behavior in Alzheimer's Disease and related disorders using technological biomarkers. Presented Personally Assisted Living (PAL) Workshop at the French Institute for Research in Computer Science and AutomationINRIA. 2012 in Nancy, France (Oral Presentation)

Prof Philippe Robert and Alexandra KONIG; Innovation Alzheimer Workshop 2012: "Intersection between ICT \& Health - Defining guidelines“. 30th October 2012, Monaco during the Clinical Trials Conference on Alzheimer' Disease (CTAD Meeting) 2012 by Organized by the University of Nice Sophia Antipolis CoBTeK team with the association Innovation Alzheimer (IA).The overall aim of this second workshop is to bridge the gap between the worlds of ICT and Health.

Sacco, G. Joumier, V. Derreumaux, A. Lee, J. H. Piano, J. Bordone, N. Konig, A. Teboul, B. Mulin, E. David, R. Guerin, O Bremond, F. Robert, P. Assistive technologies for the assessment of instrumental activities of daily living in pre demential Alzheimer's disease. Presented at 8th World Conference of International Society for Gerontechnology (ISG*ISARC), June 2012 in Eindhoven, Netherlands.

Sacco, G, Joumier, V, Derreumaux, A, Lee, JH, Piano, J, Bordone, N, Konig, A, Mulin, E, David, R, Guerin, O, Bremond, F, Robert, P. IADL: Apport de l'évaluation écologique utilisant la vidéo. Presented at $11^{\text {th }}$ Réunion Francophone sur la maladie d'Alzheimer et les syndromes apparentés (ALZtoulouse 2012,), 22-24 May 2012, Toulouse, France. (Oral presentation), Gerontechnology 2012;11(2):218; doi: 10.4017/gt.2012.11.02.656.00 


\section{Author information}

Alexandra König is born in Aachen, Germany on the 26th of April 1983 and grew up, due partly to her father's work, in many different places around the world from Conakry in Guinea, West Africa to Vienna in Austria and Bonn in Germany.

After graduating from high school at the St. Leonhard Gymnasium in Aachen in 2003, and two years of internships in social work in different schools for kids with intellectual and physical deficiency, she moved to Montréal in Québec, Canada to study Psychology at the University of Montréal. She worked after graduating with a Bachelor of Science, for two years in a non-profit association for the support of family members of people who suffer from mental disorders such as schizophrenia, depression or borderline personality disorder.

In 2011, she moves back to Europe to start the Master in Neuropsychology at Maastricht University in the Netherlands, for which she performed a research and clinical internship at the Memory Clinic in the Geriatric Hospital in Nice, France under the supervision of Prof Philippe Robert within a European FP7 project «Dem@care ». In 2012, she graduated and started working as a $\mathrm{PhD}$ candidate in two institutions, the Department of Psychiatry and Neuropsychology in Maastricht, Netherlands and the Memory Clinic of the Geriatric University Hospital. in Nice, France. She continued her work in Nice as a project coordinator and neuropsychologist for the European project «Dem@care » until October 2015 when she received her $\mathrm{PhD}$ diploma from Maastricht University. She will start with a postdoctoral fellowship position at Intelligent Assistive Technology and Systems Laboratory (IATSL) at the University of Toronto, and the Computational Health Informatics Laboratory (CHIL) at the University of Waterloo.the University of Waterloo in November 2015 working on an assisstive technology project for the elderly funded by the American Alzheimer's Association and by the Canadian Consortium on Neurodegeneration in Aging (CCNA). 


\section{Acknowledgements}

It seems impossible to me to find the right words to thank all of you appropriately, my supervisors, colleagues, friends and family, but I will try anyways.

First of all, I would like to thank my supervisors, Dr. Pauline Aalten and Dr. Renaud David for guiding and mentoring me with patience. I would have not made it through these past three years without your help and support and I am very grateful for knowing you boths, you inspired me and were partly reason why I would like to continue working in research.

I would like to thank Prof. Frans Verhey and Prof. Philippe Robert, I appreciate that you set high academic standards and helped me to reach for them.

Prof Robert, it was an honour for me working with you and your team in Nice, in France. You are an inspirational and dynamic person and a great scientist. Thank you for letting me become part of your research team. I am glad that our work resulted in terrific publications and I am grateful for all these years. I hope we will continue working and collaborating together!

Mes amis et mes collègues du Centre de Mémoire de Ressources et de Recherche de Nice, j'aurais jamais réussi ce travail sans votre support et collaboration, nos pauses café et surtout le partage de nos expériences. Cindy Menez, Emilie Vaillant et Signe Brink, Valeria Manera, vous resterez toujours dans mon cœur et ça grâce à vous j'ai été capable de surpasser les moments difficiles de cette thèse.

I cannot forget to mention that this research was generously supported by a grant (288199), that came from the European Research project «Dem@care ». I would like to thank the whole «Dem@care»project consortium: Yiannis Kompatsiaris, Anastasios Karakostas, Alexia 
Briassouli, Ioulietta Lazarou, Vivi Ntrigkogi, Thanos Stavropoulos, Georgios Meditskos, Stamatia Dasiopoulou, Agnes Ntounta, Athina Kokonozi from the Centre for Research and Technology Hellas (CERTH), Alexander Sorin, Aharon Satt, Orith Toledo-Ronen and Ron Hoory from IBM Research in Haifa, Israel, Francois Bremond, Carlos Crispim, Serhan Cosar, Jacques Serlan, Baptiste Fosty from INRIA in Sophia Antipolis, France, Louise Hopper, Kate Irving, Rachael Joyce, Eamonn Newman, Joanna McHugh from Dublin City University (DCU), Ireland, Dafni Stampouli, Jennifer Renoux, Marc Contat, Emilien Bondu from Cassidian (now Airbus), in Val-de-Reuil, France, Stefan Sävenstedt, Basel Kikhia, Catharina Melander, Johan E. Bengtsson, Josef Hallberg from Lulea Technology University, in Sweden, Laura Klaming, Marten Pijl, Heribert Baldus, Erik Schuijers from Philips Research in Eindhoven, Netherlands, Ceyhun Burak Akgul from Vistek in Istanbul, Turkey, Jenny Benois-Pineau, Vincent Buso, Guillaume Bourmaud from University of Bordeaux, and Etienne Corvee from Link Care Service, it was a great pleasure and adventure working with you all.

All members of the reading committee : Prof. Rudolf Ponds, Prof. Luc de Witte, Prof. Magda Tsolaki, Dr. Martin van Boxtel and Dr. Franka Meiland, thank you for taking the time to read and judge my dissertation.

All co-authors of my articles, thank you very much for your thoughtful comments, which provided significant contributions to the quality of this dissertation.

Meine Familie und Freunde in Deutschland, ohne euch wäre diese Arbeit nicht möglich gewesen. Ganz besonders möchte ich mich bei meiner Mutter bedanken, der ich diese Arbeit widme, für ihre Unterstützung und dass sie in guten wie auch in schlechten Zeiten immer an mich geglaubt hat. Einen besonderen Dank auch an mein Bruderherz Lutz König-ich bin so froh dass wir uns haben! Mein Vater Martin König und Athena, meine liebe Tante Marika Breuer, die Kuckelmänner, die Ulli, und Carla 
\& Manfred, die Otto's und mein Onkel Bernhard; Katharina Theede, meine Frau an meiner Seite, Trixi Brause, Sandra Pahlke und Basti, Laura und die Richterichs, Sabine Theis, Lena Reineke und Susi Sie, Nina Ghane, Sarah Schultz und Eri Beckey.

Mon amour, Jonathan Renard, t'été le plus grand support imaginable et je suis la femme la plus chanceuse d'avoir un homme comme toi à mon côté et seulement grâce à ton support, ta compréhension et ton écoute et l'amour inconditionnelle que j'ai été capable de réaliser ce grand projet de thèse de doctorat. Merci de tout mon cœur. Je t'aime !

Merci aussi à Yolande et Jean-Yves Renard, et Anthony je suis très heureuse de vous avoir dans ma vie et d'avoir reçu votre support ces derniers trois ans.

Montréal, all my friends over there, you were always in my heart and in my mind during these past years and I would have not made it through this PhD without your regular visits and support, particularly Caitlin Bentley, I think if you would have not been there, as such a great believer in me, I am not sure if I would have ever even decided to do a $\mathrm{PhD}$. Thank you for that. But also Isabel \& Nic, Catherine, Erin H., Erin W., Kubba, Muriel, Alice, Sary, Cynthia et l'ancienne équipe d'ALPABEM, Marcin, Marc \& Vincent and Eugenie, Tarek, Mira, Amjad, Sasha, Marie-Christine, Mat, Jan, Melissa \& Manu, Nadir, and everyone else I forgot there. I am so lucky to have met such amazing friends like you all and even though I left Montréal, you are with me during all those past years.

Mes amis niçois, Florent et Ganaelle, Julien, Elodie et Wladimir, Ceb et Johara, Nelly, Ludo \& Valeria, Aurelie, Chacha, Katja \& Matthias, Adriana, Andrea, Iliena \& Alberto, Ben, Kiki et Nanou et tous ceux que j'ai oublieé, je suis très contente de vous avoir dans ma vie et sans nos petites 'breaks' et aventures les week-ends, je n'aurais pas pu affronter ce grand défi de cette thèse. J'éspère que notre départ à Toronto sera juste temporaire. 
Die Mensch Maschine Halb Wesen und halb Ding Die Mensch Maschine Halb Wesen und halb Überding

- Kraftwerk- 
